FREDERICO KEIZO ODAN

\title{
Estudo de Confiabilidade aplicado \\ à Otimização da Operação em Tempo Real de Redes de Abastecimento de Água
}

Tese apresentada à Escola de Engenharia de São Carlos da Universidade de São Paulo, como parte dos requisitos para obtenção do título de Doutor em Ciências, Programa De Engenharia Hidráulica e Saneamento.

Orientadora: Prof ${ }^{\mathrm{a}}$. Dra. Luisa Fernanda Ribeiro Reis

Coorientador: Prof. Dr. Zoran Kapelan (GB)

\section{Versão Corrigida}

São Carlos 
AUTORIZO A REPRODUÇÃO TOTAL OU PARCIAL DESTE TRABALHO, POR QUALQUER MEIO CONVENCIONAL OU ELETRÔNICO, PARA FINS DE ESTUDO E PESQUISA, DESDE QUE CITADA A FONTE.

Estudo de confiabilidade aplicado à otimização da operação em tempo real de redes de abastecimento de agua / Frederico Keizo Odan; orientadora Profa Luisa Fernanda Ribeiro Reis; coorientador Prof Zoran Kapelan. São Carlos, 2013.

Tese (Doutorado) - Programa de Pós-Graduação e Área de Concentração em Hidráulica e Saneamento -- Escola de Engenharia de São Carlos da Universidade de São Paulo, 2013.

1. Otimização estocástica. 2. Operação em tempo real. 3. Abastecimento de água.. I. Título. 
FOLHA DE JULGAMENTO

Candidato: Engenheiro FREDERICO KEIZO ODAN.

Título da tese: "Estudo de confiabilidade aplicado à otimização da operação em tempo real de redes de abastecimento de água".

Data da defesa: 28/06/2013

\section{Comissão Julgadora:}

Profa. Titular Luisa Fernanda Ribeiro Reis (Orientadora)

(Escola de Engenharia de São Carlos/EESC)

Prof. Associado Rodrigo de Melo Porto

(Escola de Engenharia de São Carlos/EESC)

Prof. Titular Edson Cezar Wendland

(Escola de Engenharia de São Carlos/EESC)

Prof. Dr. Sérgio Koide

(Universidade de Brasília/UnB)

Prof. Dr. Erich Kellner

(Universidade Federal de São Carlos/UFSCar)
Resultado:
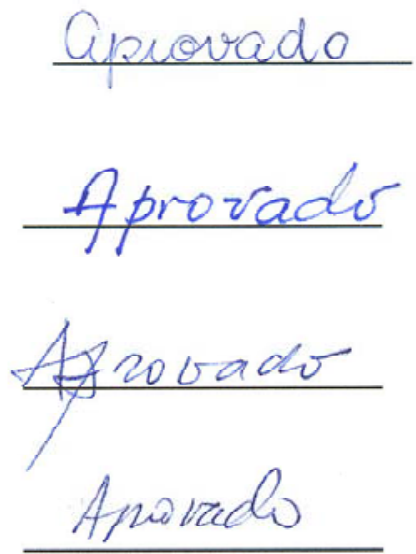

APROUADO

Coordenador do Programa de Pós-Graduação em Engenharia Hidráulica e Saneamento:

Prof. Titular Edson Cezar Wendland

Presidente da Comissão de Pós-Graduação:

Prof. Titular Denis Vinicius Coury 

À minha esposa, pelo apoio e compreensão em todos os momentos.

Ao meu filho pela inspiração. 


\section{Agradecimentos}

A Deus.

À minha esposa, pelo apoio e amor incondicional, que me incita a desenvolver-me cada vez mais.

À Prof. Fernanda, pelas valiosas orientações e paciência.

Ao Prof. Zoran Kapelan pelas importantes sugestões e recomendações.

Ao meu filho, por me proporcionar momentos únicos.

Aos familiares, pelo suporte nas etapas de minha vida.

Aos amigos e colegas do LabSiN: Aline, Daysy, Maria, Narumi, Renata e Taís.

Ao pessoal da pós-graduação, Sá e Priscila, e demais colaboradores do departamento.

Ao Departamento de Hidráulica e Saneamento, pela oportunidade de realizar o curso de doutorado.

Ao DAAE pela colaboração com os dados de estudo, em especial ao Fernando e Rogério.

À FAPESP e CAPES pela concessão da bolsa de doutorado e auxílios. 


\section{Resumo}

Odan, F.K. Estudo de Confiabilidade aplicado à Otimização da Operação em Tempo Real de Redes de Abastecimento de Água. (2013). 210 p. Tese (Doutorado) Escola de Engenharia de São Carlos, Universidade de São Paulo, São Carlos.

A presente pesquisa realizou o estudo da confiabilidade aplicado à otimização da operação em tempo real de sistemas de abastecimento de água (SAA).

Almeja-se que a otimização da operação em tempo real empregue técnicas que a tornem robusta, ou seja, que considerem as incertezas inerentes a um SAA real. Para tanto, é necessário associar ao modelo de otimização um previsor de demanda e um simulador hidráulico. O previsor produzirá estimativas de demandas futuras para o horizonte desejado, o qual alimentará o simulador, a fim de que sejam determinadas as estratégias operacionais otimizadas para atendimento das demandas previstas.

Implementou-se o método de otimização AMALGAM ("A Multialgorithm Genetically Adaptive Method"), juntamente com as demais rotinas computacionais necessárias para integrar o simulador hidráulico (EPANET 2) e o previsor de demanda baseado na Rede Neural Dinâmica (DAN2).

O modelo desenvolvido foi aplicado nos setores de abastecimento Eliana, Iguatemi e Martinez, os quais são operados pelo Departamento Autônomo de Água e Esgotos (DAAE) da cidade de Araraquara, SP. Os modelos das redes de água foram calibrados por meio de dados de vazão e carga de pressão coletados em campanhas de campo.

As estratégias operacionais resultantes foram comparadas as operações praticadas pelo DAAE, resultando em reduções no custo do consumo de energia de $14 \%$, $13 \%$ e $30 \%$ para os setores Eliana, Iguatemi e Martinez, respectivamente.

Palavras-chave: Otimização estocástica, operação em tempo real, abastecimento de água. 


\begin{abstract}
Odan, F.K. Study of Reliability applied to Real Time Optimization of Operation of Water Network Supply. (2013). 210 p. Thesis (Doctorate) - School of Engineer of São Carlos, University of São Paulo, São Carlos.
\end{abstract}

This research project proposes the study of reliability applied to real time optimization of operation of water supply network (WSN).

It is desired to obtain robust real time optimization of operation through the use of adequate techniques which accounts the inherent uncertainty of a real WSN. To accomplish the task it is necessary to associate to the optimization model a demand forecaster and a hydraulic simulator. The forecaster will produce the future demand for the planning horizon to serve as input for the simulator, so it is possible to obtain the optimized operation to meet the predicted demand.

It was implemented the AMALGAM ("A Multialgorithm Genetically Adaptive Method") to serve as optimization model as well as the necessary computational routine to link the EPANET hydraulic simulator as well as the demand forecaster based on DAN2.

The developed model was applied to the sectors Eliana, Iguatemi and Martinez, which are part of the water system operated by the Autonomous Department of Water and Sewer (DAAE) of Araraquara, SP. The water network model was calibrated using data collected on field campaign to gather pressure and flow data.

The optimized operation was compared to the operation from DAAE, resulting in reduction of energy consumption cost of $14 \%, 13 \%$ and $30 \%$ respectively for the sectors Eliana, Iguatemi and Martinez.

Keywords: Stochastic Optimization, real time operation, water supply. 


\section{Lista de Ilustrações}

Figura 3-1 - Diagrama da Estrutura básica do AG ............................................................. 30

Figura 3-2 - Classificação das Hiperheurísticas. Adaptado de Burke et al. (2010) ................. 33

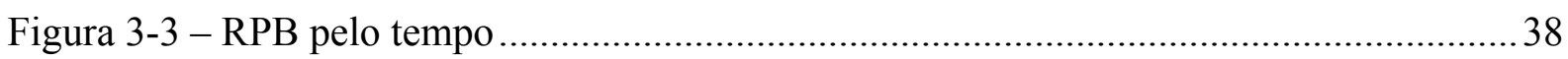

Figura 3-4 - Comparação entre neurônio biológico e artificial ................................................64

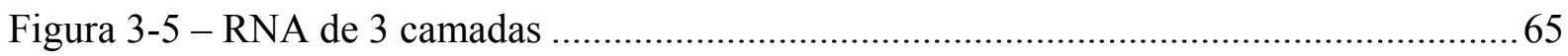

Figura 3-6 - Funções de ativação: (a) função degrau, (b) função rampa, (c) função logística e (d) função gaussiana. .66

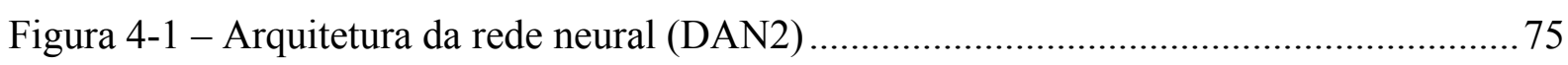

Figura 4-2 - Esquema da previsão de demanda das próximas $24 \mathrm{~h}$...................................... 78

Figura 4-3 - Esqueletonização de um trecho de rede com nós seriais .................................... 82

Figura 4-4 - Fluxograma da geração aleatória de dados para treinamento do metamodelo ....83

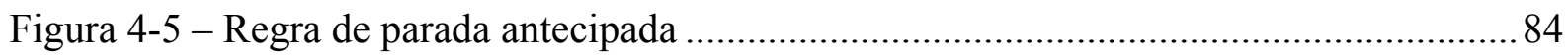

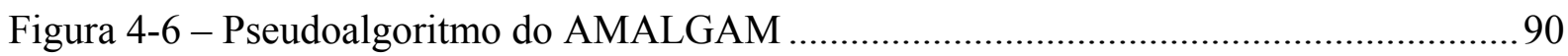

Figura 4-7 - (a) Ilustração das frentes de dominação, (b) Ilustração do conceito de distância de agrupamento (comprimento médio dos lados do cubóide) ......................................91

Figura 4-8 - Esquema da geração da solução pela DE........................................................... 95

Figura 4-9 - Pares de variáveis de decisão utilizando a RPB “time-controlled trigger” .........99

Figura 4-10 - Exemplo da representação das variáveis de decisão segundo a RPB

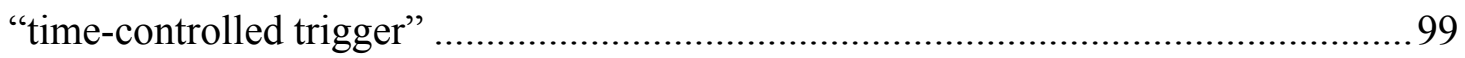

Figura 4-11 - Fluxograma da Operação em Tempo Real - Abordagem I............................. 103

Figura 4-12 - Otimização Multiobjetivo com Abordagem II................................................ 104

Figura 4-13 - Otimização Multiobjetivo com Abordagem III .............................................. 105

Figura 4-14 - Exemplificação das 24 otimizações realizadas para o dia ................................ 106

Figura 4-15 - Exemplificação da combinação entre a Decisão Otimizada das próximas 24h e

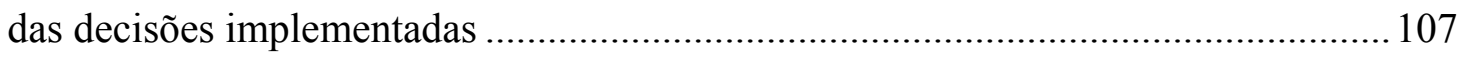

Figura 4-16 - Representação da distância euclidiana entre a solução da Frente $e_{i}$ e a melhor solução fictícia para minimização de duas funções objetivo.

Figura 4-17 - Exemplificação do Passo 2 - Técnica para minimizar número de acionamento de bombas 110

Figura 4-18 - Exemplificação do Passo 4 - Técnica para minimizar número de acionamento de bombas 
Figura 4-19 - Exemplificação do passo 3.1 - Técnica para minimizar.

Figura 4-20 - Exemplificação do passo 3.3 (a) - Técnica para minimizar.............................. 112

Figura 4-21 - Exemplificação do passo 3.3 (b) - Técnica para minimizar.............................. 112

Figura 4-22 - Representação esquemática do Setor de estudo............................................ 115

Figura 4-23 - Representação do modelo hidráulico do Setor Eliana ..................................... 117

Figura 4-24 - Perfil de Consumo médio do Setor Eliana ........................................................ 118

Figura 4-25 - Representação do modelo hidráulico do Setor Iguatemi ................................ 120

Figura 4-26 - Perfil de Consumo médio do Setor Iguatemi-Zona Alta ................................ 120

Figura 4-27 - Perfil de Consumo médio do Setor Iguatemi - Zona Baixa............................. 121

Figura 4-28 - Representação do modelo hidráulico do setor Martinez.................................. 122

Figura 4-29 - Perfil de Consumo médio do Setor Martinez.................................................. 123

Figura 4-30 - Medidor de carga de pressão da Technolog, modelo Metrolog P.................... 124

Figura 4-31 - Medidor de vazão ultrassônico Portaflow 300 da Micronics........................... 125

Figura 4-32 - Esquema de medição de vazão por meio de ultrassom..................................... 126

Figura 4-33 - Representação do modelo hidráulico Simplificado do Setor Eliana ................ 128

Figura 4-34 - Representação do modelo hidráulico Simplificado do Setor Iguatemi ........... 128

Figura 4-35 - Representação do modelo hidráulico Simplificado do Setor Martinez............ 129

Figura 5-1 - Vazão de saída do reservatório R8 - Setor Eliana ............................................ 131

Figura 5-2 - Carga de pressão observada e calibrada para o nó n60 - Setor Eliana .............. 133

Figura 5-3 - Carga de pressão observada e calibrada para o nó n60 utilizando dados da

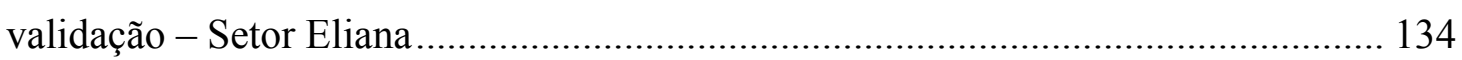

Figura 5-4 - Desvios da carga de pressão entre valor observado e os respectivos valores obtidos nas calibrações (1) e (2) - Setor Eliana ........................................................ 135

Figura 5-5 - Carga de pressão observada e calibrada para o nó n296 - Setor Martinez........ 137

Figura 5-6 - Desvios da carga de pressão entre valor observado e os respectivos valores obtidos nas calibrações (1) e (2) para o período entre 4 e 5h - Setor Martinez........ 139

Figura 5-7 - Gráfico da Calibração do Setor Iguatemi n109 - Zona Alta ............................... 141

Figura 5-8 - Gráfico da Calibração do Setor Iguatemi para o nó n404 - Zona Baixa............. 142

Figura 5-9 - Desvios da carga de pressão entre valor observado e a calibração (1) para o período entre 1 e $24 \mathrm{~h}$ - Setor Iguatemi, Zona Alta ................................................. 145

Figura 5-10 - Desvios da carga de pressão entre valor observado e a calibração (1) para o período entre 1 e 24h - Setor Iguatemi, Zona Baixa............................................... 146

Figura 5-11 - Relação entre valores observados e simulados pelo metamodelo para: (a) Consumo da Bomba do Poço Santa Marta I; (b) Consumo da Bomba do Poço Santa 
Marta II; (c) Nível do reservatório R8 e (d) Carga de pressão do nó n29d - Setor Eliana

Figura 5-12 - Relação entre valores observados e simulados pelo metamodelo para: (a) Consumo da Bomba do Poço Aldo Lupo; (b) Consumo da Bomba do Poço Iguatemi; (c) Consumo da Bomba de recalque entre R25 e R11 Superior; (d) Nível do reservatório R11 Superior; (e) Nível do reservatório R11 Inferior; (f) Nível do reservatório R25; (g) Carga de pressão do nó n283; e (h) Carga de pressão do nó n633 - Setor Iguatemi.

Figura 5-13 - Relação entre valores observados e simulados pelo metamodelo para: (a) Consumo das Bombas do Poço Standard e do booster Standard; (b) Nível do reservatório R15; (c) Nível do reservatório R29 e (d) Carga de pressão do nó n7f Setor Martinez

Figura 5-14 - Comparação entre consumo observado e previsões das próximas $1 \mathrm{~h}$ e $24 \mathrm{~h}-$ Setor Eliana

Figura 5-15 - Comparação entre consumo observado e previsões das próximas $1 \mathrm{~h}$ e $24 \mathrm{~h}-$ Setor Iguatemi, Zona Alta.

Figura 5-16 - Comparação entre consumo observado e previsões das próximas $1 \mathrm{~h}$ e $24 \mathrm{~h}-$ Setor Iguatemi, Zona Baixa

Figura 5-17 - Comparação entre consumo observado e previsões das próximas $1 \mathrm{~h}$ e $24 \mathrm{~h}-$ Setor Martinez 154

Figura 5-18 - Esquema da rede de abastecimento hipotética Anytown 155

Figura 5-19 - Gráfico do custo de operação e violação das restrições x Número de avaliações da função objetivo para a rede Anytown 156

Figura 5-20 - Esquema da rede de abastecimento real Richmond 157

Figura 5-21 - Gráfico do custo de operação e violação das restrições x Número de avaliações da função objetivo para a rede Richmond 158

Figura 5-22 - Esquema da rede de abastecimento hipotética de van Zyl. 158

Figura 5-23 - Gráfico do custo de operação e violação das restrições x Número de avaliações da função objetivo para a rede de van Zyl

Figura 5-24 - Gráfico de Avaliação entre Custo e Número de Avaliações da FO - Setor Eliana

Figura 5-25 - Gráfico de Avaliação entre Custo e Número de Avaliações da FO - Setor Iguatemi 
Figura 5-26 - Gráfico de Avaliação entre Custo e Número de Avaliações da FO - Setor Martinez

Figura 5-27 - Energia utilizada pelas bombas durante as 24 horas e durante as horas de ponta

- Setor Eliana 165

Figura 5-28 - Energia utilizada pelas bombas durante as 24 horas e durante as horas de ponta -

Setor Iguatemi

Figura 5-29 - Energia utilizada pelas bombas durante as 24 horas e durante as horas de ponta Setor Martinez

Figura 5-30 - Nível do reservatório R8 para as diferentes soluções Multiobjetivo - Setor Eliana.....

Figura 5-31 - Nível do reservatório R11 Superior para as diferentes soluções Multiobjetivo -

Setor Iguatemi 174

Figura 5-32 - Nível do reservatório R25 para as diferentes soluções Multiobjetivo - Setor Iguatemi. 175

Figura 5-33 - Nível do reservatório R15 para as diferentes soluções Multiobjetivo - Setor Martinez 177

Figura 5-34 - Soluções da Frente Pareto entre Entropia e Custo da operação com da Abordagem I e III 179

Figura 5-35 - Soluções da Frente Pareto entre Resiliência e Custo da operação com uso da Abordagem I e III 179

Figura 5-36 - Soluções Multiobjetivo entre Entropia e Custo da operação com diferentes números de soluções iniciais para Abordagem III

Figura 5-37 - Soluções Multiobjetivo entre Resiliência e Custo da operação com diferentes números de soluções iniciais para Abordagem III

Figura 5-38 - Custo x número de avaliações da Função Objetivo, otimizando-se apenas o custo 185

Figura 5-39 - Custo x Número de avaliações da FO, otimizando-se custo e entropia..... 187

Figura 5-40 - Entropia x Número de avaliações da FO, otimizando-se custo e entropia

Figura 5-41 - Custo x Número de avaliações da FO, otimizando-se custo e resiliência com uso da Abordagem III 188

Figura 5-42 - Resiliência x Número de avaliações da FO, otimizando-se custo e resiliência com uso da Abordagem III 188 


\section{Lista de Tabelas}

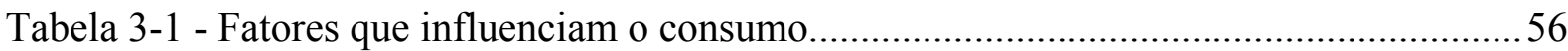

Tabela 4-1 - Modelo de previsão da rede neural DAN2-H...................................................78

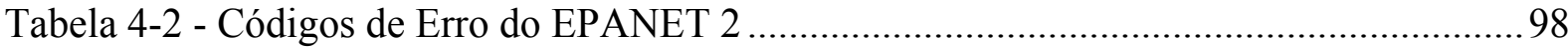

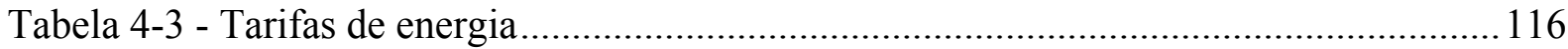

Tabela 4-4 - Dados do Reservatório R8 - Setor Eliana ....................................................... 117

Tabela 4-5 - Dados dos reservatórios do Setor Iguatemi........................................................ 119

Tabela 4-6 - Dados dos reservatórios do Setor Martinez ....................................................... 122

Tabela 5-1 - Resumo dos resultados da Calibração para o Setor Eliana ................................ 132

Tabela 5-2 - Resumo das rugosidades calibradas para os grupos de tubos - Setor Eliana ..... 132

Tabela 5-3 - Resumo dos resultados da Calibração para o Setor Martinez............................. 136

Tabela 5-4 - Resumo das rugosidades calibradas para os grupos de tubos - Setor Martinez. 138

Tabela 5-5 - Resumo dos resultados da Calibração para o Setor Iguatemi - Zona Alta......... 141

Tabela 5-6 - Resumo dos resultados da Calibração para o Setor Iguatemi - Zona Baixa ...... 142

Tabela 5-7 - Resumo das rugosidades calibradas para os grupos de tubos ............................ 143

Tabela 5-8 - Resumo das rugosidades calibradas para os grupos de tubos ........................... 143

Tabela 5-9 - Resumo das avaliações dos resultados para o metamodelo do Setor Eliana .... 147

Tabela 5-10 - Resumo das avaliações dos resultados para o metamodelo do Setor Iguatemi

Tabela 5-11 - Resumo das avaliações dos resultados para o metamodelo do Setor Martinez

Tabela 5-12 - Resumo das avaliações de desempenho das Previsões de demanda da próxima hora para os setores de estudo

Tabela 5-13 - Resumo das avaliações de desempenho das Previsões de demanda das próximas

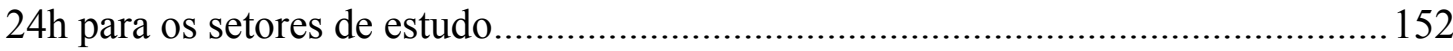

Tabela 5.14 - Custos de operação para a rede Anytown....................................................... 155

Tabela 5.15 - Resumo dos custos para a rede de Richmond ............................................... 157

Tabela 5.16 - Resumo dos custos para a rede de van Zyl.................................................... 159

Tabela 5-17 - Custos Custos da Estratégia Otimizada e da Operação praticada pelo DAAE -

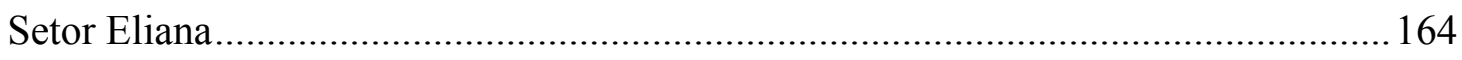

Tabela 5-18 - Custos da Estratégia Otimizada e da Operação praticada pelo DAAE - Setor Iguatemi 
Tabela 5-19 - Custos da Estratégia Otimizada e da Operação praticada pelo DAAE - Setor Martinez

Tabela 5-20 - Resumo dos valores das Funções Objetivo para a otimização multiobjetivo e operação do DAAE - Setor Eliana 170

Tabela 5-21 - Programação das bombas gerada via otimização multiobjetivo - Setor Eliana171

Tabela 5-22- Resumo das Funções Objetivo para a otimização multiobjetivo e operação do DAAE - Setor Iguatemi. 173

Tabela 5-23 - Programação das bombas gerada via otimização multiobjetivo - Setor Iguatemi 173

Tabela 5-24 - Resumo das Funções Objetivo para a otimização multiobjetivo e operação do DAAE - Setor Martinez 176

Tabela 5-25 - Programação das bombas gerada via otimização multiobjetivo - Setor Martinez 176

Tabela 5-26 - Resumo dos resultados utilizando 1 a 2 funções objetivo com uso da Abordagem I. 178

Tabela 5-27 - Resumo dos resultados da otimização multiobjetivo utilizando-se Abordagem III.

Tabela 5-28 - Resumo dos resultados com 3 funções objetivo utilizando Abordagem I e III181 Tabela 5-29 - Programação da bomba do reservatório R11 (superior) para as soluções de 1-6 utilizando Abordagem I e III. 182

Tabela 5-30 - Programação da bomba do Poço Iguatemi para as soluções de 1-6 utilizando Abordagem I e III. 182

Tabela 5-31 - Programação da bomba do Poço Aldo Lupo para as soluções de 1-6 utilizando Abordagem I e III

Tabela 5-32 - Resumo dos resultados otimizando-se o Custo, a Entropia e a Resiliência, com variação da população inicial para Abordagem III 184

Tabela 5-33 - Programação do booster entre o reservatório R11 Inferior e R11 Superior para

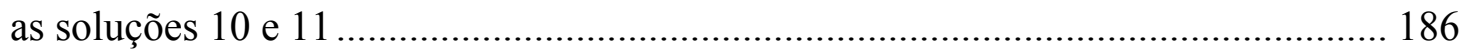

Tabela 5-34 - Programação da bomba do Poço Iguatemi para as soluções 10 e 11 .............. 186

Tabela 5-35 - Programação da bomba do Poço Aldo Lupo para as soluções 10 e 11 ........... 186

Tabela 5-36 - Comparação dos resultados das soluções multiobjetivo com uso das diferentes Abordagens de otimização - Setor Eliana 190

Tabela 5-37 - Comparação dos resultados das soluções multiobjetivo com uso das diferentes Abordagens de otimização - Setor Iguatemi 190 
Tabela 5-38 - Comparação dos resultados das soluções multiobjetivo com uso das diferentes Abordagens de otimização - Setor Martinez

\section{Lista de Abreviaturas e Siglas}

$\mathrm{AG}$

AMALGAM

AMGA

AMS

ANN

ARIMA

ARMA

BP

CAKE

CAPES

CD

CMA

CR

CURNOLE

DAAE

DAN2

DAN2-H

DAN2-H

DDA

DDA

DE

DEX

DLL

EOC

EPA

ETA

EUA

FAPESP
Algoritmo Genético

A Multialgorithm Genetically Adaptive Method

Adaptive Merging and Growing Algorithm

Adaptive Metropolis Search

Artificial Neural Network

Auto-regressive Integrated Moving Average

Auto-regressive Moving Average

BackPropagation

Current Accumulated Knowledge Element

Coordenação de aperfeiçoamento de Pessoal de Nível Superior

Crowding Distance

Covariance Matrix Adpation

Centro de Reservação

Current Residual Nonlinear Element

Departamento de Água e Esgoto

Dynamic Architecture for Artificial Neural Networks

Rede Neural Dinâmica Híbrida

Rede Neural Dinâmica Híbrida

Demand Driven Analysis

Demand Driven Analysis

Diferential Evolution

Despesa de Exploração

Biblioteca de vínculo dinâmico (Dynamic Link Library)

Estratégia Otimizada Combinada

Enviromental Protection Agency

Estação de Tratamento de Água

Estados Unidos da América

Fundação de Amparo à Pesquisa do Estado de São Paulo 
FDP

FNS

FO

FOSM

GA

GMDH

GRASP

GRG2

HDA

HDA

H-W

LabSiN

LHS

LPG

m.c.a.

MAE

MAPE

$\mathrm{MCMC}$

MCS

MLP

MOEAs

MOGA

MOM-BP

MPE

NPR

NSGA

POWADIMA

PSO

PVC

Q

$\mathrm{R}^{2}$

RBF

RMSE
Função de Densidade de Probabilidade

Fast Nondominated Sorting

Função objetivo

First Order Second Moment

Genetic Algorithm

Group Method of Data Handling

Greedy Randomized Adaptive Search Procedure

Gradiente Reduzido Generalizado 2

Head Driven Analysis

Head Driven Analysis

Hazen-William

Laboratório de Simulação Numérica

Latin Hypercupe Sampling

Linear Programming - Greedy

metros de coluna de água

Mean Absolute Error

Mean Absolute Percentual Error

Markov Chain Monte Carlo

Monte Carlo Sampling

MultiLayer Perceptron

Multiobjective Evolutionary Algorithms

Multiple Objective Genetic Algorithm

Momentum com BackPropagation

Mean Percentage Error

Node Pair Reliability

Nondominated Sorting Genetic Algorithm

Potable Water Distribution Management

Particle Swarm Optimization

Policloreto de vinila

Representação da Programação das Bombas

Coeficiente de Determinação

Radial Basis Function

Root Mean Squared Error 
RNA

RNA-H

rNSGAII

ROADEF

RTCT

SAA

SAM

SNIS

SPEA

UMDA
Rede Neural Artificial

Rede Neural Artificial Híbrida

Robust Nondominated Sorting Genetic Algorithm II

Recherche Opérationnelle et d'Aide à la Décision

Relative Time Control Trigger

Sistema de Abastecimento de água

Subsistema Adutor Metropolitano

Sistema de Informações sobre Saneamento

Strength Pareto Evolutionary Algorithm

Univariate Marginal Distribution Algorithm 


\section{Lista de Símbolos}

D matriz de dados de entrada (DAN2)

$D_{i} \quad n$ padrões independentes de cada entrada de $D$ (DAN2)

$d_{i j} \quad m$ atributos de $D_{i}$

Ref vetor de referência (DAN2)

ref elementos do vetor de referência $\operatorname{Ref}(\mathrm{DAN} 2)$

$\alpha_{i} \quad$ ângulo entre o vetor de observação i e o vetor de referência $\operatorname{Ref}$ (DAN2)

$c \quad$ constante (DAN2)

$F_{k} \quad$ nó denominado CAKE (DAN2)

$G_{k}$ e $H_{k} \quad$ nós CURNOLE (DAN2)

$\varepsilon_{1} \quad$ valor do critério para avaliação do "underfitting" (DAN2)

$\varepsilon_{1}{ }^{*} \quad$ limite para critério de "underfitting" (DAN2)

$S S E_{k} \quad$ somatório dos erros quadráricos da iteração $k$ (DAN2)

$\varepsilon_{2}{ }^{*} \quad$ valor do critério para avaliação do "overfitting" (DAN2)

$\varepsilon_{2}{ }^{*} \quad$ limite para o critério de "overfitting" (DAN2)

$M S E_{T}$ e erro quadrático médio para o conjunto de treino $(T)$ e validação $(V)$, $\mathrm{MSE}_{V} \quad$ respectivamente (DAN2)

$a_{k}, b_{k}, c_{k}, \quad$ constantes (DAN2)

$d_{k} e \mu_{k}$

$r_{i} \quad m$ componentes do vetor de referência $\operatorname{Ref}(\mathrm{DAN} 2)$

$\hat{F}\left(D_{i}\right) \quad$ valor de consumo observado

C consumo observado ou previsto (DAN2)

SF $\quad$ valor previsto pela Série de Fourier

$s a_{0}, s a_{k}, \quad$ coeficientes utilizados na previsão da Série de Fourier

$s b_{k} e s a_{N}$

NH número de harmônicos

$2 N h$ período em horas coincidente com o intervalo 0 a $2 \pi$

$f\left(s x_{j}\right) \quad j$-ésimo valor de consumo observado utilizado na previsão da Série de Fourier

nciclo contador de ciclos de treinamento do neurônio (AMGA)

$n c i_{\text {inicial }} \quad$ número inicial de neurônios na camada intermediária (AMGA) 


\begin{tabular}{|c|c|}
\hline$h_{i}$ & neurônio $i$ camada intermediária (AMGA) \\
\hline$\tau$ & número de ciclos de treinamento especificado (AMGA) \\
\hline$n c i$ & número de neurônios na camada intermediária atual (AMGA) \\
\hline$E Q M$ & erro quadrático médio (AMGA) \\
\hline$o_{\max }$ & valor máximo da saída da RNA (AMGA) \\
\hline$o_{\text {min }}$ & valor mínimo da saída da RNA (AMGA) \\
\hline$V n$ & número de exemplos do conjunto de validação (AMGA) \\
\hline$n s$ & número de neurônios na camada de saída (AMGA) \\
\hline$Y_{i}(v)$ & saída produzida pela RNA (AMGA) \\
\hline$Z i(v)$ & saída desejada (alvo) (AMGA) \\
\hline$\eta_{i}$ & significância do neurônio intermediário $h_{i}$ (AMGA) \\
\hline$\sigma_{i}$ & desvio padrão da saída do neurônio intermediário $h_{i}$ (AMGA) \\
\hline Lsign & neurônio intermediário $h_{i}$ rotulado como não significativo (AMGA) \\
\hline$h_{a} e h_{b}$ & neurônios a serem mesclados (AMGA) \\
\hline ne & número de neurônios na camada de entrada (AMGA) \\
\hline$w_{a i} e w_{b i}$ & pesos dos neurônios a serem mesclados $h_{a}$ e $h_{b}$ (AMGA) \\
\hline$\varepsilon_{q m}$ & limite do critério de adição de neurônio (AMGA) \\
\hline$w^{1} e w^{2}$ & peso dos neurônios divididos pelo critério da adição (AMGA) \\
\hline$\alpha r$ & valor aleatório entre 0 e 1 para divisão dos pesos dos neurônios $w^{1}$ e $w^{2}$ \\
\hline$F$ & vetor de funções objetivo do problema de otimização (AMALGAM) \\
\hline$c a_{i}$ & $\begin{array}{l}\text { coeficiente de ajuste para minimização/maximização do problema de } \\
\text { otimização (AMALGAM) }\end{array}$ \\
\hline$F O i(V)$ & funções objetivos do problema de otimização (AMALGAM) \\
\hline$M$ & número de funções objetivo (AMALGAM) \\
\hline$V$ & $\begin{array}{l}\text { vetor variável de decisão }\left\{v_{i}, v_{2}, \ldots, v_{n}\right\} \text { do problema de otimização } \\
\text { (AMALGAM) }\end{array}$ \\
\hline$N$ & $\begin{array}{l}\text { número de variáveis de decisão (dimensão do problema de otimização) } \\
\text { (AMALGAM) }\end{array}$ \\
\hline$R_{r}$ & vetor de restrições do problema de otimização de dimensão $n_{r}$ (AMALGAM) \\
\hline
\end{tabular}


(AMALGAM)

$Q_{t} \quad$ população criada pelo AMALGAM a partir de $P_{t}$

geração da população (AMALGAM)

$k \quad$ algoritmos individuais do AMALGAM

$Q_{t}^{k} \quad$ soluções geradas pelo algoritmo $k$ (AMALGAM)

$N_{t}^{k} \quad$ número de soluções geradas pelo algoritmo $k$ (AMALGAM) na geração $t$

$p_{i} \quad$ elementos de $P_{t}, i=1, \ldots, N($ AMALGAM)

$n p_{i} \quad$ número de elementos que dominam $p_{i}$ (AMALGAM)

$S p_{i} \quad$ conjunto de soluções dominadas por $p_{i}$ (AMALGAM)

FD frente de dominação (AMALGAM)

$R D \quad$ conjunto utilizado no FNS para identificar frentes de dominação (AMALGAM)

$r D \quad$ elementos do conjunto $R D$ (AMALGAM)

$C D \quad$ crowded comparison - operador de comparação de agrupamento (AMALGAM)

$l \quad$ número soluções na frente de dominação $f_{M}$ (AMALGAM)

$f_{M} \quad$ frente de dominação considerada (AMALGAM)

$\prec \quad$ operador de comparação para classificar as soluções (AMALGAM)

crd distância de agrupamento (AMALGAM)

$n_{\text {sol }} \quad$ número de soluções permitidas na frente de dominação, calculado pelo elitismo controlado (AMALGAM)

Npop número total de soluções da população (AMALGAM)

$n F D \quad$ número de frentes de dominação (AMALGAM)

tr taxa de redução do elitismo controlado (AMALGAM)

X Vetor solução (DE, PSO, AMS)

FP fator de ponderação (DE)

$u \quad$ vetor experimental (DE)

Vm solução mutante (DE)

lx best melhor localização da partícula (PSO)

$p_{\text {best }} \quad$ melhor solução encontrada de toda a população (PSO)

vel velocidade da partícula (PSO)

fw fator de inércia (PSO) 


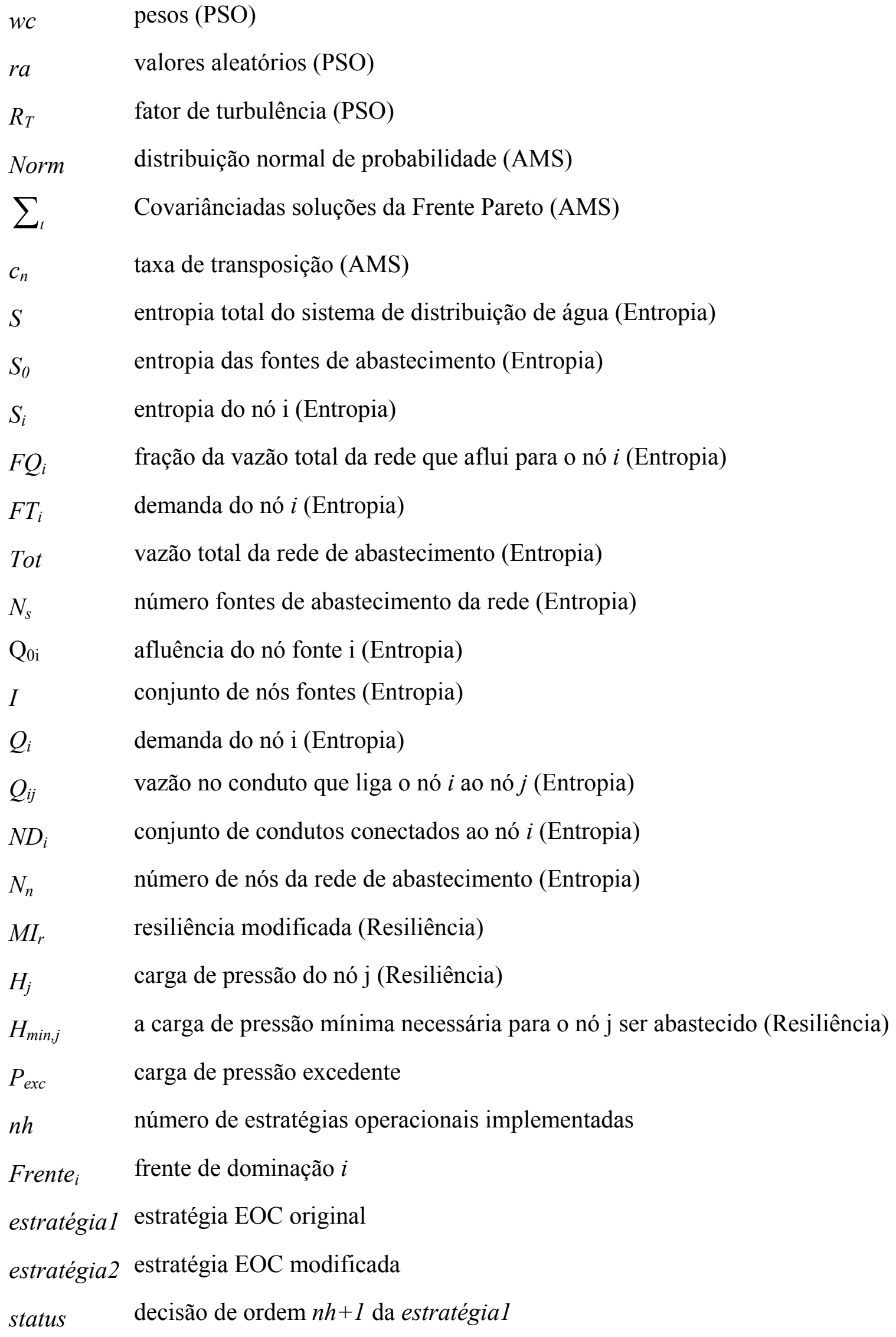


$t u b o_{j}$ tubo $j$ utilizado para cálculo da função de sensibilidade (Pontos de Monitoramento)

nnós número de nós do modelo da rede de abastecimento (Pontos de Monitoramento)

mtubos número de tubos do modelo da rede de abastecimento (Pontos de Monitoramento)

$P c^{\prime} \quad$ carga de pressão observada (Calibração)

$Q c_{j}^{\prime} \quad$ vazão observada (Calibração)

$\Delta P c_{i} \quad$ diferença entre carga de pressão simulado e observado (Calibração)

$\Delta Q c_{i}$ diferença entre vazão simulada e observada (Calibração)

Nc número de nós com carga de pressão monitorado (Calibração)

Mc número de tubos com vazão monitorada (Calibração)

$N v \quad$ número de valores analisados pelo critério de avaliação

$y_{i} \quad$ valor produzido pelo modelo (Critério de avaliação)

$\hat{y}_{i} \quad$ valor observado (Critério de avaliação) 


\section{Sumário}

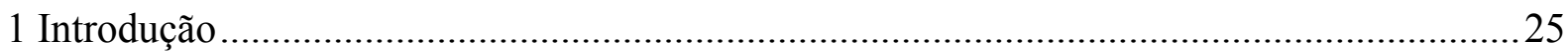

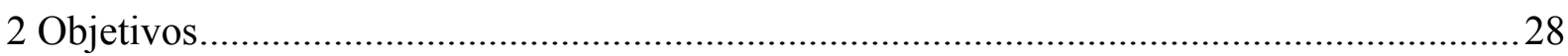

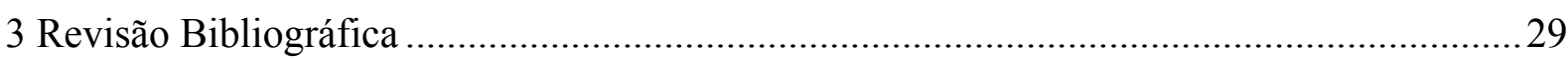

3.1 Técnicas de Otimização aplicadas aos sistemas de abastecimento de água ................29

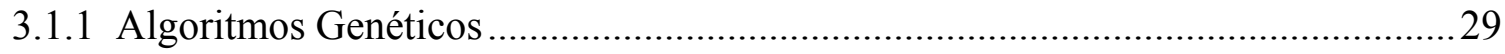

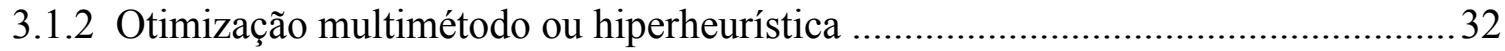

3.1.3 Representação da programação de bombas ............................................................ 37

3.2 Otimização da operação de sistemas de abastecimento de água ................................. 39

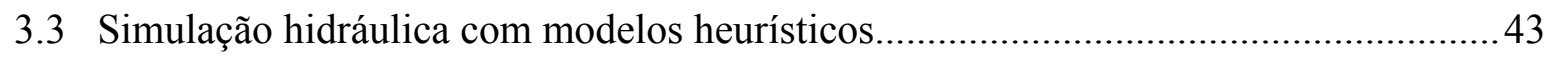

3.4 Confiabilidade aplicada aos sistemas de abastecimento de água ..............................46

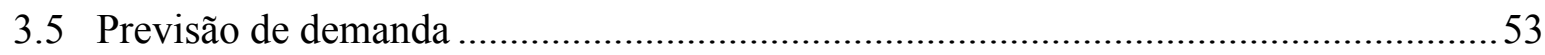

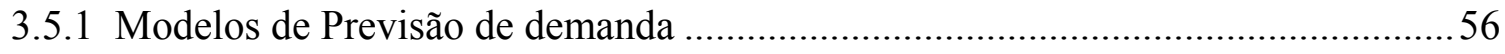

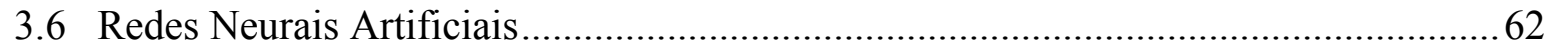

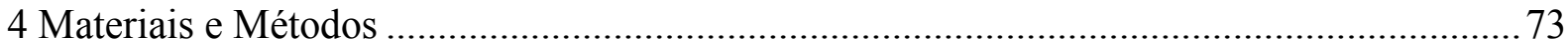

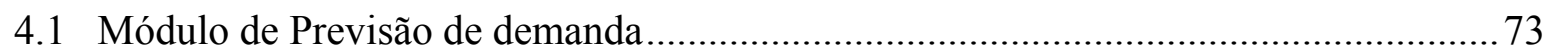

4.1.1 Modelo de previsão baseado em série de Fourier ............................................. 78

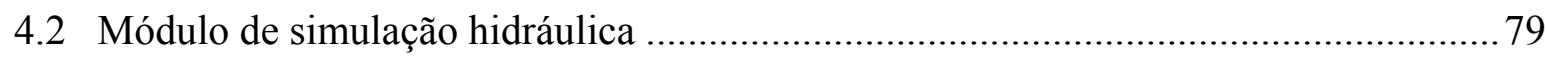

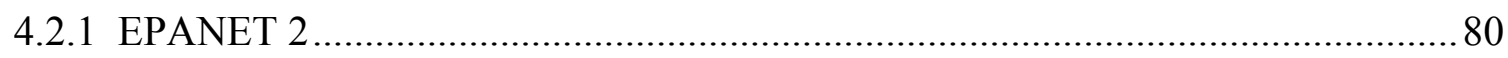

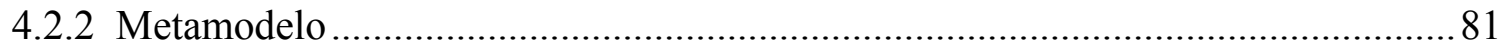

4.2.3 “Adaptive Merging and Growing Algorithm” (AMGA) ....................................... 84

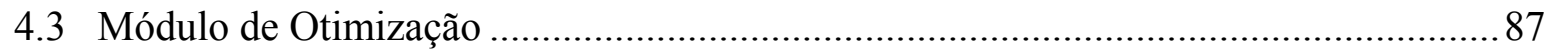

4.3.1 Métodos de otimização do AMALGAM............................................................. 93

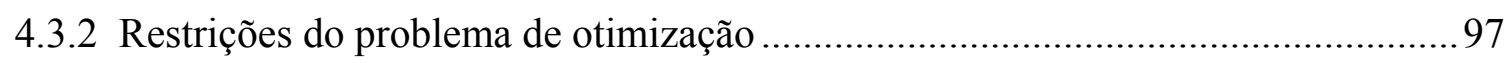

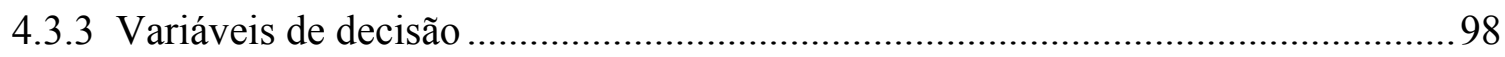

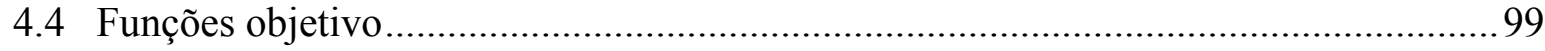

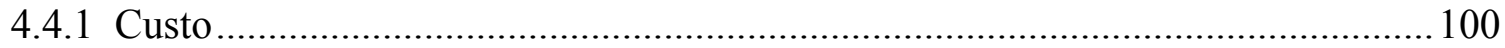

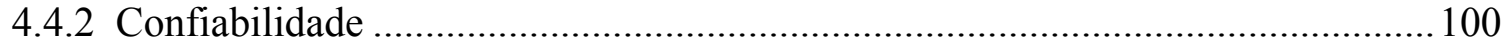

4.5 Abordagens para otimização da operação em Tempo Real........................................ 102

4.5.1 Técnica de reparação das estratégias otimizadas da operação em Tempo Real ... 106

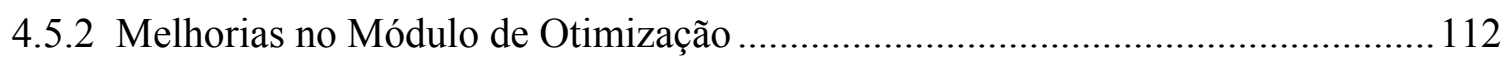

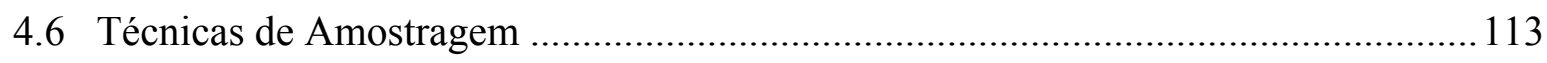

4.6.1 Técnica de amostragem do hipercubo latino (LHS) .......................................... 113 


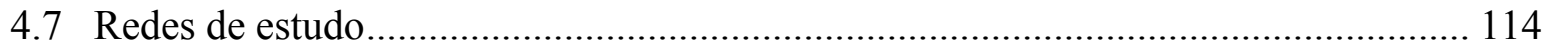

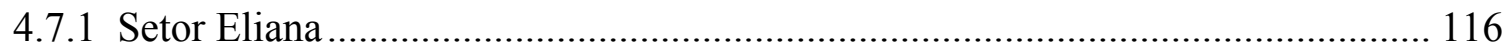

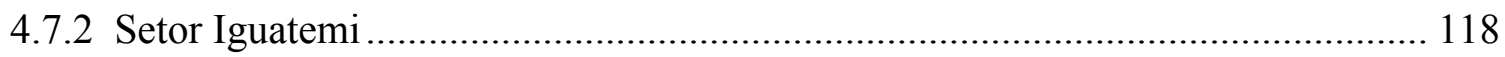

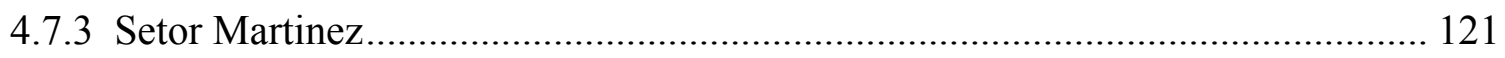

4.8 Construção e Calibração das Redes de Estudo ……………………………………..... 123

4.8.1 Modelo Simplificado da rede de estudo............................................................. 127

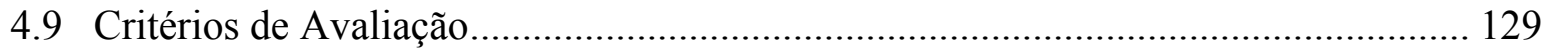

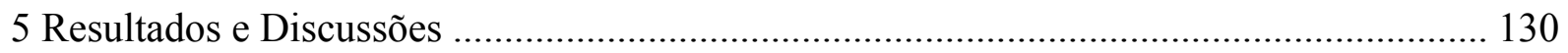

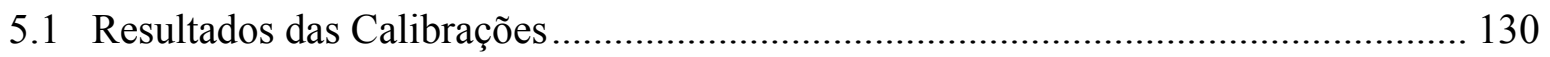

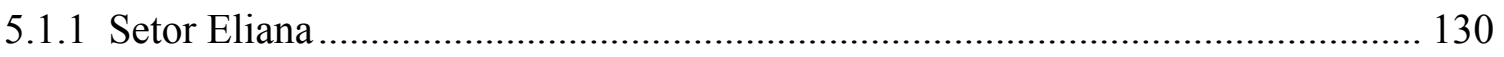

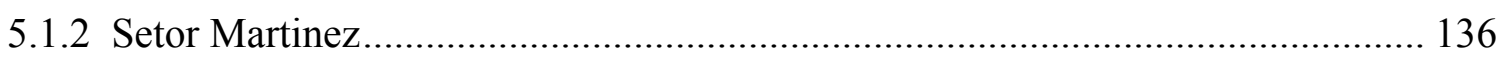

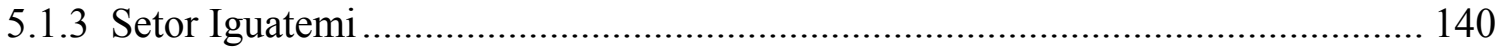

5.1.4 Metamodelo da rede de estudo........................................................................ 147

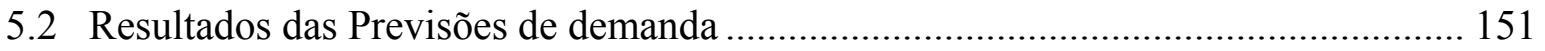

5.3 Resultados preliminares da otimização de objetivo único …………………………... 154

5.4 Análise do número necessário de avaliações da Função Objetivo................................ 160

5.5 Otimização de objetivo único da operação em Tempo Real......................................... 162

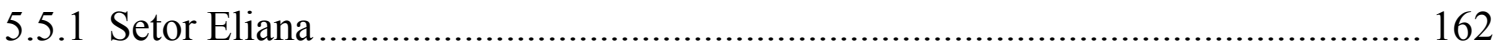

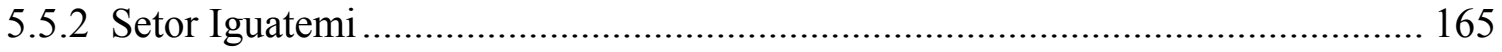

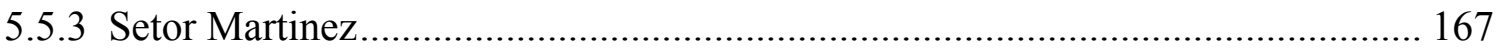

5.6 Otimização Multiobjetivo da Operação em Tempo Real............................................. 169

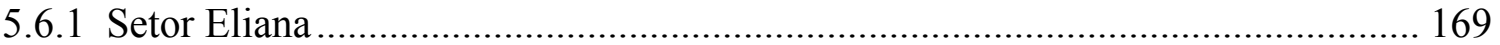

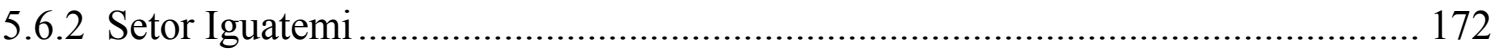

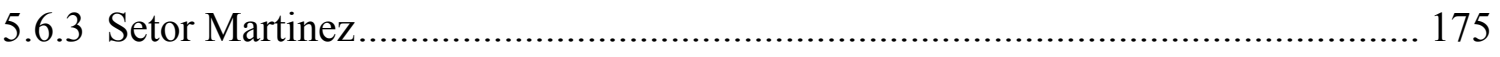

5.7 Resultados preliminares da otimização multiobjetivo com aplicação da Abordagem III 177

5.8 Aplicação das Abordagens II e III na Otimização Multiobjetivo ................................ 189

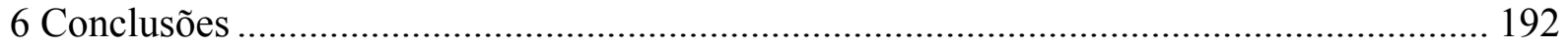

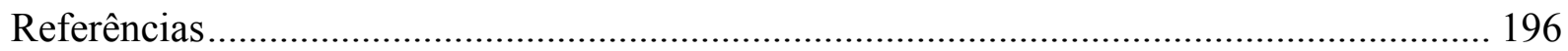




\section{Introdução}

Atualmente, há uma crescente preocupação com o uso de recursos naturais como a água, que é essencial tanto para o homem, quanto para a fauna e a flora. Além disso, devido ao crescimento urbano, a disponibilidade de água está cada vez menor, seja devido à poluição ou a devastação de mananciais.

Assim, as fontes viáveis para abastecimento estão cada vez mais distantes dos centros consumidores, tornando sua exploração mais cara, pois para realizar a sua adução a grandes distâncias, são necessárias estações elevatórias de maior porte, responsáveis pela elevação do consumo de energia.

$\mathrm{O}$ custo energético figura entre os quatro maiores custos relativo à Despesa de Exploração ${ }^{1}$ das companhias de saneamento, baseados nos dados apresentados no Sistema Nacional de Informações referente ao ano de 2006, o qual corresponde a um custo de 2,3 bilhões de reais anuais. Além disso, o consumo de energia dessas companhias responde por mais de $2 \%$ da energia total consumida no Brasil, o equivalente a 8,3 bilhões de $\mathrm{kWh} / \mathrm{ano}$, com destaque para os conjuntos motobomba, normalmente responsáveis por $90 \%$ do consumo dessas instalações.

Dentre os fatores responsáveis pelo elevado consumo de energia, é possível destacar: ausência de dados acerca do sistema, ausência de troca de dados entre os diversos setores das empresas de saneamento, ausência de planos de reabilitação, elevado índice de perdas da água tratada, além da falta de políticas de operação das redes de abastecimento, bem como dos sistemas elevatórios.

A operação dos sistemas de abastecimento de água consiste no controle do estado de funcionamento das bombas (ligado/desligado) e válvulas (fechamento/abertura), realizadas para suprir a demanda dos consumidores. A decisão sobre a melhor combinação do estado de tais elementos é complexa, pois esses elementos estão sujeitos à mudança de seus estados a cada momento. Aliado a esses fatores, há ainda o crescimento urbano e o aumento da demanda para contribuir para o aumento da complexidade dos sistemas de distribuição de água.

${ }^{1}$ A Despesa de Exploração (DEX) é um índice utilizado pelo Sistema Nacional de Informações sobre Saneamento (SNIS), que corresponde ao valor anual das despesas, compreendendo despesas com pessoal; produtos químicos; energia elétrica; serviços de terceiros; água importada; despesas fiscais ou tributárias incidentes na DEX; além de outras despesas de exploração. 
Assim, nem sempre é possível atender a todos os objetivos operacionais dos sistemas de abastecimento de água, pois, além das situações atípicas - tais como ocorrência de rompimento de tubulações, falha ou manutenção de bombas e válvulas ou mesmo incidência de incêndio. Ademais, o sistema pode estar sob diversas condições quanto a sua capacidade de atendimento da demanda, ou seja, a demanda e oferta podem estar em equilíbrio, ou ainda a capacidade de produção de água pode ser maior ou menor que a demanda.

Portanto, para se definir a melhor regra operacional, é necessário definir claramente a proposta e objetivos a serem alcançados, aliados ao conhecimento do sistema, ao mesmo tempo em que modelos matemáticos adequados podem viabilizar: a reprodução do comportamento do sistema face às diversas estratégias operacionais, a previsão de demandas para o horizonte considerado e a otimização da operação.

A obtenção de regras operacionais otimizadas é imprescindível e pode ser racionalizada com o uso de modelos matemáticos, a fim de que as companhias de saneamento atendam o objetivo de suprir a demanda de seus consumidores com o fornecimento de água de qualidade a menores custos, sem depender apenas da experiência dos operadores.

Entretanto, para se realizar a otimização da operação, podem ser utilizados um ou mais critérios para se avaliar a qualidade do resultado obtido via modelo matemático. Em geral, o objetivo básico a ser considerado é o custo energético, o qual utilizado isoladamente pode gerar soluções impraticáveis para sistemas reais. Apesar da existência de diversos estudos, os modelos de otimização da operação resultantes são pouco utilizados na prática, pois consideram como único objetivo a minimização dos custos, sem levar em conta outros critérios importantes, como a confiabilidade do sistema, a exequibilidade do projeto, dentre outros - os quais apresentam grande complexidade e não são diretamente mensuráveis.

Assim, é necessário considerar como objetivo melhorar a confiabilidade nas operações das redes de abastecimento, a fim de produzir resultados viáveis e robustos.

Outro aspecto que merece destaque é a otimização da operação em tempo real, que consiste basicamente em produzir as operações otimizadas a cada novo período, por exemplo, a cada 1 hora, para as próximas 24 horas $^{2}$, os quais devem utilizar dados constantemente atualizados, pois como a demanda, os dados variam não só ao longo do ano e da semana, mas no decorrer do dia.

2 Acredita-se que o horizonte de operação a ser otimizado deve ser no mínimo de 24 horas, para que sejam levadas em conta as diferentes tarifas de energia ao longo do dia. 
Esta tese foi organizada de maneira a definir os objetivos do trabalho (Capítulo 2), apresentar a revisão bibliográfica (Capítulo 3), estabelecer os materiais e os métodos utilizados (Capítulo 4), apresentar os resultados e discussões (Capítulo 5) e as conclusões finais (Capítulo 6) e por fim relacionar a bibliografia consultada (em Referências). 


\section{Objetivos}

Face ao exposto, a presente pesquisa visou oferecer contribuição original ao problema da operação de SAAs, tendo por objetivos:

- Otimizar a operação de sistemas de abastecimento de água segundo critérios múltiplos;

- Estudar e avaliar a confiabilidade das estratégias operacionais produzidas segundo a otimização multiobjetivo; e

- Estudar a viabilidade da avaliação de confiabilidade para a operação em tempo real. 


\section{Revisão Bibliográfica}

A revisão bibliográfica desenvolvida tem como enfoque a otimização da operação de sistemas de abastecimento de água, a confiabilidade, a previsão de demanda, bem como da simulação hidráulica com modelos heurísticos e das redes neurais artificiais.

\subsection{Técnicas de Otimização aplicadas aos sistemas de abastecimento de água}

Observam-se em diversos trabalhos que várias técnicas de otimização têm sido aplicadas à otimização de sistemas de abastecimento de água, tais como técnicas de otimização lineares (Jowitt e Germanopoulos, 1992), não-lineares (Ormsbee e Reddy, 1995), programação dinâmica (Sterling e Coulbeck, 1975). Mais recentemente, algumas metaheurísticas vêm sendo utilizadas como técnicas de otimização (Reca et al. 2007).

As metaheurísticas combinam a busca estocástica com a avaliação dos resultados produzidos para se guiarem no espaço de pesquisa das soluções. Estas têm se destacado ultimamente, e compreendem os seguintes métodos: Algoritmos Genéticos ("Genetic Algorithms" - GA), Recozimento Simulado ("Simulated Annealing” - SA), Busca Tabu, Algoritmo de Otimização da Colônia de Formigas ("Ant Colony Optimization” - ACO), Otimização por Enxame de Partículas ("Particle Swarm Optimization” - PSO) etc.

Dentre as metaheurísticas, os Algoritmos Genéticos têm sido bastante utilizados na otimização da operação de sistemas de abastecimento, sendo que no Brasil, por Carrijo (2004), Pedrosa (2006), Ribeiro (2005), Cunha (2009), dentre outros.

\subsubsection{Algoritmos Genéticos}

O AG é um método de otimização por busca estocástica que se baseia nos mecanismos de evolução natural propostos pelo naturalista Charles Darwin. Consiste basicamente em reproduzir matematicamente o princípio da seleção natural, ou seja, da sobrevivência dos indivíduos mais aptos de uma população. O método foi criado por John Holland na década de 60, e nos anos 80, foi aplicado com sucesso por seu aluno David Goldberg.

Esse método de otimização, ao contrário dos métodos tradicionais, realiza a busca da solução ótima a partir de uma população de soluções, ou seja, ao invés de utilizar uma única solução, utiliza-se de simultaneamente várias soluções para varrer o espaço de busca do problema. 
Os elementos básicos dos AGs são:

- cromossomos: conjunto de genes, estrutura de dados que codifica a solução do problema, também denominado indivíduo da população. Em termos da otimização, representa o vetor solução;

- gene: subconjunto do cromossomo, ou seja, elemento do vetor que representa o cromossomo. Em termo da otimização, representa as variáveis que compõem o vetor solução;

- alelo: valores que um gene pode assumir. Em termo da otimização, representa os valores que uma determinada variável pode assumir.

Assim, as soluções podem ser codificadas por meio de representação real, binária e outras representações. A escolha do tipo de representação mais adequada varia conforme o problema.

A estrutura básica dos AGs se resume a 4 operações: cálculo da aptidão (fitness), a seleção, o cruzamento (crossover) e a mutação, de acordo com o esquema da Figura 3-1 :

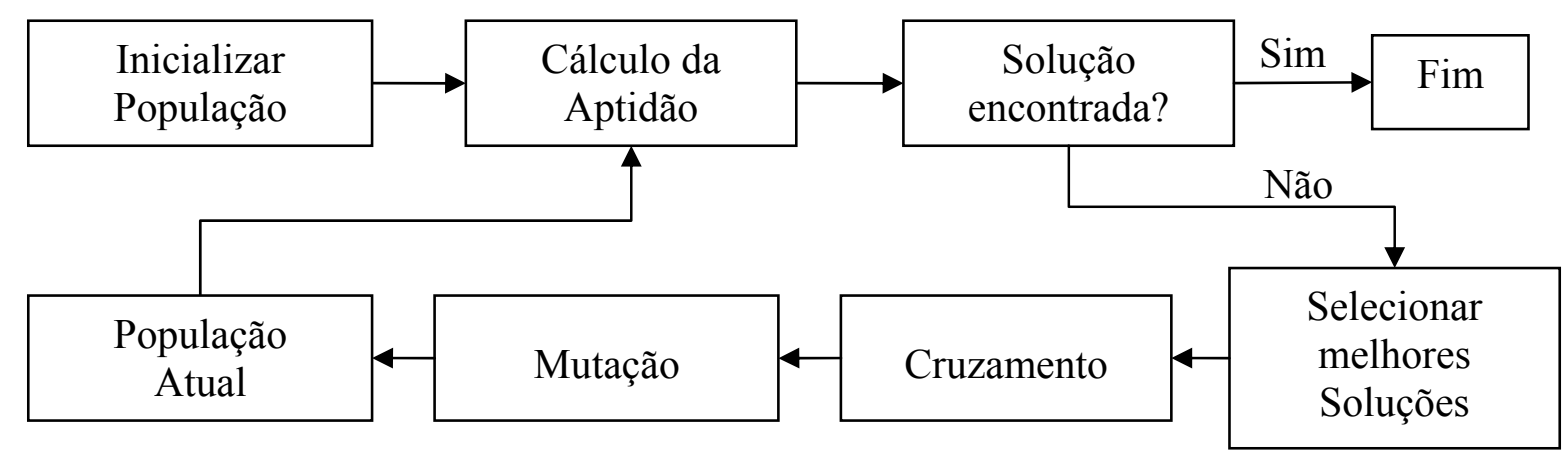

Figura 3-1 - Diagrama da Estrutura básica do AG

- Cálculo da aptidão: avalia o quão próximo a solução está da ótima ${ }^{3}$;

- Seleção: ocorre após o processo de avaliação da aptidão, e da mesma forma que na seleção natural, selecionam-se para a reprodução os organismos mais adaptados ao meio, i.e., as soluções com melhor valor de aptidão;

- Cruzamento (crossover): também denominado recombinação, consiste na combinação das soluções pais selecionadas para a criação de novas soluções filhas, podendo ser de simples permuta (representação binária) ou combinação das características correspondentes entre soluções atuais;

${ }^{3}$ Geralmente não se conhece a solução ótima, por isso a aptidão é calculada em relação a melhor solução ótima fictícia. 
- Mutação: processo que induz a introdução de pequenas mudanças aleatórias nos genes das soluções geradas por meio da combinação, que pode ser "bit" a "bit" (representação binária) ou variável por variável (representação real).

Podem-se citar algumas vantagens do AG sobre os métodos de otimização convencionais: a busca é realizada a partir de uma população de soluções ao invés de uma única solução a cada otimização, utiliza informação apenas da função objetivo, não necessitando de derivadas da função objetivo ou de outras informações, usa regras de transição probabilísticas e não determinísticas na identificação de soluções alternativas, é de fácil implementação, não necessitando conhecimentos matemáticos complexos e pode realizar buscas mesmo com grande número de variáveis.

Apesar de apresentar diversas vantagens, os AGs podem demandar grande tempo de processamento computacional, além de não garantir que a solução ótima global seja atingida.

\section{Algoritmos Genéticos Multiobjetivo}

O motivo pelo qual a otimização de sistemas de distribuição de água não são utilizados pelos operadores de sistemas de distribuição de água, é que geralmente busca-se minimizar apenas os custos, sem considerar os benefícios líquidos, os quais correspondem às diferenças entre os benefícios e os respectivos custos.

Assim, ao se diminuir o custo em R \$ 1000,00; pode-se estar diminuindo o benefício em R \$ 2000,00. Por isso é necessário considerar a otimização da operação do sistema de abastecimento como um problema multiobjetivo.

Em problemas multiobjetivo busca-se em geral otimizar um vetor de variáveis de decisão, satisfazendo-se restrições e otimizando-se a função vetorial composta de funções objetivo. Assim, na realidade, otimizar significa satisfazer o decisor com valores aceitáveis dos objetivos.

Formalmente, temos a seguinte representação do problema multiobjetivo:

$$
\begin{gathered}
\text { Min.(Max.) } z=f(x)=\left[f_{1}(x)=z_{1}, f_{2}(x)=z_{2}, \ldots, f_{r}(x)=z_{r}\right] \\
z \in Z \text {, sujeito a } x \in X
\end{gathered}
$$

Em que $x$ é o vetor de decisões, $z$ é o vetor de objetivos, $X$ denota o espaço de soluções factíveis e $Z=f(X)=\{z=f(x) \mid x \in X\}$ é a imagem de $X$ denominado espaço objetivo 
factível. Note que a imagem da solução $x=\left[x_{1}, x_{2}, \ldots, x_{n}\right]^{T} \in X$ no espaço objetivo é um ponto $z=\left[z_{1}, z_{2}, \ldots, z_{r}\right]=f(x)$, tal que $z_{j}=f_{j}(x), j=1,2, \ldots, \mathrm{r}$.

A seguir, definem-se 2 conceitos para a compreensão e resolução de problemas multiobjetivo:

- Definição 1: um ponto z domina $z^{\prime}$ se $z_{j}=f_{j}(x) \leq z_{j}^{\prime}=f_{j}\left(x^{\prime}\right)$, para pelo menos um $j$ (problema de minimização).

- Definição 2: Uma solução $x^{*} \in X$ é Pareto-ótima (ou eficiente) se não existe $x \in X$ tal que $z=f(x)$ domine $z^{*}=f\left(x^{*}\right)$. O conjunto de todas as soluções eficientes é denominado conjunto eficiente ou Pareto-ótimo.

Existem alternativas ao tratamento multiobjetivo, a fim de combinar as diversas funções objetivo em uma única função, utilizando-se funções de agregação. Os principais métodos de agregação são: Ponderação por Pesos, Métodos das Restrições $\varepsilon$ e Funções de Penalidades.

Porém, devido a dificuldades de implementação e utilização das técnicas de agregação, foram desenvolvidas técnicas de otimização populacionais, que são mais adequadas à geração de soluções não dominadas, das quais os AGs estão inclusos. As principais técnicas de AGs multiobjetivo são: MOGA ("Multiple Objective Genetic Algorithm"), NSGA ("Nondominated Sorting Genetic Algorithm"), SPEA ("Strength Pareto Evolutionary Algorithm"), NSGA II.

\subsubsection{Otimização multimétodo ou hiperheurística}

Apesar do sucesso dos métodos heurísticos em resolver diversos problemas reais, ainda há dificuldades em aplicá-los a novos problemas ou mesmo em variações de problemas existentes, seja para selecionar adequadamente os parâmetros ou mesmo para selecionar um método que seja mais eficiente para o problema em questão.

Assim, surgiram as hiperheurísticas, com o objetivo de produzir métodos de otimização mais gerais, que, de acordo com Burke et al. (2010), podem ser classificadas em: seletivas ou gerativas, conforme ilustração da Figura 3-2.

Os métodos pertencentes categoria Seletiva realizam seleção de heurísticas existentes, enquanto que os métodos da categoria Gerativa constroem heurísticas a partir dos componentes de outras heurísticas. Essas duas categorias de métodos podem ser classificadas também quanto ao tipo de heurística utilizada: construtiva ("constructive") ou perturbativa ("perturbative"). A construtiva constrói a solução de modo incremental, ou seja, inicia-se com 
uma solução "vazia", e então seleciona o método heurístico mais apropriado para construir gradualmente a solução. A classe perturbativa inicia-se com uma solução completa e iterativamente seleciona métodos heurísticos para melhorar a solução.

As hiperheurísticas podem ainda ser classificadas quanto à técnica de seleção das heurísticas: aprendizado "online", aprendizado "offline" e sem aprendizado. A primeira aprende enquanto o problema é resolvido, enquanto que a segunda aprende a partir de um conjunto de problemas de treinamento. Por fim, o último tipo não realiza a seleção de heurísticas por meio de aprendizado.

Assim, pode-se definir hiperheurística, segundo Burke et al. (2010), como "um método de busca ou mecanismo de aprendizado para selecionar ou gerar heurísticas para resolver problemas de busca computacionais", ou seja, a hiperheurística resolve o problema de maneira indireta e o espaço de busca são as heurísticas, ao contrário das metaheurísticas, em que o espaço de busca é composto pelas soluções do problema.

Pode-se ler com mais detalhes a revisão do estado da arte das hiperheurísticas em Burke et al. (2010). As idéias que precederam as hiperheurísticas não são novas, e surgiram nos anos 1960, nas mais diversas áreas das ciências da computação, da inteligência artificial e da pesquisa operacional.

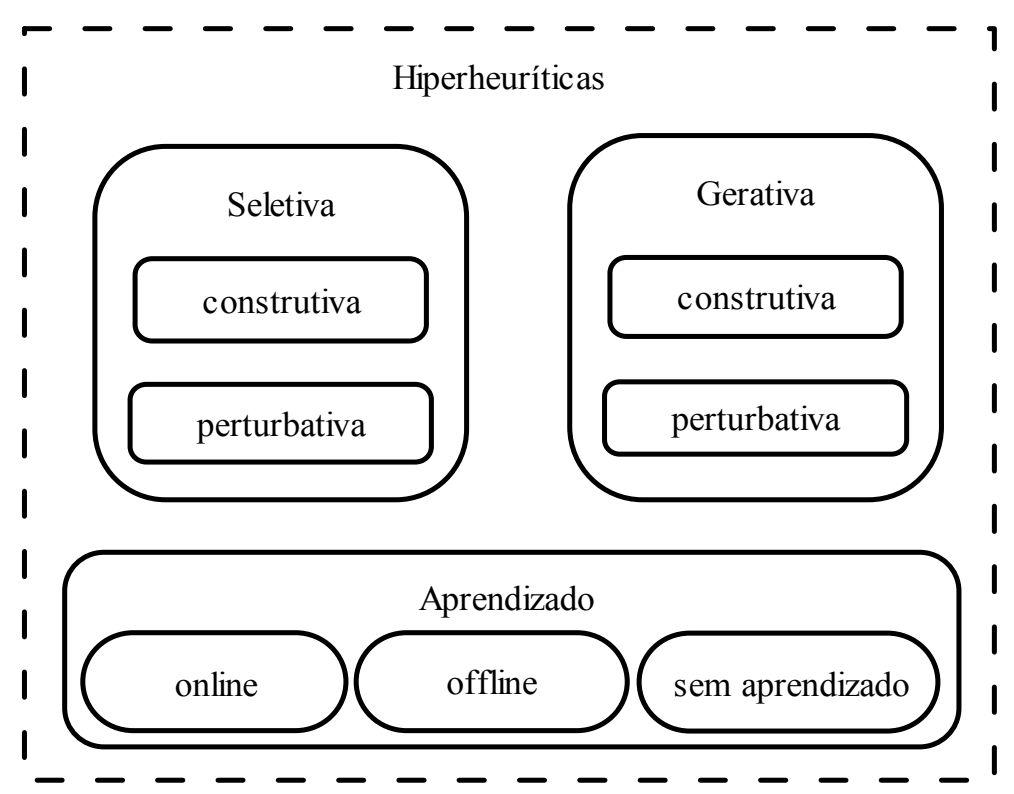

Figura 3-2 - Classificação das Hiperheurísticas. Adaptado de Burke et al. (2010)

Após o trabalho de Cowling et al. (2000), que utilizou o termo hiperheurística pela primeira vez na área da otimização, é que o termo começou a ser empregado largamente. 
Bilgin et al. (2006), Ozcan et al. (2006, 2008) e Bai et al. (2008) realizaram estudos comparativos entre diversas hiperheurísticas.

Bilgin et al. (2006) compararam 35 hiperheurísticas resultantes das combinações dos métodos de seleção das heurísticas e critérios de aceitação das heurísticas selecionadas. As hiperheurísticas estudadas foram testadas com e sem o aprendizado, e a aceitação foi realizada com critérios determinísticos e não determinísticos. Os autores concluíram que não houve dominância entre as hiperheurísticas testadas para diversos problemas de referência.

Ozcan et al. (2006) investigaram o desempenho de diferentes hiperheurísticas usando combinações de heurísticas do tipo "hill climber", que realizam busca local para melhorar a solução, e mutacionais, que perturbam a solução sem considerar se haverá melhora da solução. Foram testadas quatro hiperheurísticas, e a melhor configuração identificada aplicou heurísticas mutacionais seguidas do "hill climber".

Ozcan et al. (2008) ampliaram os estudos de Ozcan et al. (2006) e observaram que certas heurísticas raramente eram usadas ao se empregar um algoritmo de seleção das heurísticas com aprendizado. Assim, eles reduziram os conjuntos de heurísticas disponibilizadas para seleção, e observaram que houve aperfeiçoamento do melhor modelo obtido por Ozcan et al. (2006).

Bai et al. (2008) realizaram comparação entre os modelos de otimização heurísticos como o algoritmo do gradiente reduzido modificado, heurísticas do tipo "greedy" ou GRASP ("Greedy Randomized Adaptive Search Procedure") a busca tabu e a técnica do recozimento simulado - e hiperheurísticas baseadas em recozimento simulado e busca tabu. Observaram que as hiperheurísticas baseadas no recozimento simulado produziram os melhores resultados, e resultados similares aos produzidos por tradicionais modelos heurísticos de recozimento simulado e GRASP.

No Brasil, há o trabalho de Sucupira (2007), que aborda uma classificação mais simples, baseada no tipo de heurísticas utilizadas, mas que estão inseridas na classificação apresentada anteriormente: hiperheurística de busca por entorno ou hiperheurística populacional. Ambas são hiperheurísticas do tipo seletiva - a primeira é do tipo pertubativa e a segunda do tipo construtiva. Além de comparar hiperheurísticas já existentes, o autor propôs mais algumas hiperheurísticas, as quais foram aplicadas ao desafio ROADEF $2005^{4}$ e a um

4 ROADEF - "Recherche Opérationnelle et d'Aide à la Décision”, ou Pesquisa Operacional e de Suporte à Decisão - o desafio do ano de 2005 foi proposto pela montadora Renault e consistia em um problema de sequenciamento de carros numa linha de produção. 
problema de roteamento de veículos com restrição de capacidade . As hiperheurísticas pertubativas produziram os melhores resultados médios.

A maioria dos trabalhos publicados aborda o desenvolvimento de hiperheurísticas sequenciais, em que uma heurística é selecionada por vez e aplicada a uma única solução. Ouelhadj e Petrovic (2010) afirmam que as hiperheurísticas possuem um sistema naturalmente distribuído, já que consistem de um conjunto de heurísticas dirigidas por uma heurística de nível mais elevado. Assim, é possível distribuir a otimização entre as hiperheurísticas, ou seja, executar diferentes métodos em paralelo e promover a cooperação entre os mesmos, de modo a superar as fraquezas de um método com as características superiores de outro.

Burke et al. (2003), Kumar et al. (2008), Kumar et al. (2009), Tolay e Kumar (2009) e Gomez e Terashima-Marín (2010) realizaram a otimização multiobjetivo utilizando as hiperheurísticas, sendo que os três últimos utilizaram a programação genética para desenvolver as hiperheurísticas.

Burke et al. (2003) resolveram os problemas multiobjetivos de alocação de espaço em uma instituição acadêmica para diversos usos e também para resolver o problema de alocação de eventos durante o ano letivo. A resolução do problema foi realizada por meio de hiperheurísticas baseadas na busca tabu. Os resultados permitem concluir que as hiperheurísticas com abordagem multiobjetivo produziram resultados satisfatórios.

Kumar et al. (2008) produziram hiperheurísticas multiobjetivo para resolver o clássico problema da mochila ${ }^{5}$, o qual considera dois objetivos: maximização do lucro e minimização do peso.

Tolay e Kumar (2009) desenvolveram hiperheurísticas com o objetivo de resolver o problema da coloração de grafos ${ }^{6}$, de modo a minimizar o número de cores utilizadas, bem como o número de arestas que conectam os vértices da mesma cor.

Gomez e Terashima-Marín (2010) aplicaram as hiperheurísticas multiobjetivo na resolução do problema de estoque e corte irregular bidimensional.

${ }^{5} \mathrm{O}$ problema da mochila consiste em preencher uma mochila com objetos de diferentes pesos e valores, sem que exceda o peso máximo.

${ }^{6}$ Grafos são conjuntos de pontos. O ponto resultante de duas ou mais linhas é denominado vértice, e a linha formada pelo encontro de superfícies é denominado aresta. A coloração de vértices/arestas deve ser realizada de modo que não haja vértices/arestas adjacentes que compartilhem da mesma cor. 
Nos trabalhos de Kumar et al. (2008), Kumar et al. (2009), Tolay e Kumar (2009) e Gomez e Terashima-Marín (2010), foram obtidos resultados comparáveis aos produzidos com outros métodos heurísticos específicos para os problemas, em alguns casos, produziram resultados até melhores.

Ouelhadj e Petrovic (2010) adaptaram a estratégia de cooperação proposta por Crainic e Toulouse (2008) às hiperheurísticas, possibilitando que a melhor solução produzida e as melhores soluções de cada heurística fossem armazenadas e atualizadas a cada ciclo de otimização. A cooperação pode ser síncrona ou assíncrona. No primeiro tipo, a seleção e atualização das melhores soluções são realizadas somente após todas as heurísticas finalizarem a busca para a dada iteração, enquanto que no método assíncrono, sempre que uma heurística melhora a solução, realiza-se o processo de seleção e atualização. Além disso, nesse último tipo de cooperação, quando a heurística não consegue melhorar a solução após certo número de iterações, uma das soluções armazenadas, que ainda não foi usada pela mesma heurística, é empregada como solução inicial para o novo ciclo de otimização. As hiperheurísticas cooperativas produziram os melhores resultados que as hiperheurísticas sequenciais, e entre as cooperativas, as do tipo assíncronas apresentaram o melhor desempenho.

Com base no trabalho de Ouelhadj e Petrovic (2010), observa-se que realizar otimizações paralelas com compartilhamento de informações entre as heurísticas resultam em melhor desempenho da otimização, como também foi observado por Vrugt e Robinson (2007), que propuseram um método de busca multimétodo, o qual não se encaixa nas classificações de hiperheurísticas propostas por Burke et al. (2010). O método foi denominado Método Multi-algoritmo Geneticamente Adaptado (“A Multialgorithm Genetically Adaptive Method" - AMALGAM). A otimização proposta pelos autores consiste em utilizar diferentes algoritmos de busca simultaneamente, os quais aprendem uns com os outros através do compartilhamento de informação usando uma população de soluções em comum. Nesse trabalho foram utilizados o NSGA-II, o PSO, a busca "Adaptative Metropolis Search" (AMS) e Evolução Diferencial ("Diferential Evolution” - DE). O AMALGAM foi aplicado a diversos problemas multiobjetivos de referência e produziu resultados até 10 vezes melhores que os algoritmos utilizados isoladamente, e em certos problemas conseguiu identificar mais rapidamente as soluções otimizadas.

Raad et al. (2010) aplicaram o AMALGAM à otimização multiobjetivo de projetos de referência de redes de abastecimento de água, os quais combinaram além do NSGA-II e do DE, o UMDA (“Univariate Marginal Distribution Algorithm”) e um algoritmo tipo "greedy". 
O AMALGAM também foi aplicado com sucesso a problemas de objetivo único por Vrugt et al. (2009), os quais utilizaram como conjunto de algoritmos de otimização o AG, o PSO e o método da adaptação da matriz de covariância ("Covariance Matrix Adaptation" - CMA). Em ambos os trabalhos, a otimização multimétodo produziu melhores resultados em relação as otimizações que utilizaram os algoritmos isoladamente.

Wang e Li (2010) propuseram um método de otimização semelhante ao AMALGAM, e o aplicaram a um problema multiobjetivo dinâmico ${ }^{7}$. Os autores combinaram o AG e a DE para aliar a rápida convergência ao relativo baixo custo computacional do $\mathrm{AG}$ - considerando o desempenho entre os algoritmos multiobjetivo evolucionários ("Multiobjective Evolutionary Algorithms" - MOEAs) - e da geração diversificada da frente Pareto da DE, após um longo processo de otimização. Assim, inicialmente o AG foi utilizado até se obter uma boa convergência, e então a DE foi utilizada para diversificar as soluções nãodominadas. Tal estratégia se mostrou superior aos demais métodos de otimização testados.

Da análise realizada sobre os trabalhos apontados nesta seção, pode-se depreender que o uso de conjuntos de algoritmos para realizar a otimização de problemas tem sido cada vez mais investigado, pois as combinações possibilitam superar as fraquezas dos algoritmos quando usados isoladamente, sobretudo com a cooperação entre os algoritmos, ou seja, através do compartilhamento das informações entre os mesmos. Tal estratégia pode produzir soluções otimizadas mais rapidamente ou soluções ainda melhores, como foi demonstrado por Vrugt e Robinson (2007).

\subsubsection{Representação da programação de bombas}

Além do algoritmo de otimização a ser utilizado, a representação da programação de bombas (RPB), ou seja, como o estado das bombas é representado durante o processo de otimização, também influencia na qualidade e velocidade do processo de otimização.

Segundo López-Ibáñez (2009), a RPB pode ser explícita ou implícita. A representação explícita define diretamente o estado da bomba (ligado/desligado) para determinados períodos, ou a fração de tempo que as bombas permanecem ativas (Savic e Walters, 1995; Pezeshk e Helweg, 1996; Boulos et al., 2001). Já a representação implícita é definida em função da propriedade de outros elementos da rede de abastecimento, tais como os níveis do reservatório (Atkinson, 2000; van Zyl et al. 2004).

${ }^{7}$ O problema é dito dinâmico porque a função objetivo e as restrições são variáveis com o decorrer do tempo. 
A representação explícita mais utilizada é a binária, em que a programação da bomba é codificada em uma cadeia de "bits", sendo que cada bit, o qual assume valor 0 (desligado) ou 1 (ligado), representa o estado da bomba para um determinado intervalo.

O controle da bomba por meio dos níveis do reservatório é a representação implícita mais utilizada, sendo que a bomba é desligada quando o nível do reservatório ultrapassa o nível máximo, e ligada ao atingir um nível mínimo.

Ainda segundo López-Ibáñez (2009), há outras RPB apresentadas na literatura, criadas para aplicações específicas ou em função de limitações da formulação do problema de otimização, mas que não possuem vantagens sobre a representação binária ou através do controle de bomba por meio do nível do reservatório. Existem ainda outras representações que são apenas extensões desses dois métodos principais.

Sakarya e Mays (2000) e McCornick e Powell (2004) utilizaram o tempo para controlar as bombas, mas López-Ibáñez (2009) propôs uma nova representação explícita, denominada "time-controlled trigger", em que a bomba, além de ser controlada por meio do tempo, permite limitar explicitamente a quantidade de acionamentos da bomba. O controle é representado por pares de variáveis de decisão $t_{i}$ e $t^{\prime}$, ilustrados na Figura 3-3. A representação temporal da bomba pode ser absoluta ou relativa:

- Representação absoluta: as variáveis de decisão são períodos absolutos em relação ao início da programação. Para cada par $\left(t_{i}, t^{\prime}{ }_{i}\right)$, o primeiro elemento indica o instante em que a bomba deve ser acionada, e o segundo indica o instante em que se deve desativá-la;

- Representação relativa: as variáveis de decisão são relativas ao estado anterior da bomba. Cada par $\left(t_{i}, t_{i}{ }_{i}\right)$ representa respectivamente o período em que a bomba deve permanecer ligada e desligada.

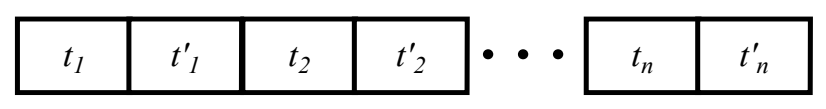

Figura 3-3 - RPB pelo tempo

O método de RPB proposto por López-Ibáñez (2009) permite controlar explicitamente a quantidade de acionamento de bombas, ao se limitar o número de pares de variáveis, sendo que $n$ pares significa que haverá no máximo $n$ acionamentos da bomba. Além disso, tal representação permite reduzir consideravelmente o espaço de busca de soluções. Por exemplo, para o caso da representação binária, em que cada intervalo pode assumir o estado ativo ou 
inativo, a programação de uma bomba para 24 intervalos horários totalizará $2^{24}=16.777 .216$ combinações possíveis; enquanto que para a nova representação, restringindo-se o número de acionamento para três, haverá 290.998 soluções possíveis.

López-Ibáñez (2009) comparou a representação binária, a RPB por meio do nível do reservatório e as duas novas representações de sua autoria, utilizando um AG simples. Os testes foram realizados para as redes de Richmond e van Zyl (van Zyl, 2004) e avaliaram-se os resultados para diferentes quantidades de população e diferentes métodos de recombinação e mutação. Observando-se os resultados, pode-se concluir que o melhor método é o de representação relativa, que produziu o menor custo de bombeamento médio ${ }^{8}$.

\subsection{Otimização da operação de sistemas de abastecimento de água}

Suprir a demanda hídrica é o principal objetivo da operação de sistemas de abastecimento de água, a qual deve atender aos requisitos de quantidade e qualidade a custos operacionais razoáveis (custos com energia, manutenção etc) e de modo confiável.

Cunha (2009) propôs a otimização de sistemas de distribuição de água sob os enfoques do Planejamento Operacional em Nível Estratégico e da Operação em Tempo Real. Embora ambos os enfoques visem à otimização da operação dos componentes do sistema, como bombas e válvulas, eles respondem às distintas necessidades de ordem práticas.

O Planejamento Operacional em Nível Estratégico apóia-se em curvas de demanda típicas (médias) conhecidas e níveis de água iniciais estabelecidos para os reservatórios com vistas à determinação das trajetórias operacionais otimizadas, de maneira tal que os níveis de água dos reservatórios, no final do horizonte de planejamento (24 horas), sejam coincidentes com os do início do período.

O Planejamento Operacional Estratégico possibilita a investigação do comportamento dos níveis dos reservatórios, indica o grau de utilização da capacidade existente do sistema e também oferece subsídios para decisões relativas à contratação de tarifas de energia elétrica, futuros investimentos na infra-estrutura etc.

No entanto, a utilização de curvas de demanda típicas não é diretamente aplicável à operação, pois, no decorrer do dia, as demandas, apesar de seguirem a tendência das curvas médias, apresentam desvios por possuírem comportamento aleatório. Assim as operações

${ }^{8}$ Cada configuração dos diferentes método foi testado 15 vezes com diferentes sementes aleatórias iniciais. 
otimizadas produzidas pelo Planejamento Estratégico podem não ser soluções otimizadas para a situação corrente.

Com isso, é necessário usar regras operacionais otimizadas definidas pela Operação em Tempo Real, com a capacidade de serem ajustadas continuamente, apoiadas na previsão de demanda em tempo real, ou seja, constantemente atualizada.

Se por um lado a literatura especializada demonstra grande interesse na otimização dos SAAs em nível estratégico, por outro, poucos são os trabalhos que foram dedicados à problemática da operação em tempo real. A seguir apresentam-se alguns dos autores que abordaram a mencionada problemática: Coulbeck et al. (1988), Zessler e Shamir (1989), Jowitt e Germanopoulos (1992), Coulbeck e Orr (1993), Lansey e Awumah (1994), Nitivattananon et al. (1996), Pezeshk e Helweg (1996), Boulos et al. (2000), Pasha e Lansey (2009).

Coulbeck et al. (1988) e Coulbeck e Orr (1993) apresentaram um sistema de controle operacional totalmente automatizado implementado no Reino Unido, para fins de minimização do custo operacional. O sistema, que utiliza dados telemétricos, é composto de um simulador hidráulico, um previsor de demanda e um módulo otimizador. O último módulo fornecia os comandos operacionais ótimos para as próximas 24 horas, os quais eram gerados novamente a cada nova atualização de dados do sistema de telemetria.

Zessler e Shamir (1989), Lansey e Awumah (1994) e Nitivattananon et al. (1996) utilizaram a programação dinâmica para otimizar a operação para um período de $24 \mathrm{~h}$.

Jowitt e Germanopoulos (1992) utilizaram a programação linear para otimizar o custo de bombeamento de uma rede no Reino Unido. Os autores consideraram no problema a eficiência das bombas, a tarifa de energia e as restrições hidráulicas e operacionais, além de descreverem a linearização das equações hidráulicas e das restrições do problema. O método foi considerado pelos autores robusto e com baixo requisito computacional.

Lansey e Awumah (1994), além de considerarem a minimização do custo energético, também levaram em conta a quantidade de acionamentos dos conjuntos moto-bomba. A otimização da operação foi realizada por meio da programação dinâmica e aplicada ao sistema de Austin, Texas, e produziu uma redução do custo energético da ordem de $9 \%$.

Nitivattananon et al. (1996) também empregaram a programação dinâmica para otimizar a operação da cidade de Pittsburgo, Pensilvânia, além de também considerarem o acionamento das bombas. O modelo desenvolvido realizava a discretização do sistema de abastecimento de água em vários subssistemas, a fim de diminuir o tempo de processamento computacional. A otimização é realizada em duas fases: longo e curto prazo. A fase de longo 
prazo (mensal) fornece uma solução aproximada a fim de estimar o custo energético no período, e a fase de curto prazo (diário) atualiza as soluções da fase de longo prazo. Foram produzidas reduções no consumo de energia da ordem de $20 \%$.

Pezeshk e Helweg (1996) propuseram o método denominado algoritmo de busca adaptativa para otimizar a operação de um sistema de distribuição de água, que é um modelo de otimização de busca discreta. O algoritmo é acionado quando a carga de pressão em um determinado ponto de controle está fora do limite mínimo ou máximo. Ao ser acionado, a bomba que possui maior influência sobre o ponto de controle e fornece água a menores custos é selecionada para ser ligada ou desligada. A maior vantagem do método é a rápida convergência a uma solução otimizada, a qual possibilita sua aplicação à operação em tempo real.

Boulos et al. (2000) realizaram a otimização da operação combinando um simulador hidráulico $\left(\mathrm{H}_{2} \mathrm{ONet}\right)$ aos Algoritmos Genéticos. Além de terem como objetivo a minimização do custo energético, consideraram implicitamente restrições de carga de pressão nos nós, nível do reservatório e número de acionamentos das bombas. Os autores afirmaram terem reduzido os custos de bombeamento ao passo que mantiveram satisfatório nível de serviço.

Pasha e Lansey (2009) descreveram metodologias preliminares que podem ser utilizadas para otimizar a operação de bombas e reservatórios. Os autores utilizaram a programação linear a fim de obter soluções quase-ótimas rapidamente, que foi aplicada a um sistema hipotético com 1 reservatório.

Além dos autores citados anteriormente, destacam-se trabalhos publicados pelos autores do projeto POWADIMA ${ }^{9}$ - Jamieson et al. (2007), Rao e Salomons (2007), Salomons et al. (2007) e Martinez et al. (2007).

Jamieson et al. (2007) projetaram um modelo computacional para otimizar a operação em tempo real, para substituir o simulador hidráulico convencional por um modelo representado por uma rede neural artificial (“Artificial Neural Network" - ANN), a fim de reduzir o tempo computacional utilizado nas simulações convencionais. A otimização da operação foi realizada com o emprego da técnica dos Algoritmos Genéticos ("Genetic Algorithm" - GA). Tal modelo foi denominado ANN-GA.

Rao e Salomons (2007) aplicaram o modelo ANN-GA a uma rede hipotética da literatura com modificações, denominada Any Town (M), enquanto Salomons et al. (2007) e

9 Projeto POWADIMA (“Potable Water Distribution Management”) foi financiado pela Comissão Européia, com vistas a reduzir o custo energético nas operações em redes de abastecimento de Água 
Martinez et al. (2007) aplicaram o modelo ANN-GA a redes de abastecimento da cidade de Haifa, Israel, e da cidade de Valência, Espanha, respectivamente. Obtiveram redução nos custos energéticos em torno de $25 \%$ e $17 \%$.

O modelo ANN-GA apresentou resultados satisfatórios, representando a rede com boa precisão, pois ao comparar com o modelo de simulação EPANET produziu a raiz do erro quadrático médio ("Root Mean Squared Error" - RMSE) em torno de 1,3\%, para a cidade de Valência, e de $0,48 \%$ para a cidade de Haifa. Os desvios dos níveis dos reservatórios foram de até $6 \mathrm{~cm}$. Além disso, o modelo ANN-GA apresentou tempo de processamento computacional inferior aos tradicionais modelos de simulação.

No Brasil, os seguintes autores estudaram a otimização da operação em tempo real: Almeida (2001), Vicente (2005), Ribeiro (2005) e Cunha (2009).

Almeida (2001) utilizou a programação não-linear inteira mista para realizar a otimização da operação de uma rede hipotética e do Subsistema Adutor Metropolitano Alça Leste, da cidade de São Paulo, denominada SAM Leste. O método de otimização foi aplicado tanto para minimizar a função objetivo quanto para resolver o problema hidráulico. Foram avaliadas duas funções objetivo, com vistas a reduzir o consumo de energia: redução da vazão bombeada e da potência de eixo utilizada, em que a segunda apresentou maior economia de energia. O algoritmo empregado forneceu ótimo local e apresentou pequeno consumo de tempo computacional, característica que o torna viável a operação em tempo real, mas não realizou a previsão da demanda, pois utilizou curvas de demanda típicas, o qual insere o trabalho no escopo do Planejamento Operacional Estratégico.

Vicente (2005) realizou a otimização da operação da SAM Leste com o uso da programação linear, a qual estava integrada a um sistema SCADA ("Supervisory Control and Data Acquisition" - Sistema de Supervisão e Aquisição de Dados), um previsor de demanda e um simulador hidráulico (WaterCad). O modelo foi capaz de produzir regras operacionais mais econômicas, apesar de nem sempre gerar resultados factíveis, pois nem todas as restrições hidráulicas foram consideradas.

Ribeiro (2005) propôs a otimização da operação utilizando os algoritmos genéticos, também para o SAM Leste. Ao contrário de Vicente (2005), utilizou um simulador hidráulico gratuito, o EPANET 2, mas não realizou a previsão da demanda, usou o registro histórico como previsão perfeita.

Os trabalhos de Vicente (2005) e Ribeiro (2005), embora tivessem como objetivo a operação em tempo real, não se enquadram em tal concepção, pois ambos os autores realizaram a otimização apenas uma vez para ser aplicada no decorrer do dia. Além disso, o 
tempo de processamento computacional de ambos os trabalhos tornam-os inviáveis à aplicação em tempo real - o modelo de Vicente (2005) demandou um tempo de processamento computacional de $45 \mathrm{~min}^{10}$, além dos 12 min para realizar a previsão de demanda, e como nem sempre produz soluções factíveis, não seria possível refazer a otimização, enquanto que o modelo de Ribeiro (2005) demandou cerca de 3 horas para simular as 24 horas $^{11}$.

Cunha (2009) usou os algoritmos genéticos (AGs) para otimizar a operação, o qual foi associado a um previsor de demandas baseado em séries de Fourier e um simulador hidráulico (EPANET 2). O modelo desenvolvido foi aplicado a um sistema hipotético, o qual produziu soluções eficientes e robustas. No entanto, o tempo de processamento computacional da solução foi muito grande, de até 46 horas, o que inviabilizaria o seu uso para a operação em tempo real. Também não houve melhora significativa do tempo de processamento, apesar da autora tentar contornar tal problema por meio da utilização dos resultados produzidos pelo Planejamento Estratégico na forma de níveis metas, que consistem em (níveis) guias a serem utilizados na Operação em Tempo Real, a fim de agilizar a otimização. Além disso, tal estratégia alternativa resultou em maiores custos em relação à otimização em tempo real sem o uso dos níveis meta.

\subsection{Simulação hidráulica com modelos heurísticos}

Os simuladores hidráulicos são responsáveis por boa parte do tempo de processamento computacional gasto na otimização da operação, e podem inviabilizar seu uso para operação em tempo real.

Algumas alternativas foram sugeridas na literatura para reduzir o tempo de processamento consumido pelos simuladores hidráulicos, e entre eles está o uso de modelos heurísticos (ou metamodelos) para substituir os tradicionais simuladores hidráulicos. A metamodelagem consiste em calibrar o modelo substituto a partir de dados observados ou gerados pelo simulador, para que reproduza alguns dos resultados fornecidos pelo simulador, os quais são utilizados na otimização do problema.

Apesar do tempo despedido para desenvolver o metamodelo, o seu uso é compensado quando se recorre a algoritmos que irão utilizá-lo repetidas vezes, como o AG. Existem diversos tipos de metamodelos, como os modelos regressivos e as RNAs (Broad et al., 2005).

\footnotetext{
${ }^{10} \mathrm{O}$ modelo foi usado em um computador Pentium 4, 1GHz, 512 MB RAM.

${ }^{11} \mathrm{O}$ modelo foi aplicado em um computador Pentium 4, 2,2 GHz.
} 
A RNA tem recebido destaque na metamodelagem devido a sua capacidade de se equiparar ou mesmo superar os demais modelos, especialmente pela sua capacidade de modelar comportamentos não lineares e complexos.

A metamodelagem tem sido utilizada em diversas aplicações, tais como a modelagem: de reatores químicos (Kalagnanam and Diwekar, 1997), da operação de aviões (Meckesheimer et al., 2002), de complexos modelos de água subterrâneas (Aly e Peralta, 1999; Johnson e Rogers, 2000; Yan e Minsker, 2006) e da alocação de água em bacias (Mousavi e Shourian, 2010), sendo que os quatro últimos trabalhos são de particular interesse por empregarem metamodelos baseados em RNAs.

Mais recentemente, Broad et al. (2005), Jayaram (2006), Rao e Salomons (2007), Salomons et al. (2007), Martínez et al. (2007) e Broad et al. (2010) utilizaram os modelos heurísticos baseados em redes neurais artificiais para substituir o simulador hidráulico EPANET, o qual é utilizado para modelar sistemas de abastecimento de água.

Broad et al. (2005) usaram um metamodelo para simular o comportamento hidráulico e a qualidade da água, mais especificamente o cloro residual na água. O metamodelo foi usado em conjunto com o AG, denominado ANN-GA, para otimizar o projeto dos túneis de Nova Iorque. Após a convergência da otimização usando o modelo heurístico, o simulador hidráulico tradicional era utilizado para avaliar se a solução encontrada pelo ANN-GA era factível. Na tentativa de melhorar a solução, efetuaram uma busca local, pois a solução encontrada com o modelo heurístico pode ser subótimo. O uso do ANN-GA tornou o processo 700 vezes mais rápido em comparação ao uso do tradicional simulador hidráulico EPANET no processo de otimização.

Jayaram (2006) realizou a otimização multiobjetivo do projeto em conjunto com a reabilitação de um sistema de distribuição de água hipotético. Construiu metamodelos para simuladores hidráulicos com análise baseada na demanda ("Demand Driven Analysis" DDA) e também na carga de pressão ("Head Driven Analysis" - HDA), com o objetivo de fornecer medidas alternativas de confiabilidade. O autor propôs uma inovação no uso de metamodelos - utilizou RNAs de múltiplos níveis, que compreendem 3 níveis, denominadas ANN-I, ANN-II e ANN-III, para obtenção de resultados mais precisos no intervalo de medida de maior interesse do projetista. A primeira rede neural (ANN-I), do primeiro nível fornece resultados para todo o intervalo possível da medida alternativa (0-100\%). A segunda RNA, a ANN-II, fornece a medida para um intervalo de 90 a $100 \%$, enquanto que a última RNA (ANN-III) fornece resultados para o intervalo de 96 a 100\%. O uso da RNA em substituição à simulação tradicional tornou o processo de otimização 58 vezes mais rápido. 
Os autores do projeto POWADIMA, Rao e Salomons (2007), Salomons et al. (2007) e Martinez et al. (2007), aplicaram a metamodelagem respectivamente ao sistema hipotético de Anytown; ao sistema de distribuição de Haifa, Israel; e ao sistema de Valência, Espanha. A redução do tempo de simulação para os dois últimos sistemas foi de 25 e 94 vezes, respectivamente.

Uma outra alternativa para resolver o problema do tempo de processamento computacional dos modelos de simulação tradicionais seria o uso de modelos esqueletonizados ${ }^{12}$ proposto por Shamir e Salomons (2008).

Shamir e Salomons (2008), diferentemente dos autores envolvidos no projeto POWADIMA citados acima, usaram um simulador hidráulico convencional com um modelo esqueletonizado, da cidade de Haifa, Israel. Apesar de utilizar como base o mesmo sistema de distribuição utilizado por Salomons et al. (2007), Shamir e Salomons (2008) utilizaram como base para a obtenção do modelo reduzido a rede de abastecimento com mais detalhes. Assim, o custo energético foi reduzido em torno de $9 \%$, e houve redução do tempo computacional de 15 vezes em relação ao modelo convencional não reduzido.

Broad et al. (2010) apresentaram metodologia detalhada para a construção do metamodelo, a qual considerou diversos fatores relativos ao sistema de distribuição que afetam o desempenho da RNA, a fim de simplificar a representação do sistema de abastecimento pelo modelo heurístico. Para tanto, consideraram a complexidade do simulador hidráulico e do espaço de decisão das variáveis, além dos pontos do sistema para os quais é necessária a produção de respostas. Pode-se observar que a esqueletonização do sistema de distribuição, ou seja, a redução da complexidade do sistema melhora o desempenho do metamodelo, assim como o uso de informações sobre a operação do sistema, já que reduz o espaço de decisão a ser aproximado. Assim como os autores do Projeto POWADIMA, associaram a RNA ao AG para otimizar a operação do sistema de distribuição da cidade de Wallan, Austrália, um sistema mais complexo que os de Haifa e Valência. Além de produzir pressões com o modelo heurístico, eles obtiveram a concentração de cloro residual em pontos críticos do sistema. Assim, com a otimização foi possível a redução no custo de bombeamento de $21 \%$.

Recentemente, observa-se que os autores têm se dedicado à otimização da operação dos sistemas de abastecimento de água, desenvolvendo metodologias para obtenção de regras

${ }^{12}$ A esqueletonização dos modelos das redes de distribuição de água consiste em simplificar a rede, de modo a diminuir o número de nós e trechos de tubos a serem representados no modelo de simulação. 
operacionais otimizadas em tempo para aplicação em tempo real, com a utilização de modelos heurísticos para substituir os simuladores hidráulicos. No entanto, além de realizar a otimização em tempo hábil é necessária à consideração da confiabilidade das estratégias operacionais produzidas.

\subsection{Confiabilidade aplicada aos sistemas de abastecimento de água}

Nas redes de distribuição de água há variáveis incertas a serem consideradas para a adequada definição do projeto, da operação ou da reabilitação, tais como: demandas, rugosidades e diâmetros, além de outros componentes e parâmetros da rede.

Kang et al. (2009) investigaram a influência da incerteza dos parâmetros de entrada de um modelo de simulação (diâmetros, rugosidades, demandas etc.) sobre as respostas do modelo em termos das pressões. As técnicas de amostragem "First Order Second Moment" (FOSM) e "Latin Hypercupe Sampling" (LHS) foram comparadas às simulações de Monte Carlo (MCS), sendo este último usado como referência. Observaram que o LHS produziu os melhores resultados quando comparado ao MCS, tanto para simulações estáticas, como para simulações de período estendido, enquanto que o melhor desempenho do FOSM foi observado para as simulações estáticas.

Sumer e Lansey (2009) afirmaram que se pode reduzir o custo de projetos de ampliação de redes com a redução da incerteza dos dados sobre o sistema de abastecimento, visto que quanto maior a incerteza presente nos dados, maior deverá ser a margem de segurança a ser utilizada no projeto, o que resulta em maiores custos.

Assim, observa-se que as incertezas dos sistemas de abastecimento de água trazem implicações nos custos e na qualidade do serviço prestado aos consumidores, e por conseguinte a confiabilidade de tais sistemas em função de tais incertezas.

Goulter (1995) afirmou não haver uma definição bem estabelecida acerca da confiabilidade, a qual deve ser entendida como a capacidade de prover adequado nível de serviço ao consumidor, sob condições normais ou mesmo não usuais.

De acordo com Xu e Goulter (1999), a confiabilidade pode ainda ser expressa em termos das probabilidades de: falha mecânica e falha hidráulica, que impedem o fornecimento de água a vazões e pressões adequadas. A primeira refere-se à falha dos componentes da rede, como rompimento de tubulações, mau funcionamento de bombas e válvulas, enquanto que a segunda está relacionada à perda de capacidade devido ao envelhecimento dos tubos, corrosão e deposição de materiais, bem como quando a demanda supera os valores projetados. 
É razoável usar os aspectos mecânicos e hidráulicos como medidas de confiabilidade. Porém a utilização da falha mecânica necessita de análises estatísticas dos registros de reparo, modificação e substituição dos componentes do sistema (Bao e Mays, 1990), os quais geralmente não estão prontamente disponíveis.

Osfeld (2004) categorizou os métodos de avaliação da confiabilidade em: (a)conectividade/topológia, (b) hidráulica e (c) entropia. A categoria da entropia pode ser melhor generalizada pela categoria das medidas alternativas de confiabilidade ou heurísticas. $\mathrm{Na}$ sequência são apresentadas as definições de cada método, os quais são acompanhados pelas suas respectivas referências.

Os métodos que envolvem a (a) conectividade/topologia mensuram a probabilidade de determinada rede permanecer fisicamente conectada, a qual é função da confiabilidade dos componentes da rede de abastecimento.

Wagner et al. (1988a) aplicaram métodos analíticos por meio do algoritmo de Satyanarayana \& Wood $^{13}$ (1982 apud Ostfeld, 2004, p. 2) e Rosenthal (1977) para calcular: a (1) conectividade - probabilidade de um determinado nó com demanda esteja conectada a uma fonte de abastecimento e; (2) acessibilidade - probabilidade de todos os nós com demanda estejam conectados a uma fonte.

Shamsi (1990) e Quimpo e Shamsi (1991) usaram a NPR ("Node Pair Reliability") como medida de confiabilidade do sistema, que é definida como a probabilidade de que pelo menos uma fonte específica esteja conectada aos nós com demanda. O NPR foi utilizado para desenhar um mapa de contorno para estabelecer estratégias de manutenção, de modo a dar prioridade às áreas com menor NPR.

Jacobs e Goulter (1989) exploraram os impactos do uso de grafos regulares ${ }^{14}$ para o traçado de uma rede de distribuição de água.

Segundo Ostfeld (2004), medidas realizadas com o método da conectividade/topologia não consideram o nível de serviço prestado ao consumidor durante uma falha. Além disso, a existência de um caminho entre um consumidor e um nó não garante o suprimento da

13 Satyanarayana, A. \& Wood, R. K. (1982). Polygon-to-chain Reductions and Network Reliability. ORC 82-4, Operations Research Center, University of California, Berkeley, CA.

${ }^{14}$ Advém da Teoria dos Grafos, no qual um grafo é formado por vértices e arestas - ou curvas, que conectam os vértices. Um grafo é dito regular quando todos os vértices têm o mesmo grau, ou seja, todos os vértices possuem o mesmo número de ligações com outros vértices. 
demanda do mesmo. Assim, tais medidas são utilizadas para avaliar a existência de partes do sistema com baixa confiabilidade topológica.

A (b) confiabilidade hidráulica é a probabilidade de suprir a demanda dos consumidores, com a distribuição de água em quantidade, qualidade e carga de pressão adequadas, nos locais e horários apropriados. O cálculo preciso dessa probabilidade requer dados referentes a todos os componentes do sistema de abastecimento, bem como dos impactos associados à demanda. Essa é uma tarefa computacionalmente inviável, por isso geralmente o cálculo da confiabilidade hidráulica é realizado por meio de simulação estocástica (Monte Carlo). Wagner et al. (1988b) usaram a simulação estocástica através da geração de eventos de falha e reparo de bombas e tubulações, conforme uma distribuição de probabilidade, e de um simulador hidráulico para produzir as vazões e pressões. O modelo foi usado para calcular medidas de confiabilidade, tais como a porcentagem de falha para cada bomba e tubulação, ou a demanda total não atendida. Bao e Mays (1990) realizaram simulações estocásticas para calcular a confiabilidade nos nós da rede e a confiabilidade do sistema. A confiabilidade de cada nó corresponde à probabilidade de receber carga de pressão e vazão suficiente, e a confiabilidade do sistema é definida como a média da confiabilidade dos nós. Su et al. (1987) utilizaram a abordagem do corte mínimo ${ }^{15}$ (mínimo “cut-set”) para medir a confiabilidade hidráulica, realizando a simulação de todas as combinações de falhas das tubulações e os impactos na demanda dos consumidores. Desta forma, a confiabilidade do sistema foi definida como o complemento da probabilidade de não haver "cut-set" mínimo. Culliname et al. (1992) incorporaram a disponibilidade como restrição de um problema de otimização do projeto de uma rede de abastecimento de água, em que a disponibilidade é porcentagem do tempo no qual a vazão é fornecida com carga de pressão igual ou acima do mínimo requerido. Xu e Goulter (1998) desenvolveram um modelo probabilístico para avaliação da confiabilidade de redes distribuição, o qual considera as incertezas das demandas nodais, capacidade de vazão das tubulações, nível dos reservatórios e disponibilidade dos componentes do sistema. A metodologia consiste em derivar a função de distribuição da probabilidade da carga de pressão nos nós, com o uso de um modelo hidráulico linearizado baseado em funções de distribuição de probabilidade conhecidas das demandas nodais, da rugosidade das tubulações e dos níveis dos reservatórios, os quais são combinados com as

15 Também da Teoria dos Grafos, o “cut-set” são combinações de falhas nos componentes que podem causar falha no sistema. O "cut-set” é considerado mínimo quando um evento básico é removido e a combinação dos demais não é mais um "cut-set”. 
diferentes probabilidades de configuração do sistema e dos níveis de demanda. O resultado é a medida de confiabilidade para todo o sistema, ou para uma parte específica do mesmo. Shinstine et al. (2001) aplicaram o modelo de confiabilidade de Su et al. (1987), baseado na aplicação da técnica de "cut-set” mínimo em conjunto com um simulador hidráulico estático, que implicitamente resolve as equações de continuidade e de energia para duas redes de distribuição de larga escala, da área metropolitana da cidade de Tucson, Arizona, EUA. A medida de confiabilidade é definida como a probabilidade de satisfazer as demandas nodais à pressões adequadas frente a falhas nas tubulações (rompimento) em um determinado instante.

A última categoria, (c) das medidas alternativas de confiabilidade, surgiu devido à dificuldade de incorporar diretamente as medidas de confiabilidade ao processo de otimização, mesmo com a evolução das metodologias para cálculo da confiabilidade (Formiga et al., 2006), além de haver grande diminuição da carga computacional utilizada. Por isso têm sido utilizadas como medidas alternativas de confiabilidade a entropia e a resiliência.

A entropia tem sido utilizada por diversos autores nos últimos 20 anos (Awumah et al., 1991; Awumah \& Goulter, 1992; Tanyimboh \& Templeman, 1993, 2000, entre outros). A idéia fundamental é usar a medida de entropia de Shannon (1948), a qual quantifica a quantidade de informação contida em uma distribuição de probabilidade finita, para medir a redundância da rede (i.e. se um determinado componente está fora de serviço, se há outros caminhos para suprir a demanda dos nós afetados), em outras palavras, a entropia mede o grau de uniformidade das vazões.

De acordo com Formiga et al. (2006), esquemas com distribuição mais uniformes das vazões, sem caminhos preferenciais de fluxo dentro do sistema terão um valor de entropia maior. Isso significa que sistemas com valores de alta entropia tenderão a ser menos suscetíveis às falhas no caso de quebra de um trecho. Segundo Osfeld (2004), a definição de entropia está mais relacionada à categoria de conectividade/topologia do que a de confiabilidade hidráulica.

Awumah et al. $(1990,1991)$ foram os primeiros a proporem o uso da função de entropia de Shannon (1948) como uma medida alternativa de confiabilidade em redes de distribuição de água. Mas Tanyimboh e Templeman (1993) foram os primeiros a definirem corretamente a função de entropia para as redes de distribuição, os quais utilizaram um modelo espacial de múltiplas probabilidades e a probabilidade condicional de Khinchin (1953).

Awumah et al. (1991) utilizaram a entropia para avaliar o grau de uniformidade na distribuição de vazões em uma rede de distribuição por gravidade com um reservatório. 
Awumah e Goulter (1992) maximizaram a entropia na otimização do projeto de uma rede de abastecimento de água.

Tanyimboh e Templeman (2000), Tanyimboh e Sheahan (2002), Ang e Jowitt (2003), Setiadi et al. (2005) e Tanyimboh e Setiadi (2008a) estudaram a relação entre a entropia e a confiabilidade, enquanto que Tanyimboh e Templeman (1993), Yassin-Kassab et al. (1999) e Tanyimboh e Setiadi (2008b) utilizaram a entropia como medida alternativa de confiabilidade na otimização de projetos de redes de abastecimento de água, devido à facilidade de calcular, maximizar e incorporar a entropia aos processos de otimização.

Tanyimboh e Templeman (2000) quantificaram a correlação entre a entropia de sistemas de distribuição de água e a confiabilidade hidráulica. Tanyimboh e Sheahan (2002) investigaram: a relação entre o valor da máxima entropia e o número de loops da rede de abastecimento; a influência do traçado da rede sobre a correlação entre a máxima entropia e a confiabilidade hidráulica; a similaridade de projetos de redes com máxima entropia, mas com diferentes traçados; e o uso da entropia como medida alternativa de confiabilidade para identificar projetos ótimos de redes de distribuição de água. Ang e Jowitt (2003) exploraram a relação entre perda de carga e a entropia para obter melhor compreensão sobre as propriedades da entropia.

Setiadi et al. (2005) verificaram se erros de modelagem, provenientes de diferenças entre a otimização do projeto da rede e a subsequente simulação, poderiam distorcer a relação entre a entropia e a confiabilidade. Tal verificação foi realizada por meio de simulações com modelos hidráulicos dirigidos pela demanda ("Demand Driven Analysis" - DDA) e também pela demanda dirigida pela pressão ("Head Driven Analysis" - HDA). Os autores concluíram que os erros de modelagem não influenciaram a forte correlação entre a confiabilidade e a entropia, que foi mais acentuada na demanda dirigida pela pressão.

Tanyimboh e Setiadi (2008a) realizaram estudos entre a entropia e a confiabilidade hidráulica, os quais incluíram a influência do traçado da rede, a direção da vazão e do custo da tubulação. Os autores puderam concluir que projetos com máxima entropia demonstraram serem mais confiáveis que outros projetos, e que redes de diferentes traçados com iguais valores máximos de entropia possuem níveis de confiabilidade muito similares. Além disso, assim como Setiadi et al. (2005), observaram correlação mais clara entre a entropia e a confiabilidade utilizando modelos com a demanda dirigida pela pressão, em comparação ao modelo hidráulico dirigido pela demanda.

Tanyimboh e Templeman (1993) sugeriram um algoritmo para maximizar a entropia para redes com um único reservatório, enquanto que Yassin-Kassab et al. (1999) propuseram 
um método rápido e não iterativo para o cálculo da máxima entropia. Tanyimboh e Templeman (2008b) realizaram a otimização multiobjetivo do projeto de uma rede de abastecimento teórica. Os autores utilizaram o valor de máxima entropia para filtrar os traçados candidatos, para só então prosseguir para a otimização, que teve como critérios o custo, a entropia, a confiabilidade e a redundância. A utilização do mencionado filtro trouxe eficiência computacional à otimização, além do que o método se mostrou robusto e acurado.

Formiga et al. (2006) observaram que a entropia possui diversas limitações, como a impossibilidade de comparar valores entre problemas diferentes, já que a entropia não é normalizada e é particular a cada problema. Outro problema está nos valores de entropia muito próximos entre si devido à sua formulação na base logarítmica. Além disso, na formulação da entropia não se considera o atendimento da demanda, ou seja, uma solução que não atenda a demanda, mas possua distribuição uniforme das vazões pode ter maior valor de entropia que outra solução que atenda a demanda, mas que possui caminhos preferenciais.

Todini (2000) propôs o uso da resiliência como medida alternativa de confiabilidade, a qual expressa a capacidade do sistema em atender às demandas mesmo em situações de falha mecânica ou hidráulica.

Prasad e Park (2004) propuseram uma nova medida de confiabilidade denominada resiliência da rede ("Network Resilience"), a qual foi aplicada à otimização multiobjetivo de projeto de sistemas de distribuição de água de problemas hipotéticos, e incorpora os efeitos da energia excedente provida à rede e dos anéis ("loops"). O novo índice produziu melhores resultados que outros índices avaliados: o índice de carga excedente mínima ("Minimum Surplus Head Index"), o índice de carga total excedente (“Total Surplus Head Index”) e o índice de resiliência.

Jayaram e Srinivasan (2008) utilizaram o índice de resiliência modificado - baseado em Todini (2000), para otimizar o projeto e a reabilitação de redes de abastecimento de água , já que o índice de Todini (2000) não é adequado para múltiplas fontes de abastecimento.

Raad et al. (2010) compararam as medidas de confiabilidade alternativas mais utilizadas na otimização de projetos de sistemas de distribuição de água: a resiliência, a resiliência da rede, a entropia e uma medida mista entre resiliência e entropia. Eles concluíram que a resiliência produziu o melhor desempenho frente à variação de demandas puramente estocásticas, enquanto que a resiliência da rede e a medida mista foram melhores sob condições de falhas das tubulações. A entropia produziu resultados inferiores aos demais índices avaliados. 
Fu et al. (2010) realizaram análise de sensibilidade de métricas utilizadas em projetos de sistemas de abastecimento de água, utilizando o método de Sobol ${ }^{16}$. A avaliação dos índices foi realizada sob o enfoque determinístico, que teve como variável o dimensionamento do diâmetro das tubulações; e sob o enfoque estocástico, em que as variáveis foram os diâmetros e a demanda nodal com distribuição normal. O índice de resiliência foi uma das métricas mais sensíveis às variáveis consideradas para ambos os enfoques.

Podem-se citar outros autores que utilizaram o índice de resiliência: Prasad e Tanyimboh (2008) e Vasan Simonovic (2010) utilizaram o índice para a otimização de projetos, Saldarriaga et al. (2010) realizaram a otimização da reabilitação e Farmani et al. (2006) pesquisaram a otimização do projeto e da reabilitação de redes de abastecimento de água.

A resiliência possui a limitação de desconsiderar a uniformidade da distribuição de vazões, ou seja, uma rede de abastecimento que possua grande excesso de energia apresentará altos valores de resiliência mesmo que tenha vazões com caminhos preferenciais (Formiga et al., 2006).

Assim, em virtude das limitações da entropia e resiliência como medidas alternativas de confiabilidade, Formiga et al. (2006) não recomendam o uso isolado dessas medidas.

Além do uso das estratégias delineadas por Ostfeld (2004), alguns autores (Lansey et al., 1989; Tolson et al., 2004; Babayan et al., 2005; e Kapelan et al., 2005) utilizaram outras estratégias para considerar a confiabilidade no processo de otimização do projeto de sistemas de abastecimento de água.

Lansey et al. (1989) foram os primeiros a conceber e resolver o problema do projeto estocástico de custo-mínimo de sistemas de distribuição de água para abastecimento. As incertezas foram consideradas através de restrições probabilísticas. Xu e Goulter (1999) usaram o método de confiabilidade de primeira ordem para tratar a incerteza. Nesses dois trabalhos anteriormente referidos foi usado o método do Gradiente Reduzido Generalizado 2 (GRG2) para a resolução dos respectivos problemas de otimização, e ambos também consideraram os diâmetros como variáveis contínuas.

Tolson et al. (2004) tentaram melhorar a aproximação proposta por Xu e Goulter (1999), resolvendo o respectivo problema de otimização via algoritmo genético padrão. Entretanto, essa aproximação requer repetidas avaliações das derivadas de primeira ordem e

16 O método de Sobol é um método de análise de sensibilidade global, que fornece informação detalhada sobre o efeito dos parâmetros e suas interações. 
inversão matricial, o que a torna computacionalmente intensiva mesmo para redes pequenas, algumas vezes sujeita a problemas numéricos.

Babayan et al. (2005) substituíram o método baseado na amostragem pelo AG associado a uma técnica de quantificação da incerteza baseada na integração. Assumiram funções de densidade de probabilidade para as flutuações de demanda (incerteza) e definiram um conjunto de nós críticos a serem utilizados para a avaliação da função de aptidão. Apesar do método não avaliar explicitamente o nível de robustez, seu cálculo era realizado para a solução final resultante do processo de otimização. A principal limitação dos métodos descritos anteriormente reside no fornecimento de uma única solução para o problema em decorrência da otimização via objetivo único.

Kapelan et al. (2005) propuseram uma aproximação multiobjetivo para resolver o problema de projeto de sistemas de distribuição de água para abastecimento sob incerteza. As variáveis incertas (demandas nodais e rugosidades absolutas) foram modeladas pelas Funções de Densidade de Probabilidade (FDP) normal e uniforme, respectivamente, calculadas usando a técnica de amostragem do hipercubo latino (LHS). Utilizaram o Robust Nondominated Sorting Genetic Algorithm II (rNSGAII), derivado do NSGAII de Deb et al. (2002), para produzir as soluções robustas de melhor compromisso para o respectivo problema de otimização multiobjetivo, em conformidade com o conceito de Pareto.

Portanto pode-se depreender que é imprescindível aplicar o conceito de confiabilidade aos sistemas de abastecimento de água, pois as incertezas possuem implicações nos custos em virtude da maior margem de segurança que deve ser adotado caso tais incertezas não sejam consideradas, a fim de garantir a qualidade nos serviços prestados aos consumidores.

\subsection{Previsão de demanda}

Existe atualmente uma grande preocupação em planejar a operação de Sistemas de Abastecimento de Água (SAA), de forma a atender a demanda a menores custos operacionais, ao mesmo tempo em que, na área de projetos, tem-se intensificado a avaliação do uso da infra-estrutura existente e o planejamento dos investimentos.

Para tanto, faz-se necessário o uso de modelos de otimização acoplados a modelos de reprodução do comportamento dos SAAs. Considerando que tais sistemas são operados com o propósito de atender às demandas da população, o comportamento desses sistemas só pode ser reproduzido a contento se tais demandas puderem ser previstas.

As demandas em SAAs variam ao longo das horas do dia, dos dias da semana e das estações do ano. Estão sujeitas, portanto, às variações ocasionadas por fatores sócio- 
econômicos, climáticos e problemas operacionais, tais como manutenção do sistema, quebra de componentes da rede e ocorrência de incêndios, dentre outros.

Diversas são as técnicas de previsão já propostas na literatura especializada, de acordo com a finalidade e o horizonte de previsão almejado: análise de regressão, séries temporais ou ambas, e, mais recentemente, as Redes Neurais Artificiais (RNAs). As Redes Neurais Artificiais (RNAs) têm se destacado devido à sua capacidade de modelar comportamentos não lineares, apresentando grande capacidade de aprendizado e generalização.

Prever significa produzir informações acerca do futuro, permitindo que 0 planejamento possa ser realizado com base em tais previsões. Segundo Falkenberg (2005), o conhecimento prévio do perfil de consumo de água ao longo do dia permite planejar a operação do respectivo sistema de abastecimento possibilitando otimizar os custos de produção e distribuição de água, mantendo-se a qualidade exigida para o consumo. A seguir se relacionam com mais detalhes as vantagens que podem ser obtidas com o auxílio de um modelo de previsão:

- Identificação de possível perda física de água no sistema - um modelo de previsão confiável pode acusar em tempo hábil qualquer anormalidade tal como vazamentos, caso seja constatado um desvio muito grande entre a previsão de demanda e o consumo observado;

- Ganho na qualidade da água, através de estoques adequados limitando-se a transferir o volume necessário para os reservatórios, evita-se a perda de qualidade da água não consumida em tempo adequado, ou seja, a concentração de cloro residual é mantida a níveis adequados;

- Planejamento da operação das elevatórias de água in natura e tratada, segundo contratos de energia ${ }^{17}$ : conhecendo-se o consumo nos períodos de pico (ponta) de energia, pode-se planejar a reserva de água para suprir as demandas desse período e desligar os equipamentos durante o mesmo, evitando-se maiores tarifas relativas ao horário de pico;

\footnotetext{
${ }^{17}$ Existem dois tipos de tarifas: tarifa monômia e binômia. A tarifa monômia, aplica-se aos consumos sob baixa tensão, tarifando apenas o consumo de energia. Já a tarifa binômia aplica-se aos grandes consumidores, impondo pagamento tanto pela demanda como pelo consumo efetuado. Além disso, a tarifa binômia é dividida em tarifação convencional, no qual há apenas uma tarifa; e há a tarifa de energia horosazonal, que estabelece tarifas maiores no horário de ponta (período de 3 horas consecutivas de maior consumo, exemplo: $18 \mathrm{~h}$ às $21 \mathrm{~h}$ ) e tarifas menores para o horário fora de ponta (correspondente as demais 21 horas).
} 
- Planejamento da operação diária da Estação de Tratamento de Água (ETA), de modo a conferir previsibilidade à operação da ETA, pois vários fatores são funções do consumo e consequentemente da vazão necessária a ser fornecida para o abastecimento. Entre os fatores pode-se citar a dosagem de produtos químicos, programação de manutenção etc;

- Estimativa das variáveis de ajuste de controle de carga de pressão e vazão ótimas ao longo do dia, bem como níveis mínimos e máximos dos reservatórios;

- Logística de produtos químicos da ETA: através de uma previsão de consumo (diária e mensal) de longo prazo, tem-se como determinar a logística de aquisição e transporte e estocagem dos produtos químicos utilizados, evitandose perdas e atrasos.

A previsão de demanda geralmente é realizada para variáveis hidrológicas, carga elétrica, consumo de água, vendas, manchas solares, etc. Pode ser realizada para um horizonte longo ou de curto prazo (Silva e Rocha, 1999).

A previsão de longo prazo antevê as solicitações máximas dos sistemas de distribuição. Geralmente é utilizada para avaliar investimentos destinados à ampliação de capacidade e benefício líquido potencial advindo de medidas de conservação e uso racional da água voltada à redução das vazões médias demandadas.

A previsão de curto prazo fornece resposta instantânea aos sistemas produtores e de distribuição sobre as ocorrências de picos prolongados e flutuações acentuadas de demanda. É útil ao propósito de tomada de decisão sobre manobras operacionais, para contrabalançar o efeito de desequilíbrios distributivos, e avaliação do benefício líquido potencial resultante de medidas de conservação e uso racional da água voltado à redução dos picos de consumo.

Trautwein (2004) relacionou os fatores que influenciam o consumo de acordo com o horizonte de previsão, exibidos na Tabela 3-1.

Segundo Shvartser et al. (1993), geralmente realiza-se o planejamento da operação de SAAs para o horizonte de previsão de 24 horas, pois o ciclo da demanda é diário e as tarifas de energia são baseadas em períodos do dia, com exceção de regiões (ou sistemas) com reservatórios de ciclo semanal, os quais necessitam de horizontes de previsão maiores.

$\mathrm{O}$ método de previsão pode ser classificado como qualitativo ou quantitativo. $\mathrm{O}$ primeiro é baseado em métodos não analíticos através de julgamento, intuição e/ou entrevista, 
enquanto que o segundo utiliza modelos matemáticos para a previsão. Nessa categoria de métodos, podem ser mencionadas a análise de regressão e as séries temporais.

Tabela 3-1 - Fatores que influenciam o consumo

\begin{tabular}{ll}
\hline $\begin{array}{l}\text { Horizonte de } \\
\text { Previsão }\end{array}$ & Fatores que influenciam o consumo \\
\hline Horário & período do dia \\
horário e diário & temperatura, umidade ou chuva, dia da semana \\
semanal e mensal & $\begin{array}{l}\text { época do ano } \\
\text { variação do número de ligações por ampliações do } \\
\text { sistema ou mudanças nos limites das zonas de } \\
\text { abastecimento }\end{array}$ \\
\hline
\end{tabular}

Para a análise de regressão, a ordem das observações não é relevante, ao passo que as séries temporais baseiam-se na estrutura de dependência entre as observações sequenciais.

As séries temporais podem ser divididas em diversas componentes:

- Sazonal - comportamento que se repete a cada ano;

- Tendência - é a componente responsável pela variação de longo prazo nos valores das observações ao longo do tempo;

- Cíclica - variação com certo grau de regularidade, mas diferente de um ano;

- Aleatória - é a componente que resta ao remover a sazonalidade, a tendência e a componente cíclica.

\subsubsection{Modelos de Previsão de demanda}

Historicamente, técnicas de modelagem tais como análise de regressão, de séries temporais ou a combinação de ambas têm sido utilizadas por gerenciadores de sistemas hídricos. Muitos trabalhos têm sido reportados na literatura sobre modelos de previsão de demanda no curto prazo usando tais ferramentas.

A previsão de curto prazo possivelmente se iniciou com Dryar (1944), que estudou a influência das condições meteorológicas e de insolação sobre a carga consumida dos sistemas elétricos.

Graeser (1958) apontou que demandas diárias máximas em Dallas, Texas, eram significativamente afetadas pelo número de dias anteriores com temperatura máxima do ar 
acima de $37,8{ }^{\circ} \mathrm{C}$ e pelo número de semanas consecutivas com chuvas (de altura de precipitação maior que 1 polegada).

Howe e Linaweaver (1967) desenvolveram equações no oeste dos EUA para prever a demanda de irrigação residencial usando evapotranspiração potencial, área irrigável (jardim), custo da água e valor das moradias como variáveis independentes de um modelo de regressão linear múltipla.

Farmer e Potton (1968) desenvolveram um modelo de previsão para carga elétrica a partir dos valores atual e anteriores, pois afirmaram que analisar os parâmetros meteorológicos tornaria o modelo mais complexo, devido à necessidade de desenvolver outro modelo para a previsão meteorológica.

Weeks e McMahon (1973) descobriram na Austrália que a evaporação semanal e temperaturas médias máximas diárias eram as variáveis mais significativas que a chuva em um modelo de regressão linear múltipla para previsão de demanda máxima semanal.

Outros exemplos de modelos de previsão de demanda hídrica no curto prazo usando análise de regressão incluem Oh e Yamauchi (1974), Hughes (1980), Anderson et al. (1980), Steiner e Smith (1983), e Maidment e Parzen (1984).

Maidment et al. (1985) desenvolveram um modelo de séries temporais para o uso municipal diário da água como uma função da chuva e da temperatura do ar. O modelo foi aplicado aos dados de Austin, Texas, para o período de 1975 a 1981, o modelo não considerou os efeitos do dia da semana, que geralmente são decisivos sobre a demanda hídrica diária, de maneira a representar um processo médio constante. Smith (1988) propôs um modelo auto-regressivo de séries temporais de demanda hídrica municipal que considerou esses dois fatores.

Shvartser et al. (1993) desenvolveram um modelo de previsão que combinou a técnica de reconhecimento de padrões com análise de séries temporais. O modelo consiste em realizar o reconhecimento dos padrões para três segmentos do ciclo diário, denominados fase ascendente, fase oscilante e fase descendente, como "estados" da curva de demanda, os quais podem ser descritos como estados sucessivos de um processo Markoviano. Segue-se para o cálculo das probabilidades de transição entre os estados para então se realizar o ajuste de cada segmento por meio de um modelo ARIMA (Auto-regressive Integrated Moving Average). O modelo foi aplicado ao sistema de abastecimento de Israel, produzindo resultados considerados satisfatórios pelo autor.

Outros exemplos de modelos de previsão de demanda hídrica de curto prazo usando análise de séries temporais incluem: Valdes e Sastri (1989), Miaou (1990), e Jowitt and Xu 
(1992). Mas a grande inovação na área de estudos de previsão em tempo real é a consideração dos dados de consumo como uma sequência dinâmica de valores com parâmetros constantemente atualizados no tempo. Assim, dentre os modelos de previsão de demanda apresentados na literatura, destacam-se, dentre outros, aqueles apresentados por Perry (1981) e Zahed (1990).

Perry (1981) decompõe a série de consumos em uma série de harmônicos e uma série de vazões residuais, que são ajustadas por um modelo do tipo ARMA ("Auto-regressive Moving Average"). Tanto os coeficientes dos harmônicos, como os coeficientes do modelo ARMA são obtidos a partir da uma série histórica e utilizados para a previsão. A atualização dos parâmetros do modelo é efetuada dinamicamente.

Zahed (1990) desenvolveu e aplicou dois modelos de previsão de demanda na operação horária de parte do Sistema Adutor Metropolitano de São Paulo baseados no modelo de Perry (1981). Um deles baseado na série de Taylor e outro na série de Fourier. Ele tomou como premissas importantes a eliminação do efeito dos dias da semana, considerando 24 horas móveis, e os erros medidos em termos dos desvios de volumes acumulados, comparados aos volumes dos reservatórios e associação simples com dados históricos recentes para evitar utilizar modelos auxiliares. Partindo da premissa de alimentação do modelo de previsão feita com dados históricos recentes, desenvolveu a metodologia de previsão de demanda em tempo real.

Odan et al. (2009) realizaram estudos comparativos entre a Série de Fourier proposta por Zahed (1990) e o algoritmo dos vizinhos mais próximos (Ferrero, 2009) para realizar previsões de demanda de água para um setor de abastecimento da cidade de São Carlos. O primeiro modelo consiste em ajustar uma equação harmônica a uma série de dados observados e extrapolar essa série para produzir os valores futuros, sendo que os coeficientes harmônicos são atualizados na base diária com ciclos de 7 dias. Já o segundo modelo realiza o armazenamento de sequências a serem utilizadas como exemplos, dos quais se selecionam os exemplos mais próximos à sequência a ser prevista para produzir o valor futuro. Estudaram-se diversas configurações para ambos os modelos de previsão, e finalmente realizou-se uma comparação entre as melhores configurações identificadas. Os modelos de previsão utilizados produziram bons resultados, com erros percentuais médios absolutos da ordem de 7\% para a previsão da próxima hora.

Recentemente, a técnica das redes neurais artificiais (RNAs) vem sendo proposta como uma ferramenta eficiente para modelagem e previsão da demanda de água. Crommelynck et al. (1992) foram um dos pioneiros em utilizar as RNAs de múltiplas 
camadas e a técnica Backpropagation para modelar previsão de demanda hídrica horária e diária de algumas comunidades de Paris, França. Eles compararam os resultados gerados via RNAs com aqueles produzidos por alguns modelos estatísticos, mostrando que as RNAs apresentavam desempenho pelo menos comparáveis com os dos modelos estatísticos.

Leon et al. (2000) desenvolveram um modelo híbrido chamado EXPLORE para gerenciar o sistema de abastecimento de água da cidade de Sevilha, Espanha. O sistema EXPLORE foi desenvolvido para identificar estratégias operacionais diárias ou semanais, com o objetivo de atender às demandas hídricas e reduzir os custos com energia elétrica. Durante os estudos, concluíram que o desempenho de um sistema para gerenciamento de recursos hídricos (tal como o EXPLORE) poderia ser melhorado usando técnicas de estimativa de demanda hídrica. Análise de regressão, análise de séries temporais e redes neurais artificiais, poderiam ser utilizadas, pois o procedimento adotado por Leon et al. (2000) consistia em repetir o consumo da mesma hora da semana anterior, incorrendo em erros relativos entre 0 e $5 \%$ para $69 \%$ dos valores.

Muitos tipos de dados são necessários para modelar as estimativas de demanda hídrica. Eles podem ser agrupados em duas classes: variáveis socioeconômicas e variáveis climáticas. Variáveis socioeconômicas tais como população, renda, custo da água e características das moradias são responsáveis por efeitos de longo prazo sobre as demandas, enquanto variáveis climáticas tais como chuvas e temperatura máxima do ar são responsáveis pelas variações sazonais de curto prazo sobre as demandas hídricas (Miaou, 1990).

Jain et al. (2001) apresentaram estudos acerca de modelos de previsão de demanda hídrica no curto prazo usando variáveis climáticas tais como chuva e máxima temperatura do ar em adição às demandas passadas. $\mathrm{O}$ estudo utilizou dados de demanda hídrica semanal do Instituto Indiano de Tecnologia, Campus de Kanpur, Índia, de chuva semanal total e das temperaturas máximas médias do ar na cidade de Kanpur. Seis modelos diferentes de RNAs, cinco modelos de regressão e dois de séries temporais foram desenvolvidos e comparados. Os autores mostraram que as RNAs apresentaram desempenho superior aos demais modelos desenvolvidos, para os quais a demanda mostrou-se melhor correlacionada com a ocorrência da chuva do que com a altura precipitada. A melhor RNA ajustada apresentou um erro médio absoluto (MAPE) de 2,4\% na previsão, o qual utilizou como entrada a demanda da semana anterior, a temperatura média máxima da semana e a ocorrência de chuva na semana.

Zhang et al. (2006) realizaram a previsão de curto prazo para a cidade de Louisville, EUA. O trabalho diferiu dos demais por separar o ano em período de inverno e verão, sendo que para o período de inverno utilizaram apenas a série histórica de demanda diária como 
entrada, pois no período os fatores climáticos pouco interferiam na demanda. Para o período de verão, foram desenvolvidos 6 modelos de RNA, que utilizaram como entrada a série histórica de demanda diária e as variáveis climáticas temperatura, umidade relativa do ar, temperatura do ponto de orvalho e vento. O melhor modelo produzido utilizou como entrada a temperatura máxima, umidade relativa do ar, ocorrência de chuva e a demanda histórica.

Alvisi et al. (2007) utilizaram um modelo baseado nos padrões implícitos na demanda de água para realizar a previsão de demanda, pois encontraram dificuldade em realizar a previsão de demanda com redes neurais durante a transição entre os dias da semana, especialmente dos dias úteis para o fim de semana. A previsão foi realizada por dois módulos, sendo que o primeiro realizava a previsão diária média considerando a sazonalidade, padrão da semana e a persistência de médio prazo. No segundo módulo, a demanda média prevista é combinada ao padrão de demanda do dia e a persistência de curto prazo, produzindo previsões para as próximas 24 horas.

Adamowski (2008) realizou a previsão de demanda máxima diária com base na demanda histórica da cidade de Ottawa, Canadá, e confirmou a constatação de Jain et al. (2001) de que a demanda correlaciona-se melhor com a ocorrência de chuva do que com a quantidade em si. No estudo foram comparados 39 modelos de regressão linear múltipla, 9 modelos ARIMA e 39 modelos de RNAs, sendo que estas apresentaram resultados superiores aos demais modelos. O melhor resultado foi produzido considerando-se a demanda máxima do dia anterior, a temperatura do dia e do dia anterior e a ocorrência de chuva dos últimos cinco dias.

Ghiassi et al. (2008) utilizaram uma rede neural dinâmica (DAN2) para realizar a previsão de demanda de água de uma cidade da Califórnia, EUA. O modelo desenvolvido pelos autores superou os modelos ARIMA, sendo que o melhor modelo produziu erro médio absoluto para a previsão horária da ordem de 3\%. Os autores ainda observaram que a inclusão de variáveis meteorológicas melhorou o desempenho do modelo DAN2, mas demonstraram que mesmo sem a inclusão dos mesmos, obtiveram excelentes resultados.

Observa-se que dentre os modelos de previsão de demanda em tempo real, mostram-se especialmente úteis àqueles que atualizam os seus parâmetros constantemente, de maneira a incorporar os mais recentes dados de consumo.

No Brasil, alguns estudos vêm apontando as RNAs como ferramentas promissoras na previsão de demandas de sistemas de abastecimento (Silva e Barbosa, 2001, 2002a, 2002b). Sjobom e Oliveira (2005) utilizaram RNA de múltiplas camadas para realizar a previsão do nível de água de reservatórios para as próximas 24 horas, a fim de otimizar o bombeamento 
nos sistemas de distribuição de água. Trautwein (2004) utilizou modelos de previsão de consumo de água baseado em ajuste exponencial e RNA, e Falkenberg (2005) utilizou modelos baseados em regressão linear múltipla, modelos auto-regressivos e RNAs. Ambos os autores concluíram que não há um modelo que possa ser aplicado indistintamente a qualquer série de consumo de água, pois ao aplicarem diferentes modelos a diferentes séries de consumo, observaram que para cada caso específico um determinado modelo mostrava-se mais adequado.

Silva (2003) realizou comparações entre os modelos de previsão univariados e multivariados utilizando RNAs, tendo como dado de entrada o consumo médio do dia anterior e os consumos horários do respectivo dia da semana anterior, sendo que a topologia da rede neural era constituída de 3 camadas - entrada, camada intermediária e saída. Para o modelo univariado, melhores resultados foram produzidos com a divisão do período em estações do ano do que em estações seca e chuvosa, ou seja, a RNA produziu melhores resultados ao se definirem melhor os períodos sazonais. Os modelos de previsão multivariados, considerando as quatro estações e as séries históricas de dois reservatórios e também a série de consumo de todos os reservatórios, apresentou erros de previsão maiores que os modelos univariados.

Com o objetivo de melhorar a performance dos modelos de previsão de demanda, alguns autores (Zanini, 2000; Zhang, 2003; Jain and Kumar, 2007; Pulido-Calvo e GutiérrezEstrada, 2009; Odan, 2010) propuseram o uso de modelos de previsão híbridos, ou seja, que combinem duas ou mais técnicas de previsão.

Zanini (2000) propôs uma rede neural híbrida, que consistia em prever os erros produzidos por um modelo de regressão dinâmica através do uso de uma RNA, aplicado a previsão de demanda de gasolina no Brasil. O termo "dinâmica" não se refere à evolução dos parâmetros no tempo, mas advém da combinação dinâmica de séries temporais e do efeito de variáveis explicativas. O modelo de regressão, além de considerar os dados das séries históricas de demanda, também utilizou os dados exógenos bem como as defasagens de ambas as séries. Ainda segundo Zanini (2000), a rede neural híbrida apresentou resultados superiores a um modelo de regressão e produziu melhores ajustes para o conjunto de treinamento que uma RNA de aprendizado supervisionado, mas foi superada pela RNA na fase de teste.

Zhang (2003) criou um modelo híbrido entre a RNA e o modelo ARIMA, a fim de aproveitar as qualidades de cada um, que são respectivamente a capacidade de modelar séries não lineares e lineares. A metodologia do modelo híbrido consiste em dois passos: primeiro o modelo ARIMA é utilizado para modelar a parte linear da série, e na sequência a RNA 
modela os resíduos entre o modelo ARIMA e os dados observados. O modelo desenvolvido foi aplicado a três séries de referência (Série de Manchas Solares de Wolf, Série dos linces no Canadá e os dados da taxa de câmbio entre o dólar e a libra esterlina). O desempenho do modelo híbrido foi melhorado com a combinação de ambos os modelos.

Jain e Kumar (2007) combinaram modelos de previsão - baseados em RNA e modelos regressivos - com séries de vazões mensais filtradas. Três tipos de dados foram testados: (1) dados brutos, (2) dados sem a componente da tendência e (3) dados sem as componentes da tendência e da sazonalidade. A RNA combinada aos dados da última categoria (3) produziu resultados muito mais precisos que os modelos regressivos.

Pulido-Calvo e Gutiérrez-Estrada (2009) desenvolveram um modelo híbrido entre a RNA e a lógica Fuzzy, o qual foi aplicado na previsão da demanda de água para irrigação. Os autores observaram que o modelo híbrido produziu resultados significativamente melhores que a RNA univariada ou multivariada.

Odan (2010) comparou diferentes RNAs para realizar a previsão de demanda para as próximas 24h - a RNA Perceptron de Múltiplas Camadas (RNAs MLP), a Rede Neural Dinâmica (DAN2) e duas RNAs híbridas, sendo que estas últimas consistem em associar previsão por séries de Fourier com a RNA MLP e a DAN2, sendo denominadas respectivamente RNA-H e DAN2-H. As variáveis de entrada dos modelos de previsão foram escolhidas com base em análises de correlação, que foram os dados de consumo defasados e a temperatura e a umidade relativa do ar. Os melhores modelos de previsão tiveram como base a DAN2. O melhor modelo de previsão (DAN2-H) para a próxima hora produziu um erro médio absoluto (MAE) de 2,3 e 2,1e L/s para treino e teste respectivamente, representado cerca de $8 \%$ do consumo médio, enquanto que para a previsão das próximas 24 h MAE de 3,5 e $2,8 \mathrm{~L} / \mathrm{s}$ para treino e teste respectivamente.

\subsection{Redes Neurais Artificiais}

Segundo Haykin (1999), o cérebro humano assemelha-se a um computador, com um sistema de processamento de informações altamente complexo, não linear e paralelo: "Uma RNA é um processador massivo paralelamente distribuído e constituído de unidade de processamento simples, que tem propensão natural para armazenar conhecimento experimental e torná-lo disponível para uso".

As RNAs são sistemas projetados para modelar um problema baseado no funcionamento do cérebro. As unidades de processamento da RNA são os neurônios artificiais interconectados por meio de sinapses, que em termos artificiais são denominados pesos 
sinápticos, sendo que sua ativação é processada por funções de transferência ou ativação. Devido às suas propriedades e características, as RNAs apresentam as seguintes capacidades (Haykin, 1999):

- não-linearidade;

- mapeamento entrada-saída;

- adaptabilidade;

- tolerância à falhas;

- capacidade de generalização.

Segundo Trautwein (2004), as redes neurais são definidas em função de suas componentes e topologia.

\section{Componentes da RNA}

Baxter et al. (2001) definiram os componentes de uma RNA como:

- Unidades de processamento de neurônios;

- Camadas específicas de neurônios (layers);

- Pesos sinápticos ou pesos (weights);

- Função de ajuste de escala (normalização);

- Função de ativação;

- Regra de aprendizagem.

\section{Unidades de Processamento de neurônios}

Haykin (1999) define o neurônio como a unidade fundamental das RNAs devido a sua função de processar as informações, ou seja, realizar ajuste dos valores de entrada e saída, ajuste dos pesos sinápticos e ativar ou amplificar os sinais dos neurônios.

A seguir, na Figura 3-4, pode-se observar a comparação entre um neurônio biológico e um neurônio artificial, onde são feitas as seguintes correspondências: dentrito $\rightarrow>$ camada de entrada; sinapse $\rightarrow$ pesos sinápticos; corpo da célula $\rightarrow>$ neurônio artificial e axônio $\rightarrow>$ saída.

A saída pode ser representada pela Equação (2):

$$
y_{k}=\varphi\left(\sum_{j=1}^{m} w_{j k} x_{j}+b_{k}\right)
$$


em que $x_{j}$ e $y_{k}$ são os sinais pré-sinápticos e pós-sinápticos, respectivamente, $w_{j k}$ são os pesos sinápticos entre os nós $j$ e $k, b_{k}$ é o bias ${ }^{18}$ do neurônio $k, m$ é o número de neurônios, $\varphi$ é a função de ativação ou função de transferência e $y_{k}$ a saída da RNA.

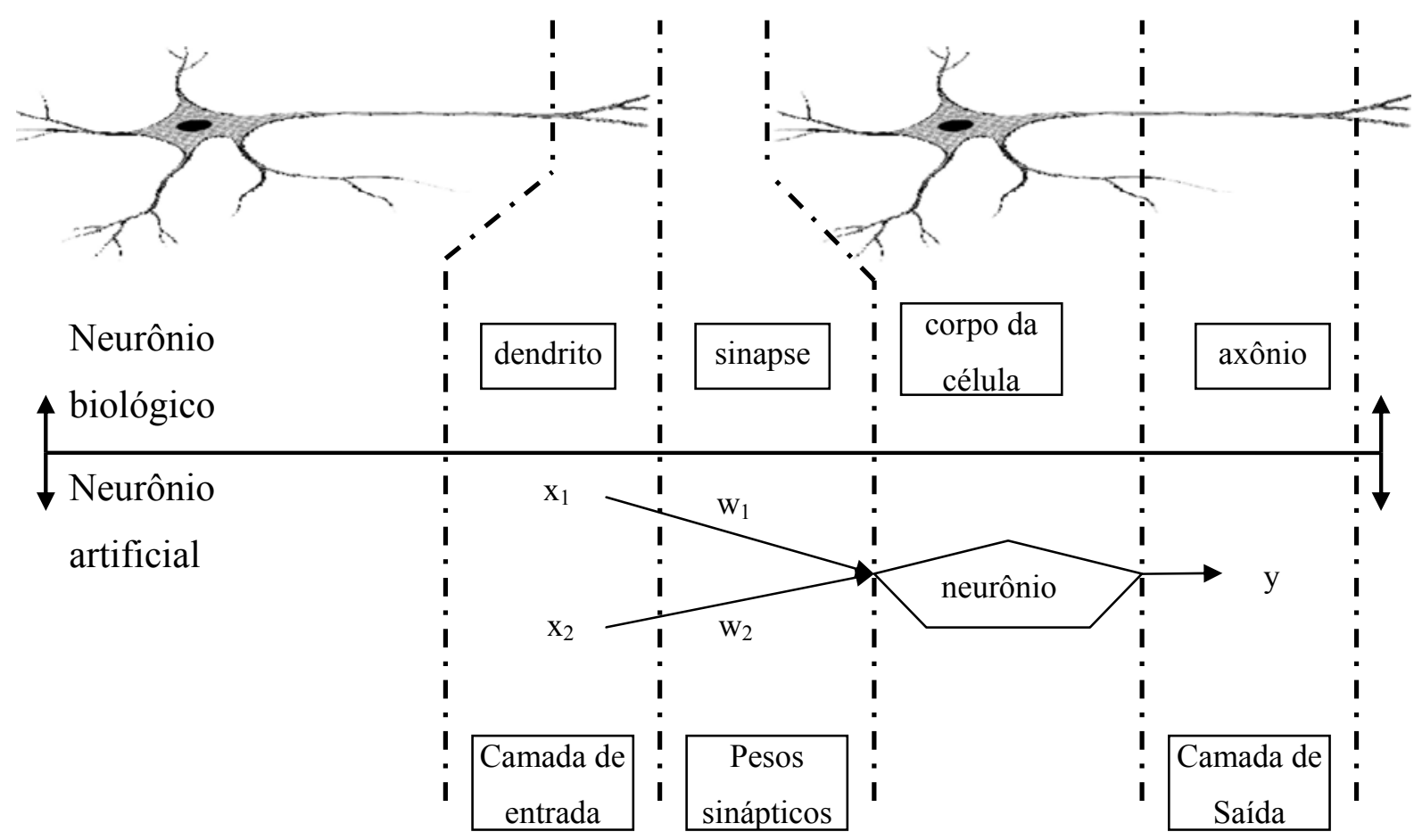

Figura 3-4 - Comparação entre neurônio biológico e artificial

(adaptado de Trautwein, 2004)

\section{Camadas específicas de neurônios (“layers”)}

Os neurônios artificiais podem estar organizados em camadas, que podem ser de três tipos, conforme ilustração da Figura 3-5:

- Entrada (input): valores a serem fornecidos à rede como entrada;

- Camada intermediária ou oculta (hidden layer): conexão entre a entrada e a saída (no caso da rede de 3 camadas), conferindo à rede capacidade para extrair conhecimento mais complexos;

- Saída (output): fornece os resultados do processamento das informações.

${ }^{18}$ Silva (2003) define uma bias como uma entrada adicional de polarização aplicada externamente a um neurônio k que aumenta ou diminui o argumento da função de ativação, caso seja positivo ou negativo, respectivamente. 


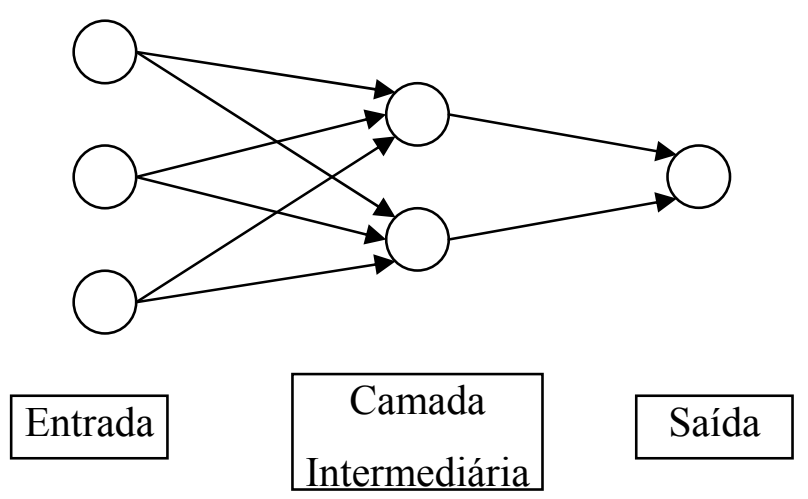

Figura 3-5 - RNA de 3 camadas

Braga et al. (2007) afirmaram que redes sem camadas intermediárias resolvem apenas problemas linearmente separáveis. Entretanto, geralmente na prática, os problemas são muito mais complexos e não lineares. Nestes casos devem ser utilizadas redes com camadas intermediárias. De acordo com Cybenko ${ }^{19}$ (1989, apud Braga et al., 2007, p. 70), uma camada intermediária é suficiente para aproximar qualquer função contínua, e Cybenko ${ }^{20}$ (1988, apud Braga et al., 2007, p. 70) afirma que duas camadas intermediárias são suficientes para aproximar qualquer função matemática. Braga et al. (2007) ainda observaram que a utilização de duas ou mais camadas intermediárias pode facilitar o treinamento da rede, mas o uso de um grande número dessas não é recomendável, pois a única camada que tem noção precisa do erro é a de saída, enquanto que a última camada intermediária recebe apenas uma estimativa do erro, a penúltima camada intermediária a estimativa da estimativa e assim por diante.

\section{Pesos sinápticos ("weights”)}

A conexão entre os neurônios é realizada pelos pesos sinápticos (weights), os quais são ajustados durante a fase de treinamento da rede neural por meio de algoritmos de otimização, tais como Método de Newton, Método do Gradiente Conjugado, etc.

\section{Normalização}

A normalização corresponde ao procedimento de pré-processamento dos valores de entrada reais para o intervalo $[0,1]$ ou $[-1,1]$.

${ }^{19}$ Cybenko, G. (1989). Approximation by superpositions of a sigmoidal function. Mathematics of control, Signals and Systems, 2:303-314.

${ }^{20}$ Cybenko, G. (1988). Continuous valued neural networks with two hidden layers are sufficient. Technical Report, Department of Computer Science, Tufts University. 


\section{Função de ativação}

A função de ativação tem o propósito de restringir a amplitude de saída do neurônio (ver Equação (2)). Geralmente, esta função é monotonicamente não-decrescente e apresenta um tipo de não-linearidade associada ao efeito da saturação ${ }^{21}$ (Haykin, 1999).

Existem diversas funções de ativação, e as mais utilizadas são: degrau (hard limiter), rampa (treshold logic), logística (sigmoid) e Gaussiana (Gaussian), conforme ilustradas na Figura 3-6.

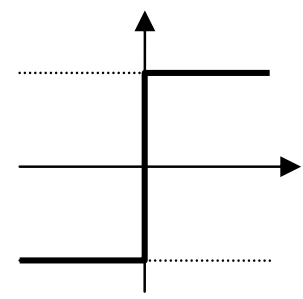

(a)

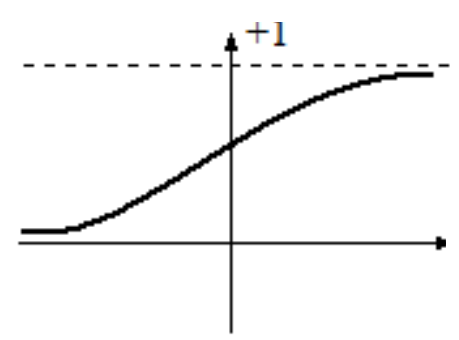

(c)

$$
\varphi(v)=\left\{\begin{array}{l}
1, \forall v>0 \\
0, \forall v=0 \\
-1, \forall v<0
\end{array}\right.
$$$$
\varphi(v)=\frac{1}{1+e^{-v}}
$$

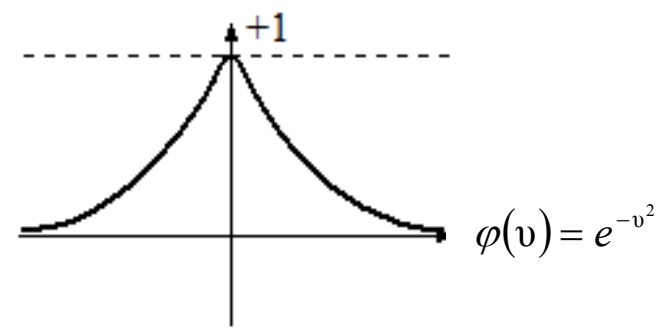

(d)

Figura 3-6 - Funções de ativação: (a) função degrau, (b) função rampa, (c) função logística e (d) função gaussiana.

\section{Regra de aprendizagem}

A regra de aprendizagem realiza o ajuste dos pesos iterativamente para que a saída produzida pela rede neural seja cada vez mais próxima da saída desejada. De acordo com Trautwein (2004), o processo de aprendizagem pode ser classificado de acordo com o paradigma de aprendizagem e com o tipo de algoritmo utilizado.

Os paradigmas de aprendizado podem ser dos seguintes tipos (Braga et al., 2007):

${ }^{21} \mathrm{O}$ efeito de saturação é ilustrado na Figura 3-6, na qual se observa que as funções de ativação atingem um patamar a partir de determinados valores da abscissa. Exemplo: a função rampa apresenta saturação (patamar) para valores de $r \geq|1|$. 
a) Aprendizado supervisionado: um agente externo indica as respostas desejadas para os respectivos padrões de entrada apresentados à rede. A correção do erro é realizada contabilizando-a entre a saída produzida e a desejada para realizar os ajustes dos pesos e gerar saídas mais próximas às desejadas

b) Aprendizado não supervisionado: é um processo auto-organizado no qual não há um agente externo que indique a resposta desejada.

O aprendizado não supervisionado possui as seguintes técnicas de implementação:

- Aprendizagem de Hebb: este método realiza o fortalecimento de uma conexão caso os neurônios em lados distintos sejam ativados simultaneamente. Dandolini (1997) afirma que a vantagem desse método reside na redução da complexidade do treinamento, pois a aprendizagem é realizada localmente, e depende apenas da ativação dos dois neurônios interconectados;

- Aprendizagem competitiva: nesta regra, há competição entre os neurônios de saída, permanecendo ativo apenas o neurônio que apresentar o maior valor de ativação. Portanto, o ajuste dos pesos é realizado a partir do neurônio vencedor até uma vizinhança de raio $R$ estipulada, sendo esta técnica de aprendizagem mais recomendada para a classificação dos dados.

c) Reforço: neste aprendizado, a única informação fornecida à rede é se uma determinada saída está correta ou não, ou seja, não é fornecida à rede a resposta correta para o padrão de entrada.

De acordo com Haykin (1999) existem ainda outras regras de aprendizagem:

- Aprendizagem baseada em memória: esta regra consiste em armazenar em uma memória conjuntos de exemplos de entrada-saída, os quais são utilizados para classificar um novo exemplo $x_{j}$ na vizinhança do mesmo por meio de buscas na memória. Este algoritmo pode ter diversas variações de acordo com a escolha do critério a ser utilizado para selecionar a vizinhança local e a escolha da regra de aprendizagem a ser aplicada a essa vizinhança.

- Aprendizagem de Boltzmann: é um algoritmo de aprendizagem estocástico que realiza o ajuste dos pesos baseado na probabilidade e na mecânica estatística 
(Haykin, 1999). Os estados dos neurônios, que podem assumir valor 1 (ligado) ou -1 (desligado) determinam o valor de uma função de energia, e o ajuste dos pesos é realizado de modo a minimizar a energia do sistema. $\mathrm{O}$ aprendizado de Boltzmann possui como desvantagem a enorme carga computacional, tornando-o inviável para treinamento de grandes redes neurais.

Quanto à frequência de correção do erro, Haykin (1999) aponta dois modos:

- Modo Padrão ("online"): A correção dos pesos é realizada após cada apresentação à rede de um exemplo do conjunto de treinamento constituído de $\mathrm{N}$ exemplos, sendo que cada correção de pesos baseia-se somente no erro do exemplo apresentado naquela iteração. Assim, em cada ciclo ocorrem N correções;

- Modo "batch" ("offline"): Neste modo, a correção dos pesos é realizada apenas uma vez por ciclo, após a apresentação de todos os exemplos do conjunto de treinamento, sendo que as correções dos pesos são efetuadas a partir do erro médio dos exemplos apresentados.

Segundo Braga et al. (2007), o modo Padrão é estável se a taxa de aprendizado for pequena, sendo aconselhável reduzir essa taxa progressivamente. "Esta abordagem geralmente é mais rápida, sobretudo se o conjunto de treinamento for grande e redundante". Além disso, essa técnica requer menos memória. Já o modo "batch" é geralmente mais estável, mas o processo de treinamento pode se tornar demasiadamente lenta se o conjunto de treinamento for muito grande ou redundante, além de necessitar de mais memória que o modo Padrão.

Além dos tipos de aprendizagem, há ainda outros fatores relevantes no processo de aprendizagem, como a inicialização dos pesos e a escolha do critério de parada, bem como o critério de erro escolhido.

Geralmente os valores para os pesos são inicializados com números aleatórios pequenos, pois valores absolutos iniciais muito grandes de pesos podem originar nós intermediários altamente ativos ou inativos para toda a amostra de treinamento e, portanto, indiferentes para o processo de treinamento. Mas, ao invés de utilizar números aleatórios, pode-se linearizar a rede, por meio de regressão linear dos pesos. Esta estratégia torna-se vantajosa se o problema for mais ou menos linear, então, a maior parte do treinamento é feita antes do ajuste iterativo dos pesos a ser iniciado (Leondes, 1998). 
Além do critério de parada baseada em um número limite de iterações (ciclos de treinamento), Haykin (1999) define outros, como quando o erro atinge um valor suficientemente pequeno ou a variação deste entre um ciclo e outro é pequeno.

Um problema presente nos treinamentos de redes neurais é a ocorrência de "underfitting" ou "overfitting". O "underfitting" ocorre quando o treinamento é encerrado prematuramente, enquanto que o "overfitting" ocorre quando a rede é excessivamente treinada, levando a rede a memorizar não só os padrões de treinamento, mas também suas peculariedades e ruídos, e consequentemente a uma piora na generalização (Braga et al., 2007).

Uma solução para resolver o problema de "overfitting" é utilizar a validação cruzada, ou seja, utilizar um conjunto de validação paralelamente ao conjunto de treinamento, para verificar a capacidade de generalização da rede durante o treinamento. Quando o erro do conjunto de validação começar a aumentar, deve-se encerrar o treinamento.

Um algoritmo de treinamento muito popular é a técnica de "Backpropagation" (BP), que implementa a regra denominada delta generalizada, derivada da regra delta. Esta por sua vez utiliza o gradiente descendente para minimizar o somatório dos erros médios quadráticos. A regra delta generalizada funciona quando são utilizadas na rede unidades com uma função de ativação diferenciável e não decrescente. Note que a função rampa não se enquadra nesse requisito. Uma função de ativação amplamente utilizada, nestes casos, é a função logística (Braga et al., 2007).

Mas o algoritmo BP, apesar de sua ampla utilização em razão de sua simplicidade, é um algoritmo lento que pode convergir para mínimos locais. Para resolver tais problemas, existem algumas técnicas para acelerar o aprendizado e evitar a convergência para os mínimos locais: utilizar taxas de aprendizado decrescente, adicionar nós intermediários, adicionar ruídos aos dados, ou incluir um termo denominado "momentum" na regra delta generalizada, uma constante que determina o efeito das mudanças passadas dos pesos na direção atual do movimento no espaço de pesos (Braga et al., 2007).

O ajuste dos pesos é expresso pela Equação (3):

$$
w_{i j}^{n+1}=w_{i j}^{n}+\Delta w_{i j}^{n}
$$

em que $w_{i j}$ é o peso sináptico entre o nó $i$ e $j, \Delta w_{i j}$ é a variação do peso e o índice $n$ e $n+1$ correspondem número da iteração durante o treinamento. 
A variação do peso é dada pela regra delta generalizada, dada a seguir pela Equação (4):

$$
\Delta w_{i j}^{n+1}=\eta \delta_{j}^{n} x_{j}^{n}
$$

em que $\eta$ é a taxa de aprendizagem no intervalo $[0,1], \delta_{j}^{n}$ é o gradiente local de erro para o neurônio $j$ e $x_{j}$ é o sinal pré-sináptico do neurônio $j$.

\section{Tipos de RNA}

Haykin (1999) exemplifica quatro tipos de arquitetura:

- Redes de camada única: nesta rede, a entrada está diretamente conectada a saída;

- Redes multicamadas: possui camadas intermediárias, além das camadas de entrada e saída;

- Redes recorrentes: Possuem conexões de realimentação que proporcionam comportamento dinâmico. Há dois tipos de redes recorrentes: aquelas em que o padrão de entrada é fixo e a saída caminha dinamicamente para um estado estável e aquelas em que ambas entrada e saída variam com o tempo, sendo estas últimas mais gerais e utilizadas com maior frequência (Segatto e Coury, 2006);

- Redes treliçadas: as camadas dos neurônios possuem uma ou mais dimensões.

Entre as diversas possibilidades de arquiteturas, pode-se citar a RNA Perceptron de múltiplas camadas (MLP), que, de acordo com Baxter (2001), é uma rede de simples implementação e de eficiência comprovada para previsão de séries temporais. As redes MLP são generalizações da rede Perceptron proposta por Rosenblatt, as quais possuem ao menos três camadas: entrada, intermediária e saída e geralmente são treinadas pelo algoritmo "Backpropagation".

Pode-se citar também a rede neural "Radial Basis Function" (RBF), "Group Method of Data Handling" (GMDH), "Dynamic Architecture for Artificial Neural Networks" (DAN2), RNAs híbridas, etc. 
A rede RBF tem como principal característica o uso de funções de ativação de base radial, como alternativa à rede MLP. O valor resultante de uma função de base radial depende da distância de um ponto de referência central, podendo ser crescente ou decrescente em relação a esse centro, assim, a ativação de um neurônio é função da distância entre um vetor de referência e o vetor de entrada. A convergência da rede RBF tende a ser mais rápida, porém, as redes MLP possuem capacidade de generalização maior.

Segundo Valença (2009), as redes baseadas em GMDH são sistemas híbridos compostos de uma combinação de redes neurais e conceitos estatísticos, incorporando os seguintes elementos: conceito de caixa-preta, como um estudo de entrada e saída; uma abordagem neural, por utilizar o conceito de conexionismo, uma abordagem indutiva, ou construtiva; e o princípio de complemento externo como critério de seleção. Em sua concepção original proposta por Ivakhnenko, a rede neural utiliza funções de ativação polinomial, sendo denominada também rede neural polinomial.

A DAN2, proposta por Ghiassi e Saidane (2005), baseia-se no princípio de apreender e acumular conhecimento a cada camada sucessiva, propagando e ajustando esse conhecimento para as próximas. Diferente das RNAs, o número de neurônios é fixo e as camadas intermediárias são adicionadas até que seja satisfeito um determinado critério de parada. Além disso, funções trigonométricas são utilizadas como funções de ativação e os dados de entrada são utilizados simultaneamente e repetidamente em cada camada adicional. 



\section{Materiais e Métodos}

Para realizar a otimização da operação em tempo real é necessário associar ao modelo de otimização um previsor de demanda e um simulador hidráulico. O previsor produzirá estimativas de demandas futuras para o horizonte desejado, que por sua vez alimentarão o simulador, a fim de que sejam determinadas as estratégias operacionais otimizadas para atendimento das demandas previstas.

Para se realizar a otimização da operação, pode-se utilizar um ou mais critérios para avaliar a qualidade das soluções geradas via modelo matemático. Em geral, o objetivo básico a ser considerado é o de custo energético mínimo, o que pode gerar soluções impraticáveis para sistemas reais. Segundo Walski (2001), apesar da existência dos diversos estudos, os modelos de otimização de projeto de redes resultantes não são utilizados na prática, pois consideram como objetivo a minimização dos custos, sem levar em conta outros critérios importantes, como a confiabilidade do sistema, a exequibilidade do projeto, dentre outros. Segundo ele, tais critérios apresentam grande complexidade e não são diretamente mensuráveis.

De modo análogo, pode-se estender tal raciocínio à otimização da operação de redes de abastecimento de água. Assim, observa-se ser necessário considerar como objetivo melhorar a confiabilidade da operação das redes de abastecimento, a fim de que os resultados produzidos sejam, além de mais econômicos, viáveis e confiáveis, objetivos esses perseguidos no presente trabalho.

A seguir serão apresentados os módulos computacionais constituído para compor as abordagens de otimização adotadas no desenvolvimento do presente trabalho. Tais módulos foram empregados na previsão de demanda, na simulação hidráulica e a otimização, além das técnicas de amostragem e das medidas de confiabilidade a serem utilizadas em conjunto com os referidos módulos. Como resultado, foram propostas as abordagens para realizar a otimização da operação.

\subsection{Módulo de Previsão de demanda}

Entre as diversas técnicas de previsão de demanda propostas na literatura, decidiu-se utilizar os modelos baseados em redes neurais artificiais, devido à sua capacidade de se equiparar ou mesmo superar os demais modelos de previsão baseados em análises de regressão e séries temporais. Assim, neste trabalho foi utilizado o modelo de previsão híbrido 
desenvolvido por Odan (2010) que produziu os melhores resultados. O modelo utilizou a rede neural dinâmica DAN2 (Ghiassi et al, 2008) ) para realizar a previsão de demanda, modelando os consumos observados em conjunto com a previsão de demanda realizada pela série de Fourier.

A DAN2 fora implementada em linguagem Scilab, de distribuição gratuita, enquanto que a previsão por Séries de Fourier fora desenvolvida pela orientadora desta tese em linguagem Fortran e modificada pelo autor desta tese.

A DAN2 é uma rede neural dinâmica proposta por Ghiassi e Saidane (2005), cuja idéia básica é aprender e acumular conhecimento a cada camada adicionada, propagando e ajustando o conhecimento até que um critério de parada seja alcançado.

A matriz dos dados de entrada $D=\left\{D_{i}, i=1, \ldots, n\right\}$ é composta de $n$ padrões independentes de $m$ atributos, ou seja, $D_{i}=\left\{d_{i j}, j=1, \ldots, m\right\}$, conforme a Figura 4-1 ("Input Matrix").

A rede proposta por Ghiassi e Saidane (2005) é composta de uma camada de entrada, uma camada de saída e uma ou mais camadas intermediárias.

O modelo utiliza normalização dos dados para evitar problemas com as diferentes métricas, que consiste em projetar cada observação $i$ sobre o vetor de referência $\operatorname{Ref}=\{r e f j$, $j$ $=1, \ldots, m\}$. A normalização define um ângulo $\alpha_{i}$, entre o vetor $i$ de observações $D i=\left\{d_{i j}, j=\right.$ $1, \ldots, m\}$ e o vetor de referência $R e f$.

Diferentemente das RNAs tradicionais, o número de nós nas camadas intermediárias é fixado em quatro, conforme ilustração da Figura 4-1. O primeiro nó é uma constante denotada por $c$. O segundo nó, que acumula o conhecimento adquirido é denominado CAKE ("Current Accumulated Knowledge Element"), representado por $F_{k}$. Por fim, os nós terceiro e quarto são denominados CURNOLE ("Current Residual Nonlinear Element"), e são responsáveis por capturar os elementos residuais não lineares, os quais são representados pelos nós $G_{k}$ e $H_{k}$.

Ghiassi e Saidane (2005) utilizaram três critérios de parada: número máximo de iterações, critério de "underfitting" e critério de "overfitting". O segundo critério evita que o modelo seja insuficientemente treinado, dado pela Equação (5), e o terceiro impede que haja excesso de treinamento (Equação (6)), ou seja, evitar que haja bom ajuste para o conjunto de treino mas desempenho ruim para o conjunto de teste. Os limites para os critérios devem ser determinados experimentalmente para cada problema.

$$
\varepsilon_{1}=\left(S S E_{k}-S S E_{k+1}\right) / S S E_{k} \leq \varepsilon_{1}^{*}
$$


em que $S S E$ é o somatório dos erros quadráticos, os índices $k$ e $k+1$ são as iterações, e $\varepsilon_{1}$ e $\varepsilon_{1}{ }^{*}$ são respectivamente o erro calculado e o erro limite para evitar o "underfitting".

$$
\varepsilon_{2}=\left|M S E_{T}-M S E_{V}\right| / M S E_{T} \leq \varepsilon_{2}^{*}
$$

em que $M S E$ é o erro quadrático médio, os índices $T$ e $V$ são respectivamente para o conjunto de treino e validação, e $\varepsilon_{2}$ e $\varepsilon_{2}{ }^{*}$ são respectivamente o erro calculado e o erro limite para evitar o "overfitting".

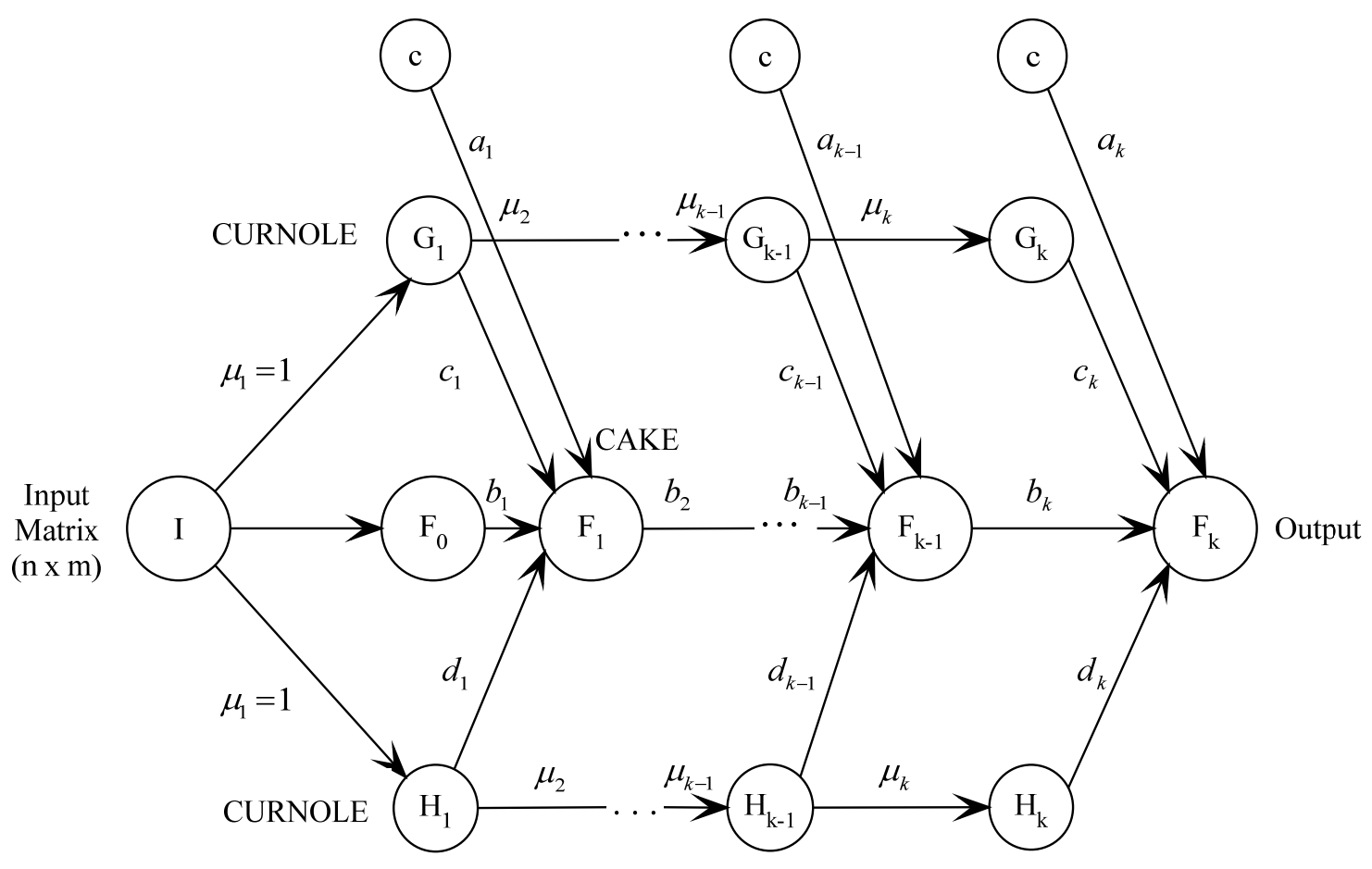

Figura 4-1 - Arquitetura da rede neural (DAN2)

No trabalho de Odan (2010), adotou-se número máximo de iterações igual a $15, \varepsilon_{1}{ }^{*}=$ $0,0001, \varepsilon_{2}^{*}=0,25$.

$\mathrm{O}$ treinamento se inicia com um nó $\mathrm{CAKE}$ especial $\mathrm{F}_{0}$, responsável por extrair os componentes lineares por meio de uma combinação linear dos dados de entrada, conforme Equação (7):

$$
F_{0}\left(D_{i}\right)=a_{0}+\sum_{j=1}^{m} b_{0 j} d_{i j}
$$


em que $a_{0}$ e $b_{0 j}$ são coeficientes determinados por regressão linear.

Caso o erro produzido ainda não seja aceitável, passa-se para a próxima camada $C A K E$, dado pela Equação (8):

$$
F_{k}\left(D_{i}\right)=a_{k}+b_{k} F_{k-1}\left(D_{i}\right)+c_{k} G_{k}\left(D_{i}\right)+d_{k} H_{k}\left(D_{i}\right)
$$

em que $G_{k}=\cos \left(\mu \cdot \alpha_{i}\right), H_{k}=\operatorname{sen}\left(\mu_{k} \cdot \alpha_{i}\right)$ e $a_{k}, b_{k}, c_{k}$ e $d_{k}$ e $\mu_{k}$ são constantes.

Substituindo $G_{k}$ e $H_{k}$ em (8), temos a Equação (9):

$$
F_{k}\left(D_{i}\right)=a_{k}+b_{k} F_{k-1}\left(D_{i}\right)+c_{k} \cos \left(\mu_{k} \cdot \alpha_{i}\right)+d_{k} \operatorname{sen}\left(\mu_{k} \cdot \alpha_{i}\right)
$$

O ângulo $\alpha_{i}$ entre o vetor $R$ e $D_{i}$ são obtidos segundo as equações (10), (11), (12), (13) e (14) representadas a seguir:

$$
\alpha_{i}=\operatorname{Arccos}\left(R * D_{i}\right)_{N} \quad \text { para } i=1, \ldots, n
$$

$$
\begin{aligned}
& \text { em que }\left(R * D_{i}\right)_{N} \\
& \left(R * D_{i}\right)=\sum_{j=1}^{m} r_{j} d_{i j}
\end{aligned}
$$

por padrão (default) $r_{j}=1$, para $j=1, \ldots, m$

$$
\begin{aligned}
& \|R\|=\sqrt{\sum_{j=1}^{m} r_{j}^{2}} \\
& \left\|D_{i}\right\|=\sqrt{\sum_{j=1}^{m} d_{i j}^{2}}
\end{aligned}
$$

As camadas intermediárias são adicionadas até que o critério de parada seja satisfeito, sendo que os coeficientes $a_{k}, b_{k}, c_{k}$ e $d_{k}$ e $\mu_{k}$ podem ser determinados por meio de um 
algoritmo de otimização, minimizando, por exemplo, o somatório dos erros quadráticos (SSE), expresso pela Equação (15):

$$
S S E_{k}=\sum_{i=1}^{n}\left[F_{k}\left(D_{i}\right)-\hat{F}\left(D_{i}\right)\right]^{2}
$$

em que $\hat{F}\left(D_{i}\right)$ é o valor do consumo observado.

Foram testadas diversas técnicas para realizar a otimização dos pesos e coeficientes da DAN2, tais como Método de Quase-Newton (Broyden, 1967), Algoritmos Genéticos (Goldberg, 1987) e também o algoritmo de Levenberg-Marquadt (Marquardt, 1963). Todos os métodos produziram resultados muito próximos, assim este último foi escolhido, por apresentar implementação e manuseio mais simples.

Com base nos resultados de Odan (2010), decidiu-se usar o modelo de previsão híbrido DAN2-H, o qual apresentou o melhor desempenho dentre as RNAs testadas. Na primeira coluna da Tabela 4-1 são apresentados os dados de entrada do modelo, e na segunda coluna os valores previstos. Na referida tabela, $\mathrm{C}$ denota o dado de consumo e SF corresponde a previsão de demanda produzida pela Série de Fourier ${ }^{22}$. O termo entre parênteses é referente ao tempo, ou seja, (t) é o instante atual e anterior à previsão. Os instantes (t-1), (t-2),..., (t-n) denotam respectivamente 1 hora, 2 horas,..., $\mathrm{n}$ horas antes do instante atual. No caso da previsão, $(\mathrm{t}+1), \ldots,(\mathrm{t}+24)$ representam as previsões de $1, \ldots, 24$ horas à frente do instante atual.

A previsão das próximas $24 \mathrm{~h}$ foi realizada em múltiplos passos. Na Figura 4-2 apresenta-se esquematicamente a previsão de demanda para as próximas $24 \mathrm{~h}$ realizada pelo modelo apresentado na Tabela 4-1, utilizando-se apenas os dados de consumo como dados de entrada. O processo é análogo com o uso de outros dados de entrada. Na referida figura, a demanda prevista para a próxima hora $(\mathrm{C}(\mathrm{t}+1)), \mathrm{P} 1$, utiliza-se dos consumos defasados de 168 horas $(\mathrm{C}(\mathrm{t}-168)), 3$ horas $(\mathrm{C}(\mathrm{t}-3)), 2$ horas $(\mathrm{C}(\mathrm{t}-2)), 1$ hora $(\mathrm{C}(\mathrm{t}-1))$ e hora atual $(\mathrm{C}(\mathrm{t}))$. Analogamente, o conjunto de dados $[\mathrm{C}(\mathrm{t}-167), \mathrm{C}(\mathrm{t}-2), \mathrm{C}(\mathrm{t}-1), \mathrm{C}(\mathrm{t})]$ associado a $\mathrm{P} 1$, do passo anterior, é utilizado para estimar o consumo de duas horas à frente $(\mathrm{C}(\mathrm{t}+2)), \mathrm{P} 2$. Desta maneira, a previsão de demanda prossegue até que sejam previstas as próximas 24 horas: a estimativa da demanda de 3 horas à frente utiliza as previsões de uma e duas horas à frente, dos passos anteriores, e assim sucessivamente.

\footnotetext{
${ }^{22}$ Este modelo de previsão foi explicado no item 4.1.1
} 
Tabela 4-1 - Modelo de previsão da rede neural DAN2-H

\begin{tabular}{cc}
\hline Entrada & Saída \\
\hline $\mathrm{C}(\mathrm{t}), \mathrm{C}(\mathrm{t}-1), \mathrm{C}(\mathrm{t}-2), \mathrm{C}(\mathrm{t}-3), \mathrm{C}(\mathrm{t}-168)$, & $\mathrm{C}(\mathrm{t}+1), \ldots, \mathrm{C}(\mathrm{t}+24)$ \\
$\mathrm{SF}(\mathrm{t}), \mathrm{SF}(\mathrm{t}-1), \mathrm{SF}(\mathrm{t}-2), \mathrm{SF}(\mathrm{t}-3), \mathrm{SF}(\mathrm{t}-168)$ & \\
\hline
\end{tabular}

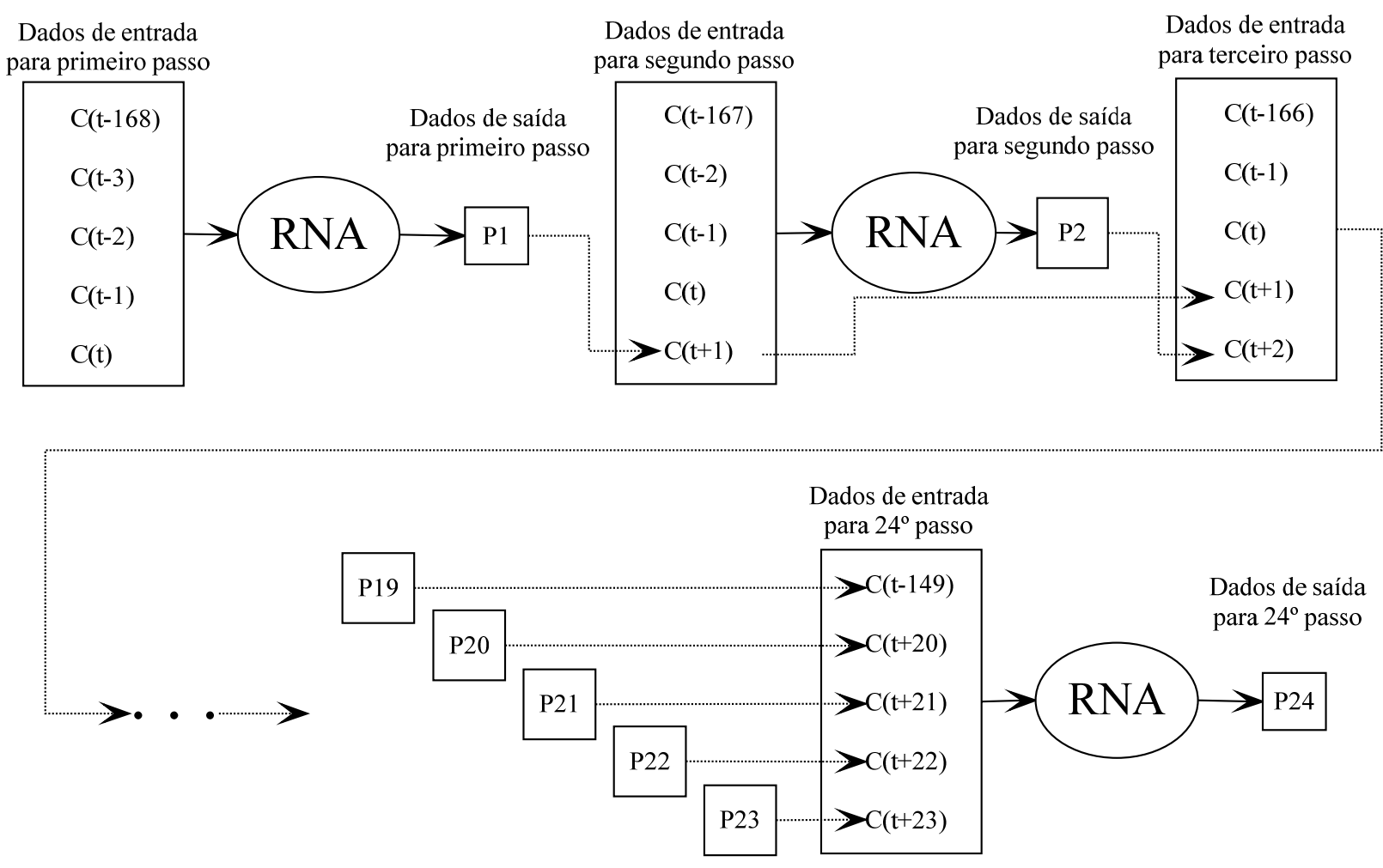

Figura 4-2 - Esquema da previsão de demanda das próximas 24h

\subsubsection{Modelo de previsão baseado em série de Fourier}

O modelo proposto por Zahed (1990) é baseado na série de Fourier e prevê coeficientes harmônicos atualizados na base diária, com ciclos de 7 dias. A idéia básica do modelo consiste em ajustar uma equação harmônica a uma série de dados observados e extrapolar essa série para o futuro, como um previsor. Assim, o modelo proposto consiste basicamente em adaptar uma série de Fourier, de forma que a função de consumo possa ser expressa pela equação (16):

$$
\begin{aligned}
& \operatorname{Fourier}\left(s x_{j}\right)=s a_{0}+\sum_{k=1}^{N H}\left[s a_{k} \cdot \cos \left(k \cdot \frac{\pi}{N h} \cdot j\right)+s b_{k} \cdot \operatorname{sen}\left(k \cdot \frac{\pi}{N h} \cdot j\right)\right] \\
& \operatorname{com} N H<N h
\end{aligned}
$$


em que $s a_{k}$ e $s b_{k}$ são coeficientes determinados pelo método dos mínimos quadrados, $s a_{0}$ o valor médio da função no intervalo utilizado, $\mathrm{NH}$ o número de harmônicos da série, $2 \mathrm{Nh}$ é o período em horas coincidente com o intervalo 0 a $2 \pi, j$ é o número de ordem do dado na série; $s x_{j}=(\pi / N h)_{j}$.

O método dos mínimos quadrados foi utilizado para a obtenção dos coeficientes expressos pelas equações (17), (18), (19) e (20) (Humes et al., 1984):

$$
\begin{aligned}
& s a_{0}=\frac{1}{2 N h} \sum_{j=1}^{2 N} f\left(s x_{j}\right) \\
& s a_{k}=\frac{1}{N h} \sum_{j=1}^{2 N} f\left(s x_{j}\right) \cos \left(k \frac{\pi}{N h} j\right) \\
& s b_{k}=\frac{1}{N h} \sum_{j=1}^{2 N} f\left(s x_{j}\right) \operatorname{sen}\left(k \frac{\pi}{N h} j\right) \\
& \operatorname{Para} N H=N h, \\
& s a_{N}=\frac{1}{2 N h} \sum_{j=1}^{2 N} f\left(s x_{j}\right) \cos (\pi j)
\end{aligned}
$$

em que $f\left(s x_{j}\right)$ é o j-ésimo valor de consumo observado, que é um valor médio calculado na base horária.

Assim, admitindo, por exemplo, o ciclo semanal e a discretização horária dos consumos tem-se, $2 N h=24$ horas $\mathrm{x} 7$ dias $=168$ horas. Para cada grau $k$ de harmônico, são necessários dois somatórios para definir os coeficientes $s a_{k}$ e $s b_{k}$. A idéia básica da aplicação desse modelo consiste em ajustar uma série de Fourier a uma sequência de 7 dias de consumos observados e extrapolar essa série 24 horas à frente (um dia "móvel" de previsão).

Diferentemente de Zahed (1990), Odan (2010) não utilizou fatores de correção à previsão de demanda, para evitar que fossem introduzidas flutuações não inerentes à própria série de Fourier.

\subsection{Módulo de simulação hidráulica}

Neste trabalho, foram utilizados dois simuladores hidráulicos: o tradicional modelo EPANET 2 e o metamodelo. No presente texto, nos casos em que não esteja especificado o 
modelo utilizado para reprodução do comportamento hidráulico, deve-se assumir que fora utilizado o EPANET 2, caso contrário, será explicitado o uso do metamodelo.

\subsubsection{EPANET 2}

O EPANET 2 (Rossman, 2000) é um programa de computador desenvolvido pela "Enviromental Protection Agency" (EPA). Este modelo realiza simulações em período estendido do comportamento hidráulico e da qualidade da água em redes de abastecimento pressurizadas.

A rede de abastecimento é composta basicamente de condutos (tubos), nós (junções dos tubos), bombas, válvulas e reservatórios. O EPANET possibilita obter a vazão nos tubos, pressão dos nós, nível dos reservatórios durante o período de simulação constituídos de múltiplos passos ou subperíodos.

É possível utilizar o EPANET por meio de uma interface gráfica, o qual permite criar e editar a rede de abastecimento por meio de um arquivo texto de extensão ".inp", realizar as simulações hidráulicas e de qualidade, observar e extrair os resultados desejados por meio de tabelas e gráficos.

As equações de continuidade da vazão e de perda de carga, que caracterizam o estado hidráulico dos tubos em um determinado instante, são resolvidas pelo Método do Gradiente (Todini e Pilati, 1987), que é uma aproximação híbrida nó-malha.

A perda de carga pode ser calculada por meio das equações de Darcy-Weisbach, pelo método de Hazen-Willians ou ainda pelas fórmulas de Chezy-Manning.

Além da interface gráfica, pode-se utilizar o EPANET por meio da interface "Toolkit", por intermédio de diferentes linguagens de programação $(\mathrm{C} / \mathrm{C}++$, Visual Basic e Delphi). A "Toolkit" nada mais é que uma biblioteca de vínculo dinâmico (DLL), a qual permite utilizar suas diversas funcionalidades em um código computacional.

Neste trabalho, as funções do EPANET foram implementadas utilizando-se o $\mathrm{C}++\mathrm{e}$ acessadas por meio de um programa executável, do qual se obtém os dados de entrada por meio de um arquivo texto, e registra os resultados em outro arquivo texto. Deste modo, a comunicação entre o Módulo de Otimização, em linguagem Scilab, e o simulador hidráulico foi realizado por meio desses arquivos texto, pois não foi possível acessar diretamente a "Toolkit" por meio da linguagem Scilab. 


\subsubsection{Metamodelo}

Geralmente o uso do tradicional simulador hidráulico demanda considerável tempo de processamento computacional no processo de otimização da operação, o que pode tornar a otimização em tempo real inviável. Para diminuir tal tempo computacional, utilizou-se neste trabalho o metamodelo baseado em redes neurais artificiais, a fim de reproduzir o comportamento do sistema de distribuição de água.

Algumas alternativas foram sugeridas na literatura para reduzir o tempo de processamento consumido pelos simuladores hidráulicos, e entre eles está o uso de modelos heurísticos (ou metamodelos) para substituir os tradicionais simuladores hidráulicos. A metamodelagem consiste em calibrar o modelo substituto a partir de dados observados ou gerados pelo simulador, para que reproduza alguns dos resultados fornecidos pelo simulador, os quais serão utilizados na otimização do problema.

A obtenção de um metamodelo satisfatório para uma pequena rede de abastecimento é bem simples, mas para redes mais complexas, vários fatores devem ser considerados, de modo a produzir um metamodelo suficientemente representativo e sem a inclusão de dados redundantes, os quais apenas irão aumentar desnecessariamente a complexidade a ser modelada. Assim, neste trabalho a metamodelagem foi baseada na metodologia proposta por Broad et al. (2010).

Para construir o metamodelo, deve-se: avaliar o grau de simplificação (esqueletonização) da rede, a duração da simulação e do controle operacional, além de se determinar os nós críticos, gerar os dados para o treinamento, calibrar e validar o metamodelo. Cada passo foi detalhado nos itens seguintes.

A implementação do metamodelo foi realizada em linguagem Scilab, utilizando-se a RNA “Adaptive Merging and Growing Algorithm” (AMGA), detalhada no item 4.2.3 (página 84).

\section{Grau de simplificação da rede}

A modelagem foi realizada sobre o sistema de distribuição completo, e portanto foi necessário simplificar a rede nos casos de nós seriais, como representado na Figura 4-3 (a), na qual os nós 1 e 2 são considerados seriais, com tubos de mesmas propriedades.

No presente trabalho, realizou-se a esqueletonização da rede de abastecimento combinando-se os tubos de mesmo diâmetro e material, de modo a obter tubos equivalentes. O processo de esqueletonização foi realizado utilizando-se a rotina computacional desenvolvida por Abe (2013). As demandas dos nós simplificados foram transpostas para os 
nós mais próximos, como exemplificado na Figura 4-3 (b), em que a demanda $\mathrm{d}_{1}$ foi atribuída ao nó $\mathrm{A}$ e portanto somadas a $\mathrm{d}_{\mathrm{A}}$, para compor $\mathrm{d}_{\mathrm{A}}$ '. Já a demanda $\mathrm{d}_{2}$ foi atribuída ao nó $\mathrm{B}$, e deste modo somada a $\mathrm{d}_{\mathrm{B}}$ para compor $\mathrm{d}_{\mathrm{B}}$ '.

Procurou-se evitar simplificar a rede nos trechos que contenham consumidores especiais, ou seja, que possuem uma grande demanda concentrada, tais como hospitais, indústrias, condomínios etc.

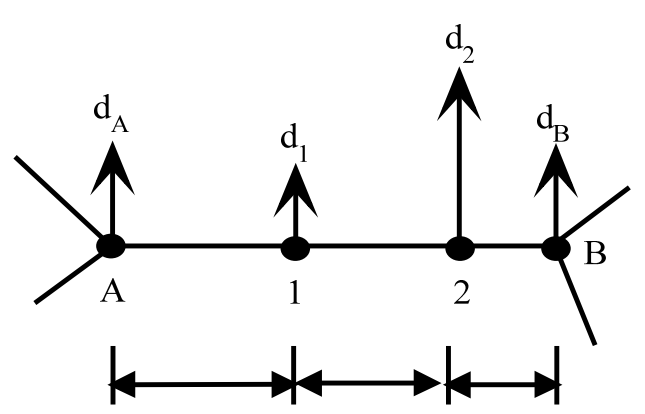

$2 \mathrm{~L}$
$2 \mathrm{~L}$

(a)

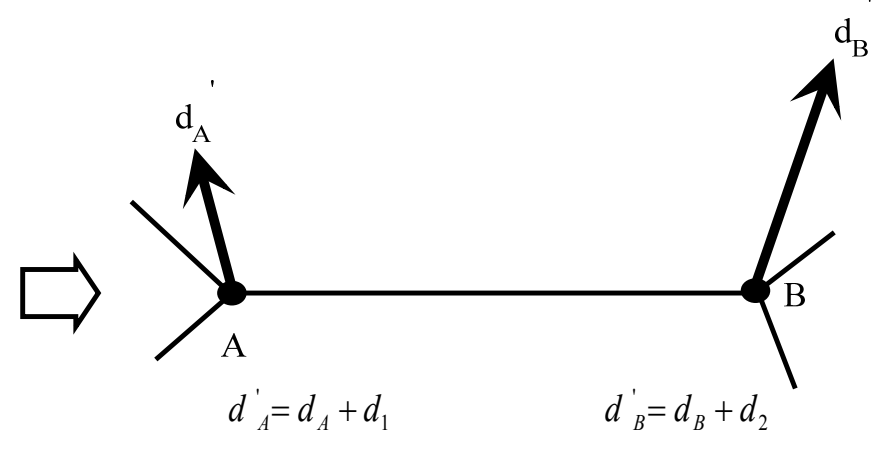

(b)

Figura 4-3 - Esqueletonização de um trecho de rede com nós seriais

\section{Duração da simulação}

Neste trabalho não houve consideração da qualidade da água, e, portanto, não houve necessidade de adotar a duração da simulação maior ou igual que a máxima idade que a água poderia ter ao percorrer as tubulações, que é imprescindível para monitorar o cloro residual nas extremidades do sistema, por exemplo. Assim, neste trabalho foram utilizadas simulações de período estendido de $24 \mathrm{~h}$, com passos hidráulicos de $1 \mathrm{~h}$.

\section{Determinação de elementos a serem monitorados}

Um dos elementos a serem monitorados é o nó, do qual se obtém a carga de pressão no simulador hidráulico. A escolha de quais nós serão monitorados deve levar em conta os seguintes aspectos: variabilidade dos dados, presença de demanda e frequência dos dados críticos, ou seja, a frequência de valores abaixo de um determinado limite.

Para o propósito de otimização da operação, outros dados devem ser monitorados, como o consumo energético nas bombas, para avaliar o custo das estratégias otimizadas; o nível dos reservatórios, a fim de verificar se o nível final será superior ao do início do dia; e a vazão em alguns tubos caso seja necessário. 


\section{Geração de dados para treinamento}

Realizou-se a geração aleatória dos dados, com o uso da amostragem do HiperCubo Latino (ver item 4.6, página 113), acoplando-se o compilador C++ a Toolkit do EPANET 2 (Rossman, 2000), conforme fluxograma da Figura 4-4.

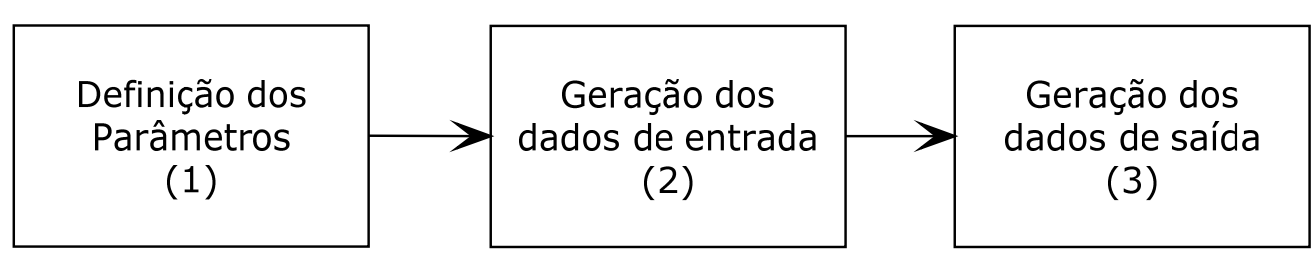

Figura 4-4 - Fluxograma da geração aleatória de dados para treinamento do metamodelo

Primeiramente, são definidos os parâmetros iniciais do modelo (1):

- número de amostras;

- número de setores com demanda, reservatórios e bombas;

- nível mínimo e máximo dos reservatórios.

Então são gerados os seguintes dados de entrada (2), utilizando-se a amostragem do hipercubo latino ${ }^{23}$ :

- demanda dos setores de abastecimento;

- Nível inicial dos reservatórios;

- status de funcionamento das bombas (ligado/desligado).

Eles são fornecidos como dados de entrada (.inp) ao simulador hidráulico EPANET, o qual irá reproduzir as respostas desejadas (3):

- carga de pressão no nós;

- nível final dos reservatórios;

- consumo energético das bombas.

Caso o simulador hidráulico aponte algum erro durante a simulação (ver 4.3.2, Tabela 4-2, página 98), gera-se uma nova entrada para ser simulada.

${ }^{23}$ O números de estratos corresponde ao número de amostras a serem geradas e a distribuição de probabilidade utilizada foi a uniforme. 
Ao final da rotina de geração de dados aleatórios, criam-se padrões formados pelas entradas e suas respectivas saídas a serem fornecidas para o treinamento da RNA, a fim de criar o metamodelo.

\section{Calibração e validação do metamodelo}

A calibração do metamodelo foi realizada por meio do método "holdout" ou "splitsample", em que se divide o conjunto de dados em duas partes: treino e teste. Mas, para auxiliar no processo de parada do treinamento, o conjunto de treino foi dividido em treino e validação. Assim, o conjunto de dados foi dividido em três subconjuntos: treino $(50 \%)$, validação (25\%) e teste (25\%), conforme Haykin (1999).

O subconjunto de treino foi usado para ajustar os pesos da rede neural, enquanto que o subconjunto de validação é utilizado para interromper o treinamento no momento que o erro calculado para a validação decresce para um valor mínimo, conforme Figura 4-5, evitando assim que a rede neural seja treinada em excesso (“overfitting”). Finalmente, o subconjunto de teste, com dados não utilizados no processo de treinamento, foi usado para avaliar o desempenho do metamodelo.

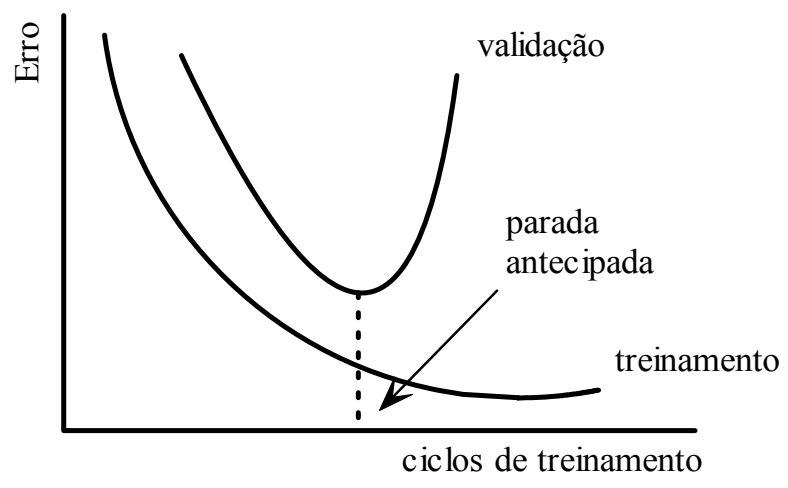

Figura 4-5 - Regra de parada antecipada

\subsection{3 "Adaptive Merging and Growing Algorithm" (AMGA)}

Islam et al. (2009) desenvolveram um algoritmo para construir RNAs denominado "Adaptive Merging and Growing Algorithm" (AMGA). O algoritmo usa mecanismos de mescla e adição de neurônios da camada intermediária, baseando-se no progresso e na habilidade de aprendizado dos neurônios dessa camada. A mescla é realizada entre neurônios com repostas correlacionadas entre si, enquanto que a adição divide o neurônio em dois, de modo a reaproveitar o treinamento anterior e reduzir o treinamento necessário após a modificação. Este algoritmo pode ser aplicado a diversos tipos de RNAs, sendo que neste 
trabalho será aplicada à RNA "feedforward" com algoritmo de treinamento Backpropagation com o termo momentum, o qual confere maior velocidade ao treinamento sem prejudicar a estabilidade. Tal termo é uma fração da alteração de peso anterior e é adicionado ao ajuste de pesos da Eq. (3), conforme descrito por Beale e Jackson (1990). Esta RNA será denominada RNA MOM-BP.

Os passos utilizados pela AMGA são descritos a seguir, com algumas modificações (denotadas por *) em relação ao algoritmo original:

1) Criar uma RNA de três camadas, com número de neurônios nas camadas de entrada e saída determinado pelo problema a ser modelado. $\mathrm{O}$ número $\mathrm{N}$ de neurônios na camada intermediária é gerado aleatoriamente, assim como a matriz de pesos iniciais;

2) Inicializar o contador de ciclos $n c i c l o r=0, i=1,2, \ldots, n c i_{\text {inicial }}$, para cada neurônio da camada intermediária $h_{i}$, sendo $n c i_{\text {inicial }}$ o número inicial de neurônios da camada intermediária. Este contador é utilizado para contabilizar o número de ciclos em que o neurônio foi treinado;

3) Treinar parcialmente a RNA para um número fixo de ciclos $\tau$, especificado pelo usuário;

4) Incrementar a contagem de ciclos, expresso pela Eq. (21), para $i=1,2, \ldots, n c i$ :

$$
\text { nciclo }_{i}=\text { nciclo }_{i}+\tau
$$

em que nci o número de neurônios na camada intermediária. Inicialmente nci e nci inicial são iguais;

5) Calcular o erro do conjunto de validação pela Eq. (22), denominado Erro Quadrático Percentual Médio (Prechelt, 1994), EQM. Se o critério de parada é satisfeito, parar o treinamento, senão continuar:

$$
E Q M=100 \frac{o_{\max }-o_{\min }}{n s \cdot V n} \sum_{v=1}^{V n} \sum_{i=1}^{n s}\left(Y_{i}(v)-Z_{i}(v)\right)^{2}
$$

em que $o_{\max }$ e $o_{\min }$ são, respectivamente, os valores máximos e mínimos para os quais a saída da RNA foi padronizada; $V n$ é o número de exemplos do conjunto de validação; $n s$ é o número de neurônios da camada de saída; $Y_{i}(v)$ e $Z_{i}(v)$ são, 
respectivamente, a saída produzida pela RNA e a saída desejada, do i-ésimo neurônio de saída para o v-ésimo exemplo do conjunto de validação;

6) Remover o rótulo ("label") dos neurônios intermediários e calcular a significância $\eta_{i}$ de cada neurônio intermediário $h_{i}$ usando a fórmula empírica da Eq (23):

$$
\eta_{i}=\frac{\sigma_{i}}{\sqrt[3]{\text { nciclos }_{i}}}
$$

em que $\sigma_{i}$ é o desvio padrão da saída de cada neurônio $h_{i}$, para os exemplos do conjunto de treino, e nciclos $_{i}$ é contador de ciclos;

7) Rotular os neurônios $h_{i}$ como não significativos (Lsign) caso a significância de um ou mais desses neurônios seja menor que um mínimo definido pelo usuário. Notar que no máximo metade dos neurônios serão rotulados;

8) Calcular a correlação entre os neurônios rotulados LSign e os neurônios não rotulados, referente à saída produzida por tais neurônios intermediários para o conjunto de treino;

9) *Realizar a mescla entre os neurônios rotulados (Lsign) e seu par mais correlacionado $\left(h_{a}\right.$ e $\left.h_{b}\right)$ e calcular a média ${ }^{24}$ entre o contador de ciclos de ambos os neurônios. Os pesos dos neurônios modificados são dados pelas Eqs. (24) e (25):

$$
\begin{array}{ll}
w_{m i}=\frac{w_{a i}+w_{b i}}{2}, & i=1,2, \ldots, n e \\
w_{j m}=w_{j a}+w_{j b}, & j=1,2, \ldots, n s
\end{array}
$$

em que ne e $n s$ correspondem aos números de neurônios nas camadas de entrada e saída, respectivamente. Os pesos $w_{a i}$ e $w_{b i}$ são os i-ésimos pesos dos neurônios $h_{a}$ e $h_{b}$, respectivamente, enquanto $w_{m i}$ é o $i$-ésimo peso da camada de entrada e $w_{m j}$ é o j-ésimo peso da camada de saída;

10) * Retreinar a RNA modificada, obtida depois da mescla de neurônios com $\tau \operatorname{ciclos}^{25}$. Caso essa nova RNA consiga produzir um erro menor ou igual ao da RNA anterior, então prosseguir para o passo 11 , caso contrário ir para o passo 12 ;

\footnotetext{
${ }^{24}$ No algoritmo original, o contador é zerado. A modificação se deve ao fato da mescla ser resultado da
} combinação de dois neurônios, e entende-se que tal operação também deve ser aplicada ao contador de ciclos. 
11) Atualizar o contador de ciclos conforme Eq. (21);

12) Verificar o critério de adição de neurônio, conforme Eq (26). Se o critério for satisfeito, continuar, senão, retornar ao passo 3:

$$
E Q M(t)-E Q M(t+\tau) \leq \varepsilon_{q m}, \quad t=\tau, 2 \tau, 3 \tau \ldots
$$

13) Adicionar um neurônio intermediário à RNA, que consiste em dividir um neurônio existente em dois, sendo que o contador de ciclos para cada um desses neurônios será nciclo/2. Os pesos dos neurônios divididos são dados pelas Eqs (27) e (28):

$$
\begin{aligned}
& w^{1}=(1+\alpha r) w \\
& w^{2}=-\alpha r \cdot w
\end{aligned}
$$

em que $\alpha r$ é um valor aleatório entre 0 e 1.

O treinamento é finalizado quando o erro do conjunto de validação (Eq. (22)) aumenta um determinado número de vezes consecutivas, que neste trabalho foi adotado como 3 . Ao fim do treinamento, a arquitetura efetivamente usada é a que apresentou o menor erro do conjunto de validação.

Este algoritmo foi utilizado na construção do metamodelo para reproduzir o comportamento do modelo de simulação hidráulica tradicional EPANET 2.

\subsection{Módulo de Otimização}

Antes de apresentar o módulo de otimização, define-se o problema de otimização.

Em termos matemáticos, a minimização das funções objetivo é representada nas Equações (29) e (30):

${ }^{25}$ No algoritmo original realiza-se o retreino até que se produza um erro menor ou igual que a RNA anterior A modificação do passo 10 foi realizada para tornar o treinamento mais rápido, já que realizar o retreinamento até obter erro menor ou igual ao da RNA anterior demanda muito tempo quando se utiliza uma grande quantidade de dados para treinamento. 


$$
\begin{aligned}
& \text { Minimizar } F=\left[c a_{i} \cdot F O_{i}(V)\right] \\
& i=1,2, \ldots, M
\end{aligned}
$$

$$
\text { sujeito a } R_{r}(V) \geq 0, r=1,2, \ldots, n_{r}
$$

em que $V$ é o vetor variáveis de decisão $\left\{v_{1}, v_{2}, \ldots, v_{N}\right\}$; em que $N$ é o número de variáveis; $\mathrm{F}$ é o vetor de funções objetivo, $F O_{i}(V)$ são as funções objetivo consideradas e $M$ é o número de funções objetivo, $c a_{i}$ são os coeficientes de ajuste, que assumem valor +1 se for uma função de minimização e -1 caso seja um função para maximização. $R_{r}$ é o vetor de restrições, em que $n_{r}$ é o número de restrições consideradas.

As restrições do problema foram estabelecidas no item restrições 4.3 .2 (página 97), enquanto que as variáveis de decisão, que definem as estratégias operacionais, foram definidas no item 4.3 .3 (página 98), enquanto as funções objetivo foram caracterizadas no item 4.4 (página 98).

Apesar da operação de sistemas de abastecimento de água se resumir ao controle operacional de bombas e válvulas, sua otimização em tempo real não é trivial, e geralmente não se pode afirmar que o ótimo global foi atingido, mas sim que regras operacionais mais racionais foram obtidas. Por isso, além de um simulador hidráulico eficiente, é necessário utilizar um método capaz de realizar a "otimização" da operação em tempo real.

Com base na literatura, escolheu-se o método AMALGAM (Vrugt e Robinson, 2007) para realizar a otimização, pois produziu ótimos resultados para diversos problemas de referência, e também foi aplicado com sucesso por Raad et al. (2010) no projeto de redes de abastecimento de água.

O algoritmo básico do AMALGAM é apresentado na forma de um pseudocódigo na Figura 4-6. O código computacional originalmente fora escrito para a linguagem MATLAB, e fora cedido por Vrugt e Robinson (2007). Por se tratar de uma linguagem comercial e de custo elevado, adaptou-se o código para a linguagem Scilab, de distribuição gratuita.

O algoritmo inicia-se com uma população inicial de soluções $P_{0}$ de dimensão $N$, gerado pelo $\mathrm{LHS}^{26}$, com distribuição uniforme. Então cada elemento de $P_{0}$ é classificado utilizando o algoritmo "fast nondominated sorting" (FNS) de Deb et al. (2002). A população de soluções $Q_{0}$, de dimensão $N$, é criada na sequência pelo método de busca multimétodo, que

\footnotetext{
26 “Latin hypercube Sampling” - LHS detalhado na seção 4.6.
} 
é o cerne do AMALGAM. Ao invés de se implementar um único operador para gerar novas soluções, utilizam-se simultaneamente $k$ algoritmos individuais para gerar a população de soluções $Q_{0}=\left\{Q_{0}^{1}, \ldots, Q_{0}^{k}\right\}$. Cada algoritmo cria um número específico de soluções, $N=\left\{N_{t}^{1}, \ldots, N_{t}^{k}\right\}$, a partir de $P_{0}$. As soluções são combinadas para produzir $R_{0}=P_{0} \cup Q_{0}$ de tamanho $2 N$, o qual é classificado pelo método FNS. Assegura-se o elitismo ao se incluirem os elementos não-dominados da populaçao anterior em R. Finalmente, são escolhidas as soluções para a próxima população $P_{1}$, baseado na sua classificação e na distância de agrupamento ("crowding distance" - CD). O método então gera a nova população de solução a partir de $P_{1}$, repetindo os passos acima até que se atinja a convergência.

De acordo com o método de ordenação e classificação FNS, inicialmente realiza-se para cada elemento $p_{i} \in P_{t}, \mathrm{i}=\{1, \ldots, \mathrm{N}\}$ a contagem de dominação $n p_{i}$, que é o número de soluções que dominam $p_{i}$; e $S p_{i}$, que é o conjunto de soluções dominadas por $p_{i}$.

Todas as soluções na primeira frente não dominada, $F D_{l}$, como exemplificado na Figura 4-7 (a), terão $n p_{i}=0$. Depois, para cada solução $p_{i}$, reduz-se o $n p_{i}$ de cada elemento $r D \in S p_{i}$ de 1 unidade. Se a contagem de dominação de algum membro $r D$ tornar-se zero, estes são separados em outro conjunto $R D$, os quais farão parte da segunda frente de dominação, $F D_{2}$. Então o processo continua para cada elemento de $R D$, até que seja identificada a terceira frente, e assim sucessivamente até que todas as frentes sejam identificadas. 
1 Gerar da população inicial $P_{0}$ de tamanho $N$ usando o LHS;

2 Classificar e ordenar de $P_{0}$ baseado no nível de dominação;

3 Criar a prole $Q_{0}$ usando $k$ diferentes algoritmos. Cada algoritmo cria inicialmente (N/k) soluções;

4 Fazer $t=0$ e $T=$ máximo número de gerações;

5 Enquanto $t<T$ faça

$6 \longrightarrow R_{t}=P_{t} \cup Q_{t}$

7 Ordenação de $R_{t}$ em diferentes frentes de dominação $F D_{1}, F D_{2}, \ldots$;

$8 \quad$ Faça $P_{t+1}=\phi$ e $i=1$;

$9 \quad$ Enquanto $\left|P_{t+1}\right|<N$ faça

Se $\left|F_{i}\right|+\left|P_{t+1}\right|=N$ então

$\left|F_{i}\right|+\left|P_{t+1}\right| \leq N$ então

Ordenar os $F_{i}$ membros em ordem decrescente de distância de agrupamento; $P_{t+1}=P_{t+1}+$ primeiros $\left(\mathrm{N}-\left|\mathrm{P}_{\mathrm{t}+1}\right|\right)$ elementos de $F_{i}$;

Fim se;

\footnotetext{
- Fim se;
}

Fim enquanto;

Calcular o operador de comparação de agrupamento $\forall i \in P_{t+1}$;

Calcular o número de soluções $P_{t+1}^{k}$ que cada algoritmo $k$ contribuiu para $P_{t+1}$; Fazer $j=1$;

Enquanto $j \leq k$ faça

$$
24 \quad \text { Calcule } N_{t+1}^{j}=N \cdot\left(\frac{P_{t+1}^{j}}{N_{t}^{j}}\right)
$$




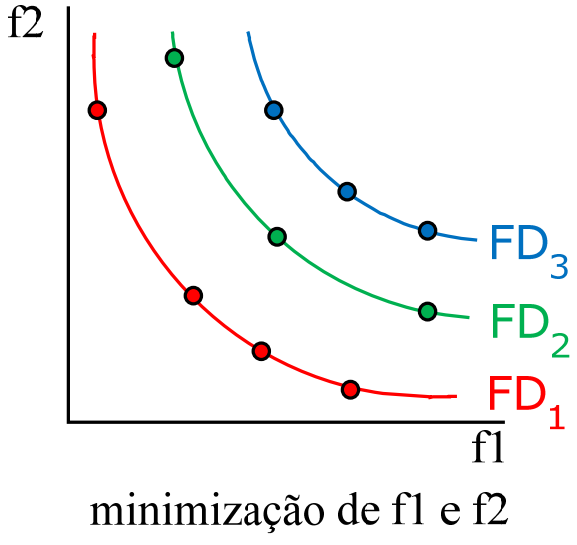

(a)

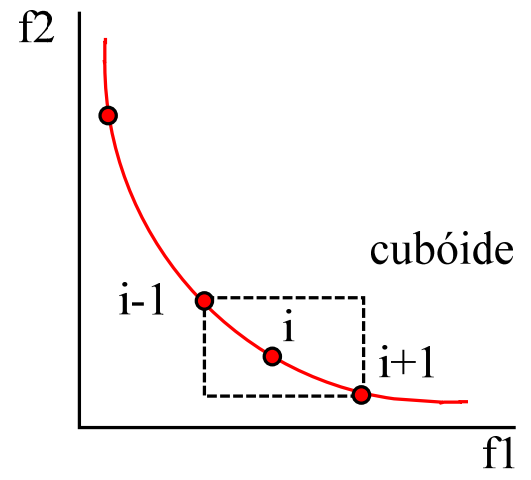

minimização de f1 e f2

Figura 4-7 - (a) Ilustração das frentes de dominação, (b) Ilustração do conceito de distância de agrupamento (comprimento médio dos lados do cubóide)

A distância de agrupamento, ilustrada na Figura 4-7 (b) para o espaço de dois objetivos (f1 e f2), é a estimativa de densidade das soluções ao redor de uma solução particular no espaço de objetivo - para manter a diversidade da população e compor um operador de comparação ("crowded comparison").

A distância de agrupamento da solução $i$ é calculada considerando os $M$ objetivos conforme Equação (31):

$$
C D_{i}=\sum_{m=1}^{M} C D_{i, m}, i=1, \ldots, l
$$

em que $C D_{i, m}$ é definida pela Equação (32):

$$
C D_{i, m}=\frac{f_{m}\left(x_{i+1}\right)-f_{m}\left(x_{i-1}\right)}{f_{m}\left(x_{\max }\right)-f_{m}\left(x_{\min }\right)}, i=2, \ldots, l-1
$$

em que $l$ é o número soluções na frente $f_{m}$ disposta em ordem crescente, sendo $=\{1, \ldots, M\}$.

O operador de comparação, $\prec$, é usado no processo de seleção para guiar o algoritmo na identificação da frente Pareto com soluções uniformemente distribuídas. Considera-se que cada solução $p$ na população tem dois atributos: a contagem de dominação, $n p$, e a distância 
de agrupamento $(c r d)$. Dessa forma, ao comparar duas soluções $p_{1}$ e $p_{2}$, tem-se $p_{1} \prec p_{2}$ se $n p_{1}$ $\leq n p_{2}$ ou $n p_{1}=n p_{2}$ e $\left.c r d\left(p_{1}\right)<\operatorname{crd}\left(p_{2}\right)\right)$, ou seja, entre duas soluções que possuem diferentes contagens de dominação, a melhor é aquela com menor $n p$ e nos casos em que estes são iguais (estão na mesma frente), a melhor solução é aquela que está na região menos povoada. Observa-se que somente a inclusão de elementos da última frente em $P_{t+1}$ é baseada na distância de agrupamento.

O método de criação adaptativa de uma nova população favorece os algoritmos individuais que mais contribuem para a formação da nova população, por meio da Equação (33):

$$
N_{t+1}^{j}=N \cdot\left(\frac{P_{t+1}^{j}}{N_{t}^{j}}\right) / \sum_{j=1}^{k}\left(\frac{P_{t+1}^{j}}{N_{t}^{j}}\right)
$$

em que $N$ é o número total de soluções da população, $\mathrm{O}$ termo $P_{t+1}^{j} / N_{t}^{j}$ é a taxa de contribuição de cada algoritmo para a nova população $P_{t+1}^{j}$, e $N_{t}^{j}$ o número de soluções criadas na geração anterior. O índice $j$ refere-se ao algoritmo utilizado para gerar a solução, e os índices $t$ e $t+1$ referem-se respectivamente a geração anterior e a geração atual de populações. O resto da expressão, $\sum_{j=1}^{k}\left(\frac{P_{t+1}^{j}}{N_{t}^{j}}\right)$, escalona a taxa de sucesso reprodutivo do algoritmo individual com o sucesso combinado dos demais algoritmos. Para evitar a possibilidade de desativar um algoritmo que poderá contribuir futuramente para a convergência, deve-se adotar um valor mínimo para $N_{t}^{j}$.

Após apresentar o algoritmo básico do AMALGAM, resta definir quais algoritmos individuais são incluídos no método de otimização para criação da população de soluções. $O$ NSGA-II e o DE foram os algoritmos escolhidos por Vrugt e Robinson (2007), Vrugt et al. (2009) e Raad et al. (2010). Além desses dois algoritmos, outros são investigados para integrarem o conjunto, tais como o PSO e o AMS, os quais são apresentados com mais detalhes no próximo subitem (4.3.1). 
Após o detalhamento desses métodos de otimização, apresenta-se também uma forma alternativa de considerar as restrições, proposta por Deb e Agrawal (1999) e adaptada por Prasad e Park (2004) para ser utilizada na otimização de redes de abastecimento de água.

\subsubsection{Métodos de otimização do AMALGAM}

\section{“Nondominated Sorting Genetic Algorithm II” (NSGA-II)}

O NSGA-II é um dos mais utilizados dentre os algoritmos genéticos multiobjetivo devido a sua simplicidade aliado ao excelente desempenho. Como os demais AGs, utiliza para a criação da prole os operadores de seleção, cruzamento e mutação.

O NSGA-II seleciona as soluções que compõem as melhores frentes Pareto, até que se obtenha o número necessário de indivíduos para compor a população. A seleção é realizada por meio de torneio entre 2 soluções da população selecionadas por sorteio.

Para melhorar a convergência das soluções, implementou-se o elitismo controlado, proposto por Deb e Goel (2001). Tal estratégia de seleção é usada não apenas para o NSGAII, mas também para os demais algoritmos de otimização.

O elitismo controlado consiste em selecionar as soluções que compõem não apenas as melhores frentes, mas também das demais frentes, de modo a conferir maior variabilidade à população. Assim, o máximo número de soluções permitidas $n s o l_{i}$ de cada frente $i$ é avaliado conforme a Equação (34):

$$
n s o l_{i}=N p o p \frac{1-t r}{1-t r^{n F D}} t^{i-1}
$$

em que Npop é o número total de soluções da população, $n F D$ é o número de frentes de dominação, e tr é a taxa de redução $(0<t r<1)$, que foi adotada como 0,3 .

Neste trabalho, adotou-se taxa de cruzamento de 0,9 e taxa de mutação $2 /\left(2 \cdot n s w \cdot N^{p}\right)$ (López-Ibáñez, 2009), em que $n s w$ é o número máximo de acionamentos das bombas e $N^{p}$ é o número de bombas elevatórias do sistema de distribuição - mais detalhes sobre os parâmetros no item 4.3.3 (página 98).

\section{“Differential Evolution” (DE)}

A evolução diferencial assemelha-se ao AG por utilizar uma população de soluções e por utilizar operadores de combinação. A DE, proposta por Storn e Price (1995) surgiu da 
idéia de realizar a mutação da solução adicionando-se a esta a diferença entre os vetores solução. Devido a essa característica, supera os demais algoritmos evolucionários quando o problema de otimização envolve variáveis interdependentes ou variáveis que apresentam rotação entre si, como, por exemplo, um vetor y que é calculado pela transformação de um vetor $x$ por uma matriz de rotação Rot, conforme problema proposto por Deb et al. (2002).

Há diversas variações do DE, e uma delas é detalhada a seguir, conforme Figura 4-8:

1) Uma solução é selecionada de forma aleatória para ser substituída (vetor alvo), juntamente com outra solução, denominada genitora principal, $X_{\gamma 0, g}$ (vetor base);

2) São selecionadas aleatoriamente mais duas soluções, as genitoras secundárias, $X_{\gamma 1, g}$ e $X_{\gamma 2, g}$

3) Calcula-se a diferença entre os vetores $X_{\gamma 1, g}$ e $X_{\gamma 2, g}$, a qual é ponderada por um fator $F P$, de valor aleatório entre 0 e 1 ;

4) Mutação de $X_{\gamma 0, g}$, consiste em realizar a adição do vetor de diferenças ponderado ao vetor base, que resulta em um vetor mutante;

5) Combinação entre o vetor alvo e o vetor mutante, que consiste em substituir os parâmetros do vetor alvo pelos parâmetros do vetor mutante, em que cada parâmetro tem uma probabilidade CR de ser substituído. Da combinação resulta o vetor experimental $u_{0, g}$;

6) Realiza-se a seleção entre o vetor alvo e o vetor experimental, em que se seleciona o vetor com melhor aptidão ou menor valor das funções objetivo (minimização). 
1) Seleção do vetor alvo e do vetor base

2) Seleção aleatória de mais 2 soluções da população

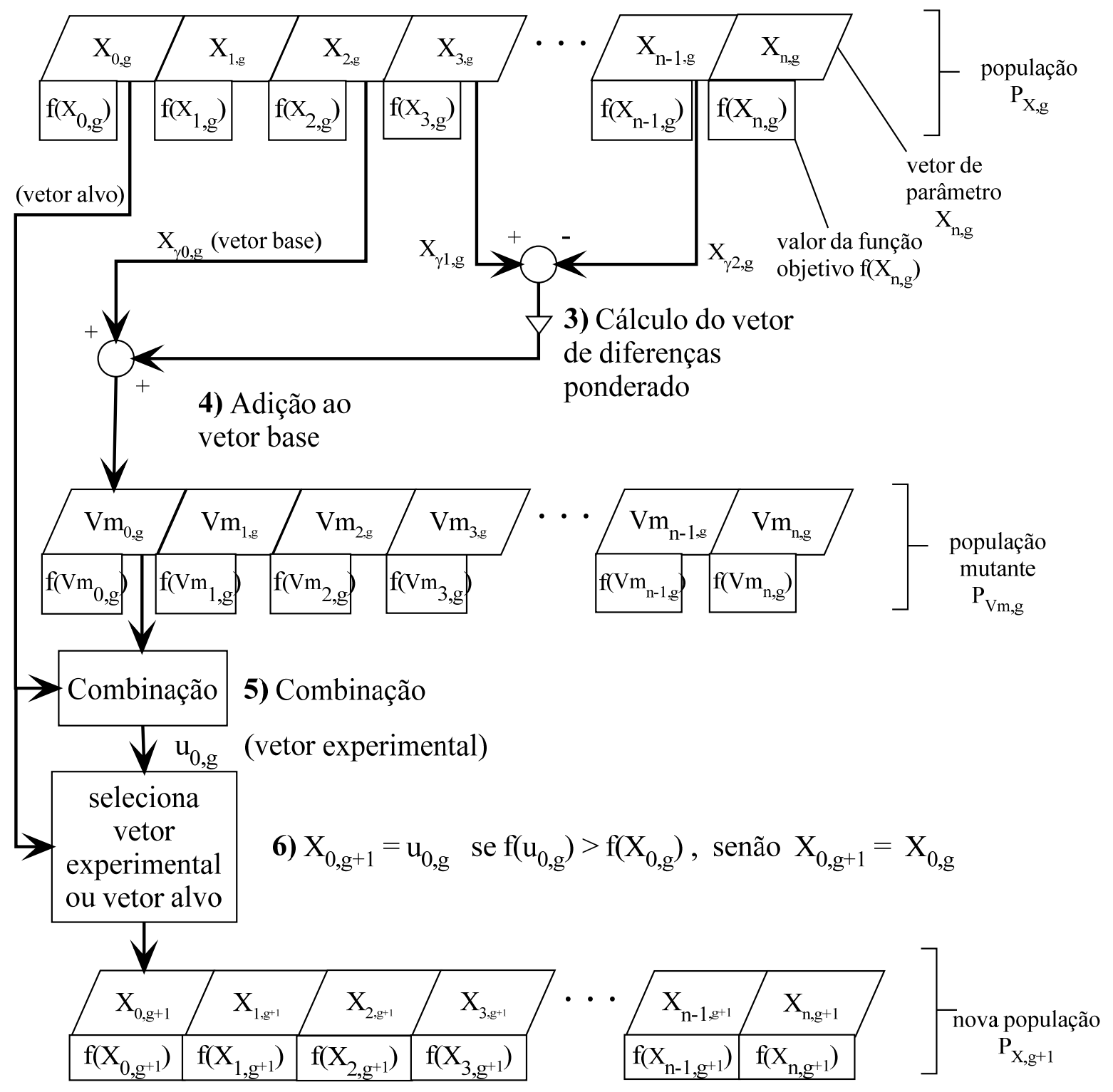

Figura 4-8 - Esquema da geração da solução pela DE

\section{“Particle Swarm Optimization” (PSO)}

Este método de otimização é baseado no comportamento em grupo de pássaros e insetos, introduzido por Eberhart e Kennedy (1995). Tal como os demais métodos de busca populacionais, trabalha com um grupo de soluções, denominadas partículas, realizando a busca continuamente através das gerações.

Inicialmente são atribuídas aleatoriamente posição e velocidade às partículas em um espaço n-dimensional. Após a inicialização, cada partícula ajusta iterativamente a posição de acordo com a sua própria experiência e também das demais partículas, por meio do uso da 
melhor posição encontrada por si mesma, $X_{\text {best }}$, e de toda a população, $p_{\text {best }}$. Ao contrário do NSGA-II, o PSO combina princípios de busca local e global, na evolução das soluções em direção à frente Pareto.

O operador de reprodução para criar a população de novas soluções é dado pela Equação (35):

$$
\begin{aligned}
& v e l_{t+1}^{i}=f w \cdot v e l_{t}^{i}+w c_{1} r a_{1}\left(X_{b e s t}^{i}-x_{t}^{i}\right)+w c_{2} r a_{2}\left(p_{\text {best }}-x_{t}^{i}\right) \\
& X_{t+1}^{i}=X_{t}^{i}+v e l_{t+1}^{i}
\end{aligned}
$$

em que $v e l_{t}^{i}$ e $X_{t}^{i}$ são respectivamente a velocidade e a localização da partícula (vetor solução); $f w=0,5+0,5 u$, é o fator de inércia, sendo u valor aleatório entre 0 e $1 ; w c_{1}$ e $w c_{2}$ são os pesos que refletem a cognição e o fator social da partícula, respectivamente, adotados com valor 1,5 (Hu et al., 2003); e $r a_{1}$ e $r a_{2}$ são valores aleatórios entre 0 e 1.

Para escapar de ótimos locais, adiciona-se um fator de turbulência a posição de cada partícula (Parsopoulos e Vrahatis, 2002), conforme Equação (36):

$$
X_{t+1}^{i}=X_{t}^{i}+v e l_{t+1}^{i}+R_{T} X_{t}^{i}
$$

em que $R_{T} \in[-1,1]$ é uma variável aleatória uniforme.

\section{“Adaptive Metropolis Search” (AMS)}

Os algoritmos evolucionários em geral empregam a busca populacional para realizar a otimização. Apesar das suas utilidades e pontos fortes, tendem a convergir para uma única solução, o que pode deixar certas regiões de busca inexploradas. A AMS é um método de amostragem do tipo Monte Carlo via Cadeias de Markov ("Markov Chain Monte Carlo" MCMC) que previne que a busca se restrinja a vizinhança da melhor solução encontrada. De acordo com o método são realizadas amostragens em distribuições de grandes dimensões, a qual implica em rápida exploração da frente Pareto.

A geração das soluções é realizada conforme Equação (37):

$$
X_{t+1}^{i}=\operatorname{Norm}\left(X_{t}^{i}, c_{n}^{2} \sum_{t}\right)
$$


em que Norm representa a distribuição de probabilidade normal para amostrar as novas soluções, $X_{t}^{i}$ e $\sum_{t}$ são respectivamente a posição atual e a covariância do melhor conjunto de soluções não-dominadas da população $P_{t}$. A taxa de transposição $c_{n}=2.4 / \sqrt{N}$ (Gelman et al., 1995) determina o espalhamento das soluções em torno de $X_{t}^{i}$, em que $N$ é o número de variáveis de decisão.

\subsubsection{Restrições do problema de otimização}

Além de atender às restrições hidráulicas do modelo de otimização, como o balanço de massa e conservação da energia, é necessário considerar outras restrições para que as soluções sejam viáveis à aplicação real.

Diversos métodos foram propostos para lidar com as restrições nos problemas de otimização, ou de modo mais geral, para métodos de busca populacionais. No entanto, apesar das melhorias propostas, todos eles requerem o uso de coeficientes de penalidades.

A determinação de um coeficiente de penalidade é uma tarefa difícil, sendo específico para cada problema. Deve-se assumir um valor suficientemente alto, que impeça que a melhor solução infactível não seja superior a qualquer outra solução factível, contudo, valores excessivamente altos podem prejudicar a diversidade de soluções e ocasionar uma convergência prematura do processo de otimização. Por isso, é utilizado neste trabalho um método alternativo para se considerarem as restrições nos métodos de busca populacionais, que foi proposto por Deb e Agrawal (1999) e modificado por Prasad e Park (2004) para ser utilizado na otimização de projetos redes de abastecimento de água.

Uma solução $x_{i}$ domina uma solução $x_{j}$ nos seguintes casos:

- Solução $x_{i}$ é factível e solução $x_{j}$ é infactível;

- Ambas as soluções $x_{i}$ e $x_{j}$ são infactíveis, mas a solução $x_{i}$ viola menos a restrição; ou

- Ambas as soluções $x_{i}$ e $x_{j}$ são factíveis, mas a solução $x_{i}$ domina a solução $x_{j}$.

Desta forma, as soluções factíveis sempre dominarão as soluções infactíveis, e as últimas serão comparadas com base no coeficiente de violação. Porém, as soluções factíveis são comparadas com base no nível de dominação.

Neste trabalho foram considerados as seguintes violações de restrição, em ordem de importância, com base no trabalho de Cunha (2009): 
- Código de Erro do simulador hidráulico: caso o simulador hidráulico EPANET 2 produza os códigos "3" ou "6", conforme Tabela 4-2, extraídos e traduzidos do módulo de programação "Toolkit" (Rossman, 2000). Tais erros não são toleráveis, pois significam descontinuidade do abastecimento para as determinadas condições do sistema, e portanto as soluções que produzem tais erros não são factíveis;

- Carga de pressão inferior à mínima: caso a carga de pressão nos nós críticos sejam inferiores à mínima necessária para garantir continuidade do abastecimento, a solução é penalizada. Adotou-se carga de pressão mínima de 10 m.c.a, conforme recomendação da NBR 12218:1994;

- Nível final do reservatório menor que o inicial: é possível obter soluções a custos reduzidos ao utilizar totalmente a água dos reservatórios, no entanto, no início do próximo dia, será necessário recuperar o nível do reservatório, podendo resultar em custos muito mais elevados, pois pode ser necessário utilizar as bombas nos períodos de ponta;

- Número de acionamento das bombas: o acionamento excessivo das bombas resultam no seu desgaste prematuro, assim é necessário limitar esse número, que neste trabalho foi limitado a 4 vezes ao dia.

Tabela 4-2 - Códigos de Erro do EPANET 2

\begin{tabular}{cl}
\hline Código & \multicolumn{2}{c}{ Descrição } \\
\hline 3 & Sistema desconectado - um ou mais nós com demandas \\
& positivas foram desconectados das fontes de abastecimento \\
& Carga de pressão negativa no sistema - há ocorrência de carga \\
6 & de pressão negativa em um ou mais nós com demanda positiva \\
\hline
\end{tabular}

\subsubsection{Variáveis de decisão}

As variáveis de decisão do problema de otimização da operação de sistemas de abastecimento de água são as estratégias operacionais das bombas, as quais podem ser representadas das mais diversas formas. A forma mais comum é a binária, que consiste em representar a programação por uma série de $\mathbf{0}$ e 1, em que $\mathbf{0}$ representa o estado desligado, e $\mathbf{1}$ ligado. 
A representação da programação das bombas (RPB) desempenha um papel importante tanto no sucesso da otimização quanto na velocidade do processo.

Com base na literatura, observou-se que a representação que produziu o melhor desempenho foi a proposta por López-Ibañez (2009), denominada "relative time-controlled trigger". Tal representação permite controlar a bomba por meio do tempo e limitar explicitamente o número de acionamentos. O controle é representado por pares de variáveis de decisão $t_{i}$ e $t^{\prime}{ }_{i}$, conforme ilustrado na Figura 4-9, relativas ao estado anterior da bomba. Cada par $\left(t_{i}, t_{i}\right)$ representa respectivamente o período em que a bomba deve permanecer desligada e ligada. A soma de todos os pares deve resultar no período $T$, e o número de pares $n s w$ representa a quantidade máxima de acionamentos da bomba.

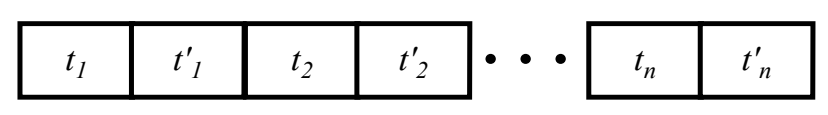

Figura 4-9 - Pares de variáveis de decisão utilizando a RPB “time-controlled trigger"

Para exemplificar, temos a Figura 4-10, com $T=24 \mathrm{~h}$, e $n s w=3: t_{1}=3 \mathrm{~h}$ significa que as bombas estão desligadas por $3 \mathrm{~h}$ desde o início do período; $t^{\prime}{ }_{1}=4 \mathrm{~h}$ representa a bomba ligada por $4 \mathrm{~h}$ após o intervalo de $t_{1} ; t_{2}=6 \mathrm{~h}$ representa a bomba desligada por $6 \mathrm{~h}$ após o intervalo de $t^{\prime}{ }_{1}$ e assim por diante.

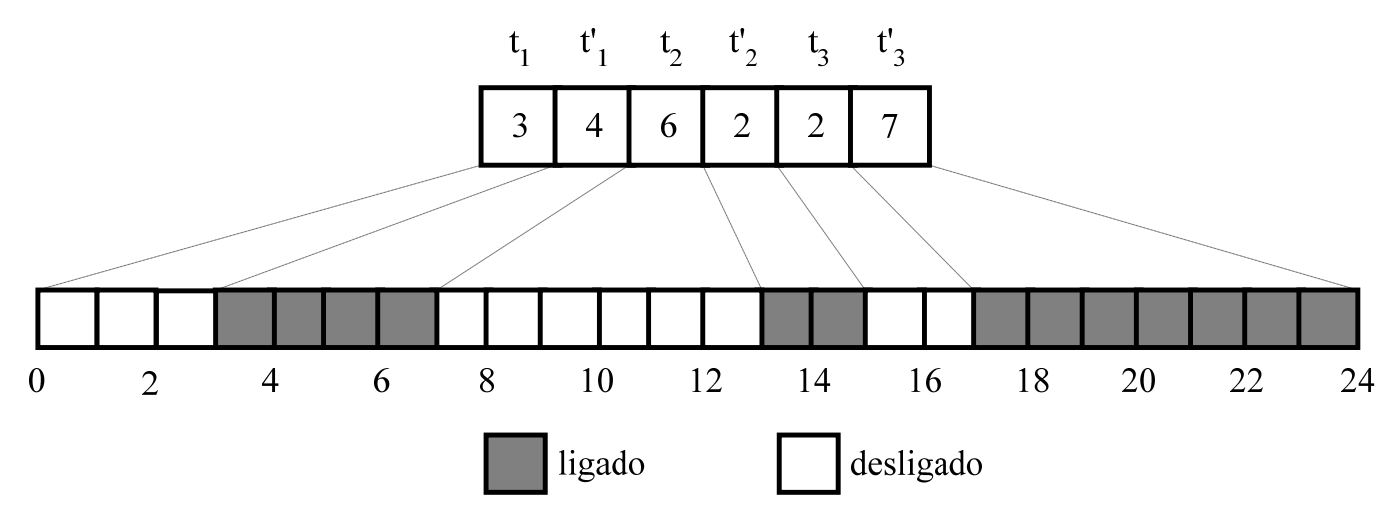

Figura 4-10 - Exemplo da representação das variáveis de decisão segundo a RPB "time-controlled trigger"

\subsection{Funções objetivo}

Foram considerados como funções objetivo o custo e a confiabilidade da operação. 


\subsubsection{Custo}

Avaliou-se o custo apenas como o dispêndio com o consumo de energia elétrica pelo conjunto moto-bomba, ou seja, sem considerar o custo da demanda contratada junto à companhia de energia elétrica.

\subsubsection{Confiabilidade}

Realizaram-se estudos para avaliação da confiabilidade utilizando-se os métodos baseados na confiabilidade hidráulica e nas medidas alternativas de confiabilidade (ver item 3.4, página 46), pois a avaliação da conectividade/topologia requer dados detalhados sobre os componentes das redes e o histórico de reparos dos mesmos, dados os quais não são facilmente obtidos junto às companhias de saneamento.

Medidas alternativas de confiabilidade são avaliadas pela: entropia, resiliência modificada, nível mínimo de reservação e carga de pressão excedente no sistema. A entropia é a medida de uniformidade da distribuição de vazões, enquanto que a resiliência expressa a capacidade do sistema atender à demanda mesmo em situações de falha mecânica ou hidráulica.

É utilizada a medida de entropia $(S)$ proposta por Tanyimboh e Templeman (1993), que permite que as vazões sejam interpretadas do ponto de vista probabilístico. A probabilidade da água ser transportada através de determinado caminho depende da vazão nos condutos daquele caminho. Assim, para uma rede em que as vazões e direções são conhecidas, a função entropia é dada pela Equação (38):

$$
S=S_{0}+\sum_{i=1}^{N_{n}} F Q_{i} S_{i}
$$

em que: $S$ é a entropia no sistema de distribuição de água, $S_{0}$ é a entropia das fontes de abastecimento, $S_{i}$ é a entropia do nó $i, F Q_{i}=F T_{i} /$ Tot é a fração da vazão total da rede que atinge o nó $i$, incluindo qualquer afluência externa, ou a probabilidade da água que entra na rede atingir o nó $i, F T_{i}$ é a vazão total que aflui para o nó $i$, Tot é a soma das demandas nodais e $N_{n}$ é o número de nós da rede.

A entropia das fontes de abastecimento é expressa pela Equação (39): 


$$
S_{0}=-\sum_{i \in I}^{N_{s}} \frac{Q_{0 i}}{T o t} \ln \left(\frac{Q_{0 i}}{T o t}\right)
$$

em que $Q_{0 i}$ é a afluência do nó fonte $i, I$ representa o conjunto de nós fonte e $N_{s} \mathrm{o}$ número de fontes de abastecimento. De maneira análoga, a entropia dos nós é dada pela Equação (40):

$$
S_{i}=-\frac{Q_{i}}{F T_{i}} \ln \left(\frac{Q_{i}}{F T_{i}}\right)-\sum_{i j \in N D i} \frac{Q_{i j}}{F T_{i}} \ln \left(\frac{Q_{i j}}{F T_{i}}\right) \quad i=1, \ldots, N_{n}
$$

em que $Q_{i}$ é a demanda do nó $i, Q_{i j}$ a vazão do conduto que liga o nó $i$ ao nó $j, N D_{i}$ o conjunto de todos os condutos conectados ao nó $i$ e $N_{n}$ é o número de nós da rede de distribuição.

Para qualquer SAA, o valor da entropia depende somente das vazões dos condutos já que as demandas nodais são especificadas, donde se conclui que a entropia é definida para um dado padrão de demanda.

A resiliência modificada $\left(M I_{r}\right)$ é baseada na formulação de Todini (2000) modificada por Jayaram e Srinivasan (2008) para considerar corretamente múltiplas fontes de abastecimento, expressa pela Equação (41):

$$
M I_{r}=\frac{\sum_{j=1}^{N_{n}} Q_{j}\left(H_{j}-H_{\min , j}\right)}{\sum_{j=1}^{N_{n}} Q_{j} H_{\min , j}} \times 100
$$

em que $Q_{j}$ é a demanda do nó $j ; H_{j}$ é a carga de pressão do nó $j ; H_{m i n, j}$ é a carga de pressão mínima necessária para o nó $j$ ser abastecido; e $N_{n}$ é o número de nós da rede de abastecimento.

A consideração do nível mínimo de reservação consiste em obter a soma dos níveis mínimos atingido pelos reservatórios da rede de abastecimento em um dado instante, de modo a garantir que haverá um mínimo volume nos reservatórios a ser utilizado em situações de emergência.

A carga de pressão excedente do sistema é similar a aplicação da Resiliência Modificada, com a diferença que esta não é adimensionalizada, mas apenas ponderada pela demanda nos nós, para se ter melhor idéia do valor numérico, conforme Equação (42): 


$$
P_{e x c}=\frac{\sum_{j=1}^{N_{n}} Q_{i}\left(H_{j}-H_{\min , j}\right)}{\sum_{j=1}^{N_{n}} Q_{i}} \times 100
$$

\subsection{Abordagens para otimização da operação em Tempo Real}

A Otimização da Operação em Tempo Real foi realizada da seguinte maneira, conforme fluxograma da Figura 4-11:

1. Obtenção dos dados do sistema via SCADA: nível dos reservatórios, estado das bombas e válvulas, consumo das últimas horas;

2. De posse dos consumos atualizados, realiza-se a previsão de demanda para as próximas 24 horas;

3. São fornecidas as previsões e os demais dados obtidos no passo 1 ao otimizador e ao simulador.

4. O otimizador fornece as estratégias operacionais das próximas $24 \mathrm{~h}$ ao simulador, o qual irá reproduzir o estado de sistema, fornecendo os dados necessários a avaliação das funções objetivo, até que se obtenha soluções otimizadas;

5. Escolha da melhor estratégia operacional para as próximas $24 \mathrm{~h}$;

6. Implementa-se a operação da $1^{\text {a }}$ hora, dentre as 24 horas fornecidas anteriormente;

7. Nas próximas horas, repete-se os passos de 1 a 6 continuamente, sempre implementando a $1^{\mathrm{a}}$ hora das estratégias operacionais produzidas.

De maneira geral, as otimizações geram soluções aleatórias para comporem a população inicial de soluções. Neste trabalho, após a geração da população inicial, escolhe-se ao acaso uma solução, a qual é substituída por uma solução em que as bombas permanecem ligadas durante $24 \mathrm{~h}$, ou seja, durante todo o período otimizado. Desta forma, garante-se que haverá ao menos uma solução factível, que contribuirá na geração de mais soluções factíveis ao longo das gerações. Esta substituição é realizada a cada geração de soluções do processo de otimização. Deste modo, define-se tal procedimento como Abordagem I. Por questão de simplicidade, nos casos em que não for especificada a abordagem utilizada, subentende-se 
que foi aplicada a Abordagem I na otimização da operação, que é aplicada tanto na otimização de objetivo único quanto na otimização multiobjetivo.

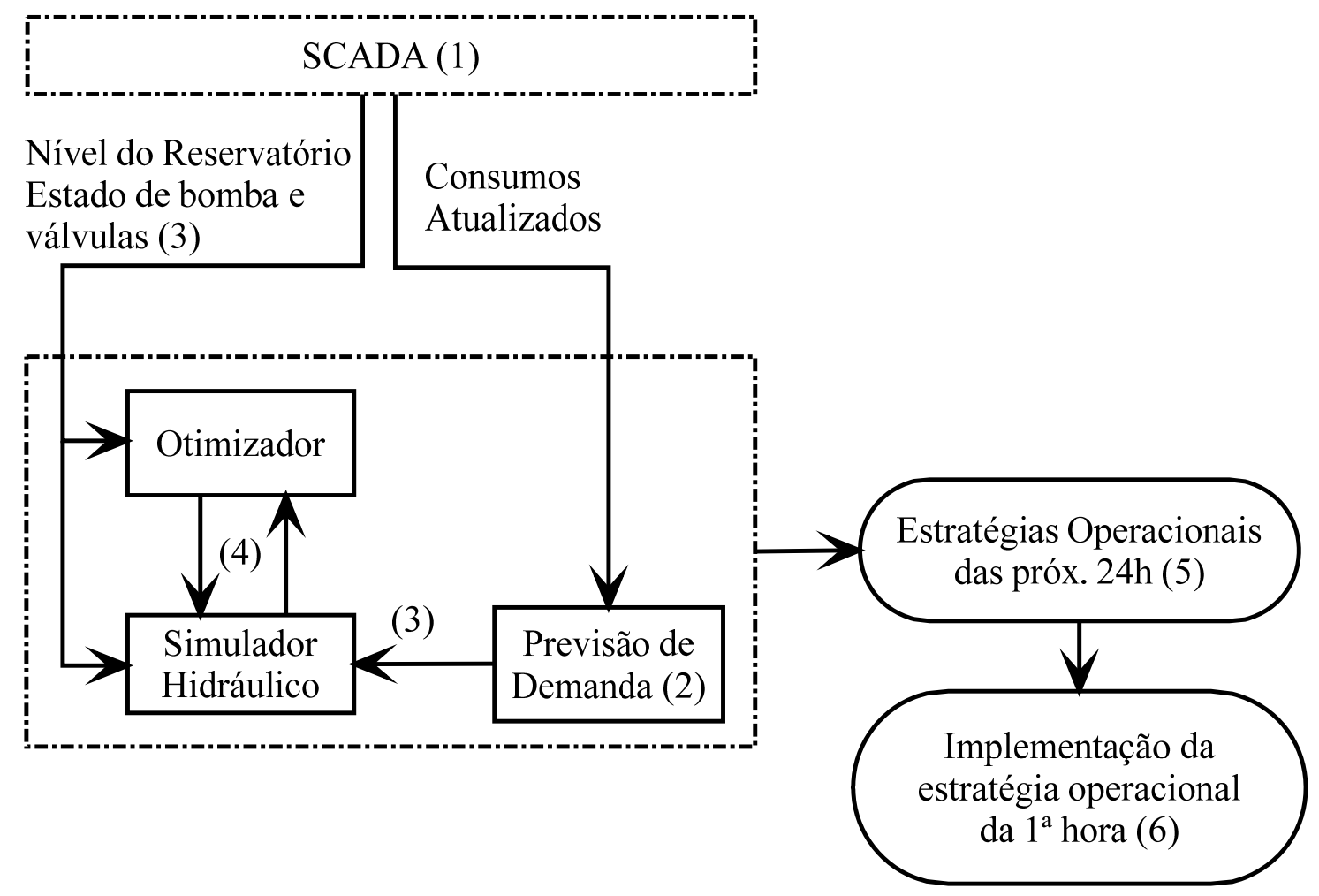

Figura 4-11 - Fluxograma da Operação em Tempo Real - Abordagem I

A otimização multiobjetivo da operação em tempo real ${ }^{27}$ foi realizada empregando-se diferentes abordagens para viabilizar sua aplicação em tempo real, ou seja, integrando-se todos os módulos necessários (otimizador + simulação hidráulica + previsão de demanda) de modo a fornecer a solução otimizada a tempo de implementá-la antes do próximo período.

Implementaram-se duas abordagens de otimização, baseadas em Cunha (2009) e Giustolisi et al. (2009).

A abordagem baseada em Cunha (2009), ilustrada na Figura 4-12, foi denominada Abordagem II e consistiu em realizar a otimização sob os enfoques do Planejamento Operacional em Nível Estratégico e da Operação em Tempo Real. O Planejamento Operacional em Nível Estratégico, que tem como objetivo único a minimização do custo, fornece a estratégia operacional otimizada com base em curvas de demanda típicas (médias)

${ }^{27}$ Consiste basicamente em obter as operações otimizadas a cada novo período, por exemplo, a cada 1 hora, para as próximas 24 horas, os quais devem utilizar dados constantemente atualizados, pois como a demanda, os dados variam não só ao longo do ano e da semana, mas no decorrer do dia. 
conhecidas e níveis de água iniciais estabelecidos para os reservatórios, de maneira tal que os níveis de água dos reservatórios, no final do horizonte de planejamento (24 horas), sejam coincidentes com os do início do período. Por outro lado, a Operação em Tempo Real utiliza a previsão de demanda em tempo real para incorporar ao processo de otimização o comportamento mais recente do sistema de distribuição, pois a demanda apresenta desvios em relação à média e, portanto deve ser constantemente atualizada, bem como os níveis dos reservatórios. Com vistas a aumentar a velocidade da otimização em tempo real, as soluções otimizadas produzidas pelo Planejamento Estratégico foram utilizadas como soluções iniciais da otimização em tempo real, a qual se configura como abordagem análoga à utilizada por Giustolisi et al. (2009).

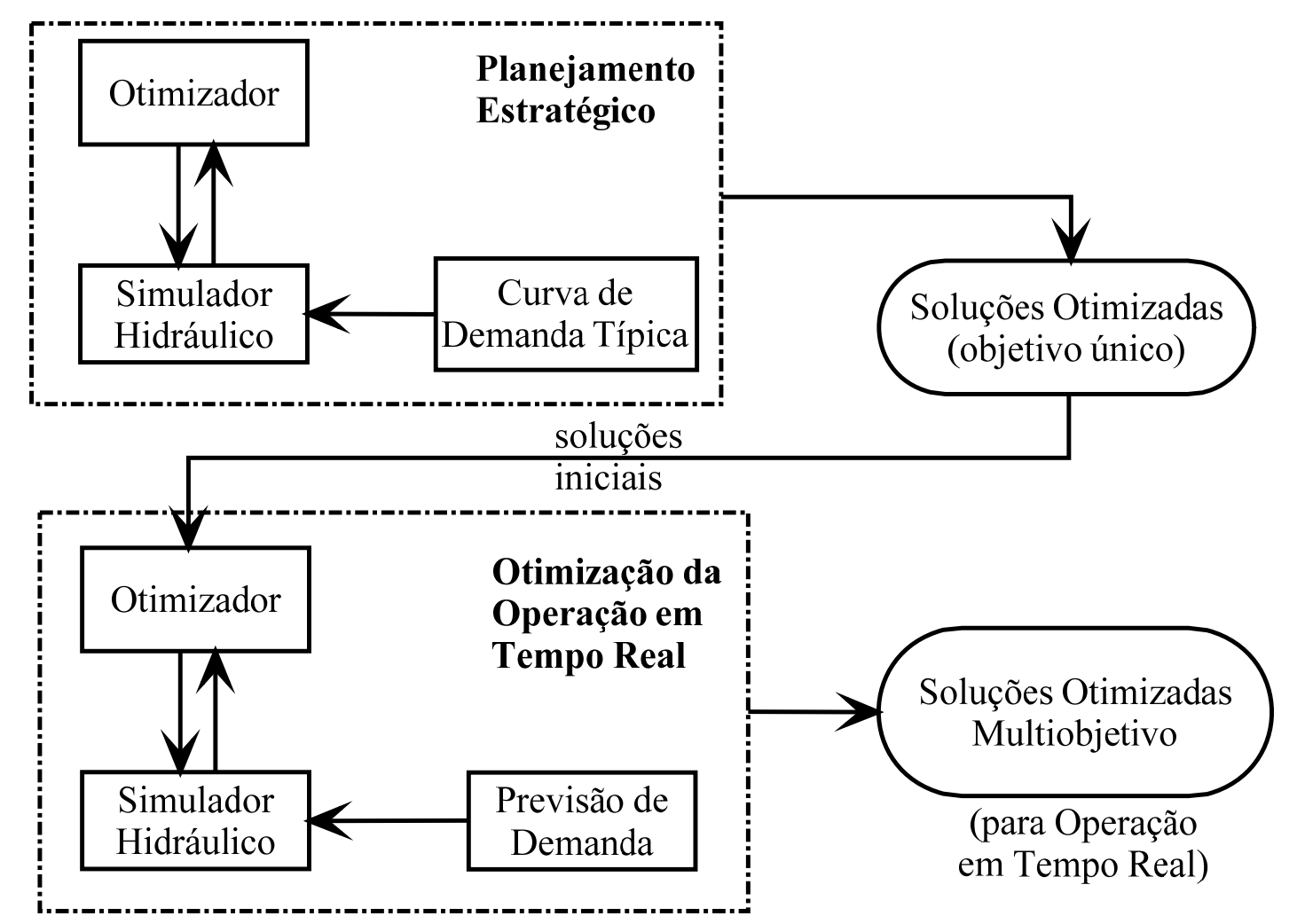

Figura 4-12 - Otimização Multiobjetivo com Abordagem II

A abordagem baseada em Giustolisi et al. (2009), ilustrada na Figura 4-13, foi denominada Abordagem III e consistiu em realizar a otimização de objetivo único das próximas $24 \mathrm{~h}$ utilizando-se a previsão de demanda para o mesmo período, considerando como objetivo a minimização do custo operacional e como restrição, a manutenção da carga de pressão acima de um nível mínimo. As soluções otimizadas de objetivo único foram empregadas como soluções iniciais da otimização multiobjetivo da operação em tempo real. 
Tal estratégia é justificada pelo fato de que as soluções determinísticas pertencem à frente Pareto ou estão pelo menos próximas a ela. Assim, pode-se reduzir consideravelmente o processamento computacional utilizado em comparação ao uso de soluções iniciais aleatórias.

Para as abordagens II e III, a otimização da operação em tempo real é multiobjetivo, de modo a minimizar os custos e maximizar a confiabilidade. Assim como ocorre na Abordagem I, a melhor solução produzida pela otimização de objetivo único é utilizada em todas as gerações do processo de otimização.

Nos casos em que foram especificados o uso dos metamodelos para realizar a simulação hidráulica, reavaliou-se a frete Pareto com o uso do simulador hidráulico EPANET, pois os metamodelos são aproximações dos modelos e portanto as soluções geradas a partir da metamodelagem podem não pertencer à frente Pareto. Assim, além da reavaliação da frente, foram realizadas buscas locais para verificar se há melhores soluções na vizinhança (Broad et al., 2005).

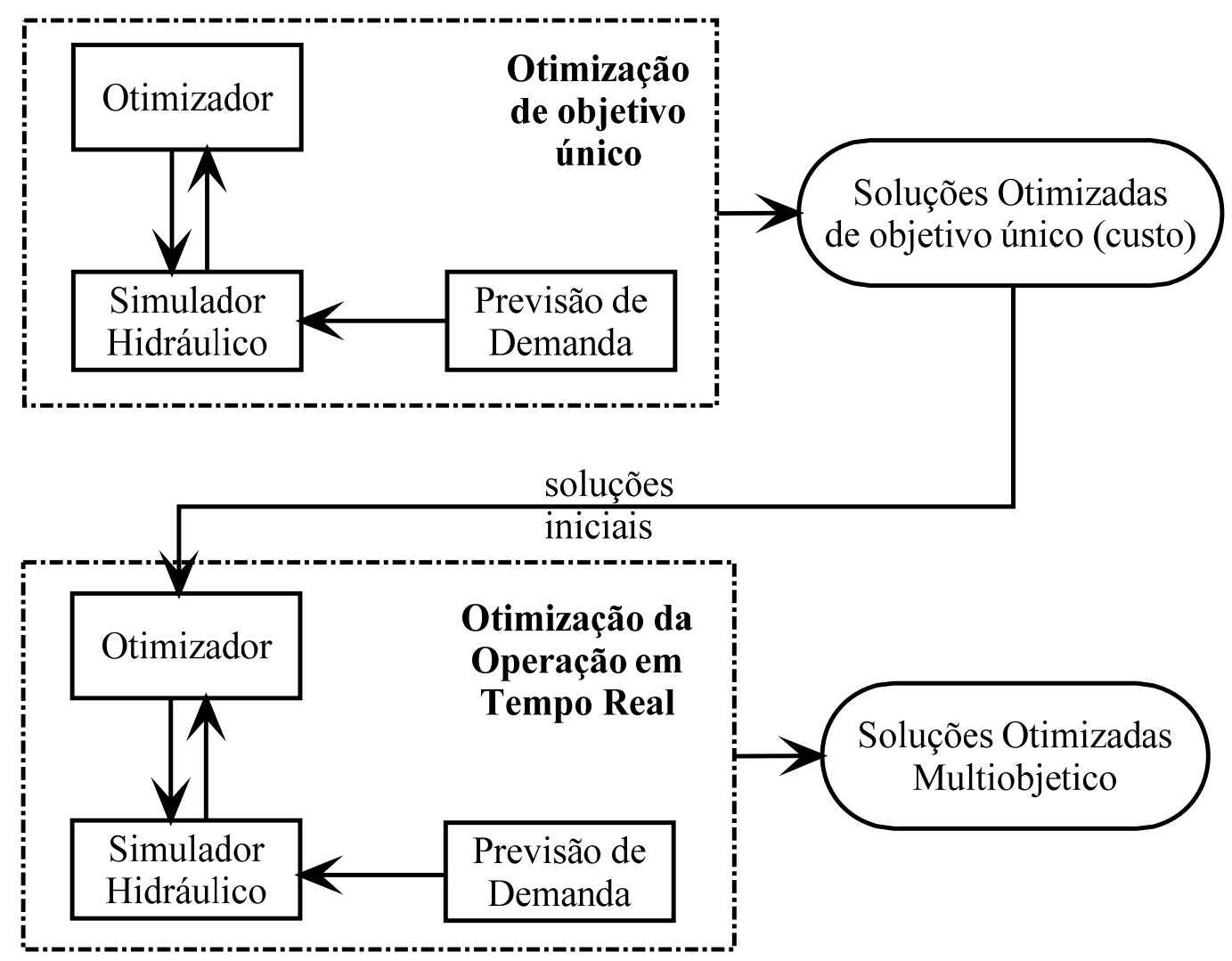

Figura 4-13 - Otimização Multiobjetivo com Abordagem III 


\subsubsection{Técnica de reparação das estratégias otimizadas da operação em Tempo Real}

A otimização da operação em tempo real de cada dia é realizada 24 vezes para produzir estratégias operacionais para as próximas $24 \mathrm{~h}$, representadas nos quadrados em vermelho da Figura 4-14. Apenas a decisão da primeira hora de cada estratégia é implementada (nos quadros em preto), sendo que cada otimização produz as estratégias operacionais defasadas de 1 hora a frente em relação à otimização anterior.

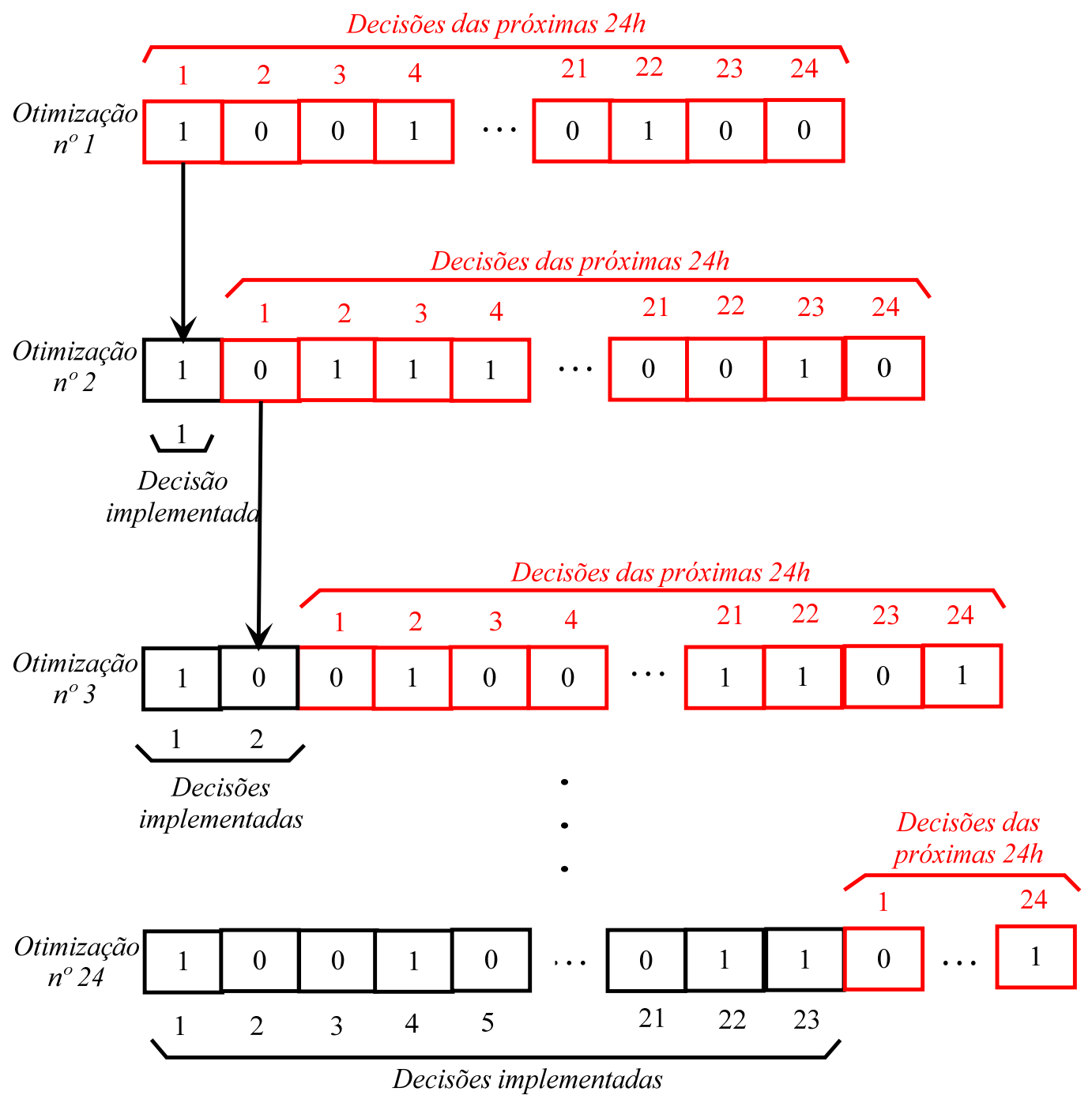

\section{Legenda}

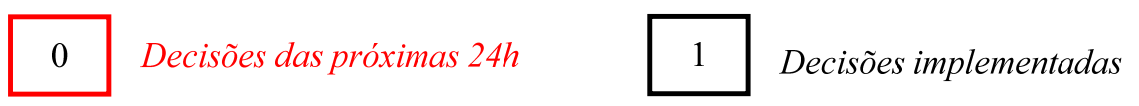

Figura 4-14 - Exemplificação das 24 otimizações realizadas para o dia 
Apesar das estratégias otimizadas das próximas $24 \mathrm{~h}$ obedecerem às restrições, não há essa garantia para a combinação das decisões da primeira hora de cada otimização.

Para garantir maior sucesso da otimização da operação em tempo real seria necessário considerar também as decisões anteriormente implementadas, além das otimizações das estratégias operacionais das próximas $24 \mathrm{~h}$. Uma forma seria realizar simulações hidráulicas combinando-se as decisões implementadas e as decisões otimizadas das próximas $24 \mathrm{~h}$ para verificar se elas serão factíveis e otimizadas.

A Figura 4-15 exemplifica a combinação entre as decisões otimizadas das próximas $24 \mathrm{~h}$ e as decisões implementadas para a terceira otimização do dia. A combinação dessas decisões será denominada Estratégia Otimizada Combinada (EOC). Na figura está o exemplo da terceira otimização do dia, em que após a obtenção das decisões otimizadas para as próximas $24 \mathrm{~h}$, combinam-se as primeiras 22 decisões com as duas decisões já implementadas, totalizando 24 decisões para o dia.

Essa estratégia combinada é então verificada utilizando-se a simulação hidráulica para obter os valores das funções objetivo e a ocorrência de violação das restrições do problema de otimização.

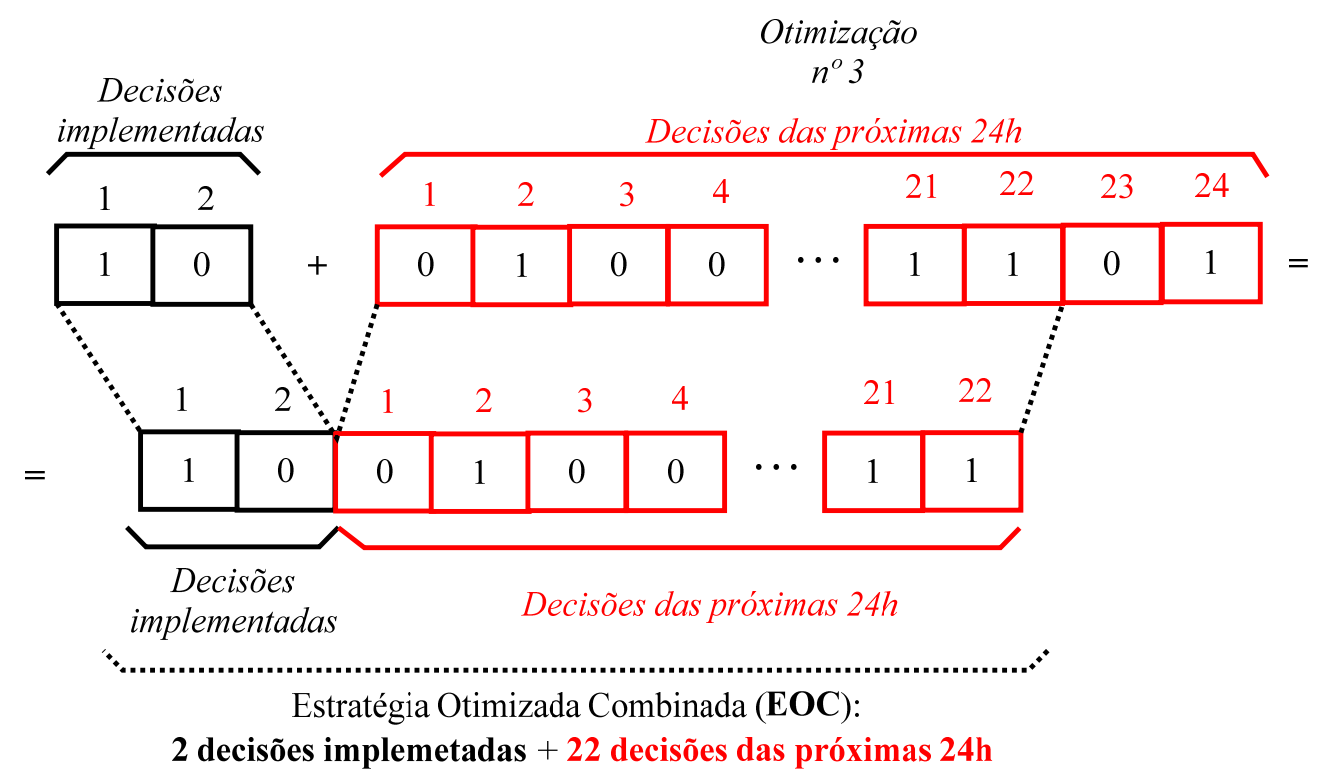

Legenda

0 Decisões das próximas $24 h \quad \square$ Decisões implementadas

Figura 4-15 - Exemplificação da combinação entre a Decisão Otimizada das próximas 24h e das decisões implementadas 
Nota-se que o procedimento deve ser adotado para cada solução da população de todas as gerações do algoritmo de otimização. Como resultado, o número de simulações hidráulicas necessárias seriam duplicadas, e isso poderia tornar a otimização em tempo real inviável, ultrapassando o limite disponível de uma hora para gerar as estratégias otimizadas.

Assim, para diminuir o número de simulações hidráulicas necessárias, as simulações das EOC foram realizadas apenas para as soluções da última geração produzidas pelo módulo de otimização.

Como já fora mencionado anteriormente, não se pode garantir que a combinação das decisões da primeira hora de cada otimização seja otimizada e factível. Portanto, para aumentar a probabilidade de se gerar soluções factíveis e otimizadas mesmo considerando-se as decisões otimizadas já implementadas, elaboraram-se três técnicas que devem ser aplicadas sequencialmente para cada EOC: escolha da estratégia otimizada combinada, minimização do número de acionamentos da bomba, e minimização do uso da bomba no horário de ponta.

Essas técnicas são empregadas à representação binária, ou seja, no caso de se utilizar a RPB RTCT, antes de se aplicar as técnicas, deve-se codificar cada EOC como binária.

\section{Escolha da estratégia otimizada combinada (EOC)}

Os algoritmos de busca populacionais geram um conjunto de soluções, dentre as quais se deve escolher uma para ser utilizada. E no caso da otimização multiobjetivo, não há uma solução melhor que a outra na Frente Pareto. Por esse motivo, deve-se utilizar alguma técnica para escolher uma solução dentre várias. Neste trabalho, será utilizada uma técnica simples para selecionar uma única solução.

A escolha da solução inicia-se na Frente Pareto $\left(\right.$ Frente $\left._{1}\right)$. Para cada solução da Frente $_{1}$, obtém-se uma EOC. Calcula-se a distância euclidiana entre cada EOC e a melhor solução fictícia (Figura 4-16). No caso da minimização de duas funções objetivo, seria a solução $(0,0)$, correspondente a origem dos eixos das funções objetivo. Tal solução fictícia representaria, por exemplo, custo zero $(f 1)$ e outra função de valor objetivo zero $(f 2)$. Dentre as soluções, escolhe-se aquela com menor distância euclidiana. Caso não seja encontrada uma solução factível na Frente ${ }_{1}$, prossegue-se a busca nas demais frentes de dominação (Frente, Frente $_{3}, . .$. Frente $_{n}$ ) até que se encontre uma solução factível de menor distância euclidiana. Se não for encontrada nenhuma solução factível, escolhe-se a solução da Frente ${ }_{1}$ com menor distância euclidiana. 


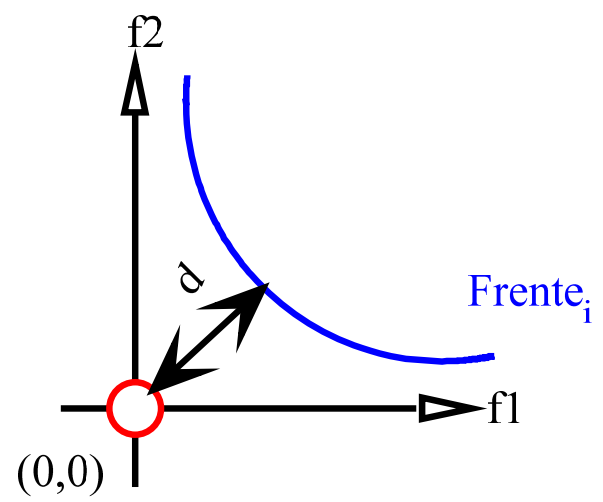

Figura 4-16 - Representação da distância euclidiana entre a solução da Frente $\mathrm{e}_{\mathrm{i}}$ e a melhor solução fictícia para minimização de duas funções objetivo

\section{Técnica para minimizar o número de acionamento das bombas}

Após a escolha anterior, procede-se à minimização do número de acionamentos das bombas da EOC. Esta técnica é empregada para cada bomba e apenas para as decisões anteriores ao horário de ponta. A técnica é realizada nos seguintes passos:

1. Armazena-se a EOC selecionada anteriormente no vetor estratégia1;

2. Se a decisão nh (Figura 4-17), no quadrado em vermelho (no caso, desligado - 0) for diferente da decisão $n h+1$, no quadrado em azul (no caso, ligado - 1), então armazena-se a decisão $n h+1$ no variável status. Depois, modifica-se a decisão $n h+1$, tornando-a igual a decisão $n h$, ou seja, tornando $1 \mathrm{em} \mathbf{0}$. A nova EOC será armazenada no vetor estratégia2;

3. Avalia-se a estratégia2. Caso não seja factível, procede-se ao próximo passo, senão prosseguir para o passo 5;

4. Procura-se a próxima decisão da estratégia2 igual a decisão armazenada em status, que no exemplo da Figura 4-18 está na posição $n h+3$. Então modifica-se a decisão imediatamente anterior e diferente de status, no caso a decisão $n h+2$, para a decisão armazenada em status ( 0 -> 1) - a nova solução é armazenada no vetor estratégia2;

5. Realiza-se a comparação entre os vetores estratégia1 e estratégia2 utilizando-se os operadores FNS e CD, definidos no item 4.3;

6. Escolhe-se a melhor estratégia entre estratégia1 e estratégia2. Se ambas forem nãodominadas, escolhe-se a estratégia2 e o procedimento é finalizado. 


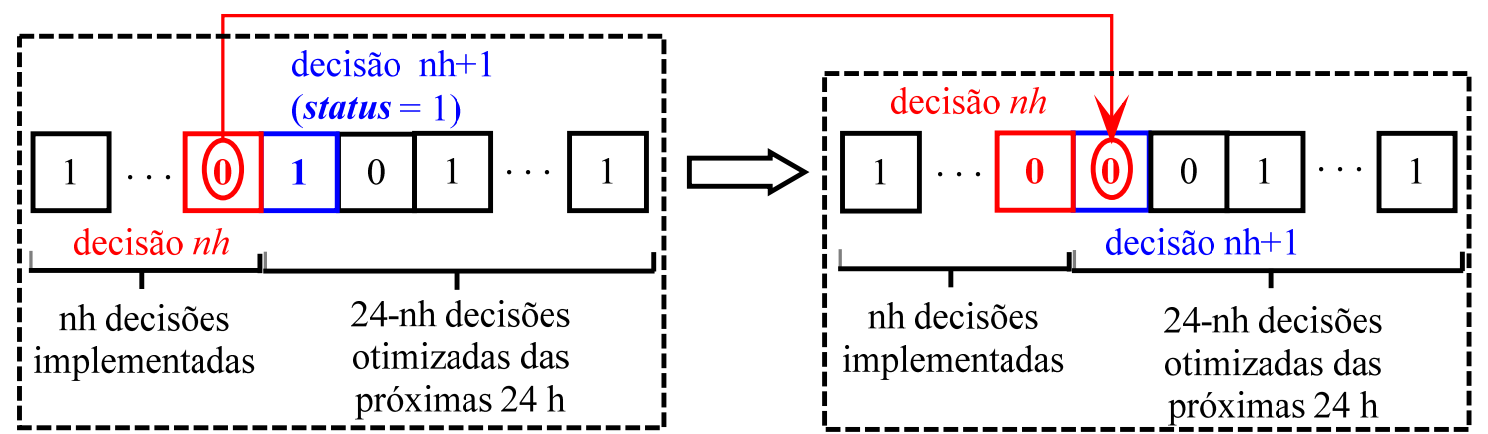

estratégia 1

estratégia 2

Figura 4-17 - Exemplificação do Passo 2 - Técnica para minimizar número de acionamento de bombas

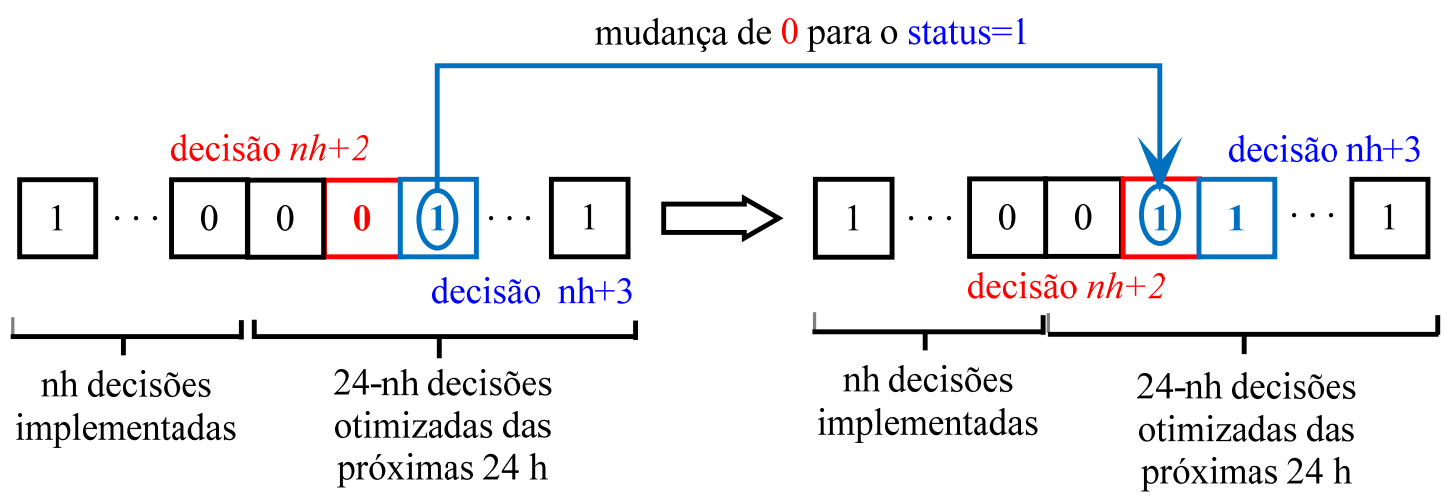

Figura 4-18 - Exemplificação do Passo 4 - Técnica para

minimizar número de acionamento de bombas

\section{Técnica para minimizar o uso da bomba no horário de ponta}

Foi proposto também um procedimento para minimizar o uso da bomba no horário de ponta. Esta técnica é aplicada nos casos em que há uso das bombas durante o horário de ponta, e somente para as estratégias otimizadas das próximas $24 \mathrm{~h}$, pois não se pode mudar as operações já implementadas. Esta técnica é aplicada após o procedimento de minimização do número de acionamentos das bombas da seguinte forma:

1. Armazenar a EOC original em estratégia1;

2. Obter o número de decisões da estratégia1 com estado ligado durante o horário de ponta. Tal número será denominado nponta;

3. Repetir os passos 3.1 a 3.4 nponta vezes, para cada decisão com o estado ligado durante o horário de ponta: 
3.1. Tornar a decisão $n h+i$ da bomba desligada $(1->0)$ e armazenar estratégia modificada em estratégia2, em que i representa a diferença entre a ordem $n h$ e a ordem do horário de ponta considerado;

3.2. Avaliar a estratégia2. Se for infactível, ir para passo 3.3, senão ir para passo 4:

3.3. a) Caso a decisão a ser implementada seja anterior ao horário de ponta, tornar as decisões anteriores ao horário de ponta ligadas, até que a estratégia se torne factível (Figura 4-20);

b) Caso da decisão a ser implementada seja durante o horário de ponta, tornar as decisões posteriores ao horário de ponta ligadas até que se torne factível, iniciando-se a partir da última decisão (Figura 4-21);

3.4. Se não for encontrada uma estratégia factível, desfazer as modificações e retornar aos status da estratégia1, senão armazenar em estratégia2 e proceder ao passo 4;

4. Caso a estratégia tenha sido modificada com sucesso, classificar as estratégia1 e estratégia2;

5. Escolher a melhor estratégia entre estratégia1 e estratégia2. Se ambas forem não dominadas, escolher a estratégia2.

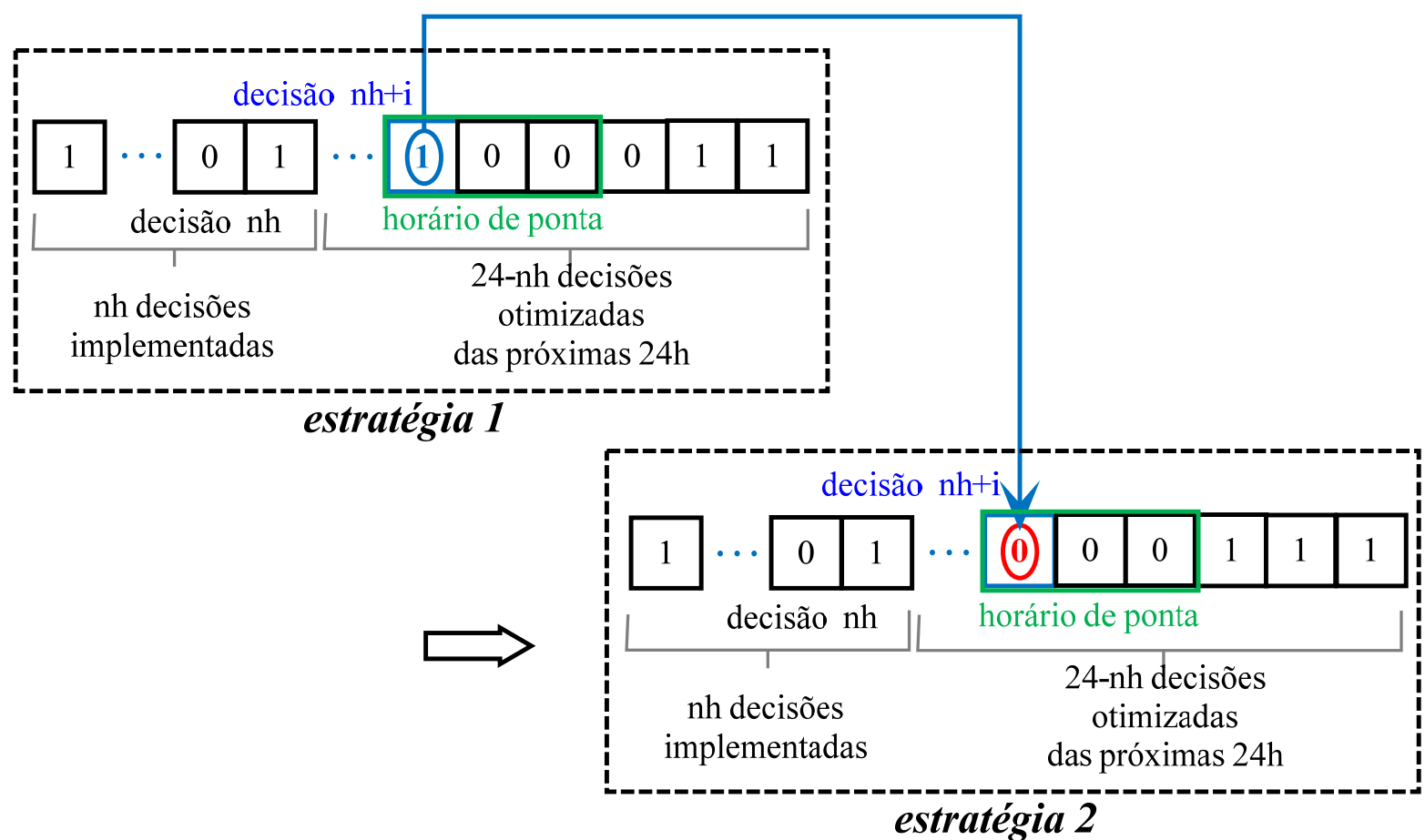

Figura 4-19 - Exemplificação do passo 3.1 - Técnica para minimizar o uso da bomba no horário de ponta 


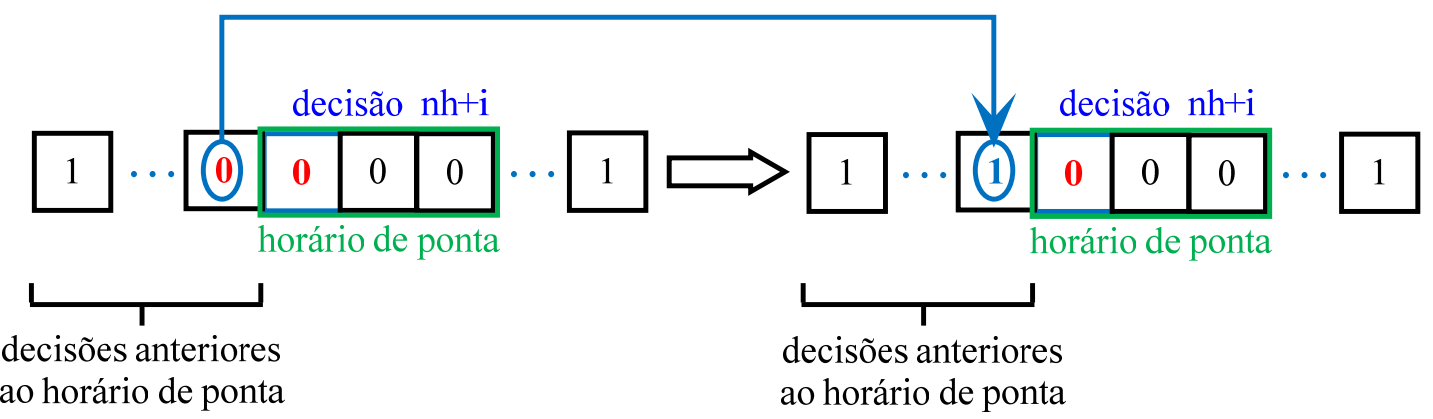

Figura 4-20 - Exemplificação do passo 3.3 (a) - Técnica para minimizar

o uso da bomba no horário de ponta

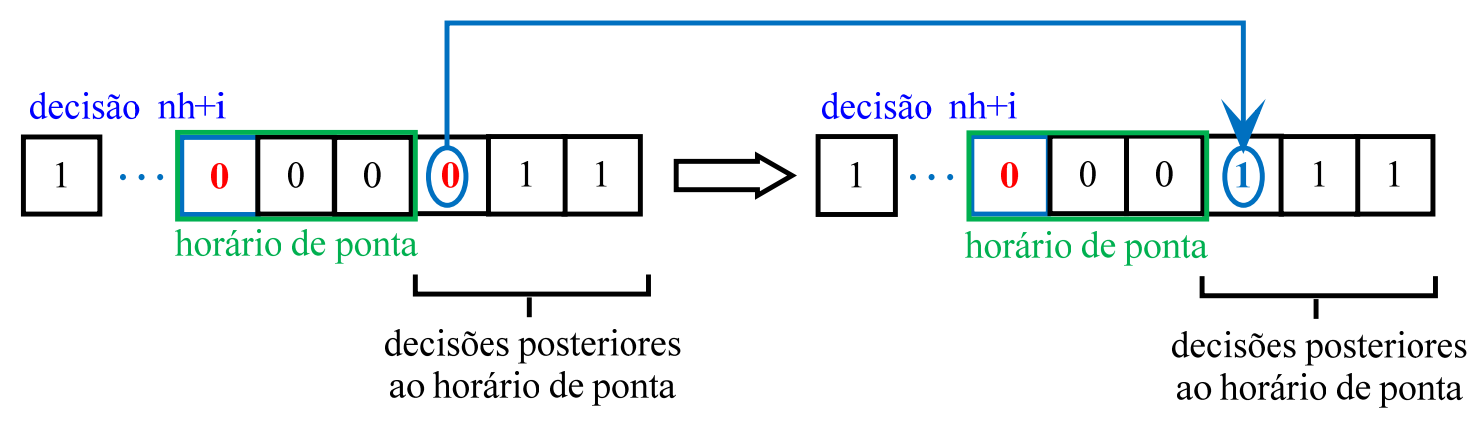

Figura 4-21 - Exemplificação do passo 3.3 (b) - Técnica para minimizar

o uso da bomba no horário de ponta

\subsubsection{Melhorias no Módulo de Otimização}

Para agilizar a velocidade de otimização em tempo real, utilizou-se a técnica de armazenamento das soluções em "cache" ${ }^{28}$ e implementou-se uma função do Scilab de paralelização dos processamento computacional denominado "parallel_run".

As soluções "cache" são armazenadas e utilizadas apenas para a própria otimização das próximas 24 horas. Após o intervalo de 1 hora, ao se realizar novamente a otimização das próximas 24 horas, cria-se um nova "cache".

A função de paralelização do processamento aproveita-se da nova arquitetura dos computadores, que utilizam múltiplos núcleos de processamento. Por exemplo, se houverem 4 núcleos de processamento, poderão ser otimizadas simultaneamente 4 soluções ao invés de apenas 1 solução, tornando o processo mais rápido. No entanto, tal função produz apenas um

${ }^{28}$ No caso, pode ser definido como área de armazenamento das soluções frequentemente utilizadas e suas respectivas funções objetivo avaliadas, para que possam ser reutilizados futuramente, sem a necessidade de simular novamente a simulação para obter a função objetivo. 
pequeno ganho de desempenho, já que foi criada para ser utilizada em sistemas operacionais baseados em ambiente Linux ${ }^{29}$.

\subsection{Técnicas de Amostragem}

A técnica de amostragem foi utilizada na criação da população inicial de soluções do AMALGAM e também na criação de conjuntos de dados para calibração do metamodelo, pois a amostragem permite gerar um conjunto melhor distribuído de amostras do espaço de decisão, e portanto, pode-se utilizar uma menor quantidade de dados, já que tal conjunto é mais representativo do espaço amostral.

Baseado nos estudos de Saliby \& Pacheco (2002), que apresentaram um estudo comparativo dos métodos de amostragem quase Monte-Carlo, Descritiva, Hipercubo Latino (LHS) e Monte Carlo Clássico na Análise de Risco, decidiu-se utilizar o LHS, o qual produziu o melhor desempenho dentre as técnicas comparadas.

\subsubsection{Técnica de amostragem do hipercubo latino (LHS)}

A técnica de amostragem do hipercubo latino foi proposta por Mckay, Conover e Beckman (1979) e desenvolvida posteriormente por Iman e Conover (1982).

A base da amostragem do hipercubo latino é a estratificação completa da distribuição da variável com amostragem aleatória de cada estrato.

A seguir serão apresentadas explicações passo a passo da amostragem do hipercubo latino, baseadas em Mckay, Conover e Beckman (1979), Iman e Conover (1982), Wyss e Jorgensen (1998) e Deus (2010).

1 - Divide-se o intervalo de cada variável $x a_{k}(k=1,2,3, \ldots, K)$ em nest ${ }^{30}$ estratos de mesma probabilidade;

2 - Seleciona-se um valor de cada estrato iest $(i=1,2,3, \ldots$, nest $)$ de acordo com a sua densidade de probabilidade para cada variável $x a_{k}$;

3 - Após a seleção de valores, formam-se pares de maneira aleatória, dos nest valores de $x a_{1}$ com os $n$ valores de $x a_{2}$;

4 - Combinam-se os nest pares gerados com os nest valores de $x a_{3}$, formando trios, e assim sucessivamente, até que todas as variáveis façam parte da combinação.

\footnotetext{
${ }^{29}$ Sistema operacional alternativo ao Windows desenvolvido por Linus Torvalds, de distribuição livre

30 Para o caso do AMALGAM, $n$ é igual a dimensão da população, enquanto que para a metamodelagem, $n$ é igual ao número de exemplos a serem gerados para a calibração.
} 


\subsection{Redes de estudo}

A obtenção dos dados de estudo foi possível com realização de um convênio entre a Universidade de São Paulo e o Departamento Autônomo de Água e Esgoto (DAAE), da cidade de Araraquara-SP.

As redes de estudo são representadas esquematicamente na Figura 4-22, as quais são constituídas de três setores: Eliana, Iguatemi e Martinez. Os arquivos dos modelos foram anexados no CD em formato ".inp", utilizado pelo simulador hidráulico EPANET 2.

O sistema possui cerca de $200 \mathrm{~km}$ de rede, incluindo o macrosistema e o microsistema de abastecimento com diâmetros variando de 50 a $400 \mathrm{~mm}$, compostos de ferro fundido, PVC e cimento amianto.

No ano de 2010, foram abastecidas cerca de 13 mil ligações, com faturamento de 258 mil m³ mês, os quais correspondem ao abastecimento de $360 \mathrm{~m}^{3} / \mathrm{h}$. No período foram mensurados $461 \mathrm{~m}^{3} / \mathrm{h}$ pelos macromedidores nas saídas dos reservatórios. Assim, estima-se a perda total $^{31}$ em cerca $22 \%$ da vazão abastecida.

A energia elétrica dos setores em estudo é tarifada segundo a modalidade tarifária Horossazonal Verde ${ }^{32}$, sendo que o horário de ponta é composto pelas três horas consecutivas entre $18 \mathrm{~h} 00$ e $21 \mathrm{~h} 00$.

Foram realizadas otimizações para cada setor para um mês do ano de 2010, pois há muitas falhas de registro do sistema de telemetria, e para possibilitar a comparação entre o custo praticado pelo DAAE e da operação otimizada, era necessário um período de dados contínuos e sem falhas. Assim, na Tabela 4-3, são apresentados os meses utilizados para otimização e as tarifas aplicadas no período.

${ }^{31}$ Representa a soma das perdas reais, causadas por vazamentos e por perdas aparentes, devido a erros ou falta de medição nos macromedidores e micromedidores.

${ }^{32}$ Modalidade caracterizada pela aplicação de uma única tarifa para demanda, e duas para o consumo, conforme o seguimento horário (ponta e fora de ponta) e período do ano (seco e úmido). 


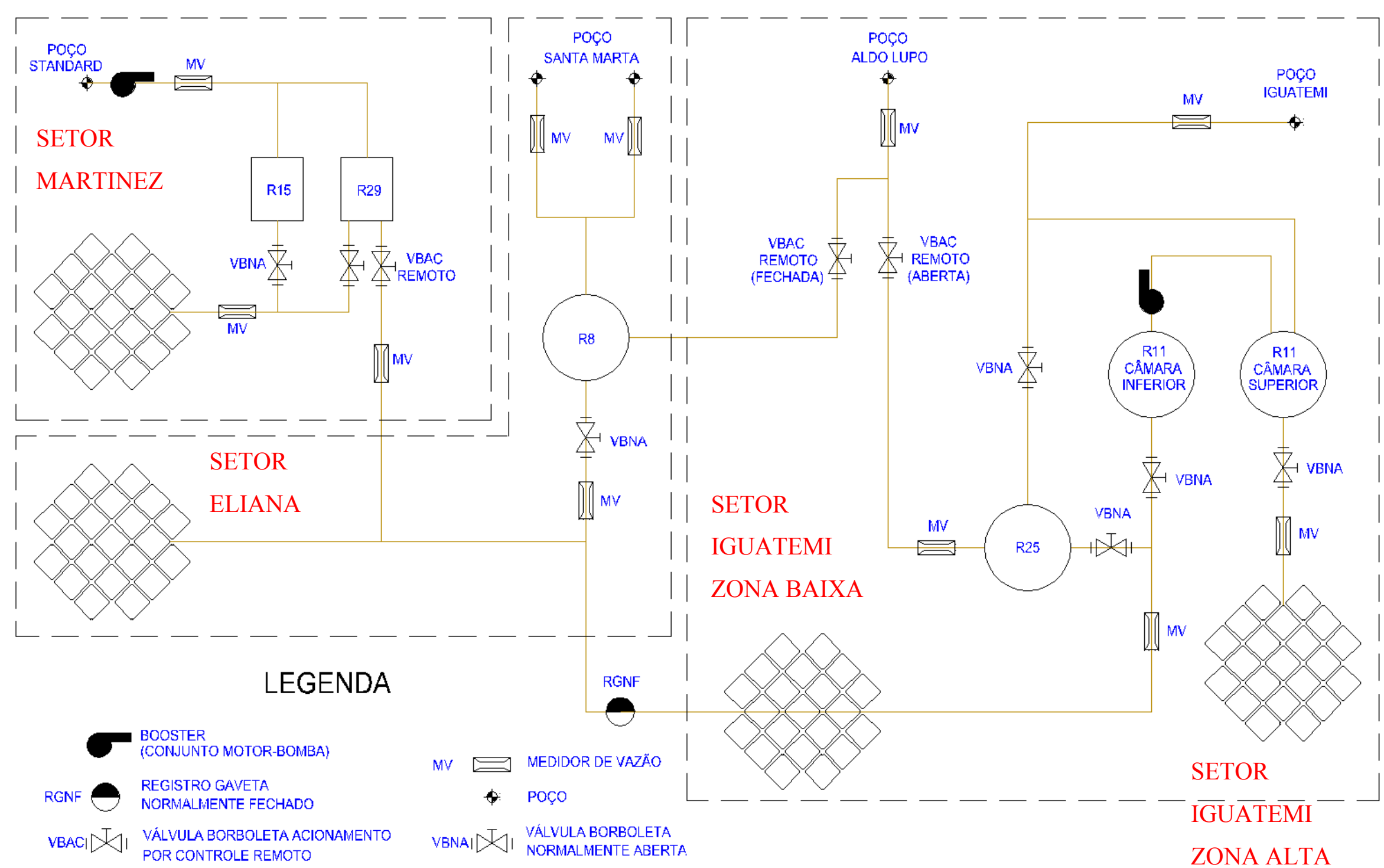

Figura 4-22 - Representação esquemática do Setor de estudo 
Tabela 4-3 - Tarifas de energia

\begin{tabular}{cccc}
\hline Setor & Mês faturado & \multicolumn{2}{c}{ Tarifa $(\mathbf{R} \mathbf{S} \mathbf{k W h})$} \\
\cline { 3 - 4 } & & Ponta & Fora de Ponta \\
\hline Eliana & maio & 5,406 & 0,760053 \\
Iguatemi & setembro & 5,406 & 0,760053 \\
Martinez & fevereiro & 5,731967 & 0,776269 \\
\hline
\end{tabular}

A seguir são fornecidos maiores detalhes de cada setor de abastecimento nos itens 4.7.1, 4.7.2 e 4.7.3.

\subsubsection{Setor Eliana}

O Setor Eliana é o menor dos setores de estudo, com cerca de 18,5 km de rede, o qual consome cerca de $54 \mathrm{~m}^{3} / \mathrm{h}$, caracterizado por consumo residencial.

O modelo hidráulico completo (Figura 4-23) é representado por 252 nós e 282 trechos de tubos. O Centro de Reservação (CR) é composto de dois poços (Santa Marta I e II) e um reservatório elevado (R8). Em caso de necessidade, pode-se aduzir água para o Setor Martinez e para a parte baixa do Setor Iguatemi, além de poder receber água do Poço Aldo Lupo, conforme esquema da Figura 4-22. A escolha dos pontos de monitoramento (囚) será detalhada no item 4.8 . 


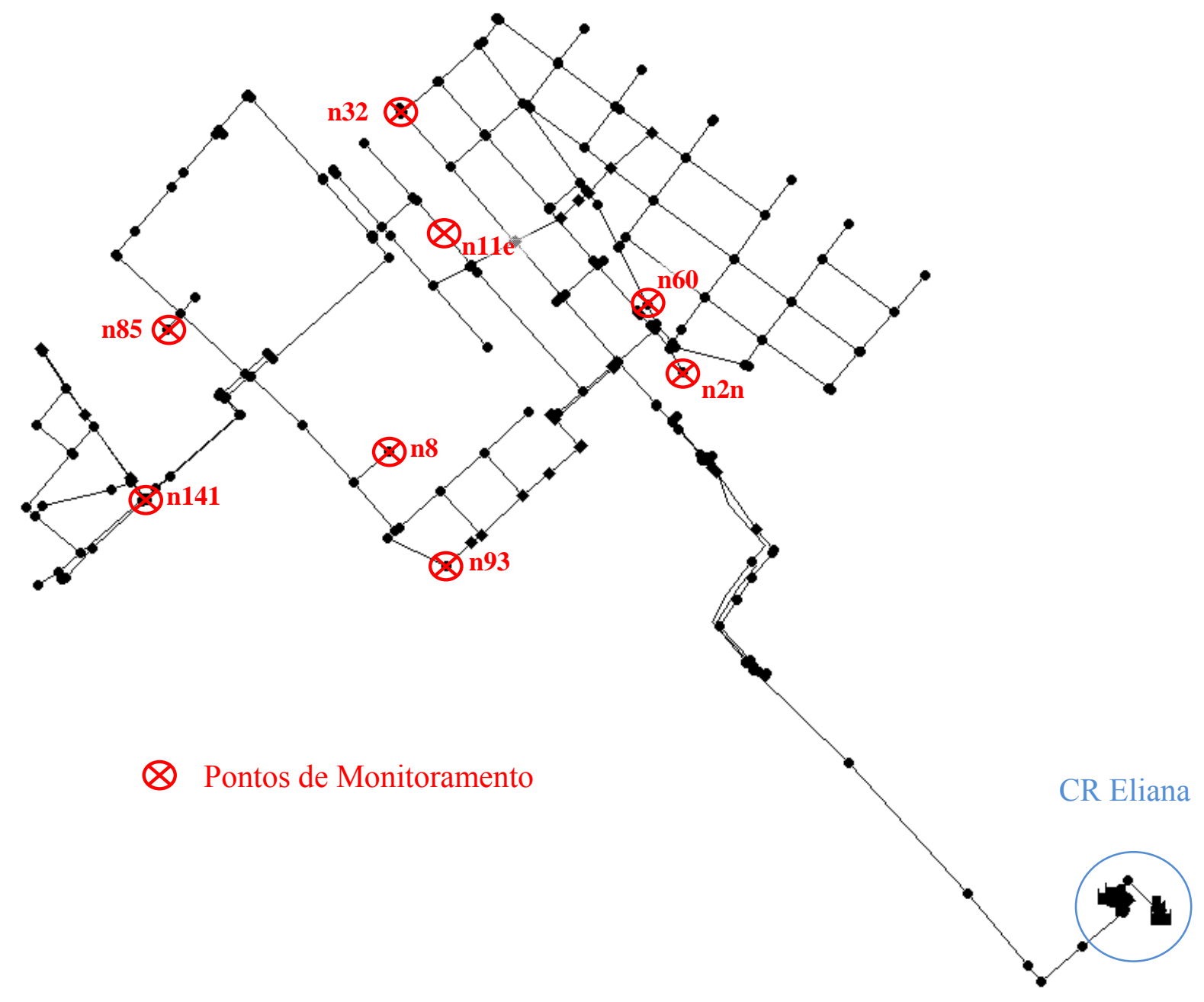

Figura 4-23 - Representação do modelo hidráulico do Setor Eliana

As bombas dos poços são da marca Ebara, modelo BHS1010 de 6 estágios, com potência de $142 \mathrm{cv}$, com produção média de $115 \mathrm{~m}^{3} / \mathrm{h}$.

Na Tabela 4-4 são fornecidos os dados do reservatório R8.

Tabela 4-4 - Dados do Reservatório R8 - Setor Eliana

\begin{tabular}{cc}
\hline Dado & Cota/Volume \\
\hline Cota de Fundo & $715,59 \mathrm{~m}$ \\
Nível de água Máximo & $721,99 \mathrm{~m}$ \\
Volume útil & $500 \mathrm{~m}^{3}$ \\
\hline
\end{tabular}

Na Figura 4-24 é ilustrado o consumo médio do Setor Eliana para os diferentes dias da semana. 


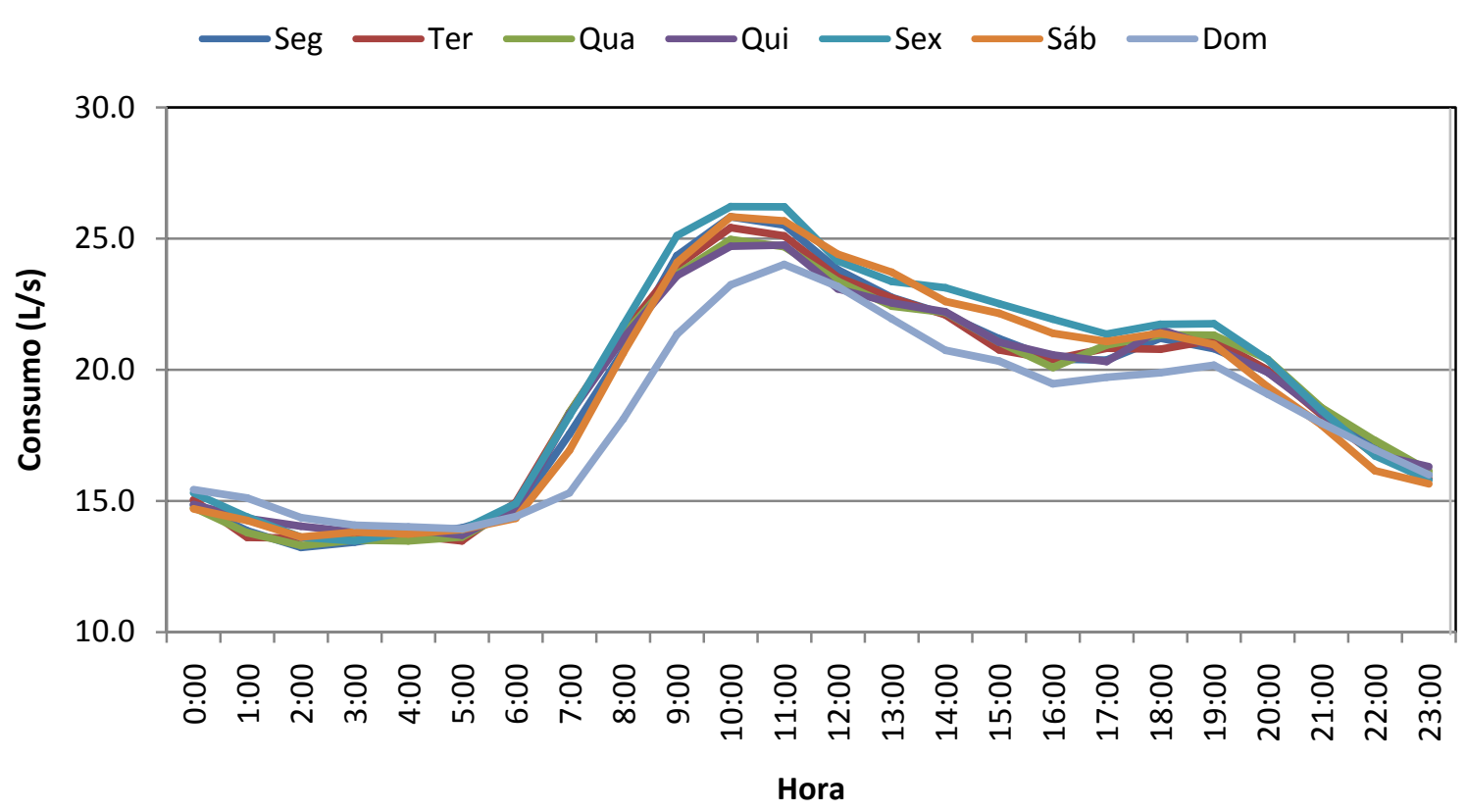

Figura 4-24 - Perfil de Consumo médio do Setor Eliana

\subsubsection{Setor Iguatemi}

O Setor Iguatemi é o maior dos setores de estudo, e subdivide-se em Zona Alta e Zona Baixa, os quais consomem em média 144 e $122 \mathrm{~m}^{3} / \mathrm{h}$, respectivamente. O consumo é de natureza residencial e industrial. O comprimento total da rede totaliza cerca de $125 \mathrm{~km}$ de rede.

O modelo hidráulico completo, representado na Figura 4-25, possui 1236 nós e 1491 trechos de tubos. O CR é composto pelo Poço Iguatemi, uma estação elevatória entre o reservatório R11 (Câmara) Inferior e o R11 (Câmara) Superior, e o reservatório apoiado R25.

Os dados dos reservatórios R11 Inferior, R11 Superior e R25 são apresentados na Tabela 4-5.

As fontes de abastecimento são o Poço Aldo Lupo, que aduz água para o R25, e o Poço Iguatemi. Geralmente o Poço Iguatemi envia a água para o R25, mas também pode enviar diretamente ao R11 Superior, caso a válvula a montante do R25 esteja fechada.

Os reservatórios R25 e o R11 Inferior são interligados e juntos abastecem a parte baixa do Setor Iguatemi, que ocupa a parte Noroeste do setor, à esquerda da linha em azul (Figura 4-25). O R11 Superior é um reservatório elevado e abastece a parte alta do setor, à direita da linha azul. Em caso de necessidade, a Zona Baixa pode receber água do Setor Eliana. 
Tabela 4-5 - Dados dos reservatórios do Setor Iguatemi

\begin{tabular}{ccc}
\hline Reservatório & Dado & Cota/Volume \\
\hline \multirow{2}{*}{ R11 Inferior } & Cota de Fundo & $725,71 \mathrm{~m}$ \\
& Nível de água máximo & $740,01 \mathrm{~m}$ \\
& Volume útil & $400 \mathrm{~m}^{3}$ \\
R11 Superior & Cota de Fundo & $740,71 \mathrm{~m}$ \\
& Nível de água máximo & $754,71 \mathrm{~m}$ \\
& Volume útil & $400 \mathrm{~m}^{3}$ \\
R25 & Cota de Fundo & $722,80 \mathrm{~m}$ \\
& Nível de água máximo & $734,21 \mathrm{~m}$ \\
& Volume útil & $3.000 \mathrm{~m}^{3}$ \\
\hline
\end{tabular}

A bomba dos Poços Iguatemi e Aldo Lupo, são da marca Ebara, modelo 1015 de 5 estágios, possui $188 \mathrm{cv}$ e produção média respectivamente de 235 e $180 \mathrm{~m}^{3} / \mathrm{h}$, enquanto que a bomba que recalca água do R11 Inferior ao R11 Superior utiliza uma bomba Imbil, modelo INI 125-315, de $46 \mathrm{cv}$, e capacidade nominal de $240 \mathrm{~m}^{3} / \mathrm{h}$.

$\mathrm{Na}$ Figura 4-25 são representados os pontos de monitoramento (囚) e os pontos de descarga $(\square)$, que serão detalhados no item 4.8 . 


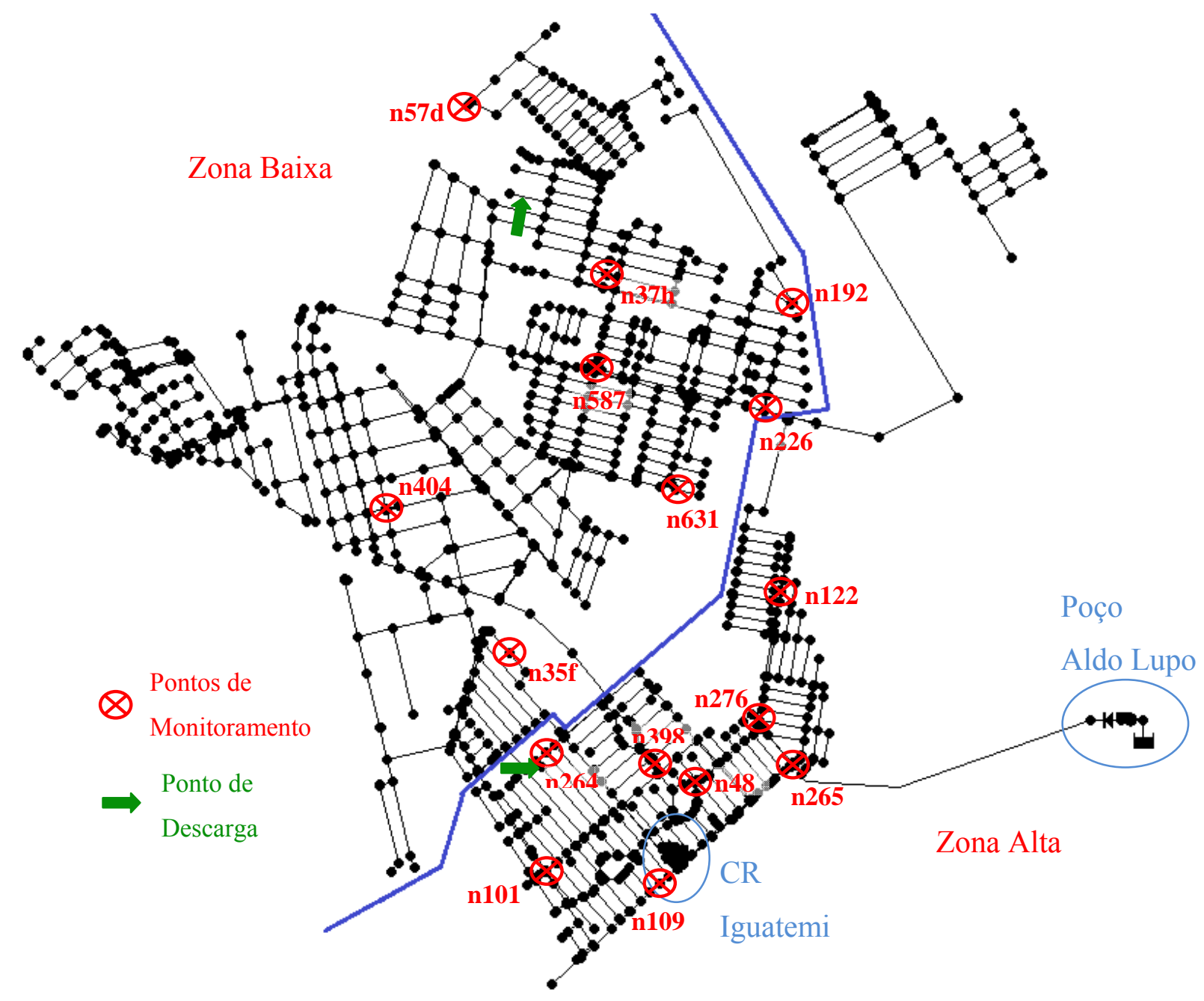

Figura 4-25 - Representação do modelo hidráulico do Setor Iguatemi

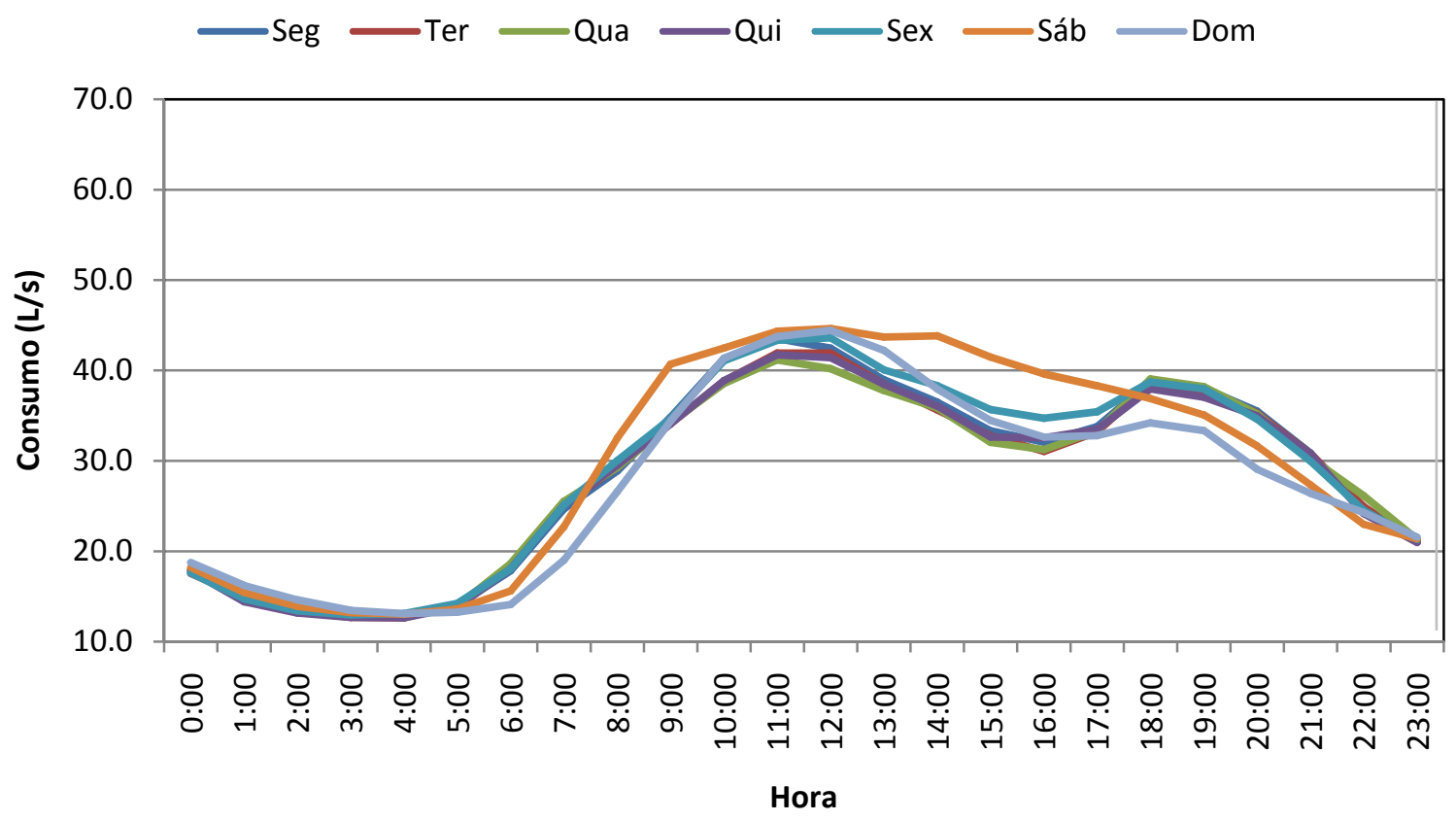

Figura 4-26 - Perfil de Consumo médio do Setor Iguatemi-Zona Alta 


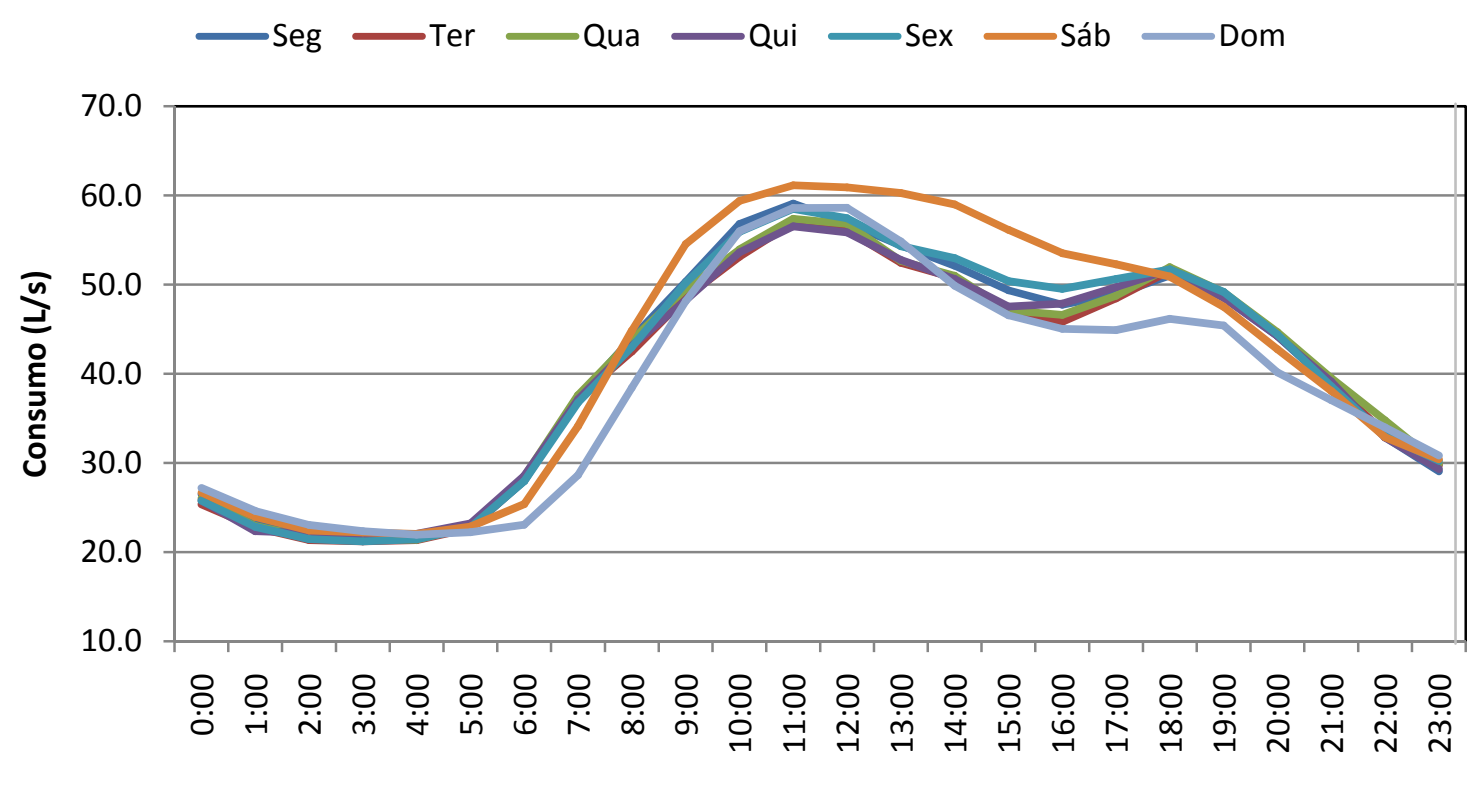

Hora

Figura 4-27 - Perfil de Consumo médio do Setor Iguatemi - Zona Baixa

\subsubsection{Setor Martinez}

O Setor Martinez possui cerca de $57 \mathrm{~km}$ de rede e um consumo médio de $140 \mathrm{~m}^{3} / \mathrm{h}$, de natureza residencial.

O modelo hidráulico (Figura 4-28) é representado por 896 nós e 1074 trechos de tubos. O Centro de Reservação é composto pelos reservatórios apoiados R15 e R29. Tais reservatórios recebem água do Poço Standard, e em caso de necessidade pode receber água do Setor Eliana.

A bomba do Poço Standard, da marca ESCO, modelo 12-CEB de 14 estágios, possui $248 \mathrm{cv}$. À jusante do poço há um reservatório de passagem seguido do booster denominado Standard, da marca KSB, modelo ETA 125-50/2 de $106 \mathrm{cv}$.

Na Figura 4-28 são representados os pontos de monitoramento (囚) e os pontos de descarga $(\longrightarrow)$, que serão detalhados no item 4.8.

Na Tabela 4-6 apresentam-se os dados dos reservatórios do Setor Martinez. 


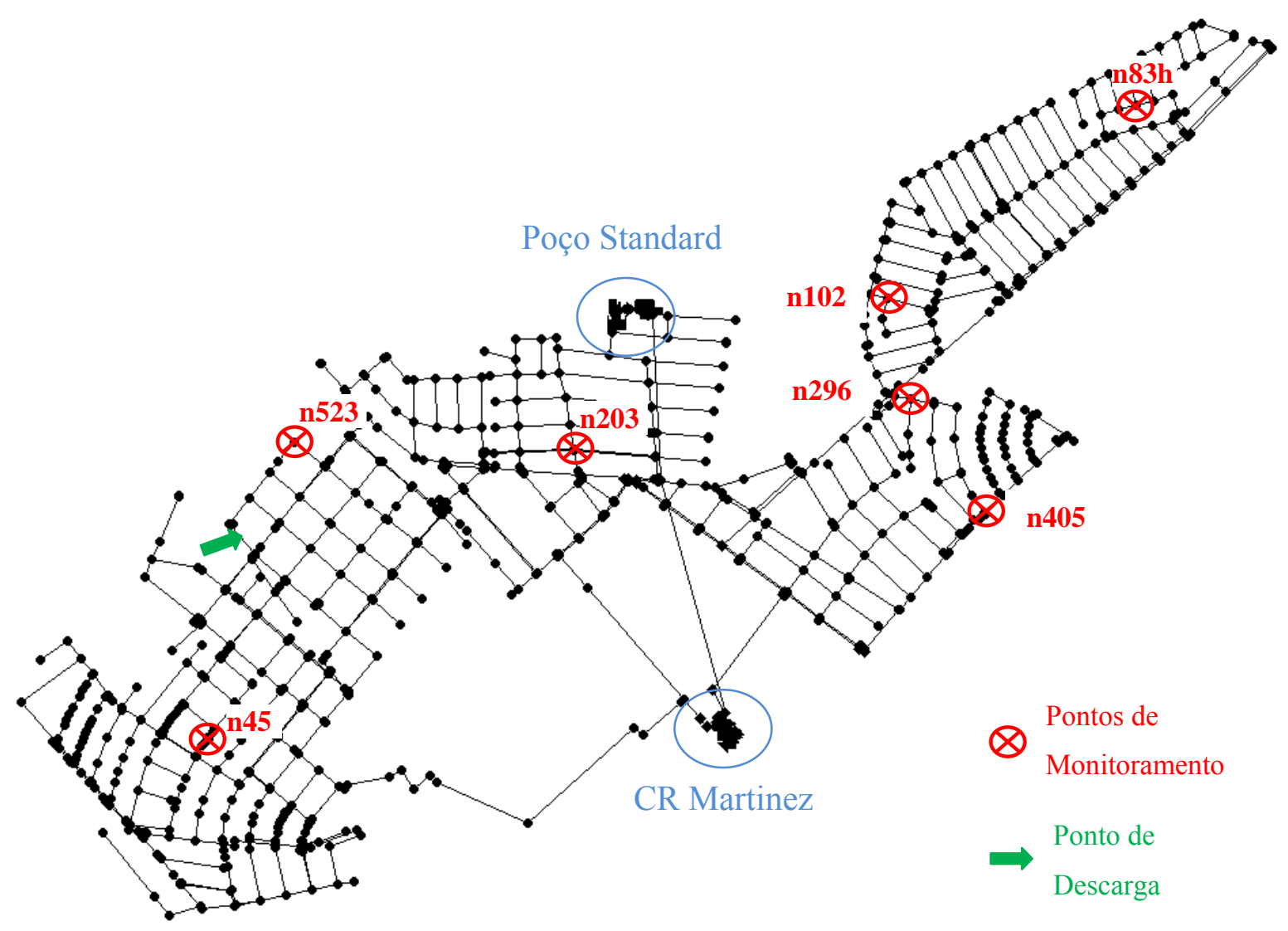

Figura 4-28 - Representação do modelo hidráulico do setor Martinez

Na Figura 4-29 são mostradas as curvas de consumo do Setor Martinez.

Tabela 4-6 - Dados dos reservatórios do Setor Martinez

\begin{tabular}{ccc}
\hline Reservatório & Dado & Cota/Volume \\
\hline \multirow{2}{*}{ R15 e R29 } & Cota de Fundo & $679,75 \mathrm{~m}$ \\
& Nível de água máximo & $683,95 \mathrm{~m}$ \\
& Volume útil & $1.400 \mathrm{~m}^{3}$ \\
Standard & Cota de Fundo & $625 \mathrm{~m}$ \\
& Nível de água máximo & $627 \mathrm{~m}^{3}$ \\
& Volume útil & $145 \mathrm{~m}^{3}$ \\
\hline
\end{tabular}




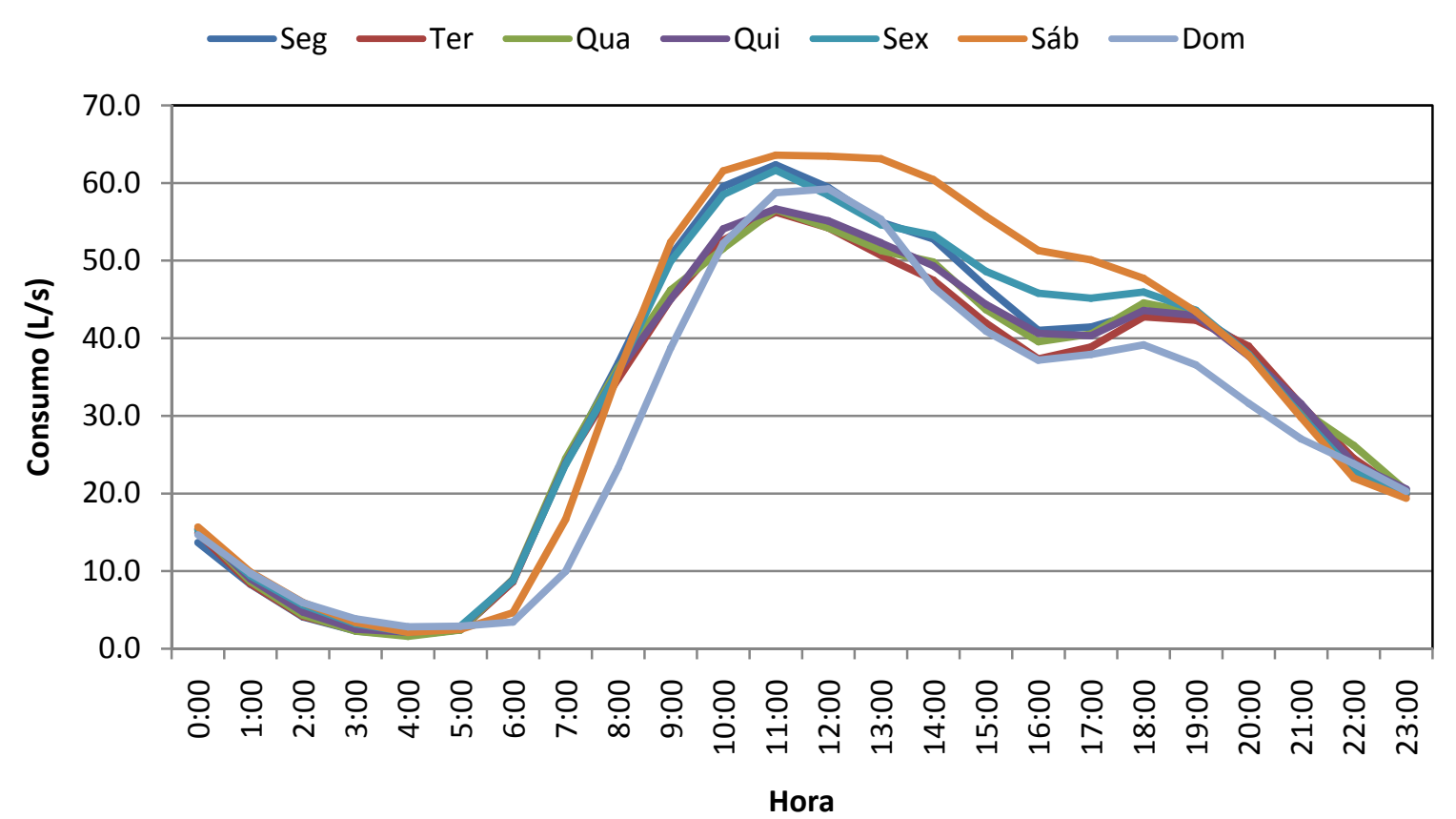

Figura 4-29 - Perfil de Consumo médio do Setor Martinez

\subsection{Construção e Calibração das Redes de Estudo}

Os modelos das redes de estudo foram construídos com base nos dados fornecidos pela companhia de saneamento: topologia das redes, material e diâmetros das tubulações, dados de telemetria, dados dos reservatórios e consumo micromedidos mensais das ligações de água.

A companhia de saneamento forneceu a representação da rede de abastecimento em arquivos do AutoCad ${ }^{33}$. Tais arquivos foram convertidos para formato compatível com o EPANET 2, por meio do EPACAD, programa gratuito desenvolvido pela Universidade Politécnica de Valência.

Após a conversão da rede, esqueletonizou-se a rede, de modo a combinar os tubos de mesmo diâmetro e material utilizando-se uma rotina computacional desenvolvida por Abe (2013). O procedimento foi detalhado no item 4.2.2 (Simplificação da Rede - página 81).

As demandas dos nós foram alocadas utilizando-se outra rotina desenvolvida por Abe (2013), em que os consumos faturados mensais de cada economia (consumidor) foram convertidos para a unidade $\mathrm{L} / \mathrm{s}$ e distribuídos aos nós mais próximos.

${ }^{33}$ AutoCAD é um programa de computador da Autodesk utilizado principalmente na elaboração de desenho técnico em duas dimensões. 
A calibração da rede de abastecimento envolveu a realização de campanhas de campo para obtenção de dados de carga de pressão e vazão. Para cada setor, limitou-se o monitoramento da carga de pressão a 8 nós, restrição imposta pela disponibilidade de medidores de carga de pressão.

Os medidores de carga de pressão utilizados são da Technolog, modelo Metrolog P, que tem capacidade de medir carga de pressão (0-100 m.c.a) e armazenar dados de pressão e vazão. Inicialmente planejava-se instalar os medidores diretamente na rede, mas devido à indisponibilidade de pontos disponíveis (tap), não restou alternativa a não ser instalá-los nos cavaletes residenciais dos consumidores, em uma tubulação que recebia água diretamente da rede de abastecimento. A carga de pressão fora registrada em intervalos de 5 minutos durante 1 semana.

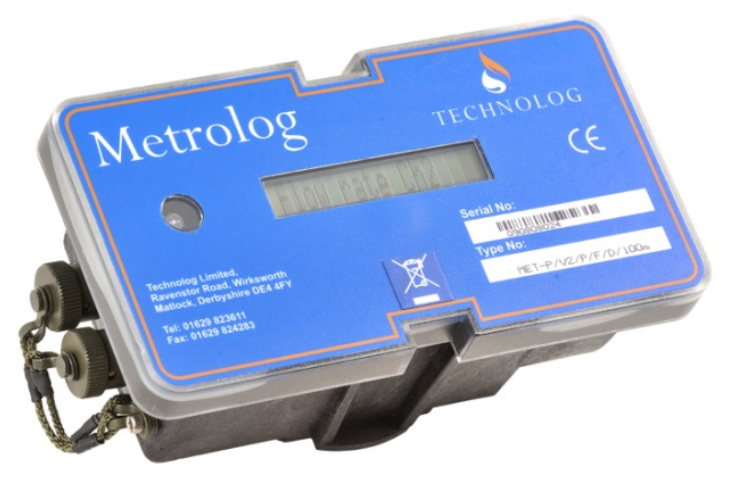

Figura 4-30 - Medidor de carga de pressão da Technolog, modelo Metrolog P

Os pontos de monitoramento, representados pelo símbolo $\otimes$ nas Figuras 4-21, 4-23 e 4-26 foram escolhidos utilizando-se um programa implementado por Abe (2013), utilizando o método proposto por Shaetzen et al. (2000).

O método consiste em identificar o conjunto ótimo de pontos de monitoramento, maximizando uma função de sensibilidade e a função de entropia de Shannon (1948). A função de sensibilidade quantifica a sensibilidade da carga de pressão em um determinado nó $\left(n o_{i}\right)$ à variação do coeficiente de rugosidade no tubo $\left(t u b o_{j}\right)$. Combinando-se a função de sensibilidade e de entropia, gera-se uma matriz de sensibilidade de tamanho nnós x mtubos, em que nnós e mtubos são respectivamente o número de nós e tubos do modelo. Dado o número de nós a serem escolhidos, utiliza-se o Algoritmo Genético para selecionar o conjunto ótimo de nós mais sensíveis à variação da rugosidade ao mesmo tempo em que se busca a distribuição espacial mais uniforme desses nós através da função de entropia de Shannon(1948). 
Após a escolha dos pontos de monitoramento, procedeu-se à busca de residências mais próximas do referido ponto. A instalação dos medidores de carga de pressão foi acompanhada por funcionário do DAAE. Houve certa dificuldade em instalar os medidores de pressão, devido à disponibilidade e disposição das pessoas em permitir a instalação do equipamento.

Devido às diferenças de cota entre os pontos de instalação do medidor de pressão e os pontos de monitoramento, foi necessário realizar uma compensação para transpor as cargas de pressão medidas para os pontos de monitoramento, corrigindo-se os valores em função da diferença de cota.

As pressões foram monitoradas por 1 semana em cada setor, sendo que ao final de cada semana, realizaram-se descargas com duração de 1 hora em um ponto da rede, para obter dados simultâneos de vazão e carga de pressão.

As descargas realizadas, similares a teste de vazão de incêndio, foram realizadas em pontos utilizados para limpeza das redes, representados por $\Rightarrow$ nas Figura 4-23 e 4-26. Assim, conectou-se um tubo de PVC de $50 \mathrm{~mm}$ ao ponto de descarga para permitir a instalação do medidor de vazão ultrassônico: modelo Portaflow 300 da Micronics, composto pelos transdutores (Figura 431 (a)) e pelo medidor/logger de vazão (Figura 4-31(b)). Durante as descargas, outro medidor de vazão ultrassônico foi instalado na saída do reservatório. As vazões foram registradas em intervalos de 10 segundos.

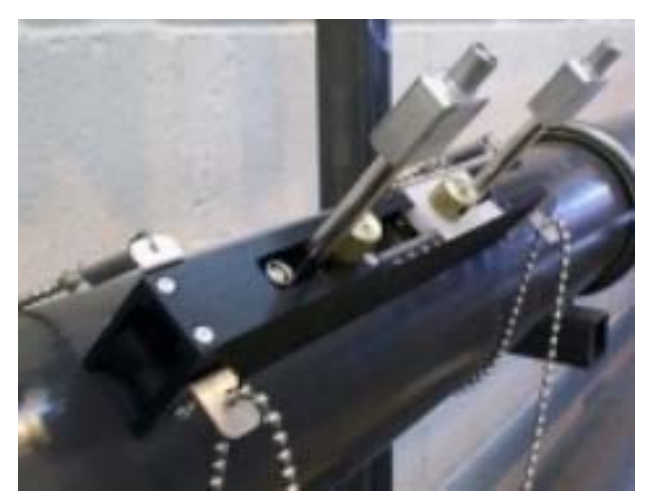

(a)

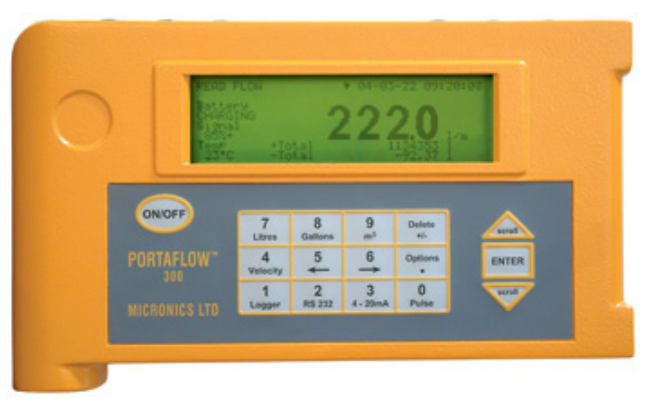

(b)

Figura 4-31 - Medidor de vazão ultrassônico Portaflow 300 da Micronics

Os medidores ultrassônicos usados possuem capacidade para medir vazões em tubos de diâmetros de 50 a $2.500 \mathrm{~mm}$, e velocidades de 0,03 a $25 \mathrm{~m} / \mathrm{s}$. Na Figura 4-32 pode-se visualizar o esquema de medição de vazão, em que o Transdutor A emite o ultrassom, que é refletido pela parede do tubo e é captado pelo Transdutor B. A vazão é calculada pelo medidor de vazão a partir do tempo trânsito das ondas de um transdutor a outro. 


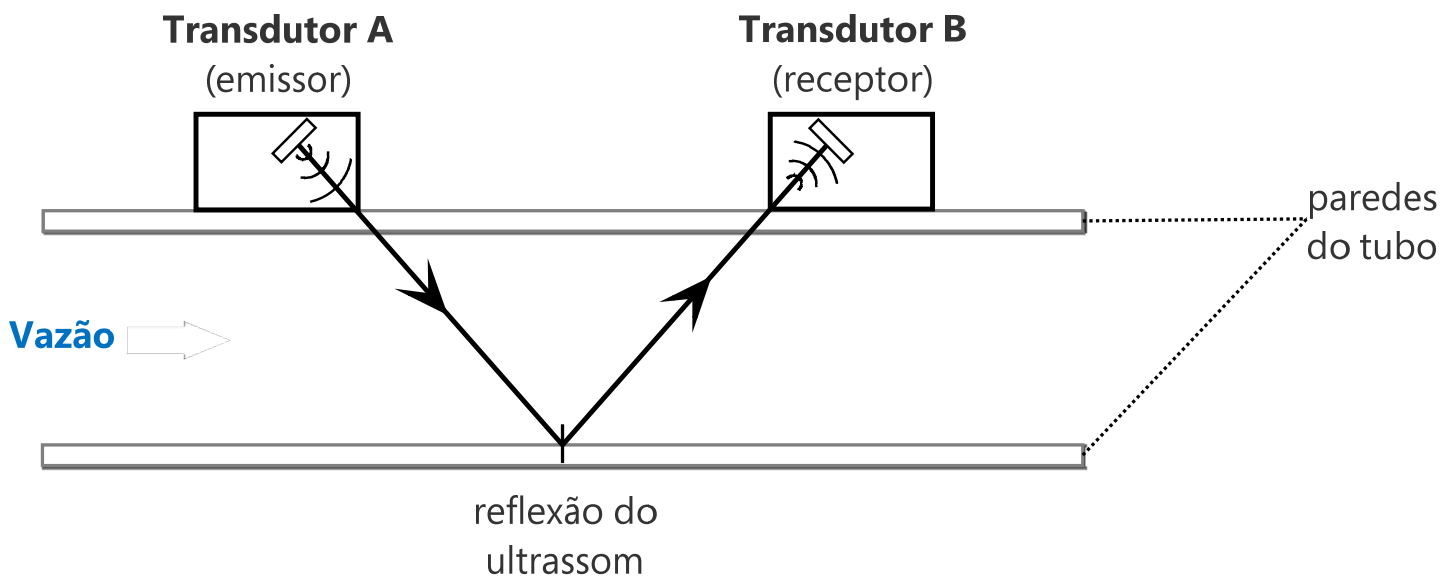

Figura 4-32 - Esquema de medição de vazão por meio de ultrassom

Após a construção dos modelos preliminares e coleta de dados de campo, procedeu-se aos agrupamento dos tubos de acordo com o diâmetro e material (Abe, 2013).

Finalmente realizou-se a calibração das rugosidades dos tubos e o coeficiente de vazamento nodal ("emitter coeficient"), utilizando-se o programa de computador desenvolvido por Abe e Cheung (2009). O programa, de distribuição gratuita, é integrado à interface gráfica do EPANET 2 e utiliza a otimização baseada em Algoritmos Genéticos para minimizar o erro entre as medidas observadas e as produzidas pelo simulador hidráulico em termos de carga de pressão e vazão. A calibração desenvolvida pelos referidos autores tem como objetivo minimizar a função expressa pela Equação (43):

$\operatorname{Min} F O=\sum_{i=1}^{N c}\left(\frac{\Delta P c_{i}}{\frac{\sum_{i=1}^{N c} P c_{i}^{\prime}}{N c}}\right)^{2}+\sum_{j=1}^{M c}\left(\frac{\Delta Q c_{j}}{\frac{\sum_{j=1}^{M c} Q c_{j}^{\prime}}{M c}}\right)$

em que $P c^{\prime}{ }_{i}$ e $Q c^{\prime}{ }_{j}$ são respectivamente o conjunto de valores de carga de pressão e vazão observados; $\Delta P c_{i}$ e $\Delta Q c_{i}$ são respectivamente as diferenças entre os valores simulados e observados de carga de pressão e vazão, $N c$ e $M c$ são respectivamente os números de nós e tubos de monitoramento de carga de pressão e vazão.

Em decorrência da instalação dos medidores de pressão nas residências, nos momentos em que havia consumo nas mesmas observou-se uma grande perturbação nas medidas, pois a vazão consumida gerava uma grande perda de carga devido ao reduzido diâmetro do ramal 
predial. Para minimizar tais perturbações, foram usados os valores de carga de pressão máxima registrados para cada hora.

Apesar de se dispor de 1 semana de dados, a calibração foi efetuada selecionando-se apenas um dia da semana, pois nem todos os dias apresentavam dados utilizáveis devido a diversos fatores que influenciam no abastecimento, tais como desabastecimento, falha no sistema de telemetria etc. Validou-se a calibração utilizando-se outro dia.

Os consumos foram distribuídos alocando-se os consumidores aos nós mais próximos, com base nos valores faturados mensalmente nos hidrômetros, os quais foram posteriormente convertidos de m³/mês para L/s, utilizando-se outra rotina desenvolvida por Abe (2013).

A perda de carga foi calculada utilizando-se a formulação de Hazen-Willians (H-W) (Hazen e William, 1914), pois em testes preliminares não se observou diferença de resultados nas calibrações em relação a formulação de Darcy-Weisbach (Porto, 2006). Apesar das conhecidas limitações de H-W, este possui aplicação mais simples e valores diretamente interpretáveis.

\subsubsection{Modelo Simplificado da rede de estudo}

Utilizou-se neste trabalho um modelo simplificado das redes de estudo como alternativa ao uso da rede completa dos setores de abastecimento. Assim, o processo de otimização pode ser acelerado, já que as simulações hidráulicas despenderão menos tempo computacional.

As representações dos modelos simplificados dos Setores Eliana, Iguatemi e Martinez são ilustrados nas Figuras 4-32, 4-33 e 4-34, respectivamente. Os elementos utilizados nas

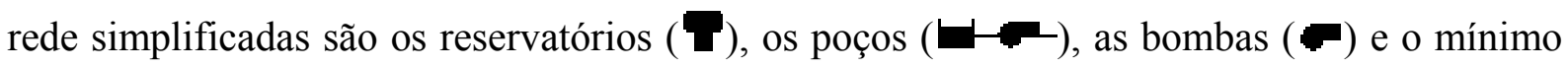
número de tubos $(\bullet \bullet)$. Os consumos foram representados por um único nó $(\bullet)$ na saída dos reservatórios que abastecem os respectivos setores.

Os modelos da rede simplificado também foram anexados no CD no formato ".inp" apra ser utilizado no EPANET 2, com a indicação Simplificado no nome do arquivo. 


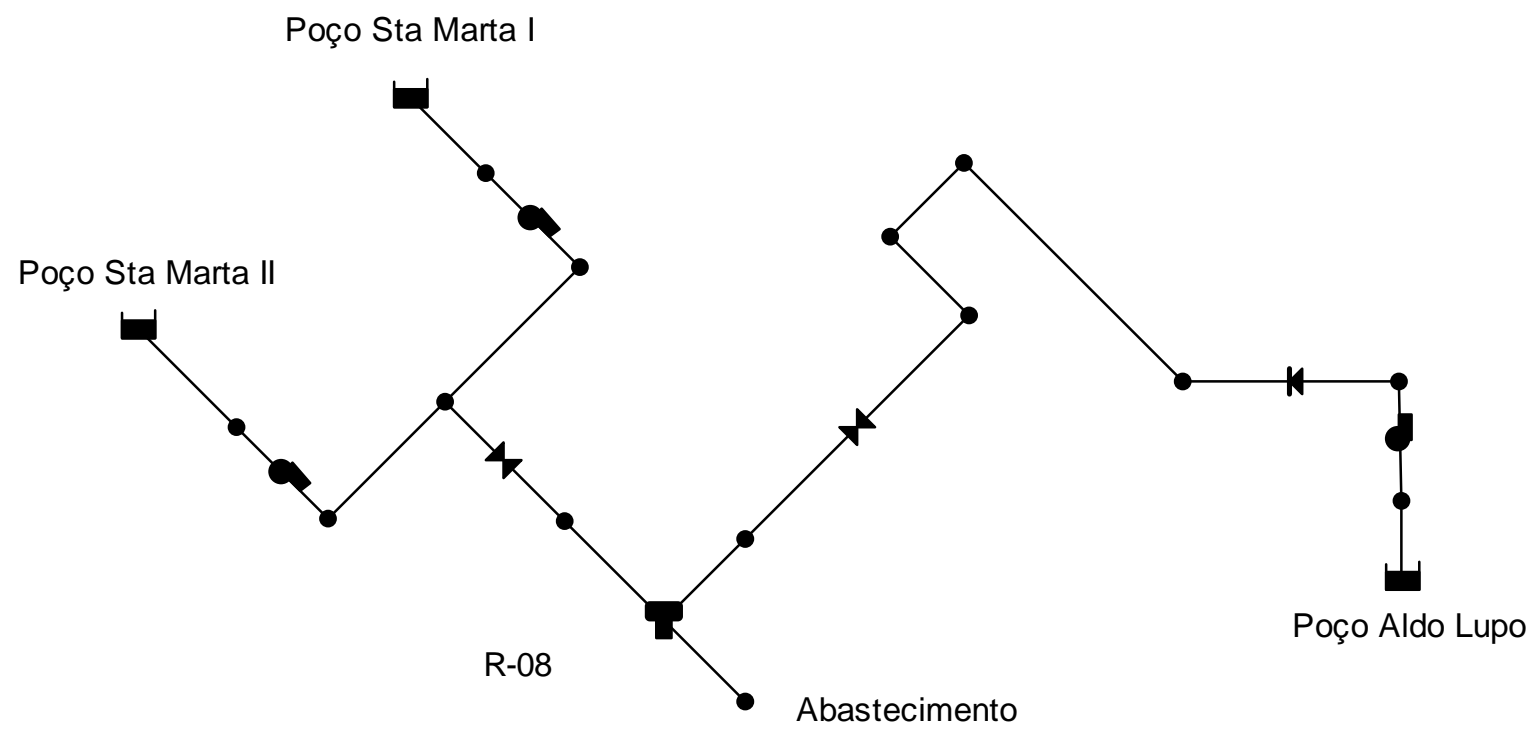

Figura 4-33 - Representação do modelo hidráulico Simplificado do Setor Eliana

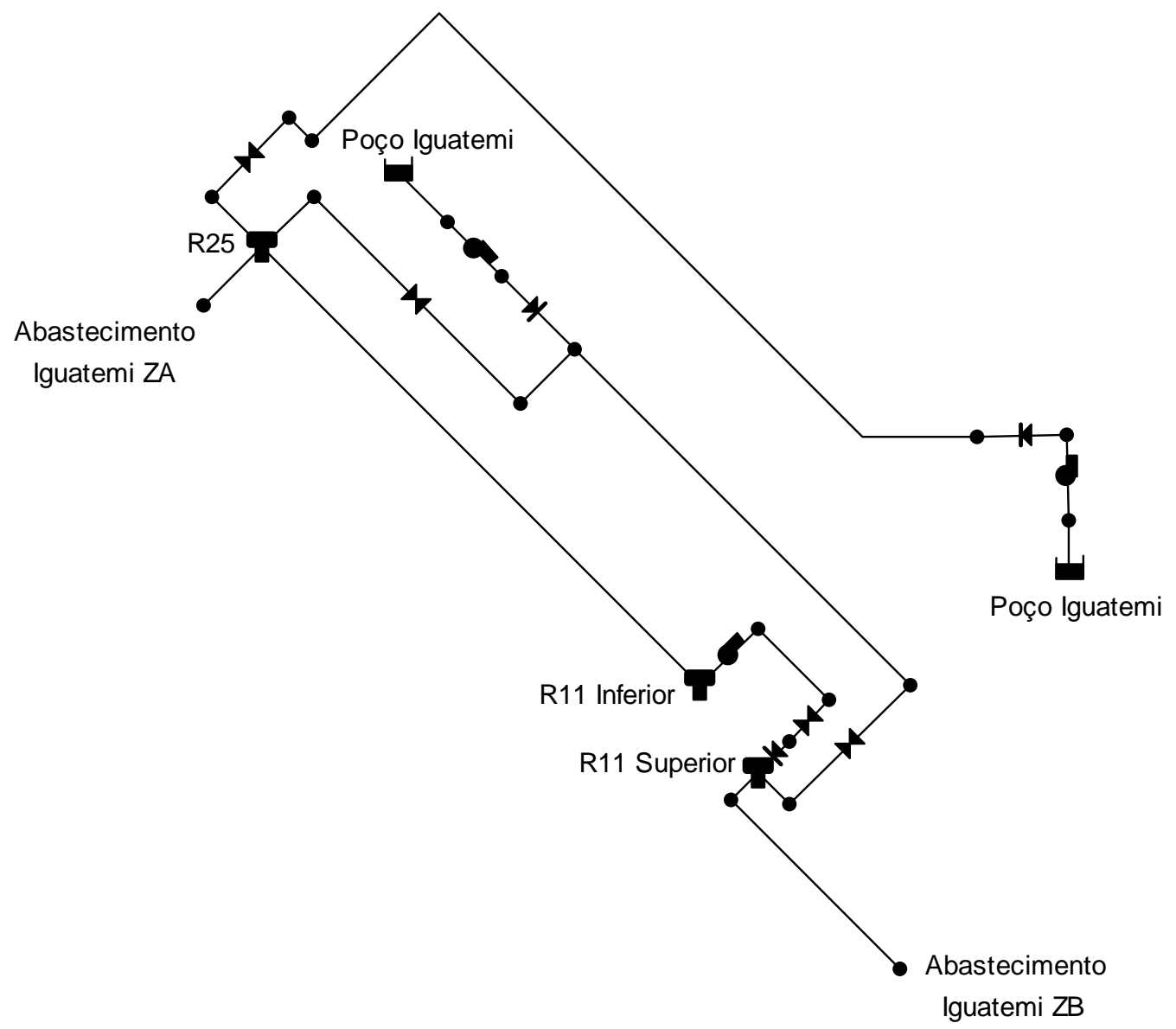

Figura 4-34 - Representação do modelo hidráulico Simplificado do Setor Iguatemi 


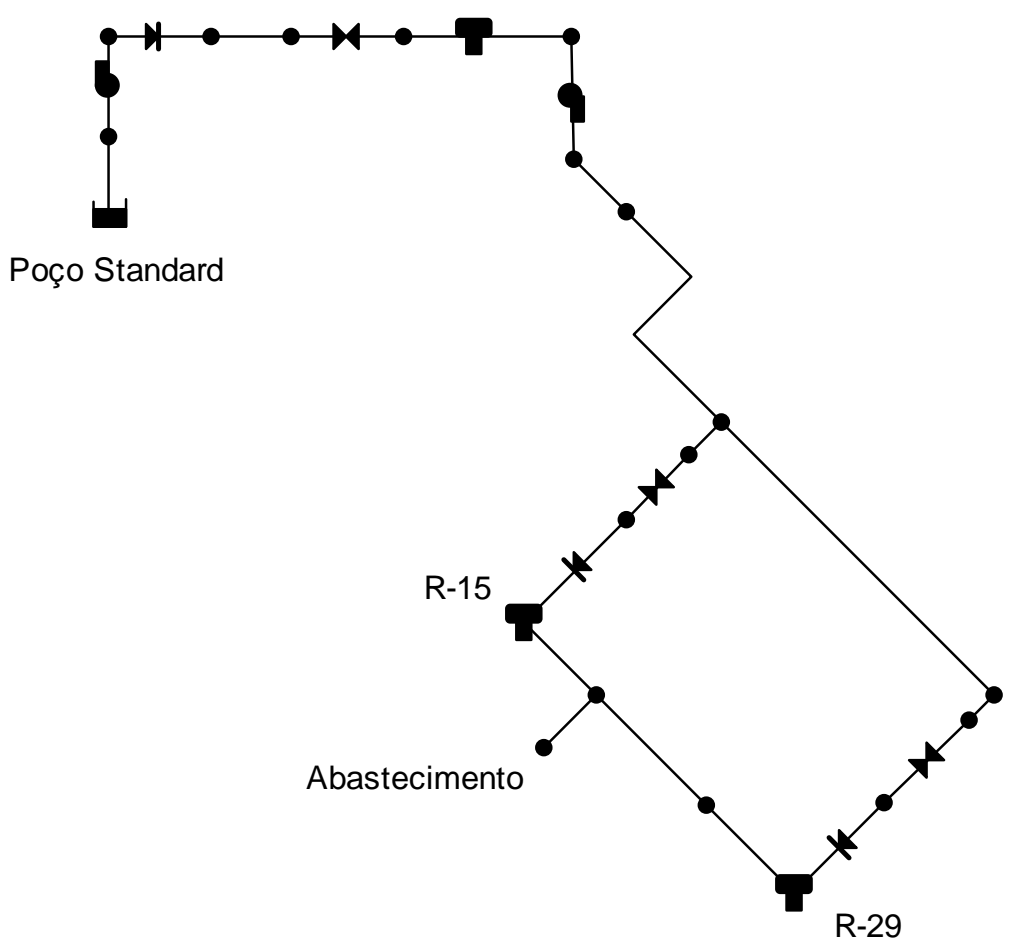

Figura 4-35 - Representação do modelo hidráulico Simplificado do Setor Martinez

\subsection{Critérios de Avaliação}

Nos casos em que foi necessário avaliar o desempenho de algum método, foram utilizados os seguintes critérios de avaliação: "Mean Absolute Error" (MAE), o "Mean Percentage Error" o coeficiente de determinação $\mathrm{R}^{2}$, representados respectivamente pelas Equações (44), (45) e (46).

$$
\begin{aligned}
& M A E=\frac{1}{N v} \sum_{i=1}^{N v}\left|y_{i}-\hat{y}_{i}\right| \\
& M P E=\frac{\sum_{i=1}^{N v}\left|y_{i}-\hat{y_{i}}\right|}{\sum_{i=1}^{N v} y_{i}} \\
& R^{2}=\frac{N v \sum_{i=1}^{N v} y_{i} \hat{y}_{i}-\sum_{i=1}^{N v} y_{i} \cdot \sum_{i=1}^{N v} \hat{y}_{i}}{\sqrt{\left[N v \sum_{i=1}^{N v} y_{i}^{2}-\left(\sum_{i=1}^{N v} y_{i}\right)^{2}\right] \cdot\left[N v \sum_{i=1}^{N v} \hat{y}_{i}^{2}-\left(\sum_{i=1}^{N v} \hat{y}_{i}\right)^{2}\right]}}
\end{aligned}
$$

em que $N v$ é o número de valores analisados, $y_{i}$ e $y_{i}$ são respectivamente o valor produzido pelo modelo e o valor observado. 


\section{Resultados e Discussões}

Nesta seção são apresentados os resultados e discussões obtidos nesta pesquisa.

$\mathrm{Na}$ subseção 5.1 são apresentados os resultados das calibrações dos setores de abastecimento de água Eliana, Iguatemi e Martinez.

Os resultados da previsão de demanda são mostrados na subseção 5.2.

$\mathrm{Na}$ subseção 5.3 são realizados testes preliminares da otimização da operação de objetivo único em redes de abastecimento da literatura, enquanto que na subseção 5.4 analisase o número necessário de avaliações da função objetivo a ser empregado na otimização da operação em tempo real.

Os resultados da otimização da operação em tempo real de objetivo único (minimização do custo) é apresentado na subseção 5.5, ao passo que a otimização multiobjetivo é mostrado na subseção 5.6.

$\mathrm{Na}$ subseção 5.7 são apresentados os resultados preliminares da otimização multiobjetivo da operação em tempo real com aplicação da Abordagem III. Na subseção 5.8 são mostrados os resultados da aplicação das Abordagens II e III.

\subsection{Resultados das Calibrações}

Nesta subseção são apresentados os resultados da calibrações para as redes dos setores Eliana (5.5.1), Iguatemi (5.5.2) e Martinez (5.5.3).

\subsubsection{Setor Eliana}

A campanha de campo para aquisição de dados para Setor Eliana foi realizada entre os dias 4 a 11 de março de 2013, sendo que se utilizaram os dados do dia 11 para realizar o ajuste e a validação do modelo foi realizada com os dados do dia 6.

Atualmente, em alguns períodos do dia, o Setor Eliana abastece o Setor Martinez devido a problemas no Poço Standard, que se encontra desativado. Deste modo, constata-se considerável diferença de vazão na saída do reservatório $\mathrm{R} 8$ em tais períodos, conforme Figura 5-1, em que a linha azul representa a vazão total, e em vermelho a vazão apenas para o Setor Martinez. Nos períodos entre $6 \mathrm{~h} 00$ e 8h00, $11 \mathrm{~h} 00$ e $12 \mathrm{~h} 00$ e das $15 \mathrm{~h} 00$ as $22 \mathrm{~h} 00 \mathrm{o}$ reservatório R8 abastece apenas o próprio setor, com vazões em torno de $30 \mathrm{~L} / \mathrm{s}$, enquanto que ao abastecer simultaneamente ambos os setores, a vazão é de cerca de $80 \mathrm{~L} / \mathrm{s}$, sendo que nesse caso a vazão para o Eliana é de cerca de $10 \mathrm{~L} / \mathrm{s}$. Essa pequena vazão sugere que a demanda do Setor Eliana esteja reprimida. 


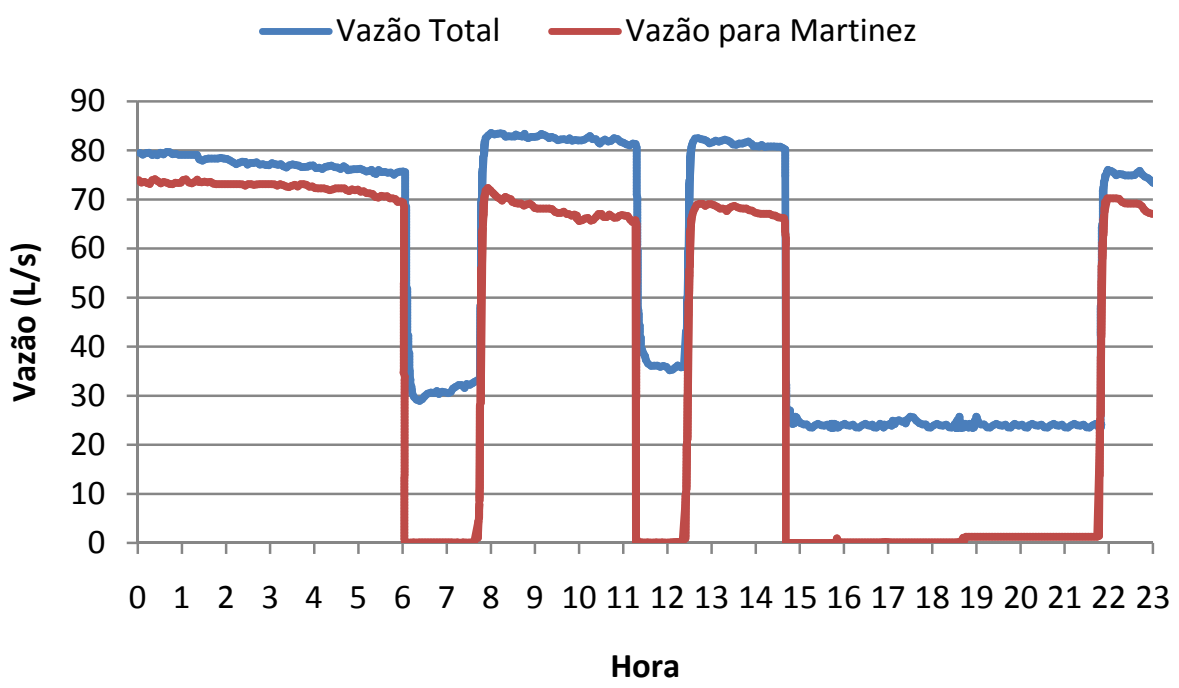

Figura 5-1 - Vazão de saída do reservatório R8 - Setor Eliana

Caso os condutos sejam solicitados por vazões muito baixas, a calibração da rugosidade pode não representar a realidade, pois sob baixas vazões, a rugosidade torna-se menos sensível ao processo de calibração. Por esse motivo, realizou-se a calibração deste setor de duas maneiras: utilizando-se os dados do período de 24h (1), e usando-se apenas os dados do período em que o R8 abastecia o próprio setor (2).

O resumo dos resultados é apresentado na

Tabela 5-1. Foram avaliados o Erro absoluto médio (MAE) e o coeficiente de determinação $\left(\mathrm{R}^{2}\right)$. Em ambas as calibrações, a avaliação do erro foi realizada apenas nos períodos em que o R8 abastecia somente o setor Eliana, e a avaliação do erro do conjunto de validação foi realizada apenas para a calibração (2). Observa-se que a calibração (2) produziu MAE de 2,32 m.c.a, que representa $7,1 \%$ da pressão média observada, e $\mathrm{R}^{2}$ de 0,82 , desempenho superior ao produzido pela calibração (1), com MAE de 3,48 m.c.a., que representa $10,6 \%$ da pressão média observada, e $\mathrm{R}^{3}$ de 0,67 . A pequena vazão que aflui para $\mathrm{o}$ Setor Eliana pode ser um dos motivos da deterioração dos resultados na calibração (1), visto que, conforme esperado, a rugosidade do condutos torna-se menos sensível ao processo de calibração sob pequenas vazões. O MAE para o conjunto de validação foi de 3,92 m.c.a, representando $12 \%$ da pressão média observada e $\mathrm{R}^{2}$ de 0,84 .

Na Tabela 5-2 são apresentados os valores das rugosidades calibradas para os grupos de tubos $^{34}$ do Setor Eliana. Percebe-se que as rugosidades dos grupos de tubos 1, 3, 4 a 9, e 11

\footnotetext{
${ }^{34}$ Os grupos foram determinados conforme explicação do item 4.8
} 
a 12 não condizem com os valores que se espera de seus respectivos materiais. Esperavam-se rugosidades em torno de 90, 100 e 130 para os condutos de ferro fundido, cimento amianto e PVC, respectivamente, considerando-se tubos com idade de 20 anos. Tais resultados se devem, ao problema de vazões baixas, que torna a rugosidade menos sensível à calibração, à instalação de medidores nos ramais dos consumidores, à falta de medidas de vazão na rede, e talvez às limitações do calibrador utilizado. A localização dos tubos pode ser melhor visualizada no arquivo "Eliana.inp" anexado no CD.

Tabela 5-1 - Resumo dos resultados da Calibração para o Setor Eliana

\begin{tabular}{cccccc}
\hline & & \multicolumn{4}{c}{ Critérios de Avaliação } \\
No & $\begin{array}{c}\text { Período de } \\
\text { Calibração }\end{array}$ & \multicolumn{2}{c}{ Calibração } & \multicolumn{2}{c}{ Validação } \\
\cline { 3 - 6 } & MAE & $\mathbf{R}^{\mathbf{2}}$ & $\begin{array}{c}\text { MAE } \\
\text { (m.c.a.) }\end{array}$ & $\mathbf{R}^{\mathbf{2}}$ \\
\hline$(1)$ & $24 \mathrm{~h}$ & 3,48 & 0,67 & - & - \\
$(2)$ & Só com Abastecimento & & & \\
& ao Eliana & 2,32 & 0,82 & 3,92 & 0,84 \\
\hline
\end{tabular}

Tabela 5-2 - Resumo das rugosidades calibradas para os grupos de tubos - Setor Eliana

\begin{tabular}{ccccc}
\hline Grupo & $\begin{array}{c}\text { No de } \\
\text { tubos }\end{array}$ & $\begin{array}{c}\text { Diâmetro } \\
(\mathbf{m m})\end{array}$ & $\begin{array}{c}\text { Rugosidade } \\
\text { Calibrada } \\
\text { H-W }\end{array}$ & Material \\
\hline 1 & 2 & 50 & 146 & Ferro Fundido \\
2 & 2 & 125 & 88 & Ferro Fundido \\
\hline 3 & 3 & 250 & 150 & Ferro Fundido \\
4 & 1 & 350 & 150 & Ferro Fundido \\
\hline 5 & 17 & 150 & 123 & Cimento Amianto \\
6 & 10 & 200 & 150 & Cimento Amianto \\
\hline 7 & 8 & 250 & 150 & Cimento Amianto \\
8 & 162 & 50 & 85 & PVC \\
\hline 9 & 24 & 100 & 85 & PVC \\
10 & 30 & 110 & 133 & PVC \\
\hline 11 & 2 & 125 & 85 & PVC \\
12 & 2 & 150 & 85 & PVC \\
\hline 13 & 1 & 200 & 150 & PVC \\
14 & 8 & 250 & 150 & PVC \\
\hline
\end{tabular}

Na Figura 5-2 pode-se comparar os valores observados de carga de pressão, representados pelos losangos azuis, com a calibração (1), em vermelho, e (2), em verde, para o nó n60 ${ }^{35}$. No caso da calibração (2), foram apresentadas apenas as pressões produzidas pelo calibrador nos

\footnotetext{
${ }^{35}$ O nó n109 foi escolhido por apresentar resultados médios em relação aos demais nós
} 
períodos que o reservatório R8 abastecia apenas o Setor Eliana. Pode-se observar que a calibração (2) produziu melhor desempenho em relação à calibração (1), em conformidade com os resultados da

Tabela 5-1.

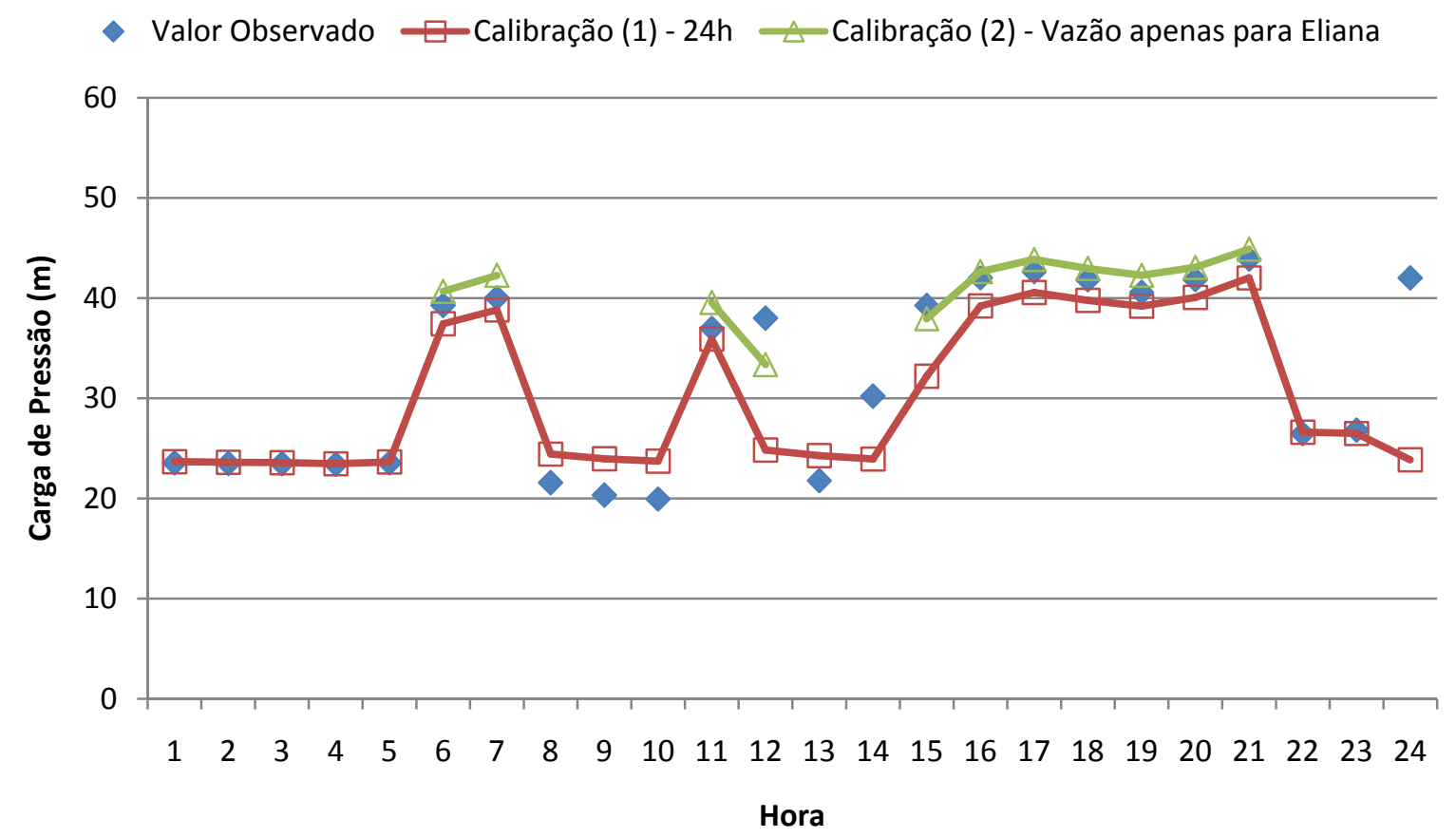

Figura 5-2 - Carga de pressão observada e calibrada para o nó n60 - Setor Eliana

O modelo hidráulico produzido pelo ajuste da Calibração (2) também apresentou bons resultados mesmo para os dados do conjunto de validação, conforme resultados da Tabela 5-1 e do gráfico da Figura 5-3. 


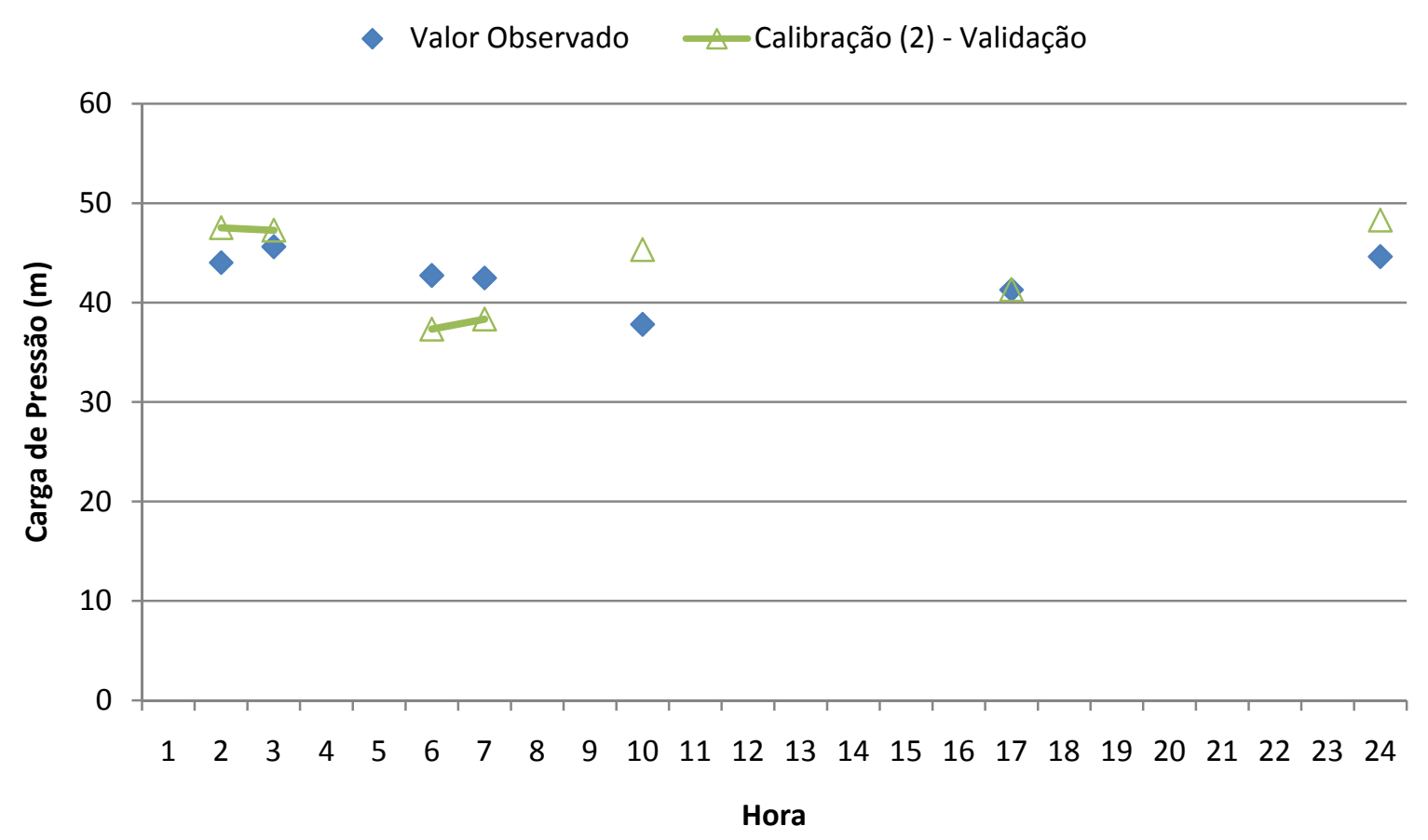

Figura 5-3 - Carga de pressão observada e calibrada para o nó n60 utilizando dados da validação - Setor Eliana

Na Figura 5-4 pode-se observar com mais detalhes os desvios da carga de pressão observada em relação aos respectivos valores calibrados (1) e (2), para os nós monitorados nos períodos em que o reservatório R8 abastecia apenas o Setor Eliana. Em geral, nota-se que a calibração (2) produziu os menores desvios, sendo que no período entre 11 e $12 \mathrm{~h}$ as diferenças entre ambas as calibrações foram mais evidentes.

Neste setor não foi possível utilizar os dados da descarga na rede, pois apesar da confirmação do DAAE que tal ponto de descarga pertencia ao Setor Eliana, não se observou mudança da vazão na saída do reservatório R8 durante a descarga. Antes da descarga, a vazão registrada era de cerca de $18 \mathrm{~L} / \mathrm{s}$, o qual permaneceu inalterado mesmo com uma descarga da ordem de $11 \mathrm{~L} / \mathrm{s}$. Por conseguinte, tal ponto de descarga não pertencia ao setor e tais dados doram descartados. 


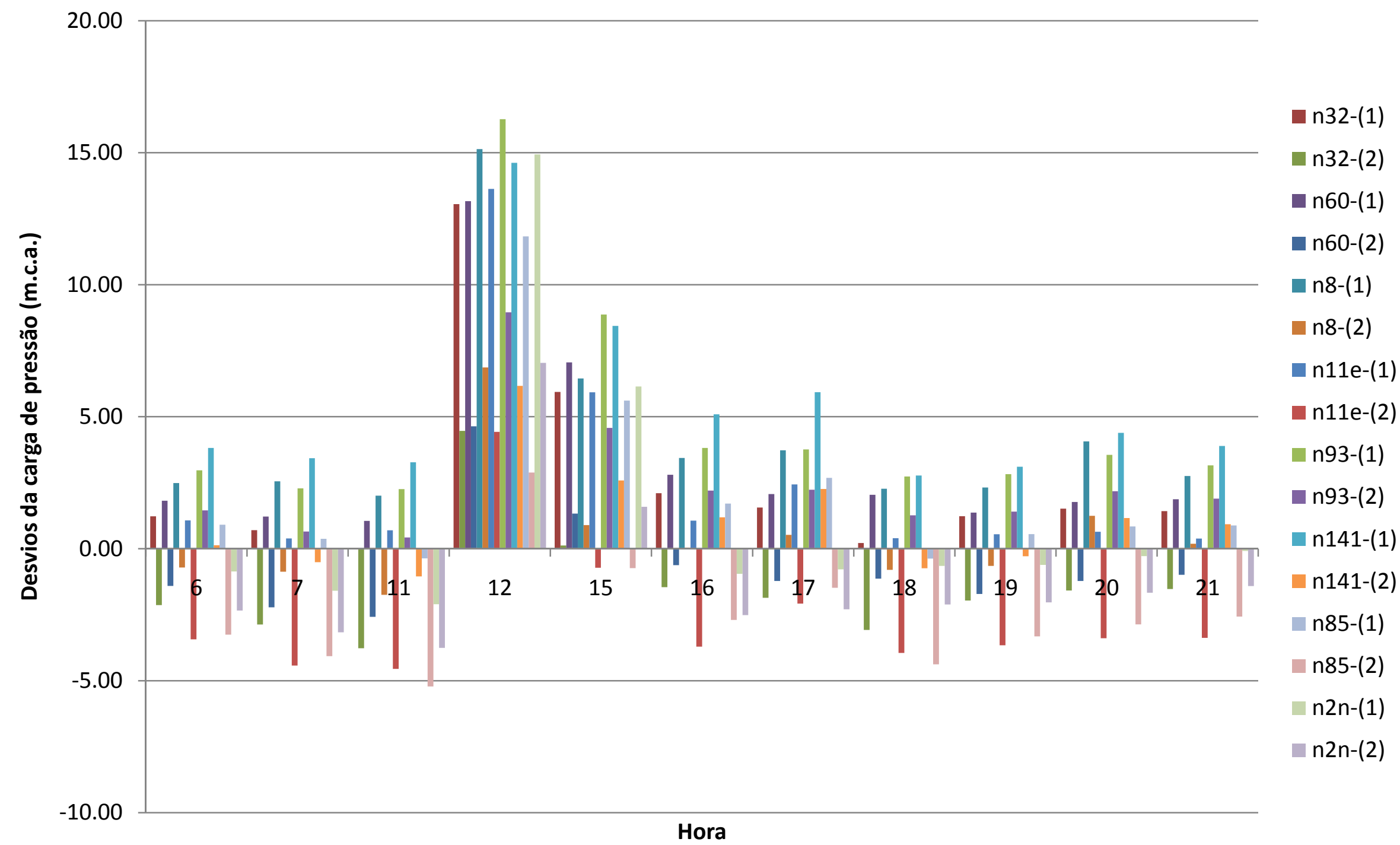

Figura 5-4 - Desvios da carga de pressão entre valor observado e os respectivos valores obtidos nas calibrações (1) e (2) - Setor Eliana 


\subsubsection{Setor Martinez}

A campanha de campo para aquisição de dados para Setor Martinez foi realizada entre os dias 25 de fevereiro a 4 de março de 2013. Mas o ajuste do modelo hidráulico foi possível utilizando-se apenas os dados da descarga realizada no dia 4 de março, pois nos demais períodos não havia registro de vazão devido a um problema do macromedidor na saída dos reservatórios R15 e R29. Por esse motivo não foi possível realizar validação por falta de dados.

Durante a análise dos dados para realizar a calibração, constatou-se que a soma das demandas nodais multiplicada pelo fator de consumo durante a descarga ultrapassava a vazão na saída do reservatório. Foram então analisados os consumidores das diversas faixas de consumo, e dividiram-se os consumidores em dois grupos: pequenos consumidores, que demandam menos que um determinado limite; e grandes consumidores, o restante. Estudaram-se dois limites, de 25 e $30 \mathrm{~m}^{3} / \mathrm{mês}$, sendo que durante a madrugada, considerou-se apenas a demanda dos grandes consumidores. O ideal seria obter os dados de consumo desses grandes consumidores ao longo do dia, mas não se dispunha de recursos para tanto.

Na Tabela 5-3 apresentam-se os resultados das calibrações. A calibração (2) produziu melhor desempenho, com MAE de 1,15 m.c.a., que representa 2,8\% da pressão média observada, e $\mathrm{R}^{2}$ de 0,98 , enquanto que a calibração (1) produziu MAE de 1,35 m.c.a., que representa $3,3 \%$ da pressão média observada, e $\mathrm{R}^{2}$ de 0,98 .

Tabela 5-3 - Resumo dos resultados da Calibração para o Setor Martinez

\begin{tabular}{cccc}
\hline \multirow{2}{*}{ No } & \multirow{2}{*}{ Tipo de Calibração } & \multicolumn{2}{c}{ Critério de } \\
\cline { 3 - 4 } & & Avaliação \\
\cline { 3 - 4 } & & MAE & $\mathbf{R}^{\mathbf{2}}$ \\
\hline (1) & Demanda $>25 \mathrm{~m}^{3} / \mathrm{mês}$ & 1,35 & 0,94 \\
(2) & Demanda $>30 \mathrm{~m}^{3} / \mathrm{mês}$ & 1,15 & 0,98 \\
\hline
\end{tabular}

Na Figura 5-5 observa-se diferença de cerca de 1 m.c.a entre a calibração (1) e (2) para o ponto de monitoramento $\mathrm{n} 296^{36}$. Como fora utilizado dados coletados durante a descarga, dispunha-se apenas de uma hora de dados discretizados em intervalos de 5 minutos, totalizando 12 intervalos.

\footnotetext{
${ }^{36}$ O nó n296 foi escolhido por apresentar resultados médios em relação aos demais nós.
} 


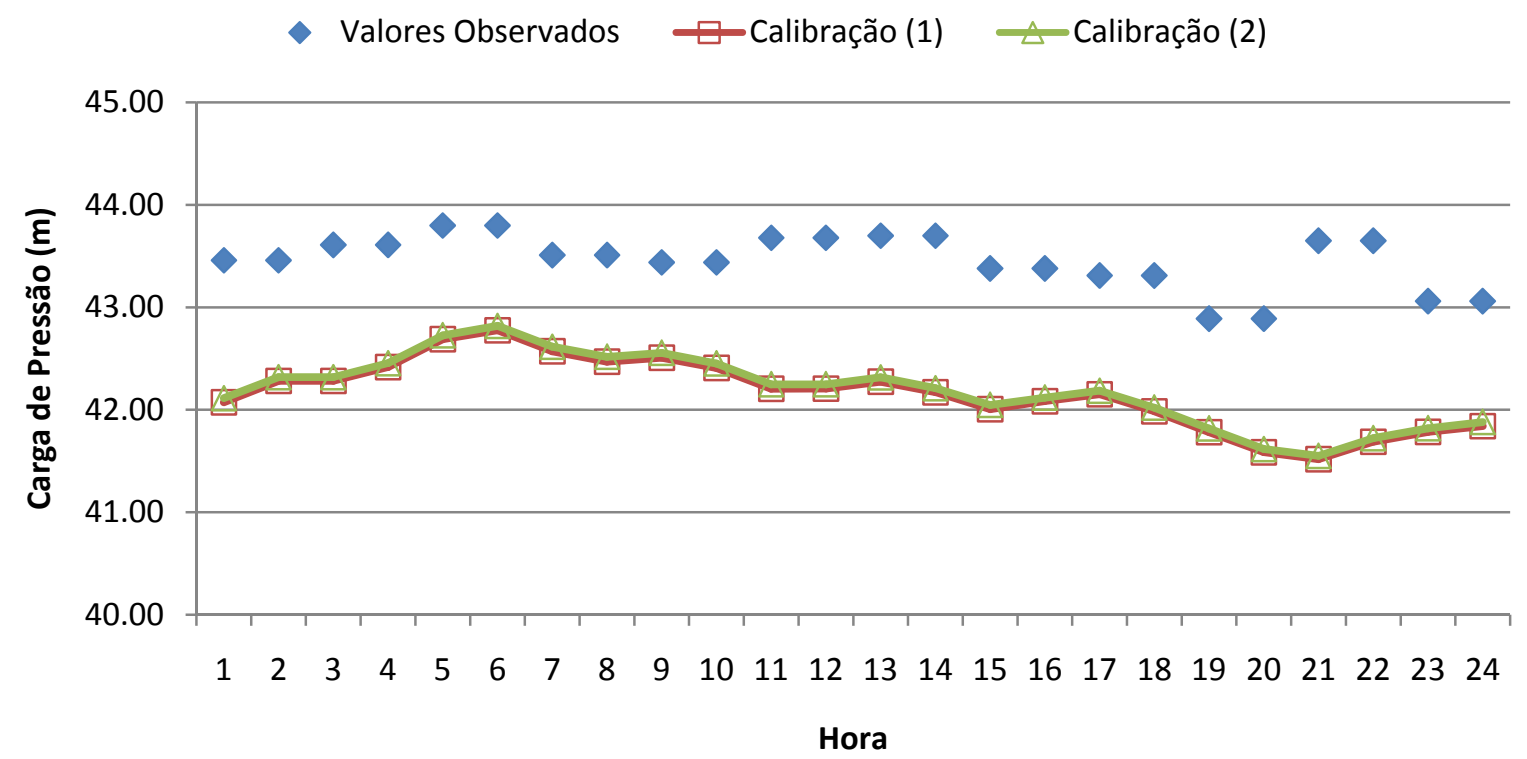

Figura 5-5 - Carga de pressão observada e calibrada para o nó n296 - Setor Martinez

Na Tabela 5-4 são apresentados os resumos das rugosidades produzidas pela calibração (2) do setor Martinez. Observa-se que as rugosidades calibradas para os materiais ferro fundido e cimento amianto estão mais condizentes com os valores esperados ${ }^{37}$, com exceção de condutos dos grupos 5 e 7, que foram calibradas com rugosidades acima do esperado. No caso das rugosidades dos tubos de PVC, foram produzidos valores muito abaixo dos esperados para as rugosidade, com exceção do grupo 20. Acredita-se que tais valores abaixo das rugosidades esperadas se devem à distribuição das demandas nodais, as quais necessitariam ser calibradas também, pois a magnitude e distribuição das demandas possuem grande influência sobre o fluxo de água nos condutos, e consequentemente sobre a calibração. A localização dos tubos pode ser melhor visualizada no arquivo "Martinez.inp" anexado no CD.

Na Figura 5-6 são comparados os desvios entre as calibrações (1) e (2), para os períodos de 4 a $5 \mathrm{~h}$, os quais não apresentaram grandes diferenças entre si, conforme observado também na avaliação de desempenho que consta na Tabela 5-3. Neste setor, foram utilizados dados de apenas sete pontos de monitoramento, pois constatou-se que um dos pontos monitorados durante a campanha de campo para o Setor Martinez pertencia ao Setor Eliana, pois o comportamento da carga de pressão no ponto apresentou comportamento totalmente atípico quando comparado com os demais pontos monitorados. Com exceção dos

\footnotetext{
${ }^{37}$ Conforme observações no item 5.1.1, página 131
} 
pontos n296 e n405, as cargas de pressão calibradas nos demais pontos foram maiores que os valores observados, sendo que o maior desvio foi observado no ponto $\mathrm{n} 102$.

Tabela 5-4 - Resumo das rugosidades calibradas para os grupos de tubos - Setor Martinez

\begin{tabular}{ccccc}
\hline Grupo & $\begin{array}{c}\text { No de } \\
\text { tubos }\end{array}$ & $\begin{array}{c}\text { Diâmetro } \\
(\mathbf{m m})\end{array}$ & $\begin{array}{c}\text { Rugosidade } \\
\text { Calibrada } \\
\text { H-W }\end{array}$ & Material \\
\hline 1 & 21 & 50 & 85 & Ferro Fundido \\
2 & 7 & 150 & 85 & Ferro Fundido \\
\hline 3 & 1 & 200 & 103 & Ferro Fundido \\
4 & 12 & 250 & 85 & Ferro Fundido \\
\hline 5 & 1 & 300 & 133 & Ferro Fundido \\
6 & 5 & 400 & 85 & Ferro Fundido \\
\hline 7 & 21 & 100 & 150 & Cimento Amianto \\
8 & 25 & 150 & 85 & Cimento Amianto \\
\hline 9 & 8 & 200 & 119 & Cimento Amianto \\
10 & 19 & 250 & 85 & Cimento Amianto \\
\hline 11 & 1 & 300 & 85 & Cimento Amianto \\
12 & 733 & 50 & 85 & PVC \\
\hline 13 & 4 & 75 & 111 & PVC \\
14 & 71 & 100 & 85 & PVC \\
\hline 15 & 48 & 110 & 85 & PVC \\
16 & 11 & 125 & 85 & PVC \\
\hline 17 & 19 & 150 & 85 & PVC \\
18 & 9 & 200 & 85 & PVC \\
\hline 19 & 37 & 250 & 85 & PVC \\
20 & 6 & 300 & 150 & PVC \\
\hline
\end{tabular}




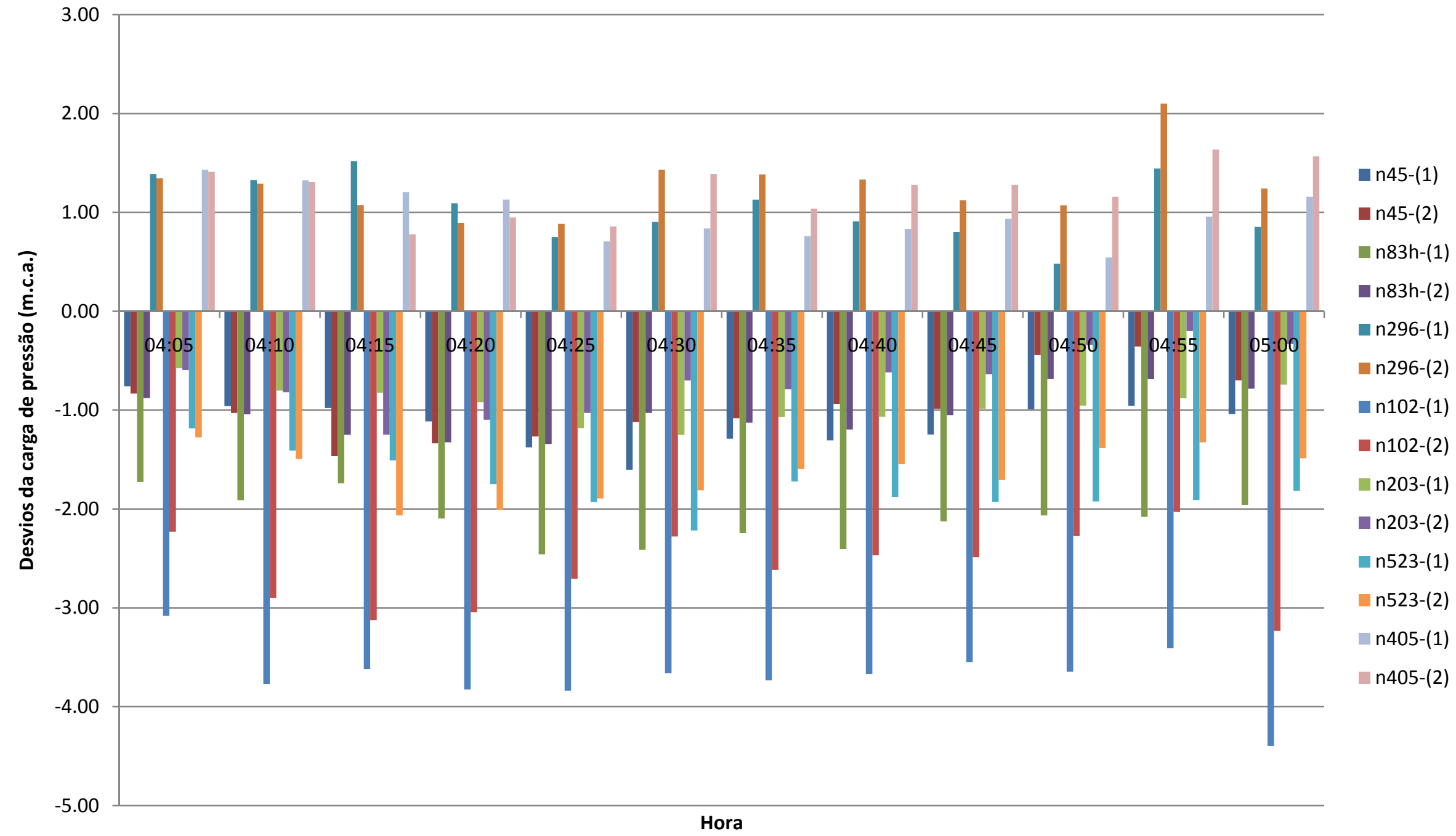

Figura 5-6 - Desvios da carga de pressão entre valor observado e os respectivos valores obtidos nas calibrações (1) e (2) para o período entre 4 e $5 \mathrm{~h}$ - Setor Martinez 


\subsubsection{Setor Iguatemi}

O Setor Iguatemi foi calibrado dividindo-se o setor em Zona Alta e Baixa, pois cada qual possui seu próprio reservatório e vazão macromedida, e com isso pode-se realizar a calibração com mais detalhamento e facilidade.

A campanha de campo para aquisição de dados para a Zona Baixa foi realizada entre os dias 18 a 25 de fevereiro de 2013, sendo que se utilizaram os dados do dia 20 para realizar o ajuste e a validação do modelo foi realizada com os dados do dia 21. No subsetor Zona Alta, realizou-se a campanha entre os dias 18 a 25 de março do mesmo ano, sendo que o ajuste foi realizado com os dados do dia 20 e a validação com os dados do dia 19.

Assim como no Setor Martinez, realizou-se a calibração dividindo-se os consumidores em diferentes faixas de consumo, de acordo com o limite de consumo: 10, 15 e $20 \mathrm{~m}^{3} / \mathrm{mês}$, e também sem divisão dos consumidores. Os consumidores abaixo de cada limite de consumo foram classificados como pequenos consumidores, e determinou-se que tais consumidores não utilizam água durante a madrugada (00h00-6h00), enquanto que o restante foram classificados como grandes consumidores que utilizam água durante o dia todo. Tal divisão dos consumidores foi realizada a fim de verificar se haveria diferença de desempenho entre essas calibrações.

Na calibração do subsetor Zona Alta não houve grande diferença de desempenho utilizando-se a divisão dos consumidores, conforme resultados das Tabela 5-5 (Zona Alta), que também pode ser observado nas comparações entre as cargas de pressão observadas e as produzidas pelas calibrações de (1) a (4) na Figura 5-7, para o nó n109 ${ }^{38}$. Na referida tabela, constata-se que o melhor desempenho foi produzido pela calibração (4), com MAE de 1,41 e 1,39 m.c.a, respectivamente para a calibração e o conjunto de validação, e $\mathrm{R}^{2}$ de 0,98 para ambos os conjuntos de dados. Mas como os resultados são muito próximos, por questão de simplicidade, utilizou-se a calibração (1), sem a divisão dos consumidores.

As calibrações ( 1 a 4 ) das rugosidades dos condutos do subsetor Zona Baixa apresentaram diferenças de desempenho ligeiramente maiores, conforme resumido na Tabela 5-6, sendo que a calibração (1), sem a divisão dos consumidores em faixas de consumo, produziu melhores resultados com MAE de 2,68 e 3,13 m.c.a, respectivamente para a calibração e o conjunto de validação, e $\mathrm{R}^{2}$ de 0,99 para ambos os conjuntos de dados. Tais

\footnotetext{
${ }^{38}$ O nó n109 foi escolhido por apresentar resultados médios em relação aos demais nós.
} 
desempenhos podem ser visualizados na Figura 5-8, para o nó n $404^{39}$, em que a calibração (1), em vermelho, demonstra a melhor performance, sendo que os resultados obtidos na calibração 1 foram utilizados na otimização.

Tabela 5-5 - Resumo dos resultados da Calibração para o Setor Iguatemi - Zona Alta

\begin{tabular}{cccccc}
\hline & & \multicolumn{4}{c}{ Critério de Avaliação } \\
No & Tipo de Calibração & \multicolumn{2}{c}{ Calibração } & \multicolumn{2}{c}{ Validação } \\
\cline { 3 - 6 } & & MAE & $\mathbf{R}^{2}$ & MAE & $\mathbf{R}^{2}$ \\
& (m.c.a.) & & (m.c.a.) & $\mathbf{R}^{2}$ \\
\hline (1) & Todos consumidores & 1.07 & 0.98 & 1.48 & 0.98 \\
(2) & Demanda $>10 \mathrm{~m}^{3} / \mathrm{mês}$ & 1.10 & 0.97 & 1.48 & 0.97 \\
(3) & Demanda $>15 \mathrm{~m}^{3} / \mathrm{mês}$ & 1.09 & 0.98 & 1.46 & 0.98 \\
(4) & Demanda $>20 \mathrm{~m}^{3} / \mathrm{mês}$ & 1.06 & 0.98 & 1.39 & 0.98 \\
\hline
\end{tabular}

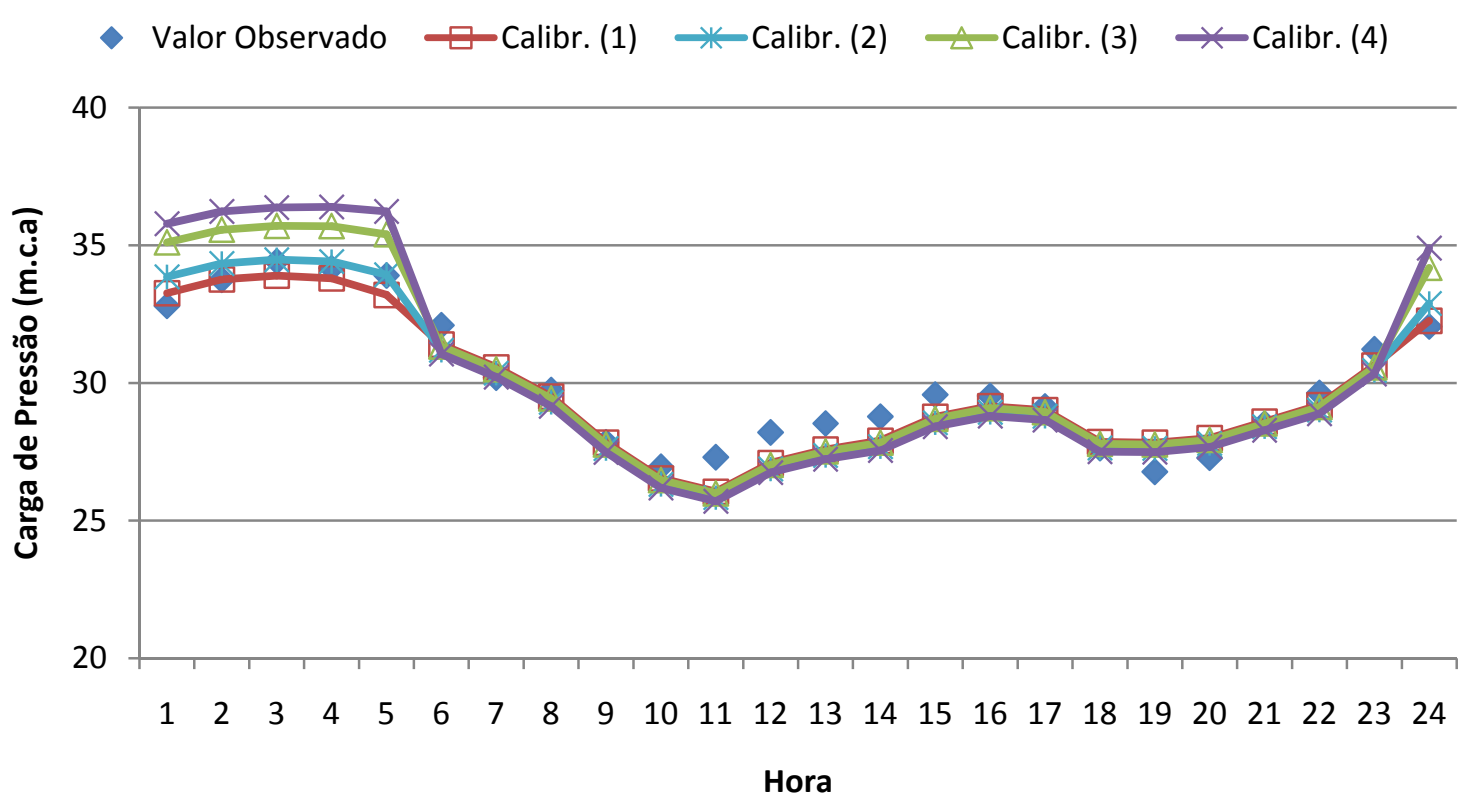

Figura 5-7 - Gráfico da Calibração do Setor Iguatemi n109 - Zona Alta

\footnotetext{
${ }^{39} \mathrm{O}$ nó $\mathrm{n} 404$ foi escolhido por apresentar resultados médios em relação aos demais nós
} 
Tabela 5-6 - Resumo dos resultados da Calibração para o Setor Iguatemi - Zona Baixa

\begin{tabular}{cccccc}
\hline & & \multicolumn{4}{c}{ Critério de Avaliação } \\
No & Tipo de Calibração & \multicolumn{2}{c}{ Calibração } & \multicolumn{2}{c}{ Validação } \\
\cline { 3 - 6 } & & $\begin{array}{c}\text { MAE } \\
\text { (m.c.a.) }\end{array}$ & $\mathbf{R}^{\mathbf{2}}$ & $\begin{array}{c}\text { MAE } \\
\text { (m.c.a.) }\end{array}$ & $\mathbf{R}^{\mathbf{2}}$ \\
\hline (1) & Todos consumidores & 1.53 & 0.99 & 3.13 & 0.99 \\
(2) & Demanda $>10 \mathrm{~m}^{3} / \mathrm{mês}$ & 1.58 & 0.99 & 3.12 & 0.99 \\
(3) & Demanda $>15 \mathrm{~m}^{3} / \mathrm{mês}$ & 1.93 & 0.99 & 3.09 & 0.99 \\
(4) & Demanda $>20 \mathrm{~m}^{3} / \mathrm{mês}$ & 2.11 & 0.99 & 3.21 & 0.99 \\
\hline
\end{tabular}

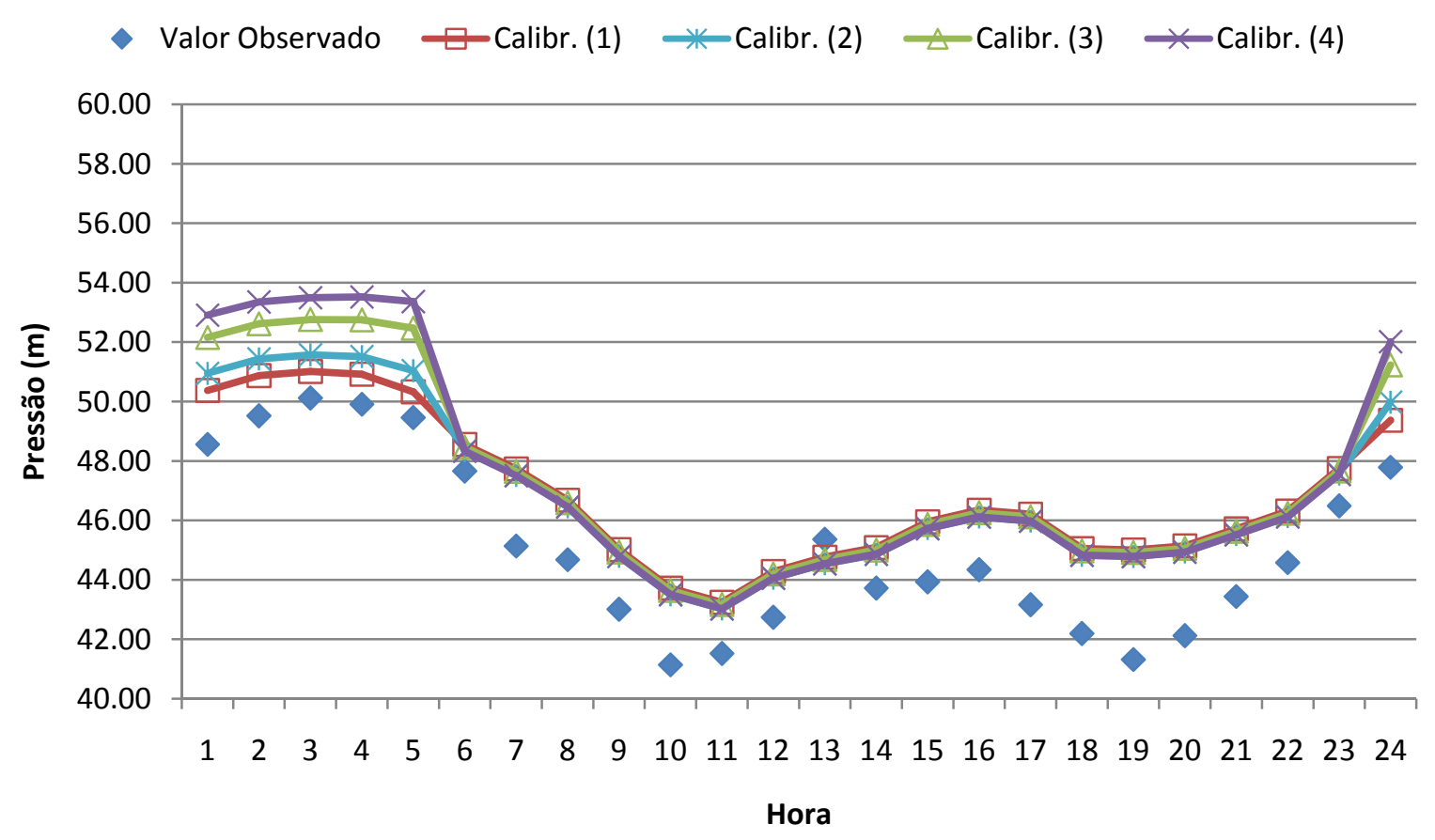

Figura 5-8 - Gráfico da Calibração do Setor Iguatemi para o nó n404 - Zona Baixa

Na Tabela 5-7 são resumidas as rugosidades calibradas para os diferentes grupos de condutos para o subsetor Zona Alta. As rugosidades para os materiais ferro fundido e cimento amianto, com exceção do grupo 2, apresentaram valores acima dos esperados ${ }^{40}$, e no caso do PVC, valores abaixo das rugosidades esperadas, com exceção dos grupos 11 e 13. A localização dos tubos pode ser melhor visualizada no arquivo "Iguatemi.inp" anexado no CD.

\footnotetext{
${ }^{40}$ Conforme observações no item 5.1.1, página 131
} 
Tabela 5-7 - Resumo das rugosidades calibradas para os grupos de tubos

Setor Iguatemi - Zona Alta

\begin{tabular}{ccccc}
\hline Grupo & $\begin{array}{c}\text { No de } \\
\text { tubos }\end{array}$ & $\begin{array}{c}\text { Diâmetro } \\
\text { (mm) }\end{array}$ & $\begin{array}{c}\text { Rugosidade } \\
\text { Calibrada } \\
\text { H-W }\end{array}$ & Material \\
\hline 1 & 9 & 200 & 150 & Ferro Fundido \\
2 & 35 & 200 & 85 & Ferro Fundido \\
\hline 3 & 1 & 300 & 144 & Ferro Fundido \\
4 & 49 & 100 & 150 & Cimento Amianto \\
\hline 5 & 3 & 125 & 150 & Cimento Amianto \\
6 & 5 & 150 & 149 & Cimento Amianto \\
\hline 7 & 4 & 200 & 150 & Cimento Amianto \\
8 & 1 & 100 & 117 & Cimento Amianto \\
\hline 9 & 310 & 50 & 85 & PVC \\
10 & 42 & 100 & 85 & PVC \\
\hline 11 & 27 & 110 & 141 & PVC \\
12 & 27 & 150 & 85 & PVC \\
\hline 13 & 8 & 200 & 149 & PVC \\
\hline
\end{tabular}

Na Tabela 5-8 são resumidas as rugosidades calibradas para os diferentes grupos de condutos para o subsetor Zona Baixa. As rugosidades para os materiais ferro fundido e cimento amianto dos grupos 1 a 4 apresentaram valores acima dos valores esperados ${ }^{41}$, e no caso do PVC, valores abaixo das rugosidades esperadas.

Tabela 5-8 - Resumo das rugosidades calibradas para os grupos de tubos

Setor Iguatemi - Zona Baixa

\begin{tabular}{ccccc}
\hline Grupo & $\begin{array}{c}\text { No de } \\
\text { tubos }\end{array}$ & $\begin{array}{c}\text { Diâmetro } \\
\text { (mm) }\end{array}$ & $\begin{array}{c}\text { Rugosidade } \\
\text { Calibrada } \\
\text { H-W }\end{array}$ & Material \\
\hline 1 & 1 & 50 & 117 & Ferro Fundido \\
2 & 2 & 75 & 120 & Ferro Fundido \\
3 & 19 & 100 & 150 & Cimento Amianto \\
4 & 7 & 125 & 150 & Cimento Amianto \\
5 & 10 & 150 & 91 & Cimento Amianto \\
6 & 18 & 200 & 85 & Cimento Amianto \\
7 & 30 & 250 & 85 & Cimento Amianto \\
8 & 612 & 50 & 85 & PVC \\
9 & 119 & 100 & 85 & PVC \\
10 & 50 & 110 & 112 & PVC \\
11 & 30 & 150 & 85 & PVC \\
12 & 36 & 200 & 85 & PVC \\
13 & 1 & 250 & 86 & PVC \\
\hline
\end{tabular}

${ }^{41}$ Conforme observações no item 5.1.1, página 131 
Na Figura 5-9 observa-se que os desvios da carga de pressão do subsetor Zona Alta não permaneceram constantes ao longo das horas do dia, como ocorreu com os Setores Eliana (Figura 5-4) e Martinez (Figura 5-6). Percebe-se que tal fato também é verificado em relação aos desvios produzidos pelo subsetor Zona Baixa. Atribui-se tal comportamento ao fato que ambos subsetores possuem consumidores heterogêneos (residencial, comercial e industrial) com perfis de consumo distintos. Desta forma, um único padrão de demanda não reflete os diferentes perfis de consumo, causando distorções na distribuição de demanda e alteração no arranjo do fluxo de água na rede, que, consequentemente, interfere na calibração das rugosidades. 


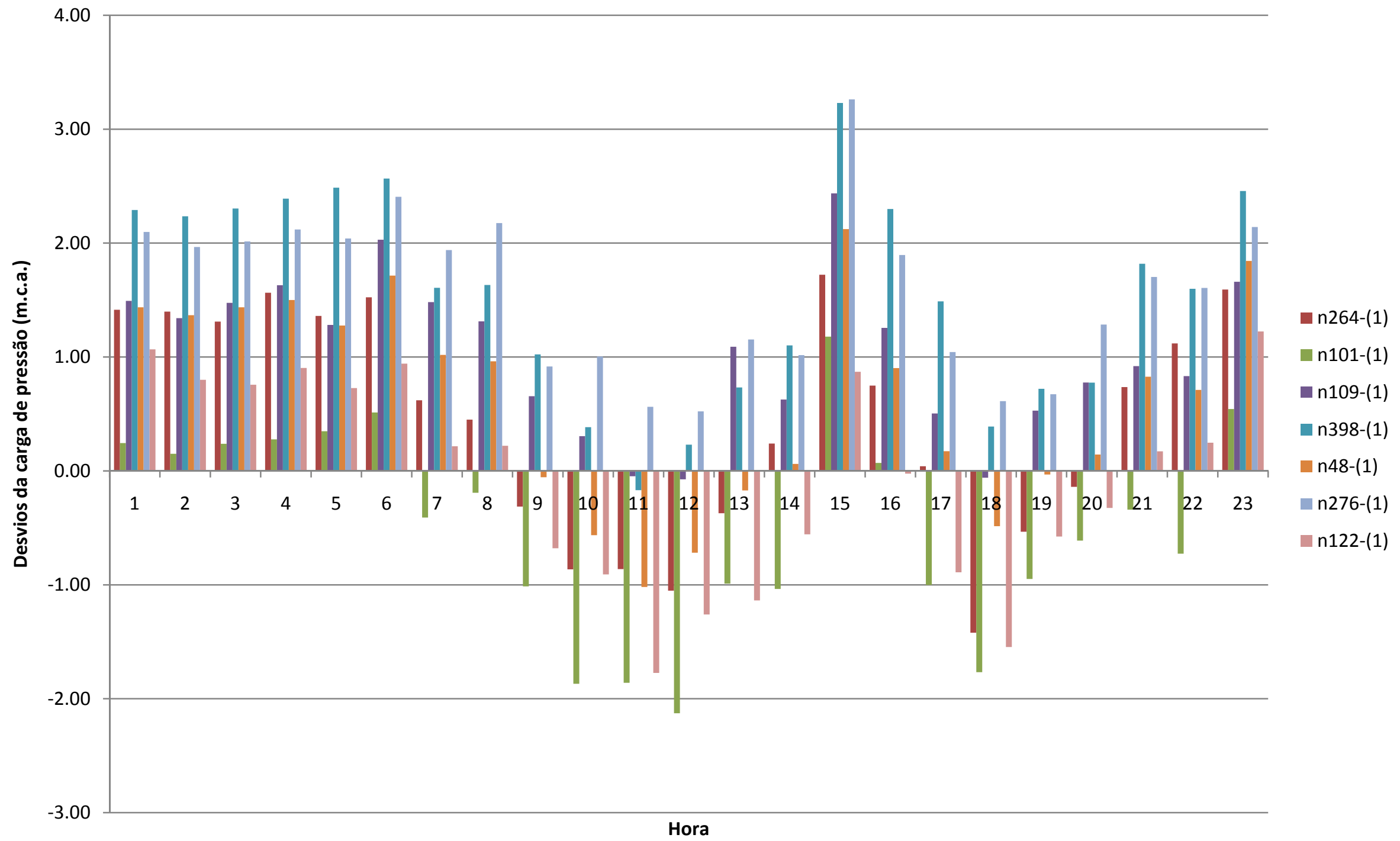

Figura 5-9 - Desvios da carga de pressão entre valor observado e a calibração (1) para o período entre 1 e 24h - Setor Iguatemi, Zona Alta 


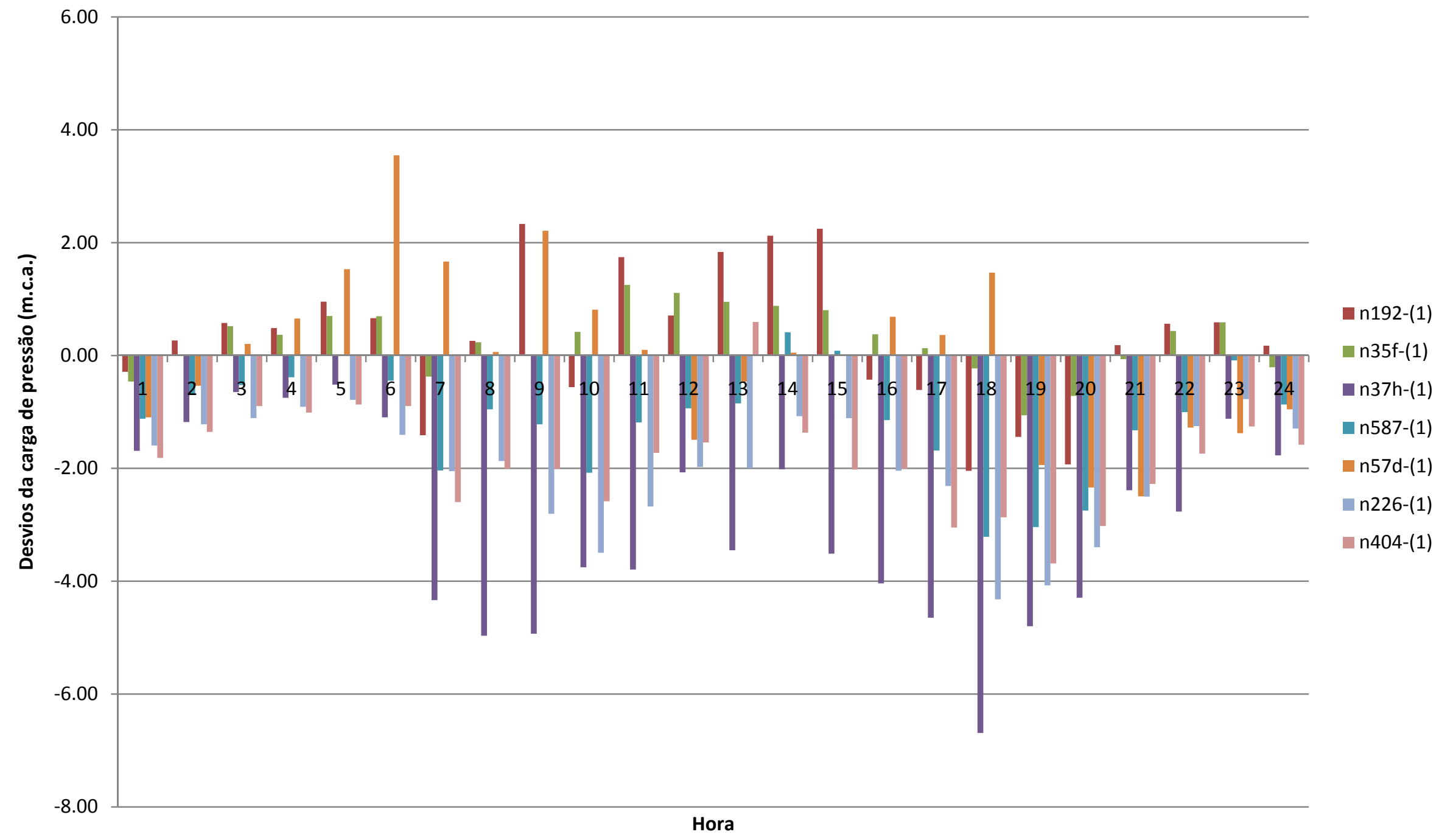

Figura 5-10 - Desvios da carga de pressão entre valor observado e a calibração (1) para o período entre 1 e 24h - Setor Iguatemi, Zona Baixa 


\subsubsection{Metamodelo da rede de estudo}

Foram reproduzidos no metamodelo do Setor Eliana a energia consumida pelas bombas dos Poços Santa Marta I e II, o nível do reservatório R8 e a carga de pressão do nó n29d. O desempenho médio do metamodelo em termos de $\mathrm{R}^{2}$ e MPE, conforme Tabela 5-9, foi respectivamente de 1,00 e $0,78 \%$

Tabela 5-9 - Resumo das avaliações dos resultados para o metamodelo do Setor Eliana

\begin{tabular}{lccc}
\hline \multicolumn{1}{c}{ Variável } & $\mathbf{R}^{\mathbf{2}}$ & MAE & $\begin{array}{c}\text { MPE } \\
\text { (\%) }\end{array}$ \\
\hline Cons. Energia Bomba P. Sta. Marta I & 1.00 & $0.014 \mathrm{kWh}$ & 0.22 \\
Cons. Energia Bomba P. Sta. Marta I & 1.00 & $0.009 \mathrm{kWh}$ & 0.14 \\
Nível R8 & 0.99 & $0.114 \mathrm{~m}$ & 2.39 \\
Pressão nó n29d & 0.99 & 0.124 m.c.a. & 0.37 \\
\hline \multicolumn{1}{c}{ Média } & 1.00 & - & 0.78
\end{tabular}

Na Figura 5-11 são relacionados os valores observados e os simulados pelo metamodelo das variáveis relacionadas na Tabela 5-9, os quais foram padronizados para o intervalo 0 e 1. Os consumos das bombas foram reproduzidos com grande exatidão (Figura 5-11 (a) e (b)), enquanto que o nível do R8 (Figura 5-11 (c)) e a carga de pressão do nó n29d (Figura 5-11 (d)) produziram maiores desvios, mas com bons resultados.

O metamodelo do Setor Iguatemi reproduziu: os consumos das bombas dos Poços Aldo Lupo e Iguatemi e da bomba que recalca água entre o R25 e R11 Superior; os níveis dos reservatórios R11 Superior e Inferior e do R25; e as cargas de pressão dos nós n283 e n633. A avaliação do desempenho dessas variáveis consta na Tabela 5-10. Conforme a referida tabela, e a relação entre os valores observados e reproduzidos pelo metamodelo na Figura 5-12, foram produzidos bons resultados, com exceção do consumo de energia da bomba no Poço Iguatemi (Figura 5-12 (b)) e dos níveis nos reservatórios R11 Superior (Figura 5-12 (d)) e Inferior (Figura 5-12 (e)). 


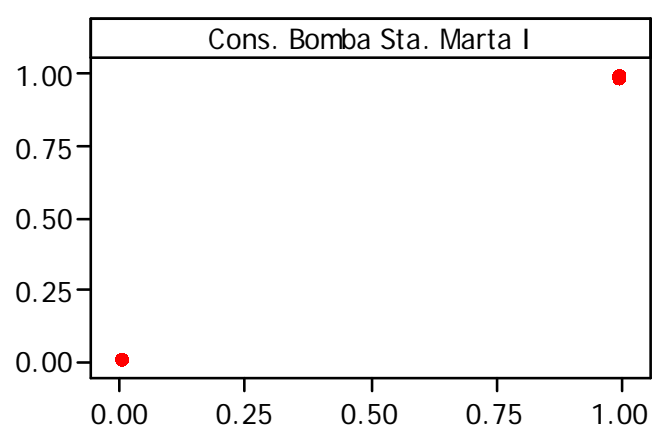

(a)

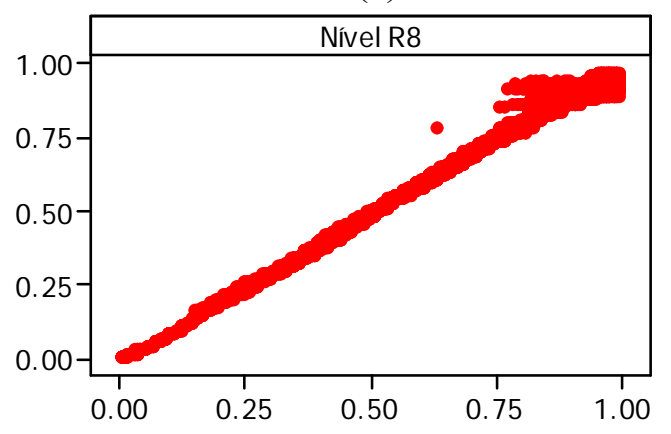

(c)

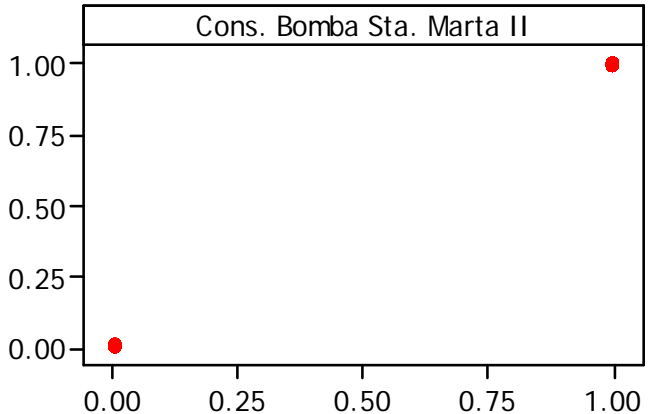

(b)

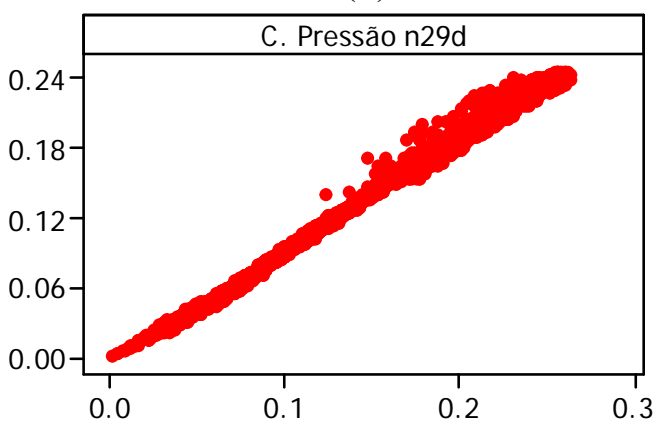

(d)

Figura 5-11 - Relação entre valores observados e simulados pelo metamodelo para: (a) Consumo da Bomba do Poço Santa Marta I; (b) Consumo da Bomba do Poço Santa Marta II; (c) Nível do reservatório R8 e (d) Carga de pressão do nó n29d - Setor Eliana

Tabela 5-10 - Resumo das avaliações dos resultados para o metamodelo do Setor Iguatemi

\begin{tabular}{|c|c|c|c|}
\hline Variável & $\mathbf{R}^{2}$ & MAE & $\begin{array}{l}\text { MPE } \\
(\%)\end{array}$ \\
\hline Poço Aldo Lupo & 1.00 & $0.10 \mathrm{kWh}$ & 1.02 \\
\hline Poço Iguatemi & 0.00 & $45.93 \mathrm{kWh}$ & 276.70 \\
\hline Recalque R11 & 0.97 & 0.19 kWh & 7.59 \\
\hline Nível R11 Inf. & 0.00 & $5.90 \mathrm{~m}$ & 95.11 \\
\hline Nível R11 Sup. & 0.00 & $5.46 \mathrm{~m}$ & 57.18 \\
\hline Nível R25 & 0.98 & $0.29 \mathrm{~m}$ & 4.00 \\
\hline $\begin{array}{l}\text { Pressão nó } \\
\text { n283 }\end{array}$ & 0.88 & 0.90 m.c.a. & 4.31 \\
\hline Pressão nó 633 & 0.99 & 0.45 m.c.a. & 3.02 \\
\hline Média & 0.60 & $x$ & 56.12 \\
\hline
\end{tabular}



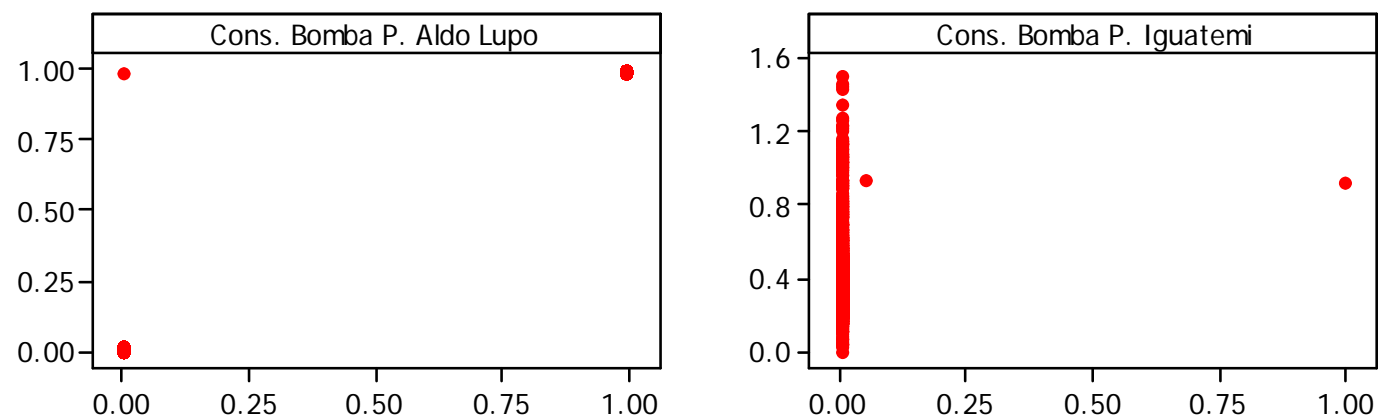

(a)

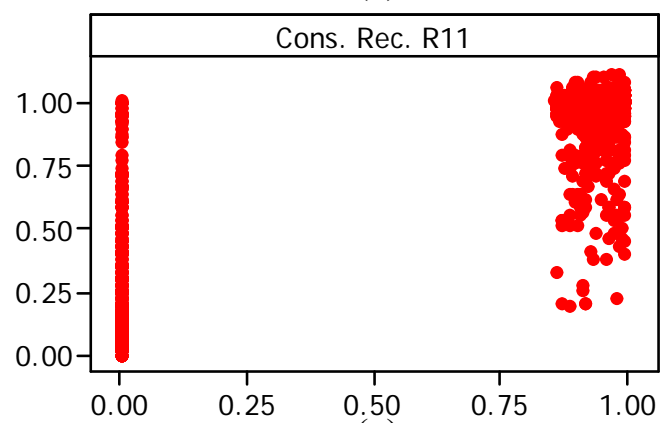

(c)

(b)

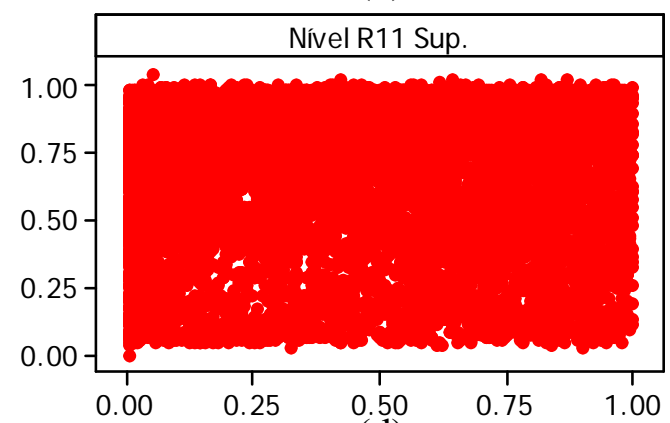

(d)

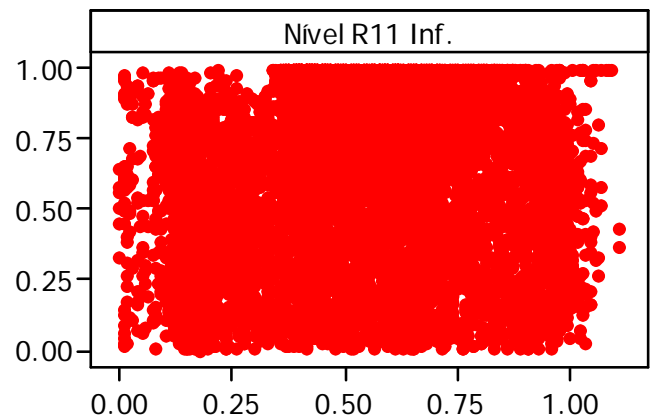

(e)

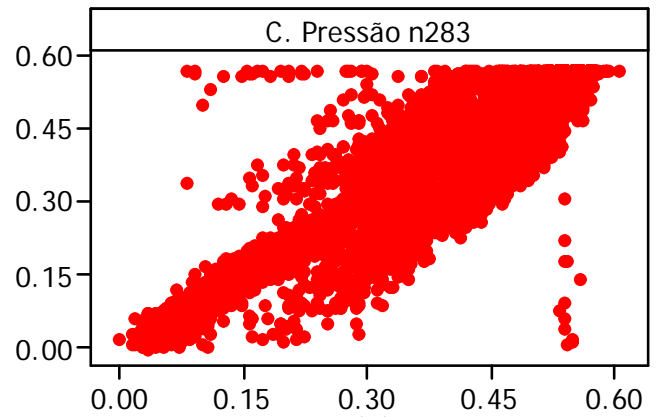

(g)

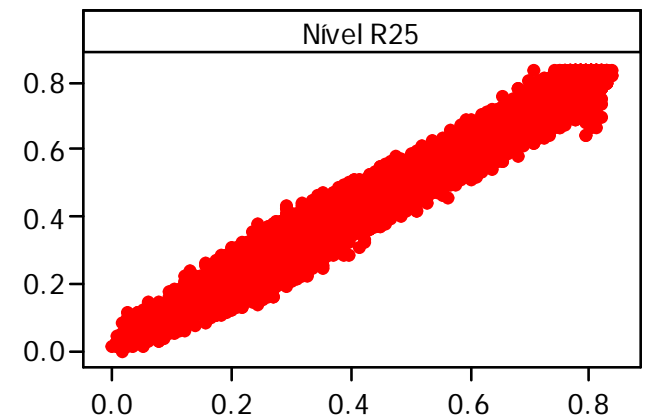

(f)

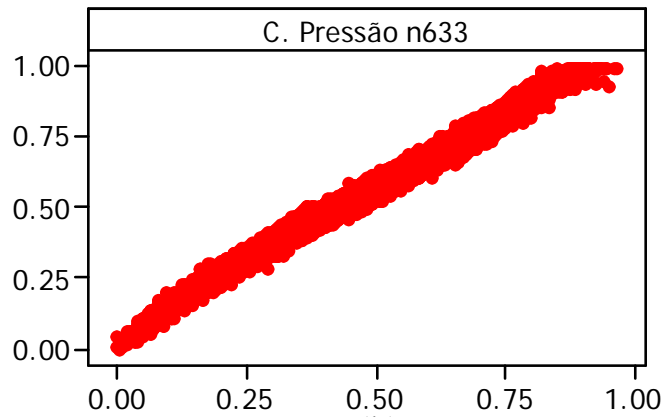

(h)

Figura 5-12 - Relação entre valores observados e simulados pelo metamodelo para: (a)

Consumo da Bomba do Poço Aldo Lupo; (b) Consumo da Bomba do Poço Iguatemi; (c) Consumo da Bomba de recalque entre R25 e R11 Superior; (d) Nível do reservatório R11 Superior; (e) Nível do reservatório R11 Inferior; (f) Nível do reservatório R25; (g) Carga de pressão do nó n283; e (h) Carga de pressão do nó n633 - Setor Iguatemi

O metamodelo do Setor Martinez produziu bons desempenhos nas reproduções: da energia consumida pela bomba do Poço Standard e pelo booster Standard, dos reservatórios 
R15 e R29 e da carga de pressão do nó n7f, com valores médios de $\mathrm{R}^{2}$ e MPE de 1,00 e $1,32 \%$, respectivamente. Observam-se desvios consideráveis na relação entre os valores observados e reproduzidos pelo metamodelo em termos do consumo de energia (Figura 5-13 (a)) e do nível do reservatório R29 (Figura 5-13 (c)), enquanto que houve boa relação quanto ao nível do R15 (Figura 5-13 (b)) e da carga de pressão do n7f (Figura 5-13 (d)).

Tabela 5-11 - Resumo das avaliações dos resultados para o metamodelo do Setor Martinez

\begin{tabular}{lccc}
\hline Variável & $\mathbf{R}^{\mathbf{2}}$ & MAE & $\begin{array}{c}\text { MPE } \\
\text { (\%) }\end{array}$ \\
\hline Bomba Poço Standard + Recalque Standard & 1.00 & $0.21 \mathrm{kWh}$ & 1.16 \\
Nível R15 & 1.00 & $0.03 \mathrm{~m}$ & 1.04 \\
Nível R29 & 0.99 & $0.03 \mathrm{~m}$ & 2.91 \\
Pressão nó n7f & 1.00 & 0.03 m.c.a. & 0.19 \\
\hline \multicolumn{1}{c}{ Média } & 1.00 & - & 1.32
\end{tabular}

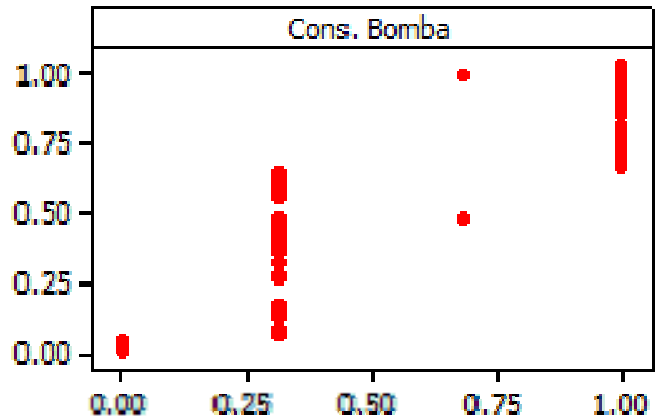

(a)

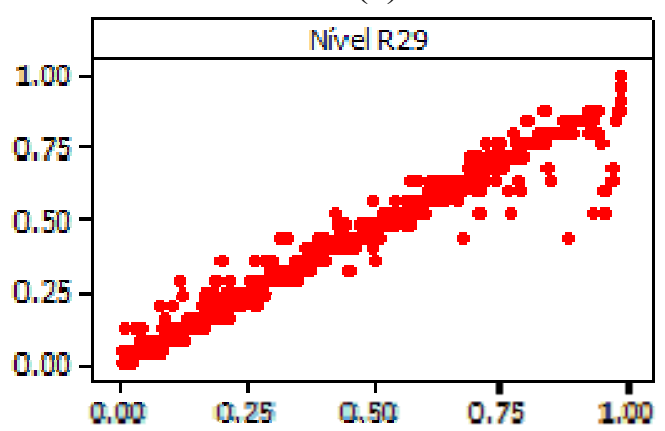

(c)

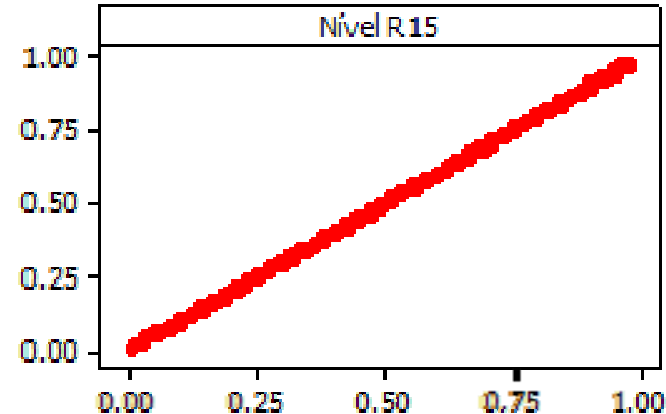

(b)

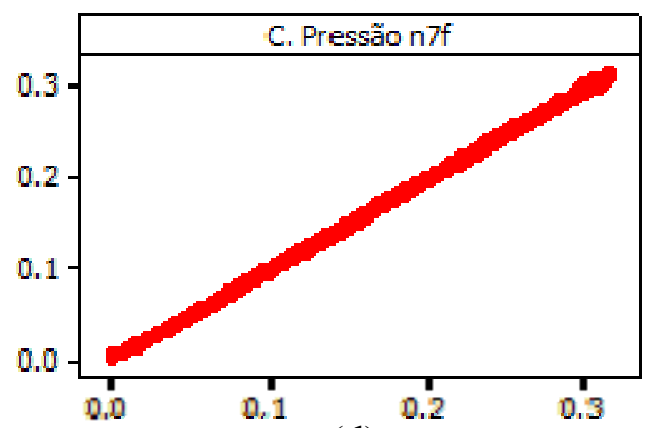

(d)

Figura 5-13 - Relação entre valores observados e simulados pelo metamodelo para: (a) Consumo das Bombas do Poço Standard e do booster Standard; (b) Nível do reservatório R15; (c) Nível do reservatório R29 e (d) Carga de pressão do nó n7f - Setor Martinez 
O objetivo do estudo e implementação dos metamodelos era utilizá-lo para fins de operação em tempo real, de modo a acelerar a geração das estratégias otimizadas.

No entanto, até o presente momento não foi possível utilizar os metamodelos com sucesso na produção das soluções otimizadas, pois foi detectado um problema entre a interface do Módulo de Otimização e do Módulo de Simulação Hidráulica.

\subsection{Resultados das Previsões de demanda}

Na Tabela 5-12 são apresentadas as avaliações de desempenho das previsões de demanda da próxima hora para os setores de estudo, para os conjuntos de treino e teste. Constata-se que em geral os resultados são bons. No Setor Eliana, obteve-se valores de correlação mais baixos do que os demais, enquanto que a previsão do Setor Martinez produziu o maior erro absoluto. No caso do Setor Iguatemi, obteve-se resultados similares para a Zona Alta e Zona Baixa.

Na Tabela 5-12 são apresentadas as avaliações de desempenho das previsões de demanda da próxima hora para os setores de estudo, para os conjuntos de treino e teste, enquanto que na Tabela 5-13 são apresentadas as avaliações de desempenho das previsões das próximas 24h. Observa-se que em geral os critérios de avaliação MAE e MPE são melhores para o conjunto de treino do que para o de teste. Tais resultados são esperados, pois a calibração do modelo de previsão é realizada com o conjunto de treino, e o conjunto de teste foi utilizado apenas para avaliar o desempenho do modelo produzido. Quanto ao $\mathrm{R}^{2}$, não se observa grande diferença entre o desempenho para ambos os conjuntos. Devido ao uso do método de múltiplos passos para realizar a previsão de demanda para as próximas $24 \mathrm{~h}$ (ver item 4.1), acumula-se erro a cada previsão, e desta maneira o desempenho médio da previsão da próxima hora é superior ao desempenho da previsão de demanda das próximas $24 \mathrm{~h}$.

Tabela 5-12 - Resumo das avaliações de desempenho das Previsões de demanda da próxima hora para os setores de estudo

\begin{tabular}{lcccccccc}
\hline \multirow{2}{*}{ Setor } & \multicolumn{3}{c}{ Treino } & & \multicolumn{3}{c}{ Teste } \\
\cline { 2 - 3 } & MAE & MPE & $\mathbf{R}^{\mathbf{2}}$ & & $\begin{array}{c}\text { MAE } \\
\text { (L/s) }\end{array}$ & MPE & $\mathbf{R}^{\mathbf{2}}$ \\
\hline Eliana & 1.57 & 8.46 & 0.88 & & 2.04 & 8.87 & 0.9 \\
Iguatemi Zona Alta & 2.31 & 8.13 & 0.96 & & 2.25 & 6.68 & 0.96 \\
Iguatemi Zona Baixa & 2.33 & 5.80 & 0.97 & & 2.39 & 6.52 & 0.97 \\
Martinez & 3.59 & 11.65 & 0.97 & & 3.66 & 11.01 & 0.97 \\
\hline
\end{tabular}


Tabela 5-13 - Resumo das avaliações de desempenho das Previsões de demanda das próximas $24 \mathrm{~h}$ para os setores de estudo

\begin{tabular}{|c|c|c|c|c|c|c|}
\hline \multirow[b]{2}{*}{ Setor } & \multicolumn{3}{|c|}{ Treino } & \multicolumn{3}{|c|}{ Teste } \\
\hline & $\begin{array}{l}\text { MAE } \\
(\mathrm{L} / \mathrm{s})\end{array}$ & MPE & $\mathbf{R}^{2}$ & $\begin{array}{l}\text { MAE } \\
(\mathrm{L} / \mathrm{s})\end{array}$ & MPE & $\mathbf{R}^{2}$ \\
\hline Eliana & 1.93 & 10.42 & 0.7 & 3.5 & 15.18 & 0.83 \\
\hline Iguatemi Zona Alta & 3.19 & 11.2 & 0.89 & 2.68 & 7.93 & 0.91 \\
\hline Iguatemi Zona Baixa & 3.94 & 9.83 & 0.91 & 4.93 & 13.45 & 0.9 \\
\hline Martinez & 5.42 & 17.61 & 0.93 & 5.43 & 16.37 & 0.92 \\
\hline
\end{tabular}

Nas Figuras 5-14 a 5-17 são comparados o consumo observado e as previsões das próximas $1 \mathrm{~h}$ e $24 \mathrm{~h}$ para os setores Eliana, Iguatemi e Martinez, referentes aos dias 27/04/2010, 17/08/2010 e 19/01/2010, respectivamente, que são as mesmas datas utilizadas para realizar a otimização multiobjetivo da operação em tempo real. Conforme comparações entre as Tabelas 5-12 e 5-13, observa-se também nas Figuras 5-14 a 5-17 diferença de desempenho entre as previsões de demanda das próximas $1 \mathrm{~h}$ e $24 \mathrm{~h}$, sendo que no Setor Iguatemi - Zona Baixa notam-se as maiores diferenças de performance.

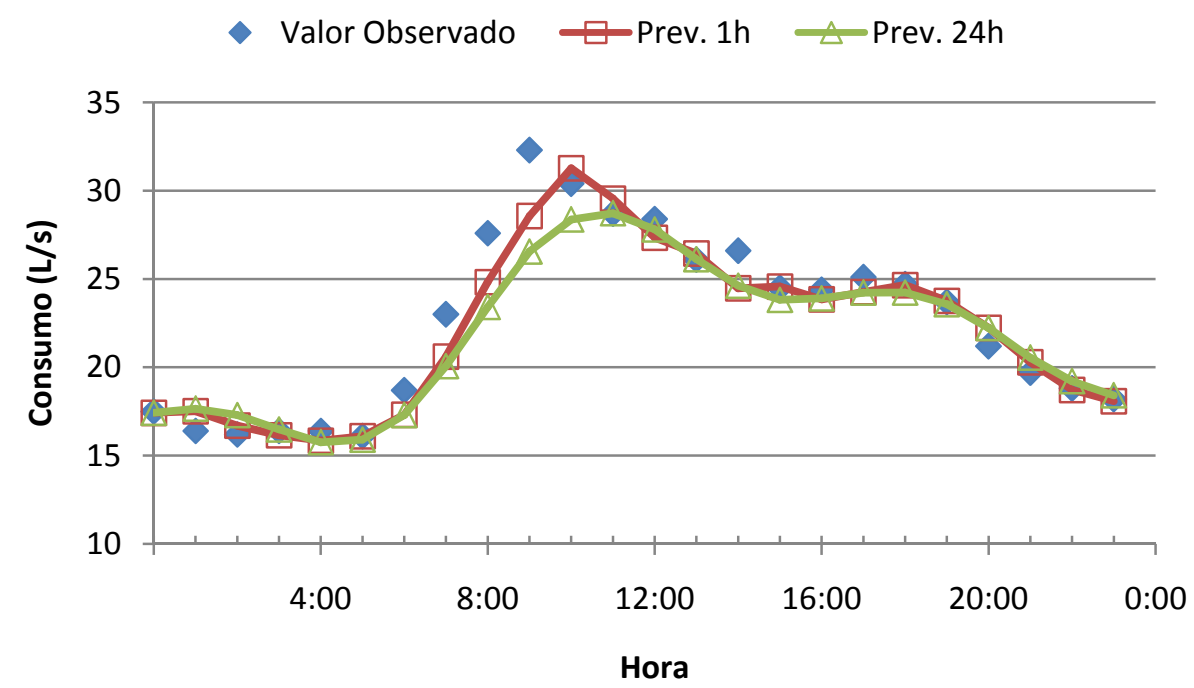

Figura 5-14 - Comparação entre consumo observado e previsões das próximas $1 \mathrm{~h}$ e $24 \mathrm{~h}-$ Setor Eliana 


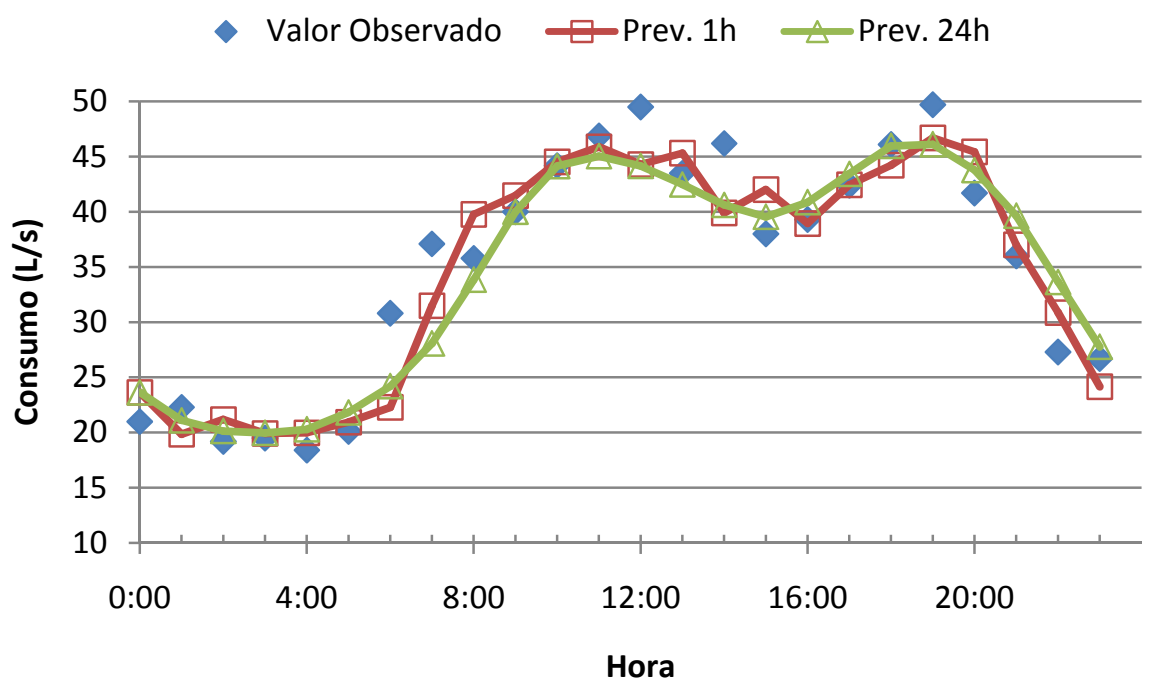

Figura 5-15 - Comparação entre consumo observado e previsões das próximas $1 \mathrm{~h}$ e $24 \mathrm{~h}-$ Setor Iguatemi, Zona Alta

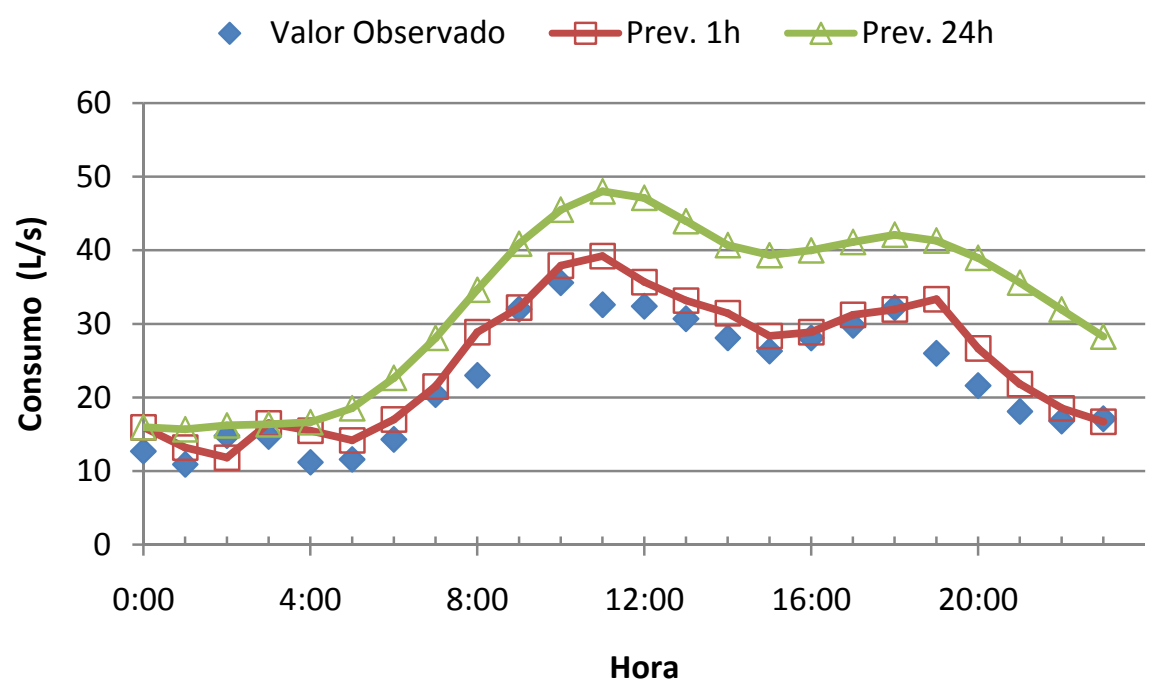

Figura 5-16 - Comparação entre consumo observado e previsões das próximas $1 \mathrm{~h}$ e $24 \mathrm{~h}$ - Setor Iguatemi, Zona Baixa 


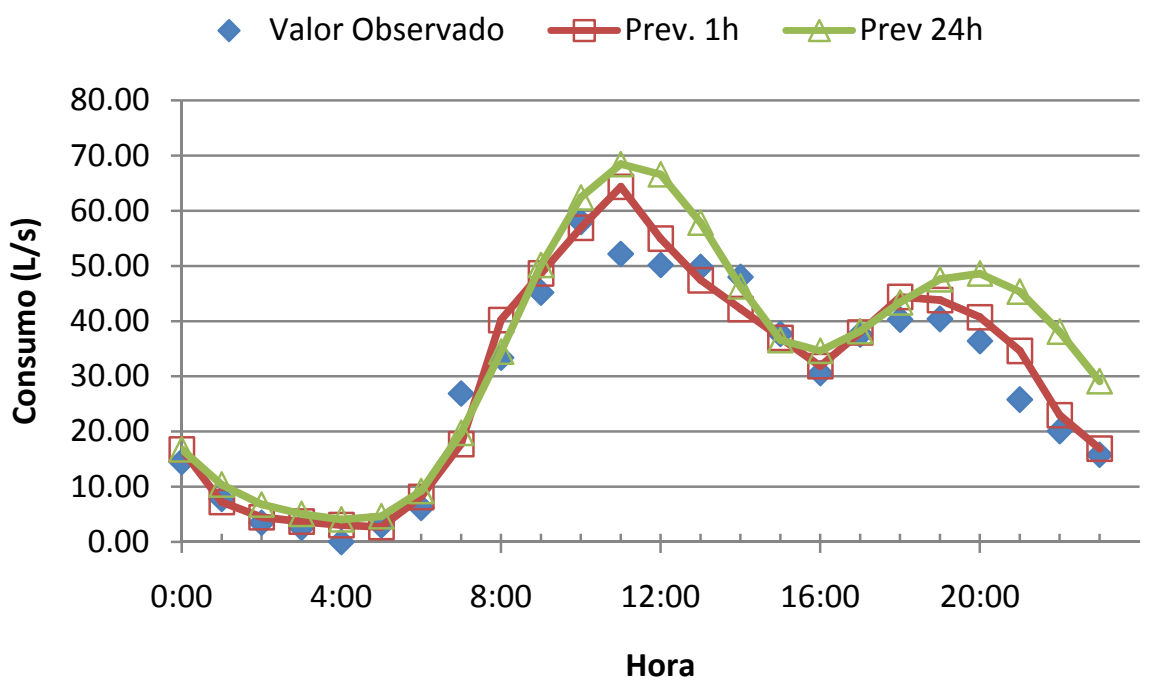

Figura 5-17 - Comparação entre consumo observado e previsões das próximas $1 \mathrm{~h}$ e $24 \mathrm{~h}-$ Setor Martinez

\subsection{Resultados preliminares da otimização de objetivo único}

Durante o desenvolvimento do Módulo de Otimização (item 4.3, página 87), realizaram-se testes preliminares do método de otimização AMALGAM, considerando-se como função objetivo a minimização do custo de bombeamento sujeito às restrições definidas anteriormente no item 4.3.2 (página 97). Nestes testes realizaram-se 6.000 avaliações da função objetivo.

Os testes preliminares foram realizados para redes hipóteticas Anytown (Walski et al., 1987) e de van Zyl (van Zyl et al., 2004) e para a rede real de Richmond (van Zyl, 2001), os quais foram comparados com resultados da literatura.

Nestes testes preliminares não foram utilizadas as técnicas de reparação de soluções (item 4.5.1, página 106), já que estas ainda não haviam sido desenvolvidas na ocasião da realização dos testes.

\section{Resultados para Anytown}

A rede Anytown é um exemplo bem conhecido da literatura, sendo utilizado em diversos problemas, principalmente de projetos de rede. A rede possui 19 nós, 4 tanques, 49 tubulações, 1 reservatório e 3 bombas (Figura 5-18).

Vamvakeridou-Lyroudia et al. (2005) utilizaram o algoritmo genético (AG) para otimizar simultaneamente o projeto e a operação da rede Anytown. Posteriormente, Giacomello et al. (2012) obtiveram resultado ligeiramente superior, vide Tabela 5.14, 
utilizando o método de otimização híbrido LPG, que combina a Programação Linear ("Linear Programming - LP) e o algoritmo "Guloso" (Greedy - G). Tal algoritmo, apesar de nem sempre produzir a operação ótima, consegue produzi-la rapidamente em segundos. Utilizando-se o AMALGAM-RTCT, foi possível obter custos ligeiramente menores, obedecendo-se as restrições já apresentadas.

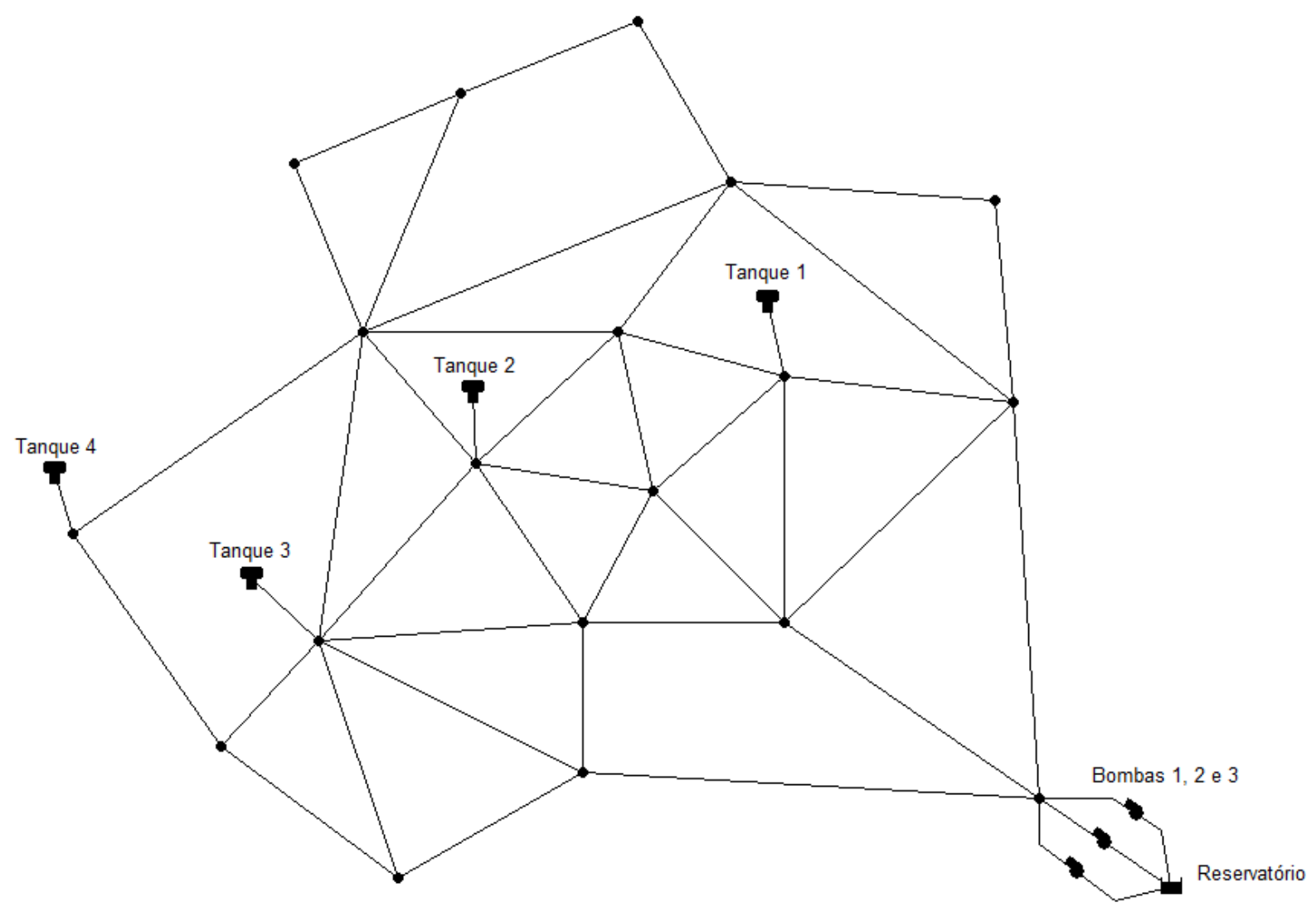

Figura 5-18 - Esquema da rede de abastecimento hipotética Anytown

Tabela 5.14 - Custos de operação para a rede Anytown

\begin{tabular}{lc}
\hline Autores & Custo de operação \\
& $\mathbf{( \$ / d i a )}$ \\
\hline Vamvakeridou-Lyroudia et al. (2005) & 6140,35 \\
Giacomello et al. (2012) & 6126,05 \\
AMALGAM-RTCT & 6096,59 \\
\hline
\end{tabular}

Na Figura 5-19 apresentam-se a evolução do custo e das violações das restrições versus o número de avaliações da função objetivo. O custo diário é representado no eixo vertical à direita, enquanto que no eixo vertical à esquerda representa-se a violação das 
restrições. A violação pode assumir valores de 0 a 24 , significando respectivamente que houveram nenhuma ou 24 violações durante as 24 horas de simulação, ou seja, 1 unidade de violação significa que no período de uma hora houve violação de alguma restrição. Os pontos em azul escuro representam o custo, e os demais pontos representam a violação das restrições: os pontos em magenta representam a ocorrência de erro do simulador EPANET, os pontos em amarelo representam ocorrência de pressões inferiores à mínima e os pontos em ciano representam a violação da restrição do nível do reservatório.

Pode-se observar na Figura 5-19 que o método AMALGAM-RTCT apresentou aumento do custo até que as restrições fossem satisfeitas quase que simultaneamente, em cerca de 500 avaliações da função objetivo (FO), e em seguida o custo diminuiu até convergir em cerca de 2000 avaliações da FO.

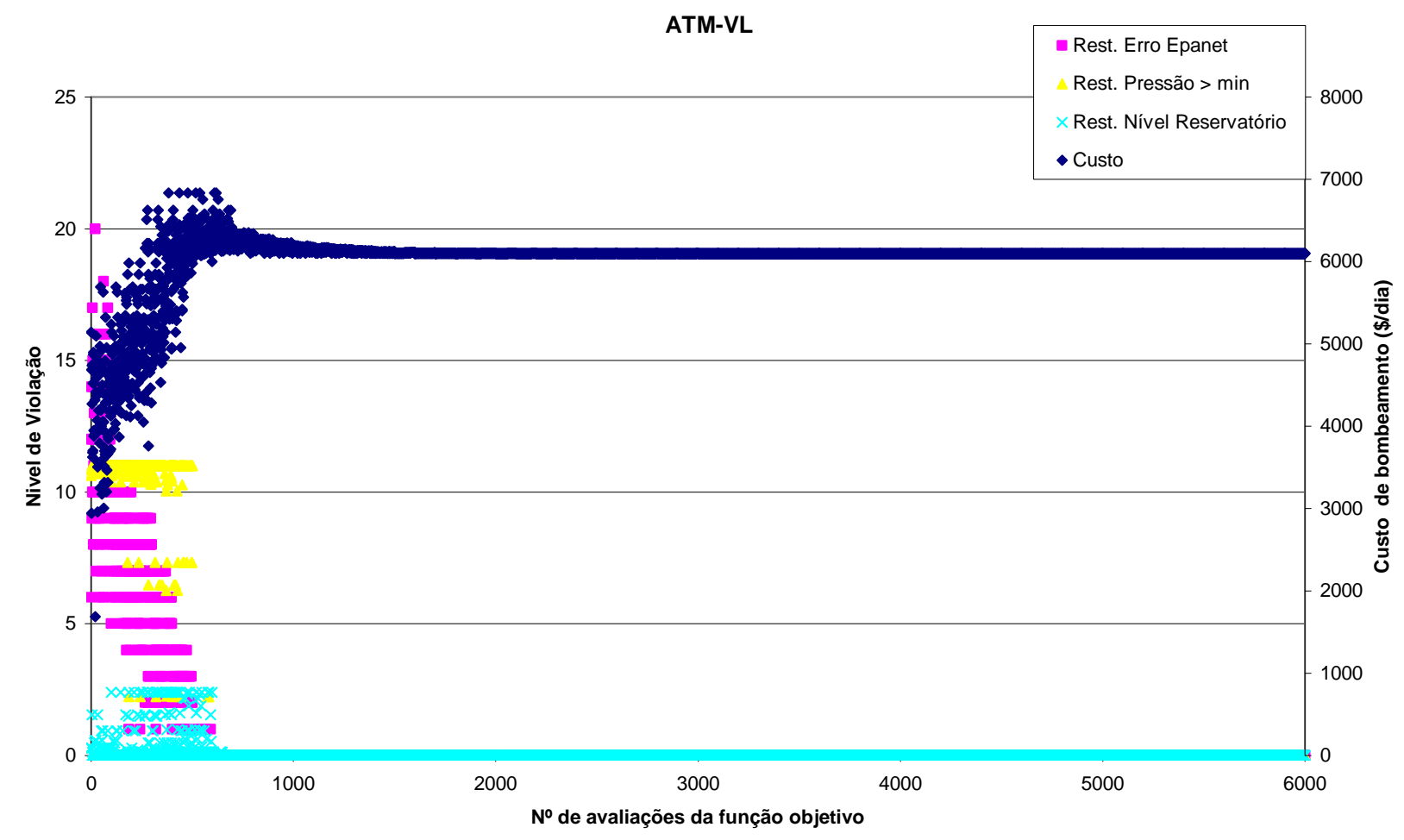

Figura 5-19 - Gráfico do custo de operação e violação das restrições x Número de avaliações da função objetivo para a rede Anytown

\section{$\underline{\text { Resultados para Richmond }}$}

A rede Richmond é uma rede real do Reino Unido. Possui seis reservatórios em cascata, que fornecem água para diferentes zonas de pressão. A água é bombeada diversas vezes dos tanques mais baixos para os mais altos, sendo que cada estação de bombeamento pode ter mais de uma bomba (Figura 5-20). 


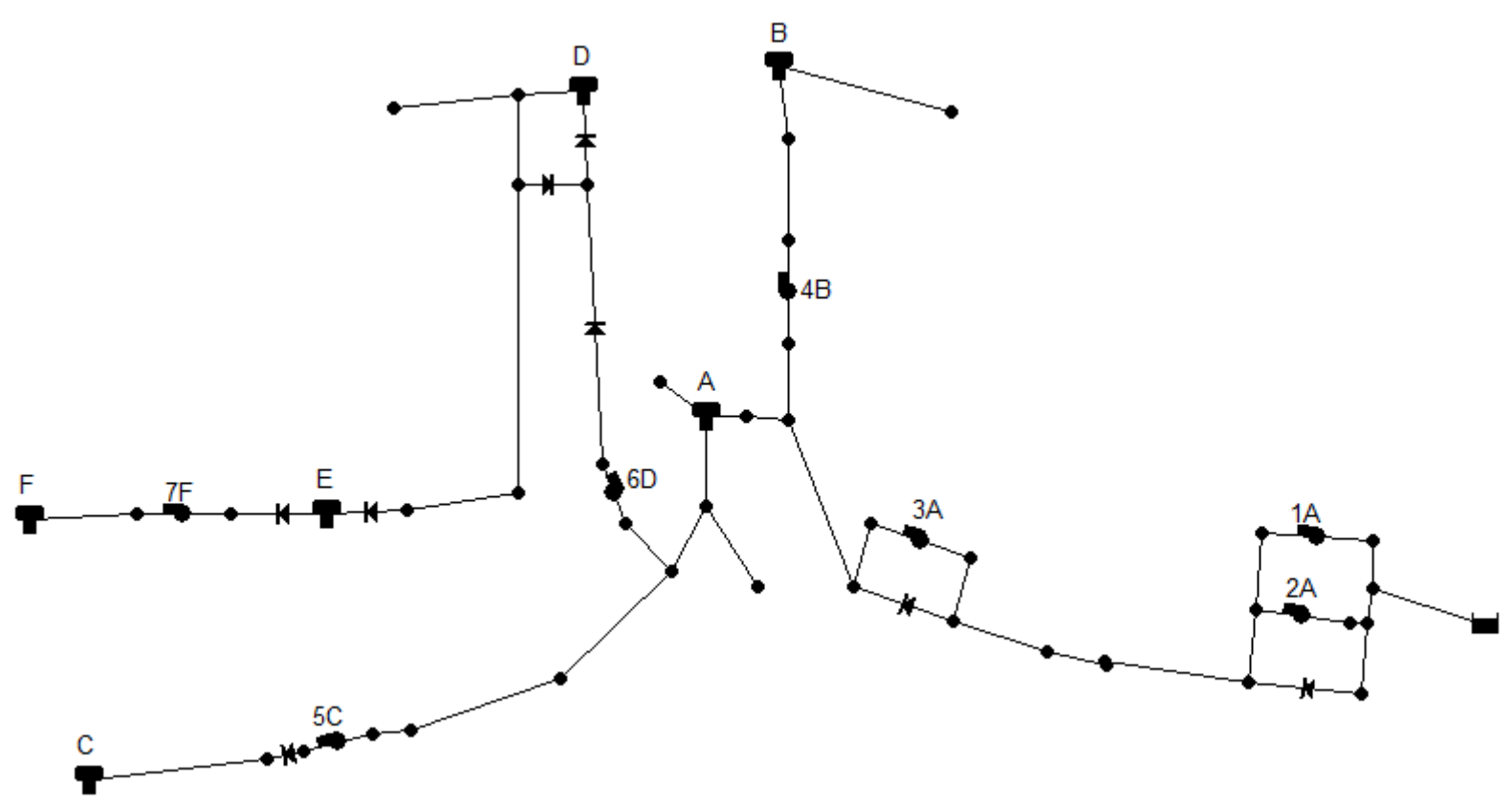

Figura 5-20 - Esquema da rede de abastecimento real Richmond

Os resultados da otimizações para a rede Richmond foram sintetizados na Tabela 5.15. Giacomello et al. (2012) conseguiram obter menore custo energético, enquanto que o AMALGAM-RTCT produziu resultados satisfatórios, e que podem ser aprimorados caso sejam realizadas mais avaliações da função objetivo.

Tabela 5.15 - Resumo dos custos para a rede de Richmond

\begin{tabular}{lc}
\hline Autores & $\begin{array}{c}\text { Custo de operação } \\
\text { (£/dia) }\end{array}$ \\
\hline Giacomello et al. (2012) & 118,58 \\
AMALGAM-RTCT & 135,15 \\
\hline
\end{tabular}

Observando-se a Figura 5-21, nota-se que os custos aumentaram até que fossem geradas soluções factíveis, em cerca de 1000 avaliações da FO. Diferente dos resultados da rede Anytown, as restrições não foram satisfeitas simultaneamente, sendo que a restrição que mais demorou a ser satisfeita foi relativa ao nível do reservatório. Pode-se observar que ainda é possível reduzir o custo de bombeamento ao se utilizar mais avaliações da FO. 


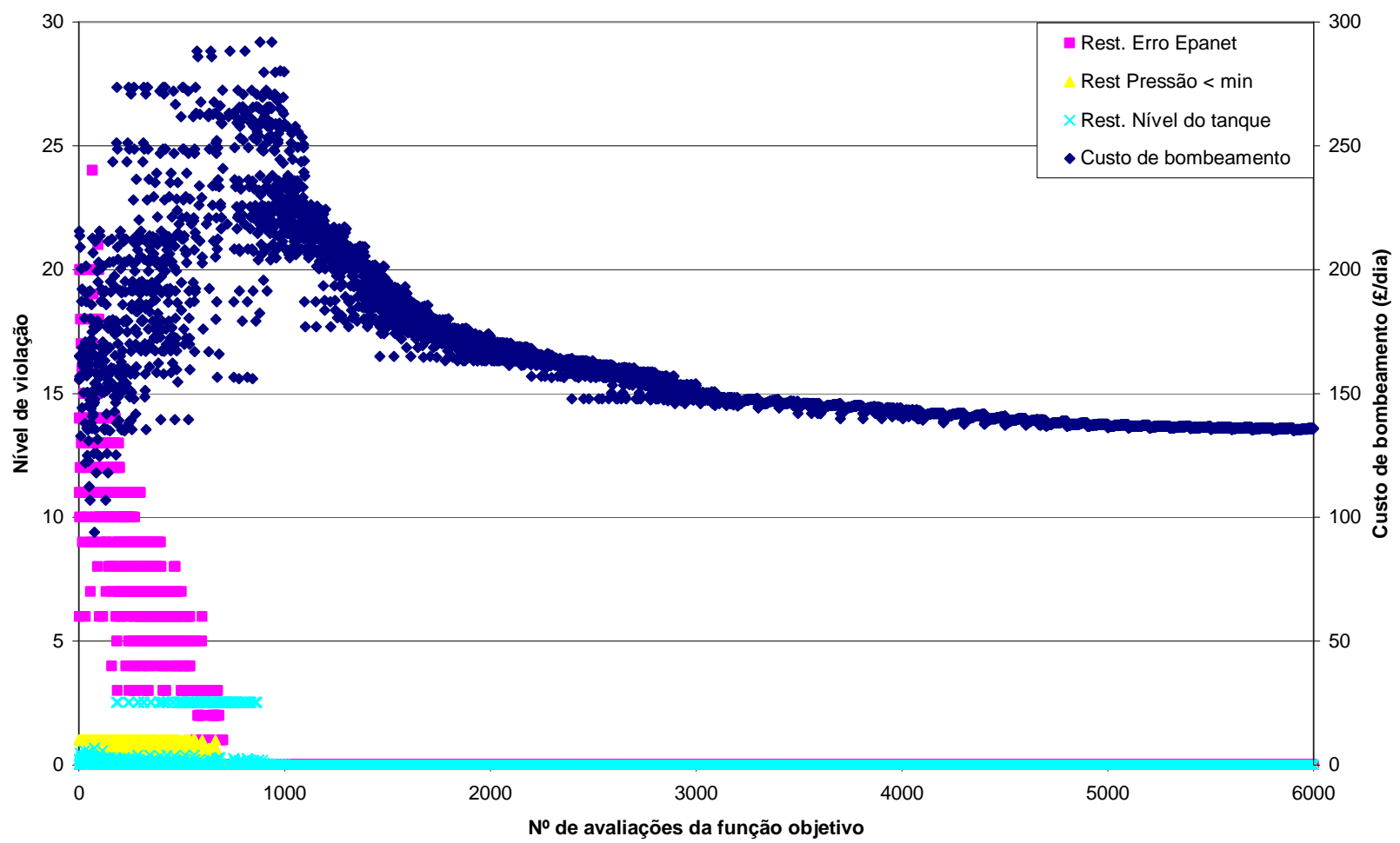

Figura 5-21 - Gráfico do custo de operação e violação das restrições x Número de avaliações da função objetivo para a rede Richmond

\section{Rede de van Zyl}

van Zyl et al. (2004) propuseram uma rede para teste do algoritmo híbrido desenvolvido por eles. A rede possui todos os elementos de uma rede real: reservatório, bombas, tanques e válvula de retenção, que impede a inversão do fluxo de água (Figura 5-22).

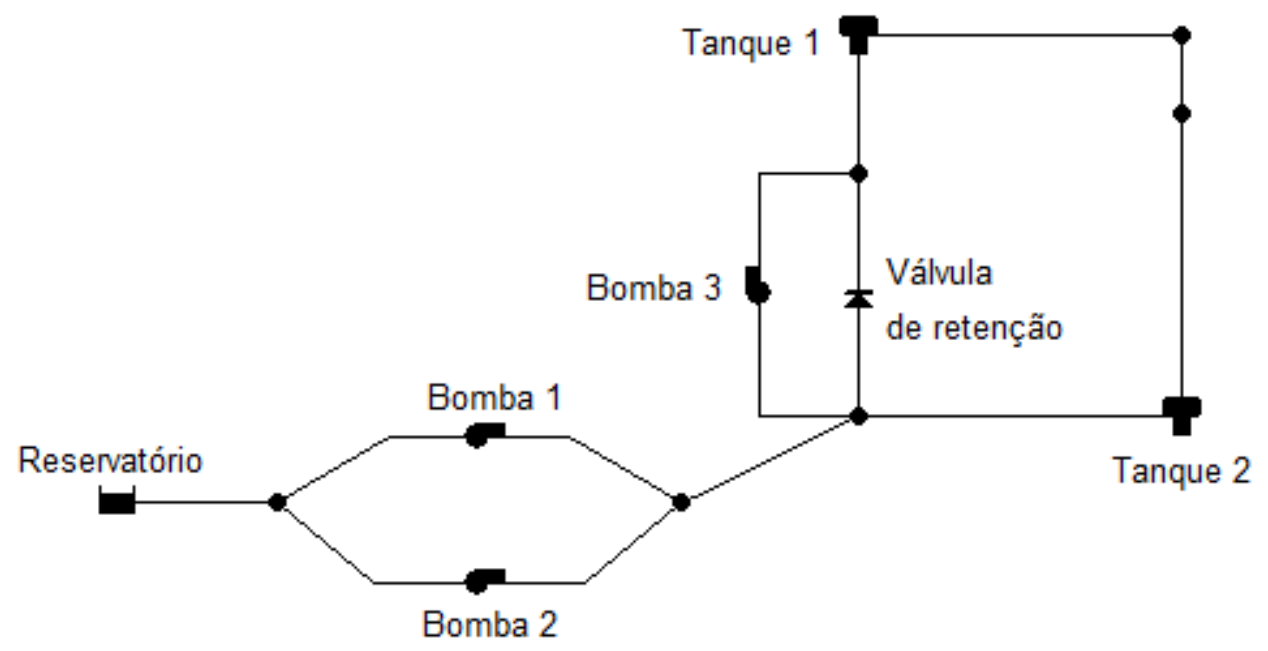

Figura 5-22 - Esquema da rede de abastecimento hipotética de van Zyl 
van Zyl et al. (2004) otimizaram a operação da rede aplicando um algoritmo de otimização híbrido, associando o AG aos algoritmos do tipo "hillclimber", a fim de obter resultados otimizados mais rapidamente. Manuel-Ibáñez (2009) realizou a otimização da operação utilizando um AG simples e obteve o menor custo, como se pode observar na Tabela 5.16, enquanto que o AMALGAM-RTCT produziu custos ligeiramente maiores.

Tabela 5.16 - Resumo dos custos para a rede de van Zyl

\begin{tabular}{lc}
\hline Autores & $\begin{array}{c}\text { Custo de operação } \\
\text { (\$/dia) }\end{array}$ \\
\hline Van Zyl et al. (2004) & 348,58 \\
Manuel-Ibáñez (2009) & 334,10 \\
AMALGAM-RTCT & 358,20 \\
\hline
\end{tabular}

Apesar da rede de van Zyl ser menor que a rede Anytown, observa-se na Figura 5-23 que a otimização demorou mais para convergir, em cerca de 3000 avaliações da FO. A restrição relativa ao nível dos tanques foi a que mais demorou a ser satisfeita.

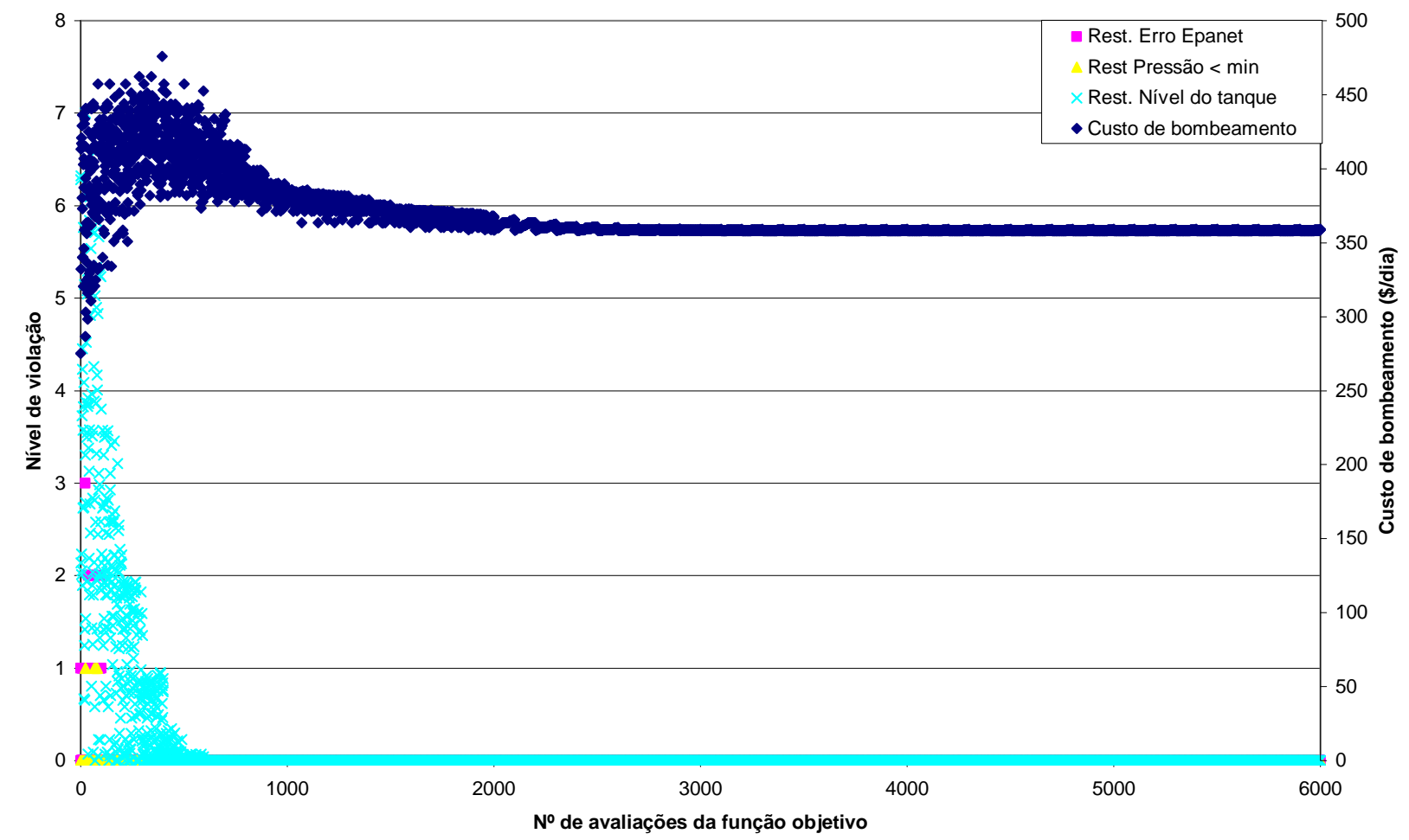

Figura 5-23 - Gráfico do custo de operação e violação das restrições x Número de avaliações da função objetivo para a rede de van Zyl 


\subsection{Análise do número necessário de avaliações da Função Objetivo}

Antes de se realizar a otimização da operação em tempo real (TR), avaliou-se a otimização para um determinado dia, a fim de verificar o número necessário de avaliações da função objetivo para produzir soluções otimizadas factíveis com reduzido custo diário de energia para realizar o bombeamento da água.

Essas avaliações foram realizadas utilizando-se a rede simplificada, já que esta pode ser simulada mais rapidamente em virtude das simplificações, conforme descrito no item 4.8.1 (página 127).

A avaliação da relação da evolução do custo da operação do setor Eliana com o número de avaliações da Função Objetivo (FO) é ilustrada na Figura 5-24. Nesse setor não houve ocorrência de soluções infactíveis ${ }^{42}$, sendo que a partir de 1.000 avaliações da FO já não se conseguem soluções mais econômicas.

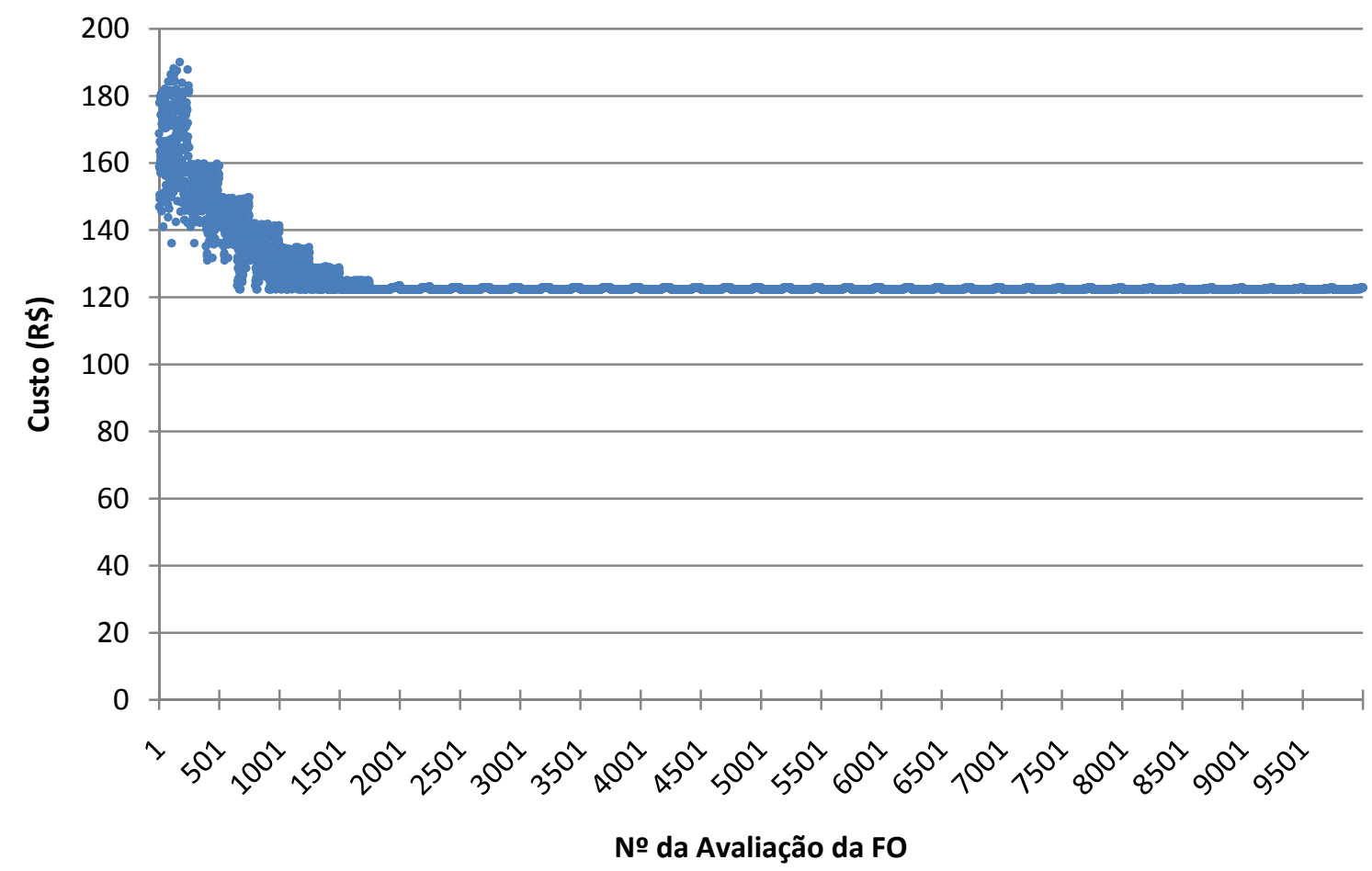

Figura 5-24 - Gráfico de Avaliação entre Custo e Número de Avaliações da FO - Setor Eliana

\footnotetext{
${ }^{42}$ Soluções que violam as restrições impostas
} 
No caso do Setor Iguatemi não se detecta a ocorrência de soluções infactíveis a partir de 1.000 avaliações da FO, sendo que entre 1.500 e 6.500 avaliações, não há aparecimento de soluções mais econômicas, apenas há uma redução da faixa de custo, conforme ilustrado na Figura 5-25.

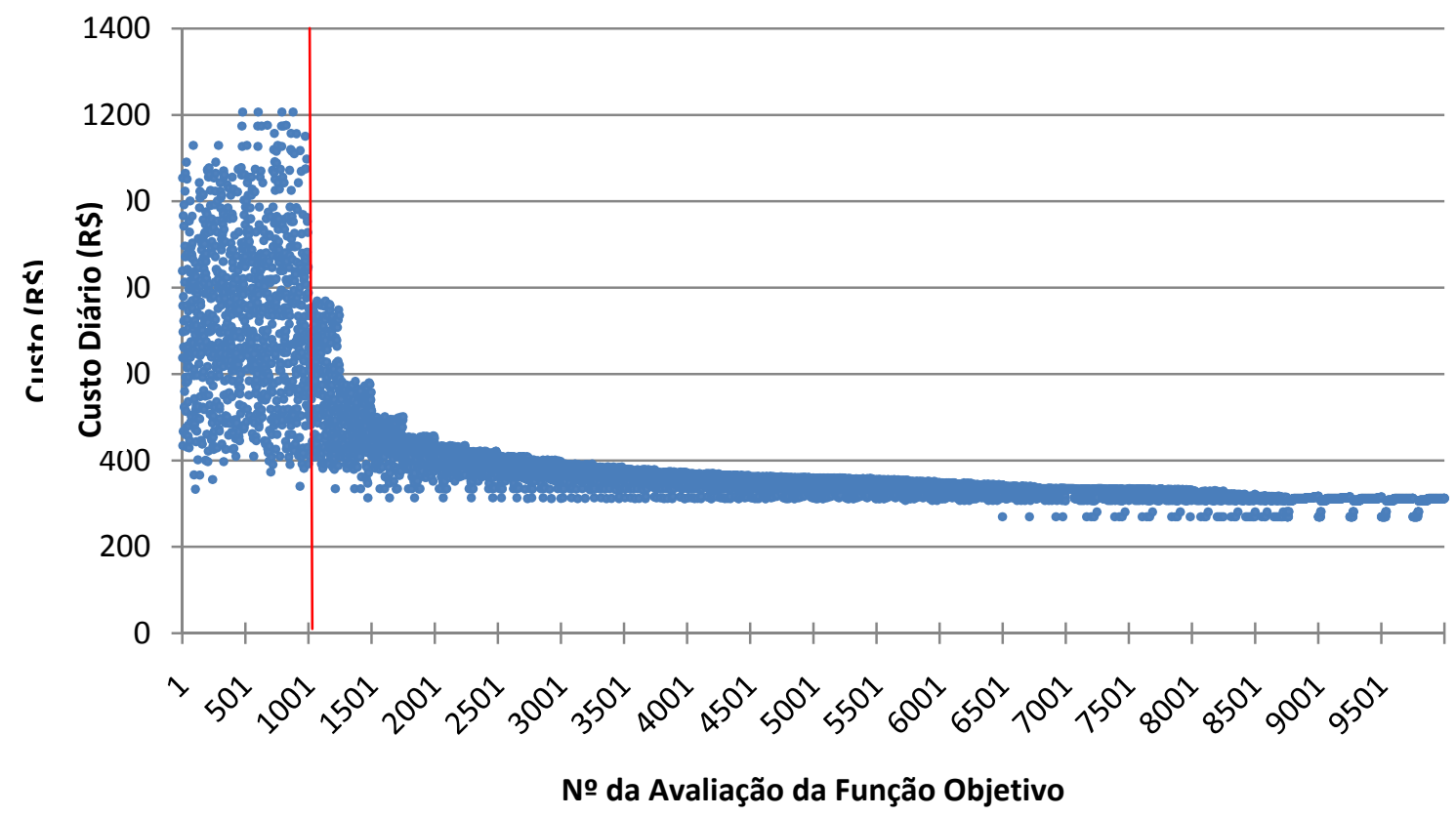

Figura 5-25 - Gráfico de Avaliação entre Custo e Número de Avaliações da FO - Setor Iguatemi

Nas avaliações para o Setor Martinez, conforme gráfico da Figura 5-26, a partir de 250 avaliações da FO não se identifica a ocorrência de soluções infactíveis. A partir de 1.000 avaliações, praticamente não se consegue redução de custo.

Observa-se que tanto no caso do Setor Iguatemi quanto no caso do Setor Martinez, até que fossem geradas soluções $100 \%$ factíveis, há um aumento no custo das operações, pois em geral a violação das restrições decorre da falta de água nos reservatórios, ocasionando ou desabastecimento da rede, ou nível final do reservatório inferior ao nível inicial. Logo após a geração de soluções $100 \%$ factíveis, há grande redução na faixa de custo de operação das soluções, o qual decai exponencialmente ao longo das avaliações da FO.

Depreende-se das avaliações do número de avaliações versus custo de operação que 2.500 avaliações da FO são suficientes para eliminar as soluções infactíveis, e o custo da operação terá chegado (próximo) ao limite gerado em 10.000 avaliações da FO. Portanto, 
decidiu-se limitar a 2.500 avaliações da FO a realização da otimização da operação dos setores de estudo.

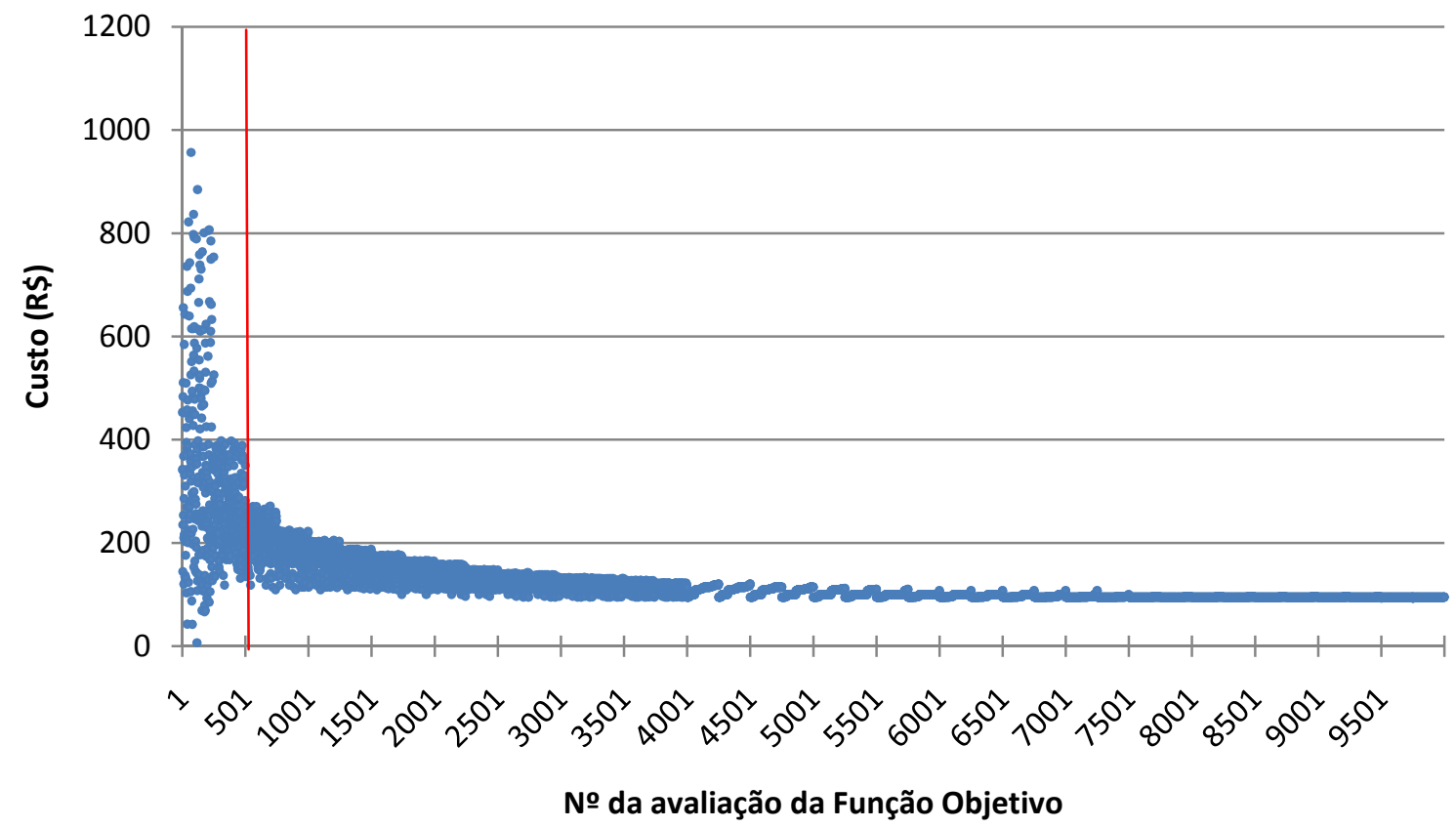

Figura 5-26 - Gráfico de Avaliação entre Custo e Número de Avaliações da FO - Setor Martinez

\subsection{Otimização de objetivo único da operação em Tempo Real}

Realizaram-se otimizações da operação em tempo real para o período de 1 mês para cada setor de abastecimento, com objetivo de comparar o custo da estratégia otimizada com o custo da operação praticada pelo DAAE. Note que a otimização de objetivo único consiste em utilizar apenas o custo como função objetivo.

Estas comparações foram realizadas utilizando-se o modelo de rede simplificada (item 4.8.1, página 127), uma vez que a otimização considerando somente a função objetivo custo não necessita de informações da rede completa, como carga de pressão e vazão ao longo da rede, sendo suficiente a representação da rede simplificada. Limitou-se a otimização em 2.500 avaliações da função objetivo para obter as estratégias operacionais otimizadas das próximas 24h. Nessas condições, cada otimização consumiu cerca de 1,5 minuto.

\subsubsection{Setor Eliana}

Na Tabela 5-17, na primeira e segunda coluna apresentam-se respectivamente a ordem do dia e a data, e nas colunas seguintes resumem-se os custos produzidos pela estratégia 
otimizada e praticada pelo $\mathrm{DAAE}^{43}$ para o Setor Eliana. As linhas sombreadas representam as estratégias que apresentaram custos menores que a operação praticada pelo DAAE, que no caso foram 27 de um total de 31 dias, representando economia de $14 \%$ no custo da operação do mês de estudo.

Apenas a estratégia otimizada do $5^{\circ}$ dia apresentou violação de restrição devido ao nível final do reservatório R8 ser ligeiramente menor que o nível do início do dia. Tal fato também ocorreu com a operação praticada pelo DAAE. Este caso pode ser ignorado, pois se verificou que haveria violação dessa restrição mesmo que a bomba funcionasse o dia inteiro, pois o nível inicial do referido dia corresponde ao máximo nível do reservatório. Por outro lado, a operação praticada pelo DAAE violou a restrição de nível do reservatório nos dias de ordem 11,16 e 20.

Na Figura 5-27 pode-se observar a energia utilizada ${ }^{44}$ pelas bombas durante as 24 horas de cada dia (linha contínua - Eixo vertical à esquerda) e para as horas de ponta ${ }^{45}$ (linha tracejada - Eixo vertical à direita). Em vermelho representa-se a energia utilizada nas estratégias otimizadas, enquanto que a linha azul representa a energia utilizada pela operação praticada pelo DAAE. Na maioria dos casos, as estratégias otimizadas utilizaram menos energia, seja durante as 24 horas do dia ou nas horas de ponta. Nos dias em que a estratégia otimizada não foi a mais econômica (Tabela 5-17), utilizou-se mais energia durante o horário de ponta, tornando a sua implementação mais custosa, como pode ser visualizado na Figura 5-27, destacados pelas elipses em azul.

$\mathrm{Na}$ fatura de energia elétrica do período otimizado para o Setor Eliana, contabilizou-se desembolso de $\mathrm{R} \$ 7.864,68$ apenas com o consumo de energia, valor 12\% superior ao valor produzido simulando-se a operação praticada pelo DAAE. Tal fato se deve principalmente, como apontado no início do capítulo, à falta de calibração das curvas das bombas e do desconhecimento da real eficiência dos conjuntos moto-bomba, pois na ausência de tais dados foram usadas informações constantes nos catálogos dos fabricantes das bombas. E à medida que esses equipamentos envelhecem, maior será a diferença entre as condições do catálogo e a realidade no campo.

${ }^{43}$ A operação praticada pelo DAAE foi inferida dos dados de telemetria, através da verificação do uso das bombas durante o dia

${ }^{44}$ Estimativa obtida multiplicando-se o número de horas de funcionamento da bomba e sua respectiva potência nominal

${ }^{45}$ Período em que a energia é mais cara 
Tabela 5-17 - Custos Custos da Estratégia Otimizada e da Operação praticada pelo DAAE - Setor Eliana

\begin{tabular}{cccc}
\hline & & \multicolumn{2}{c}{ Custo (R\$) } \\
\cline { 3 - 4 } Dia no & Data & Estratégia & Operação \\
& & Otimizada & DAAE \\
\hline 1 & $27 / 04 / 2010$ & 138,63 & 208,12 \\
\hline 2 & $28 / 04 / 2010$ & 192,99 & 148,47 \\
3 & $29 / 04 / 2010$ & 247,88 & 152,62 \\
4 & $30 / 04 / 2010$ & 155,08 & 268,56 \\
5 & $01 / 05 / 2010$ & 149,56 & 216,75 \\
6 & $02 / 05 / 2010$ & 135,24 & 143,42 \\
7 & $03 / 05 / 2010$ & 148,26 & 153,42 \\
8 & $04 / 05 / 2010$ & 150,92 & 182,2 \\
9 & $05 / 05 / 2010$ & 302,2 & 258,2 \\
10 & $06 / 05 / 2010$ & 303,66 & 365,72 \\
11 & $07 / 05 / 2010$ & 473,46 & 411,94 \\
12 & $08 / 05 / 2010$ & 308,62 & 438,69 \\
13 & $09 / 05 / 2010$ & 231,89 & 359,65 \\
14 & $10 / 05 / 2010$ & 244,32 & 356,66 \\
15 & $11 / 05 / 2010$ & 247,44 & 361,22 \\
16 & $12 / 05 / 2010$ & 240,67 & 300,3 \\
17 & $13 / 05 / 2010$ & 213,58 & 220,52 \\
18 & $14 / 05 / 2010$ & 139,73 & 148,55 \\
19 & $15 / 05 / 2010$ & 150,6 & 189,24 \\
20 & $16 / 05 / 2010$ & 138,93 & 241,51 \\
21 & $17 / 05 / 2010$ & 146,82 & 151,57 \\
22 & $18 / 05 / 2010$ & 145,07 & 150,78 \\
23 & $19 / 05 / 2010$ & 142,52 & 146,07 \\
24 & $20 / 05 / 2010$ & 149,2 & 149,73 \\
25 & $21 / 05 / 2010$ & 156,34 & 161,18 \\
26 & $22 / 05 / 2010$ & 154,77 & 212,78 \\
27 & $23 / 05 / 2010$ & 141,66 & 195,11 \\
28 & $24 / 05 / 2010$ & 143,29 & 148,71 \\
29 & $25 / 05 / 2010$ & 145,71 & 153,29 \\
30 & $26 / 05 / 2010$ & 180,75 & 181,95 \\
31 & $27 / 05 / 2010$ & 144,13 & 185,55 \\
\hline & Soma & 5964,03 & 6941,75 \\
& & & \\
\hline
\end{tabular}




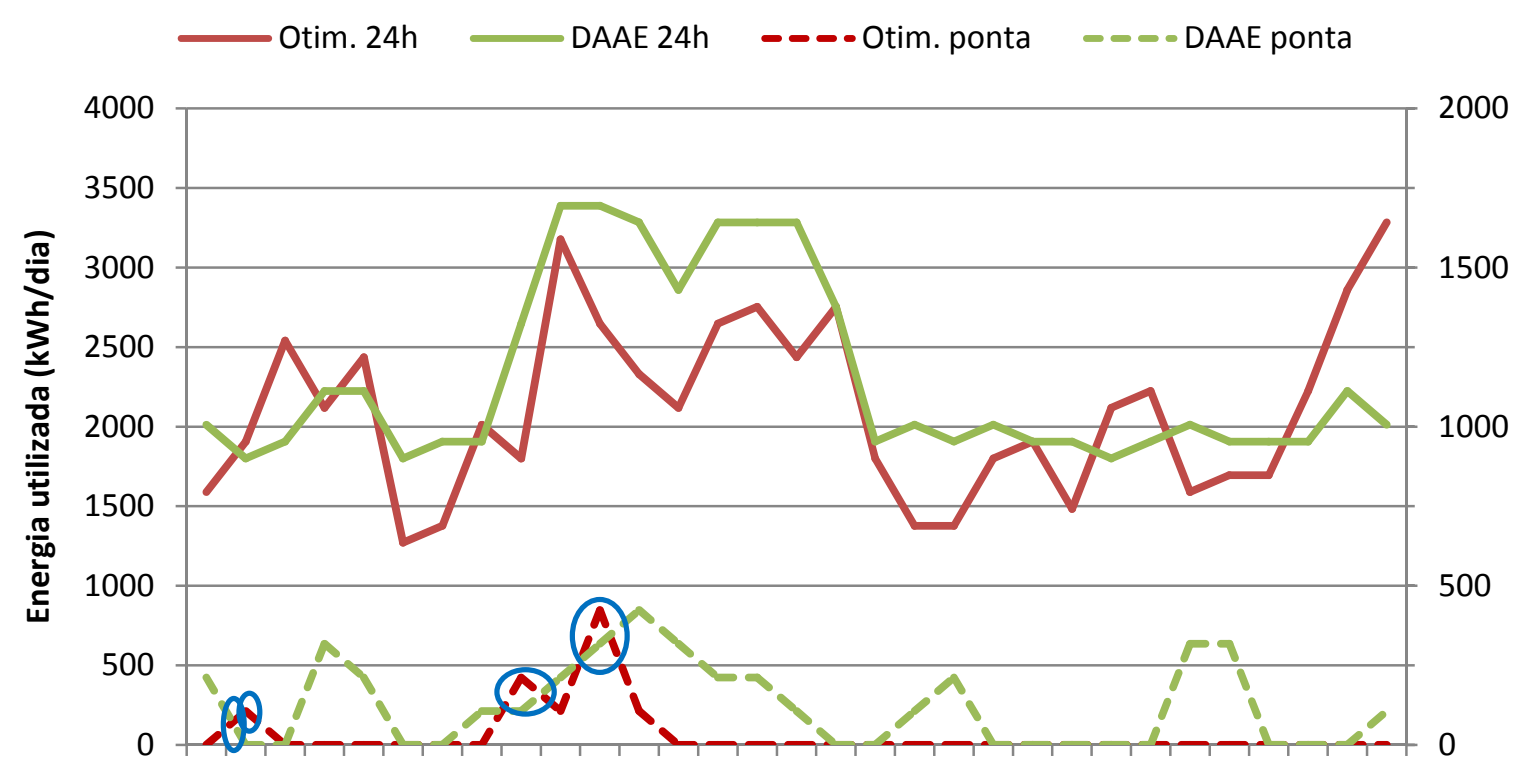

$123 \quad 3 \quad 4 \quad 5 \quad 6 \quad 7 \quad 8 \quad 910111213141516171819202122232425262728293031$

Ordem do Dia

Figura 5-27 - Energia utilizada pelas bombas durante as 24 horas e durante as horas de ponta - Setor Eliana

\subsubsection{Setor Iguatemi}

No Setor Iguatemi, a estratégia otimizada mostrou-se mais econômica em 19 de $32^{46}$ dias, conforme Tabela 5-18, representada pelas linhas sombreadas. Assim, produziu-se economia de $13 \%$ em relação à operação praticada pelo DAAE.

Na Figura 5-28 pode-se comparar a energia utilizada pela estratégia otimizada com a operação praticada pelo DAAE. Em todos os dias, a estratégia otimizada utilizou menos energia que a operação praticada pelo DAAE para o período de $24 \mathrm{~h}$. Apesar disso, o uso de energia nos horários de ponta é determinante para a composição do custo, já que a tarifa no horário de ponta é quase 5,5 vezes maior que a tarifa no horário fora de ponta (vide Tabela 4-3, página 116). Desta forma, a otimização não produziu estratégias mais econômicas justamente nos dias em que utilizou mais energia no horário de ponta, que foram destacados na figura pelas elipses em azul.

${ }^{46}$ No caso do setor Iguatemi foram considerados 32 dias, que foi o mesmo número de dias observado na fatura de energia elétrica entre os meses de agosto a setembro. 
Extraindo-se o custo do consumo de energia da fatura no período otimizado para o Setor Iguatemi, obteve-se um total de R $\$ 33.425,08$, 18\% superior ao custo produzido da simulação das operações praticadas pelo DAAE.

Tabela 5-18 - Custos da Estratégia Otimizada e da Operação praticada pelo DAAE - Setor Iguatemi

\begin{tabular}{cccc}
\hline Dia & Data & \multicolumn{2}{c}{ Custo (R\$) } \\
\cline { 3 - 4 } no & & Operação & Otimizada \\
& & DAAE \\
\hline 1 & $12 / 08 / 2010$ & 519,05 & 636,14 \\
\hline 2 & $13 / 08 / 2010$ & 818,04 & 742,62 \\
\hline 3 & $14 / 08 / 2010$ & 925,77 & 1129,45 \\
4 & $15 / 08 / 2010$ & 588,3 & 934,51 \\
\hline 5 & $16 / 08 / 2010$ & 673,26 & 567,85 \\
6 & $17 / 08 / 2010$ & 722,25 & 571,85 \\
\hline 7 & $18 / 08 / 2010$ & 393,41 & 697,49 \\
\hline 8 & $19 / 08 / 2010$ & 630,72 & 544,07 \\
9 & $20 / 08 / 2010$ & 711,11 & 755,84 \\
10 & $21 / 08 / 2010$ & 750,64 & 1066,51 \\
11 & $22 / 08 / 2010$ & 617,3 & 921,89 \\
\hline 12 & $23 / 08 / 2010$ & 691,29 & 501,02 \\
13 & $24 / 08 / 2010$ & 712,43 & 683,03 \\
\hline 14 & $25 / 08 / 2010$ & 784,36 & 815,89 \\
15 & $26 / 08 / 2010$ & 768,74 & 776,42 \\
16 & $27 / 08 / 2010$ & 798,7 & 870,1 \\
17 & $28 / 08 / 2010$ & 788,95 & 1253,3 \\
18 & $29 / 08 / 2010$ & 672,78 & 1047,67 \\
\hline 19 & $30 / 08 / 2010$ & 800,59 & 681,18 \\
\hline 20 & $31 / 08 / 2010$ & 720,82 & 750,39 \\
\hline 21 & $01 / 09 / 2010$ & 735,38 & 689,09 \\
22 & $02 / 09 / 2010$ & 768,18 & 709,52 \\
\hline 23 & $03 / 09 / 2010$ & 898,52 & 1092,27 \\
24 & $04 / 09 / 2010$ & 882,75 & 1282,08 \\
25 & $05 / 09 / 2010$ & 650,41 & 1168,01 \\
\hline 26 & $06 / 09 / 2010$ & 953,46 & 859,85 \\
27 & $07 / 09 / 2010$ & 725,55 & 694,67 \\
\hline 28 & $08 / 09 / 2010$ & 670,99 & 807,31 \\
\hline 29 & $09 / 09 / 2010$ & 846,75 & 668,08 \\
30 & $10 / 09 / 2010$ & 868,85 & 751,31 \\
\hline 31 & $11 / 09 / 2010$ & 819,65 & 1322,89 \\
32 & $12 / 09 / 2010$ & 730,12 & 1236,83 \\
\hline & Soma & 23639,12 & 27229,13 \\
& & & \\
\hline
\end{tabular}




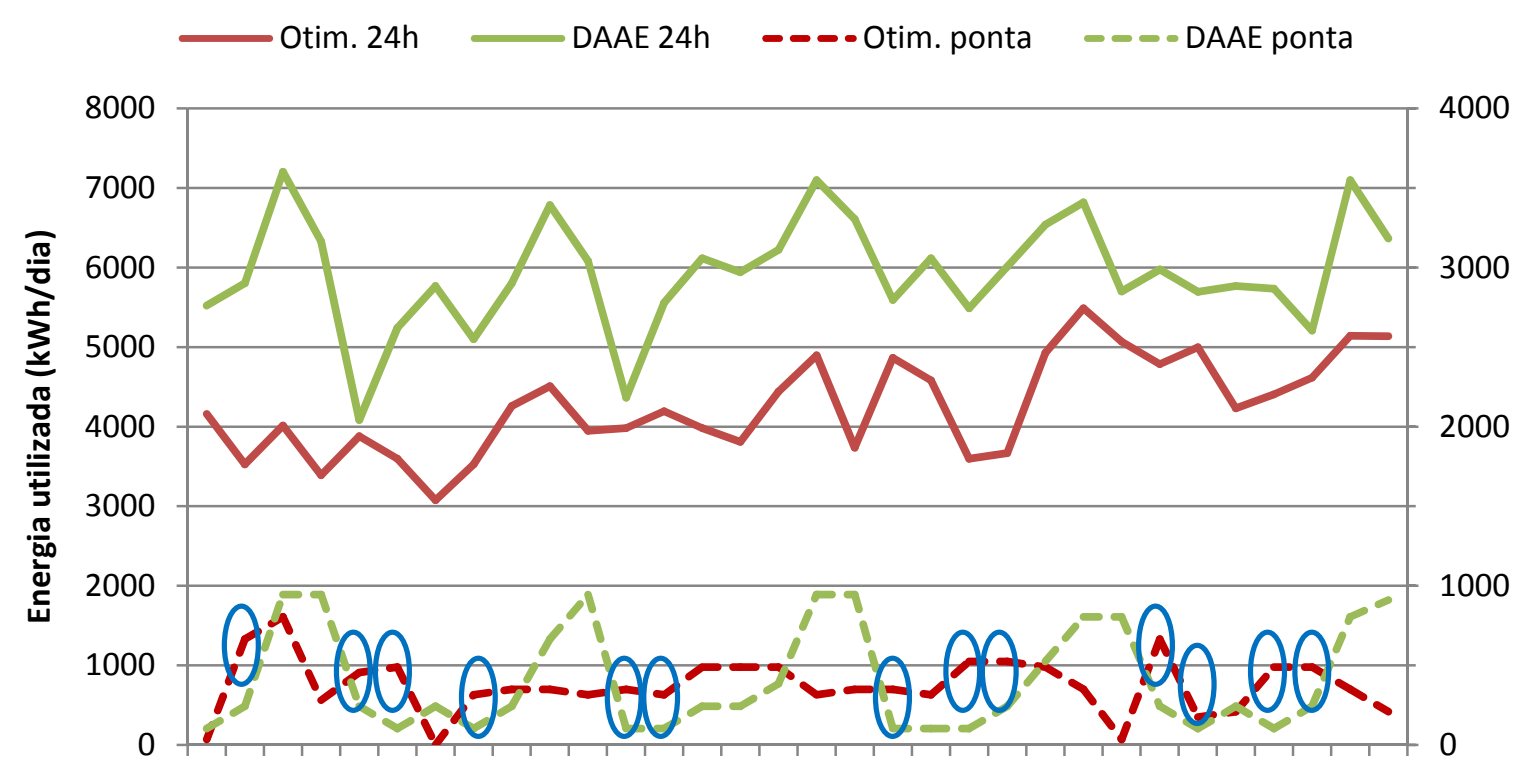

1234567891011121314151617181920212223242526272829303132

Ordem do Dia

Figura 5-28 - Energia utilizada pelas bombas durante as 24 horas e durante as horas de ponta - Setor Iguatemi

\subsubsection{Setor Martinez}

As estratégias otimizadas obtidas para o Setor Martinez foram mais econômicas que as operações praticadas pelo DAAE em 21 de 28 dias, conforme Tabela 5-19, representada pelas linhas sombreadas. A estratégia otimizada produziu economia bem mais significativa em relação aos demais setores, cerca de 30\% em relação as operações praticadas pelo DAAE.

$\mathrm{Na}$ maioria dos dias, as estratégias otimizadas utilizaram menos energia (Figura 5-29), durante as 24 horas do dia e especialmente nas horas de ponta. A grande diferença nos custos se deve ao intenso uso de energia pela operação praticada pelo DAAE durante o horário de ponta. Nos dias em que a estratégia otimizada não foi mais econômica, com exceção do $3^{\circ}$ dia, utilizou-se mais energia para o período de $24 \mathrm{~h}$ do dia, os quais foram destacados por elipses em azul.

O custo do consumo de energia na fatura de energia elétrica para o Setor Martinez, no período considerado, foi de $\mathrm{R} \$ 17.192,50$, valor $12 \%$ superior ao produzido pela simulação das operações praticadas pelo DAAE. 
Tabela 5-19 - Custos da Estratégia Otimizada e da Operação praticada pelo DAAE - Setor Martinez

\begin{tabular}{|c|c|c|c|}
\hline \multirow{2}{*}{ Dia no } & \multirow{2}{*}{ Data } & \multicolumn{2}{|c|}{ Custo (R\$) } \\
\hline & & $\begin{array}{l}\text { Operação } \\
\text { Otimizada }\end{array}$ & DAAE \\
\hline 1 & $13 / 01 / 2010$ & 397,93 & 551,74 \\
\hline 2 & $14 / 01 / 2010$ & 349,32 & 504,49 \\
\hline 3 & $15 / 01 / 2010$ & 487,25 & 381,85 \\
\hline 4 & $16 / 01 / 2010$ & 363,14 & 530,67 \\
\hline 5 & $17 / 01 / 2010$ & 287,53 & 455,67 \\
\hline 6 & $18 / 01 / 2010$ & 379,62 & 327,66 \\
\hline 7 & $19 / 01 / 2010$ & 319,19 & 476,13 \\
\hline 8 & $20 / 01 / 2010$ & 352,27 & 345,51 \\
\hline 9 & $21 / 01 / 2010$ & 346,7 & 550,34 \\
\hline 10 & $22 / 01 / 2010$ & 397,75 & 475,01 \\
\hline 11 & $23 / 01 / 2010$ & 340,33 & 331,64 \\
\hline 12 & $24 / 01 / 2010$ & 360,71 & 669,51 \\
\hline 13 & $25 / 01 / 2010$ & 407,28 & 896,66 \\
\hline 14 & $26 / 01 / 2010$ & 348,09 & 634,43 \\
\hline 15 & $27 / 01 / 2010$ & 347,75 & 358,29 \\
\hline 16 & $28 / 01 / 2010$ & 327,06 & 495,78 \\
\hline 17 & $29 / 01 / 2010$ & 326,21 & 308,36 \\
\hline 18 & $30 / 01 / 2010$ & 359,2 & 377,3 \\
\hline 19 & $31 / 01 / 2010$ & 359,57 & 328,65 \\
\hline 20 & $01 / 02 / 2010$ & 425,35 & 910,08 \\
\hline 21 & $02 / 02 / 2010$ & 358,21 & 579,37 \\
\hline 22 & 03/02/2010 & 422,71 & 591,14 \\
\hline 23 & $04 / 02 / 2010$ & 422,88 & 588,88 \\
\hline 24 & $05 / 02 / 2010$ & 307,79 & 586.1 \\
\hline 25 & 06/02/2010 & 633,74 & 614.52 \\
\hline 26 & $07 / 02 / 2010$ & 388,76 & 734.79 \\
\hline 27 & 08/02/2010 & 419,3 & 972.56 \\
\hline 28 & 09/02/2010 & 399,83 & 574.39 \\
\hline & $\mathrm{ma}$ & 10635.47 & 15151,52 \\
\hline
\end{tabular}




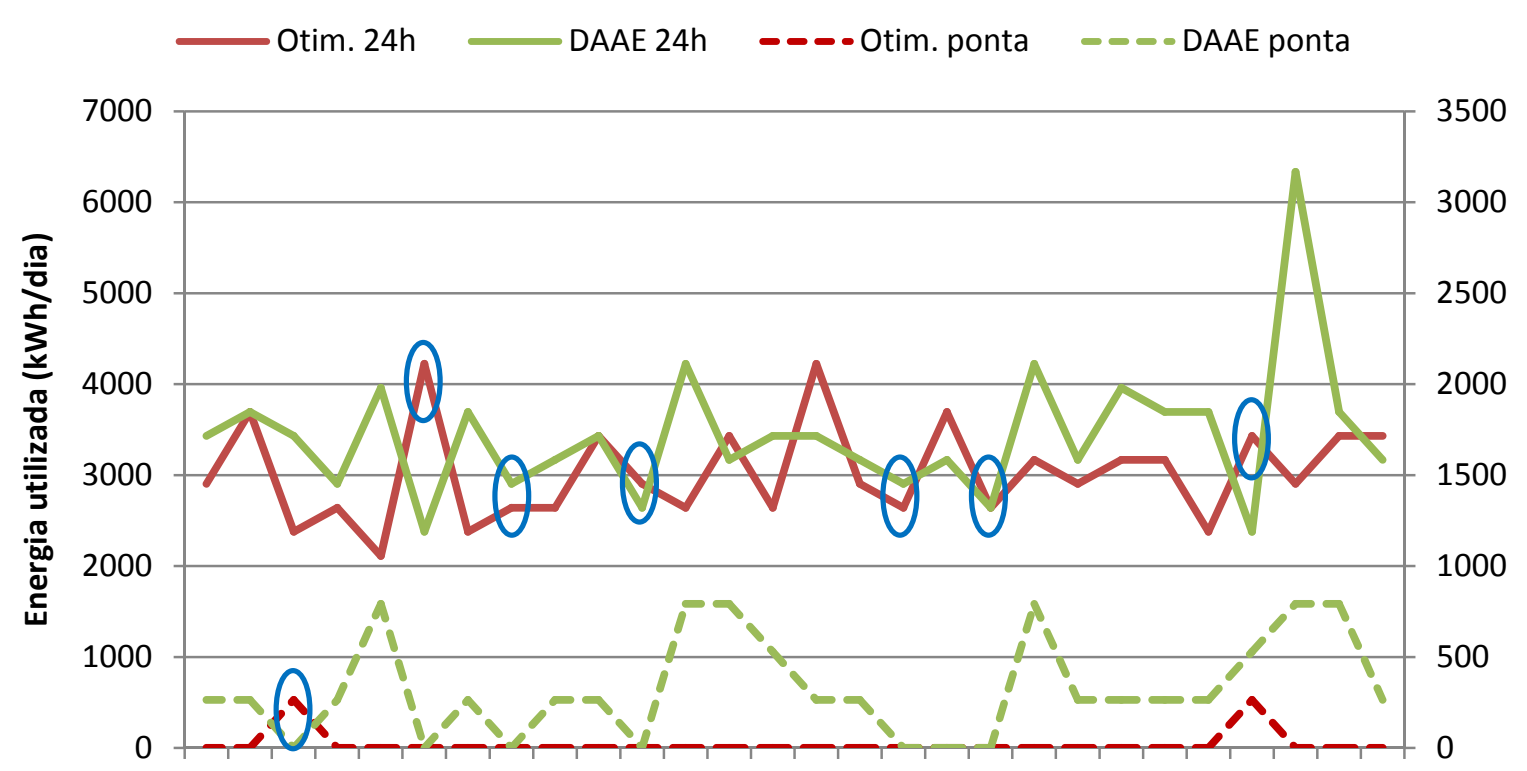

$1 \quad 2 \quad 3 \quad 4 \quad 5 \quad 6 \quad 7 \quad 8 \quad 910111213141516171819202122232425262728$

Ordem do Dia

Figura 5-29 - Energia utilizada pelas bombas durante as 24 horas e durante as horas de ponta - Setor Martinez

\subsection{Otimização Multiobjetivo da Operação em Tempo Real}

A otimização multiobjetivo foi realizada utilizando-se as redes completas dos Setores Eliana, Iguatemi e Martinez, descritos nos itens 4.7.1, 4.7.2 e 4.7.3, respectivamente. Usaramse combinações das funções objetivo custo e confiabilidade definidas no item 4.4 (página 99), aplicando-se a Abordagem I, definida no item 4.5.

Para analisar um dia típico da semana, escolheu-se a primeira terça-feira de cada período em que se realizou a otimização de objetivo único (item 5.5, página 162). Deste modo, escolheram-se os seguintes dias respectivamente para os Setores Eliana, Iguatemi e Martinez: $1^{\circ}$ dia (27/04), $6^{\circ}$ dia (17/08) e $7^{\circ}$ dia (19/08).

Consumiram-se 1,$8 ; 16,5$ e 2,5 minutos para se produzir as estratégias otimizadas da próxima hora para os Setores Eliana, Iguatemi e Martinez, respectivamente.

\subsubsection{Setor Eliana}

$\mathrm{Na}$ Tabela 5-20 foram resumidos os valores das funções objetivo resultantes da otimização multiobjetivo e da operação praticada pelo DAAE. A primeira coluna enumera as estratégias operacionais, a segunda coluna contém as respectivas funções objetivo escolhidas para serem otimizadas, enquanto que nas colunas seguintes, estão os valores das funções 
objetivo, com exceção das duas últimas colunas, que contém a energia utilizada durante o período de $24 \mathrm{~h}$ e durante o horário de ponta.

$\mathrm{Na}$ Tabela 5-21 representam-se as operações das bombas, em que a primeira coluna contém as funções objetivo utilizadas. Na segunda coluna há a bomba considerada (Bomba 1 - Poço Santa Marta I, Bomba 2 - Poço Santa Marta II), e nas colunas seguintes estão as horas do dia otimizado. As partes sombreadas indicam os períodos em que as bombas estão ligadas, sendo o sombreado em preto representa a Bomba 1 e o azul representa a Bomba 2. O período entre as 18 e $21 \mathrm{~h}$ foi hachurado em vermelho para representar o horário de ponta.

Tabela 5-20 - Resumo dos valores das Funções Objetivo para a otimização multiobjetivo e operação do DAAE - Setor Eliana

\begin{tabular}{|c|c|c|c|c|c|c|c|c|}
\hline \multirow{2}{*}{$\begin{array}{c}\text { Estratégia } \\
\text { no }\end{array}$} & \multirow[t]{2}{*}{ Função Objetivo } & \multirow{2}{*}{$\begin{array}{l}\text { Custo } \\
\text { (R\$) }\end{array}$} & \multirow[t]{2}{*}{ Entropia } & \multirow[t]{2}{*}{ Resiliência } & \multirow{2}{*}{$\begin{array}{l}\text { Nível } \\
\text { mín. } \\
\text { (m) }\end{array}$} & \multirow{2}{*}{$\begin{array}{c}\text { Pressão } \\
\text { Exced. } \\
\text { (m.c.a.) }\end{array}$} & \multicolumn{2}{|c|}{$\begin{array}{c}\text { Energia } \\
\text { Utilizada (kWh) }\end{array}$} \\
\hline & & & & & & & $24 \mathrm{~h}$ & Pico \\
\hline 1 & Custo & 167,34 & 20,77 & 3,25 & 0,68 & 42,51 & 1590 & 0 \\
\hline 2 & Custo + Entropia & 174,29 & 20,96 & 3,31 & 0,68 & 43,12 & 1696 & 0 \\
\hline 3 & Custo + Resiliência & 305,17 & 20,80 & 3,50 & 4,38 & 44,97 & 2438 & 318 \\
\hline 4 & Custo + Nível mínimo & 246,58 & 20,84 & 3,45 & 2,99 & 44,54 & 2332 & 106 \\
\hline 5 & Custo + Pressão & 180,17 & 21,19 & 3,27 & 0,68 & 42,69 & 2650 & 0 \\
\hline \multicolumn{2}{|c|}{ Operação praticada pelo DAAE } & 262,08 & 20,84 & 3,44 & 2,47 & 44,38 & 2014 & 212 \\
\hline
\end{tabular}

De acordo com a Tabela 5-20, não se percebem grandes variações dos valores de entropia e resiliência. A máxima entropia foi gerada pela estratégia 5, combinando-se o Custo e a Carga de Pressão Excedente como função objetivo, sendo que foi a que mais energia utilizou. A estratégia 3 produziu a máxima resiliência e maior nível mínimo, e a que mais utilizou energia durante o horário de ponta, tornando a operação mais custosa dentre as soluções multiobjetivo.

Na Figura 5-30 pode-se comparar a variação dos níveis do reservatório R8 para as diferentes estratégias otimizadas e para a operação praticada pelo DAAE. Nessa figura, o horário de ponta é destacado pelo sombreado em vermelho. Nas operações mais econômicas, os níveis mínimos dos reservatórios tendem a ser atingidos durante o horário de ponta (estratégias 1, 2 e 5), uma vez que não utilizaram as bombas no horário de ponta e o reservatório esvaziou-se mais rapidamente, pois nesse período ocorre o segundo pico de consumo no dia. Deste modo, para elevar o nível mínimo é necessário utilizar as bombas durante o horário de ponta, tornando a operação mais dispendiosa (estratégias 3, 4 e 6). 
As soluções mais econômicas (estratégias 1, 2, e 5) foram as que mais utilizaram o reservatório, o qual teve maiores períodos consecutivos de esvaziamento e acumulação, já que utilizaram as bombas de modo mais espaçado, conforme Tabela 5-21 e Figura 5-30.

A estratégias 4, que teve como função objetivo a maximização do nível mínimo do reservatório, foi a que mais se aproximou da operação praticada pelo DAAE, sendo que esta solução otimizada produziu menor custo e um nível mínimo maior que a operação do DAAE.

Tabela 5-21 - Programação das bombas gerada via otimização multiobjetivo - Setor Eliana

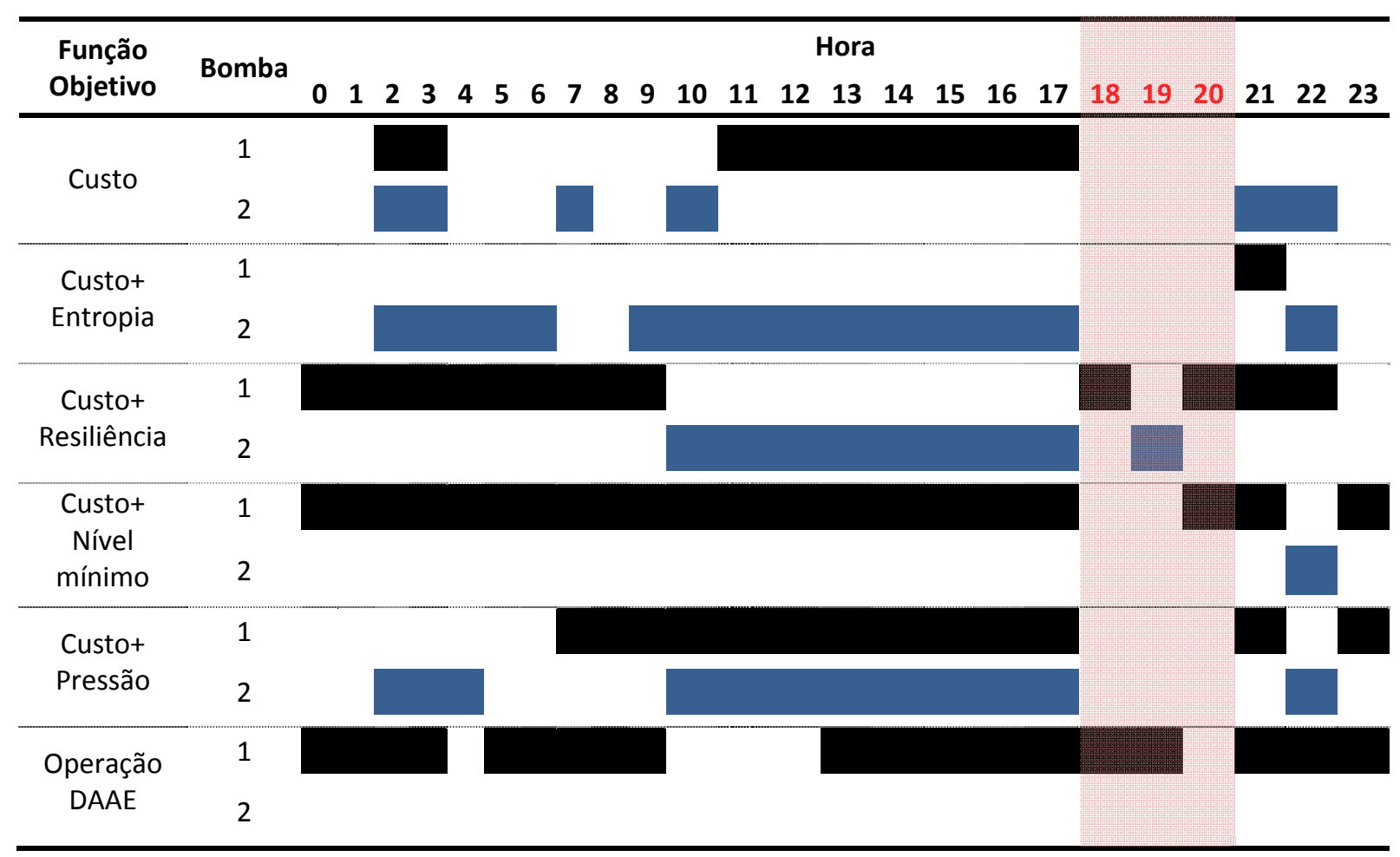

Obs.: Bomba 1

Bomba 2 Horário de Ponta 


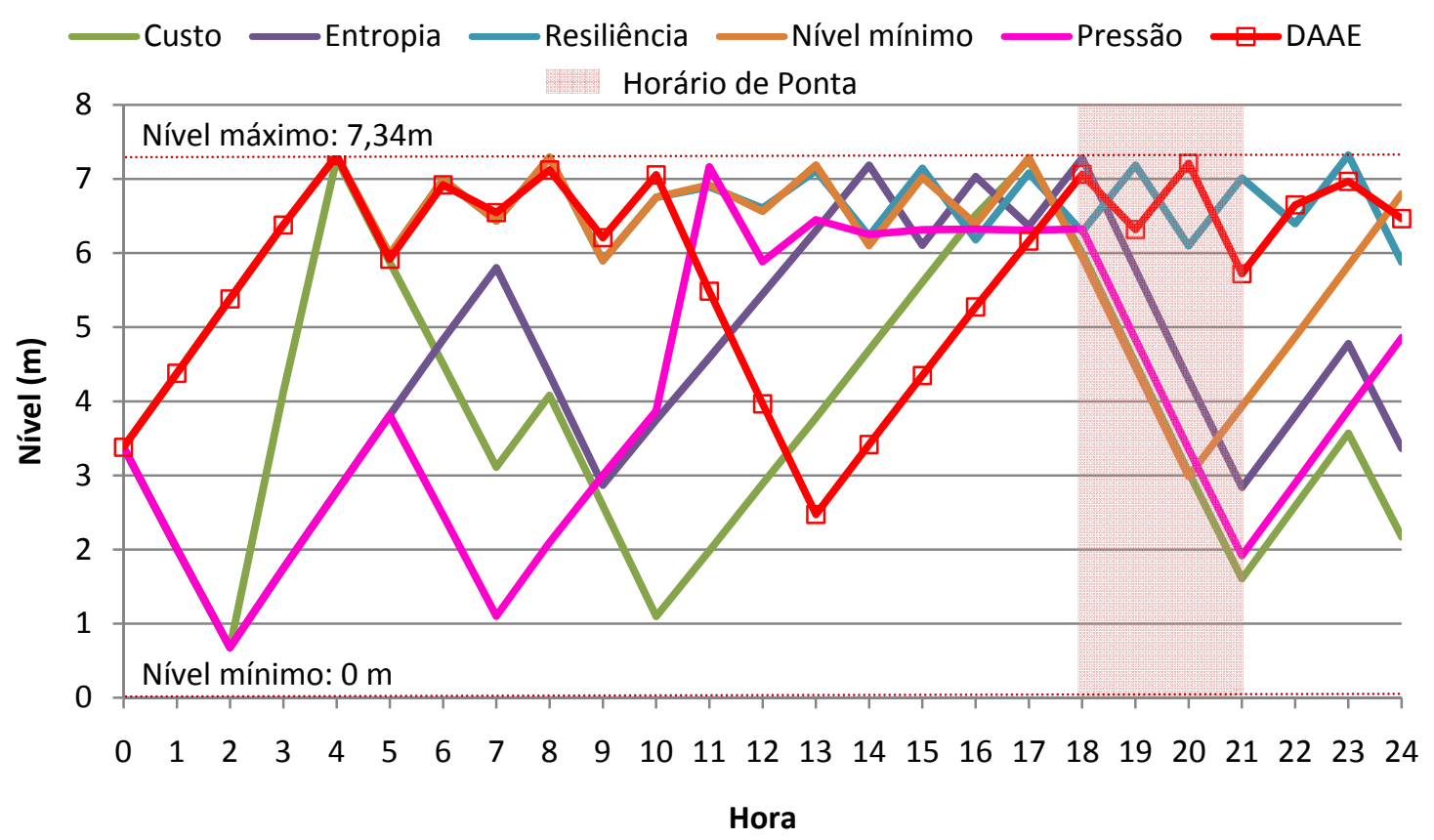

Figura 5-30 - Nível do reservatório R8 para as diferentes soluções Multiobjetivo - Setor Eliana

\subsubsection{Setor Iguatemi}

Na Tabela 5-22 são apresentados os resumos dos valores das funções objetivo produzidas pela otimização multiobjetivo e pela operação do DAAE. Observa-se que as estratégias 1, 2 e 4, de menores custos, assim como a operação praticada pelo DAAE, utilizaram menos as bombas durante o horário de ponta. Não se constataram grandes diferenças dos valores de Entropia, Resiliência e Carga de Pressão Excedente. O maior nível mínimo foi gerado pela estratégia 5, sendo que a estratégia 2 e a operação praticada pelo DAAE produziram níveis mínimos próximos a menores custos.

A programação das bombas para o Setor Iguatemi é representada na Tabela 5-23, sendo que as bombas 1, 2 e 3 correspondem as bombas do Poço Aldo Lupo, do Poço Iguatemi e a bomba de recalque entre as câmaras Inferior e Superior do R11. Observa-se que as estratégias que produziram níveis mínimos mais elevados utilizaram as bombas durante o horário de ponta, em especial a bomba 3. 
Tabela 5-22- Resumo das Funções Objetivo para a otimização multiobjetivo e operação do DAAE - Setor Iguatemi

\begin{tabular}{|c|c|c|c|c|c|c|c|c|}
\hline \multirow{2}{*}{$\begin{array}{c}\text { Estratégia } \\
\text { no }\end{array}$} & \multirow[t]{2}{*}{ Função Objetivo } & \multirow{2}{*}{$\begin{array}{l}\text { Custo } \\
\text { (R\$) }\end{array}$} & \multirow[t]{2}{*}{ Entropia } & \multirow[t]{2}{*}{ Resiliência } & \multirow{2}{*}{$\begin{array}{l}\text { Nível } \\
\text { mín. }^{47} \\
\text { (m) }\end{array}$} & \multirow{2}{*}{$\begin{array}{c}\text { Pressão } \\
\text { Exced. } \\
\text { (m.c.a.) }\end{array}$} & \multicolumn{2}{|c|}{$\begin{array}{c}\text { Energia } \\
\text { utilizada (kWh) }\end{array}$} \\
\hline & & & & & & & $24 \mathrm{~h}$ & pico \\
\hline 1 & Custo & 555.70 & 109.86 & 2.80 & 3.37 & 37.60 & 4789 & 175 \\
\hline 2 & Custo+Entropia & 599.36 & 114.14 & 2.71 & 13.92 & 37.11 & 6085 & 103 \\
\hline 3 & Custo+Resiliência & 880.52 & 113.78 & 2.75 & 13.38 & 37.50 & 5416 & 664 \\
\hline 4 & Custo+Nível mínimo & 521.85 & 113.72 & 2.67 & 9.78 & 36.71 & 4543 & 69 \\
\hline 5 & Custo+Pressão & 766.36 & 113.84 & 2.74 & 14.36 & 37.43 & 4649 & 595 \\
\hline \multicolumn{2}{|c|}{ Operação praticada pelo DAAE } & 601.14 & 113.88 & 2.73 & 14.24 & 37.28 & 5241 & 103 \\
\hline
\end{tabular}

Tabela 5-23 - Programação das bombas gerada via otimização multiobjetivo - Setor Iguatemi

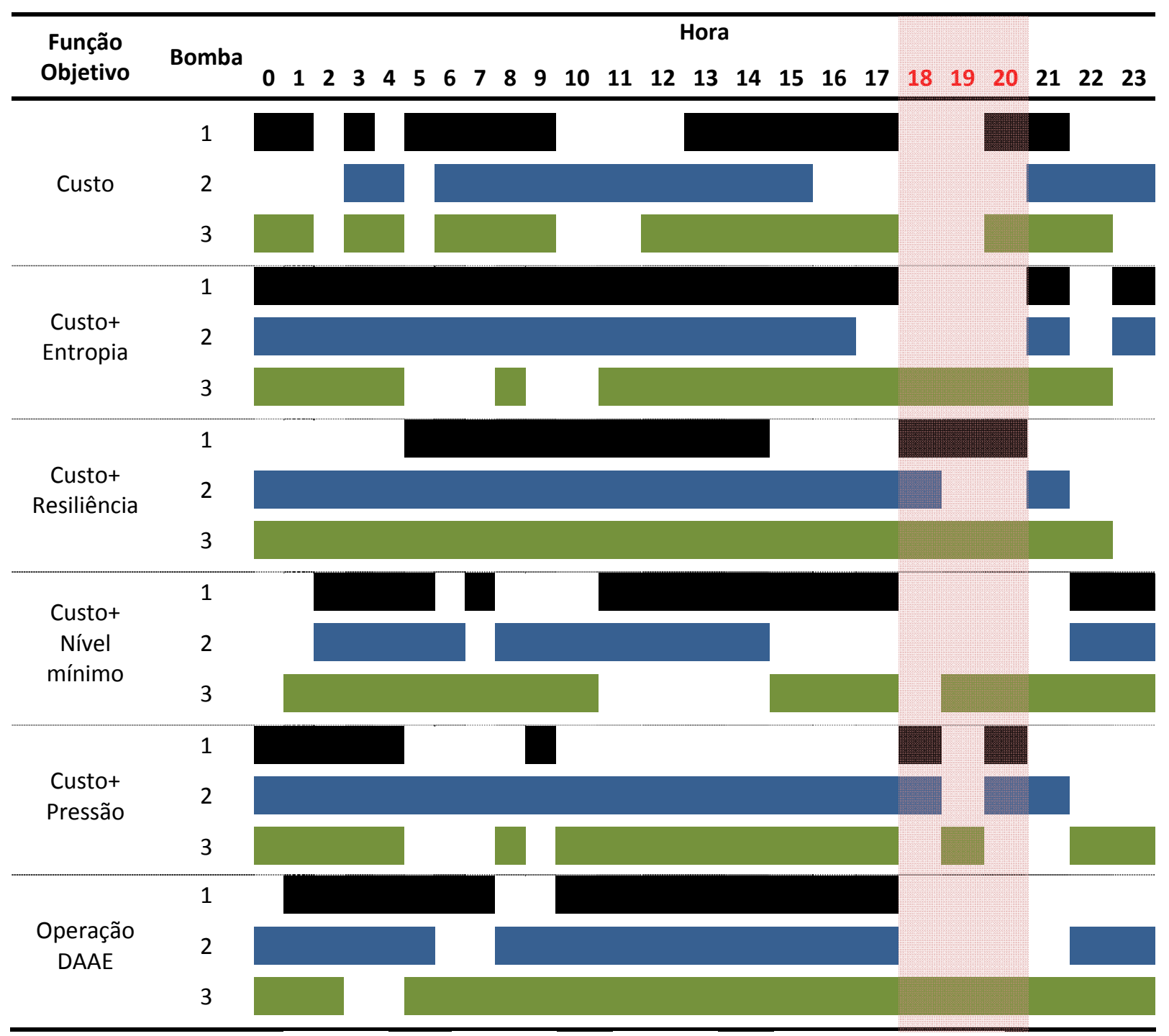

Obs.: Bomba $1 \square$ Bomba $2 \square$ Bomba $3 \quad$ Horário de Ponta

${ }^{47}$ Para o cálculo do nível mínimo ignorou-se o nível do reservatório R11 Inferior, por se tratar de um reservatório de passagem entre o R25 e o R11 Superior. 
A variação dos níveis dos reservatórios R11 Superior e R25 pode ser examinada nas Figura 5-31 e Figura 5-32, respectivamente. Ao se considerar a maximização do nível mínimo dos reservatórios, não se produziu o maior nível mínimo dentre as diversas estratégias multiobjetivo, enquanto que a solução de menor custo esvaziou quase completamente o R11 Superior. O nível dos reservatórios resultantes da operação do DAAE se mantiveram altos durante a maior parte do dia, que caracteriza uma operação geralmente praticada pelos operadores de redes de abastecimento.

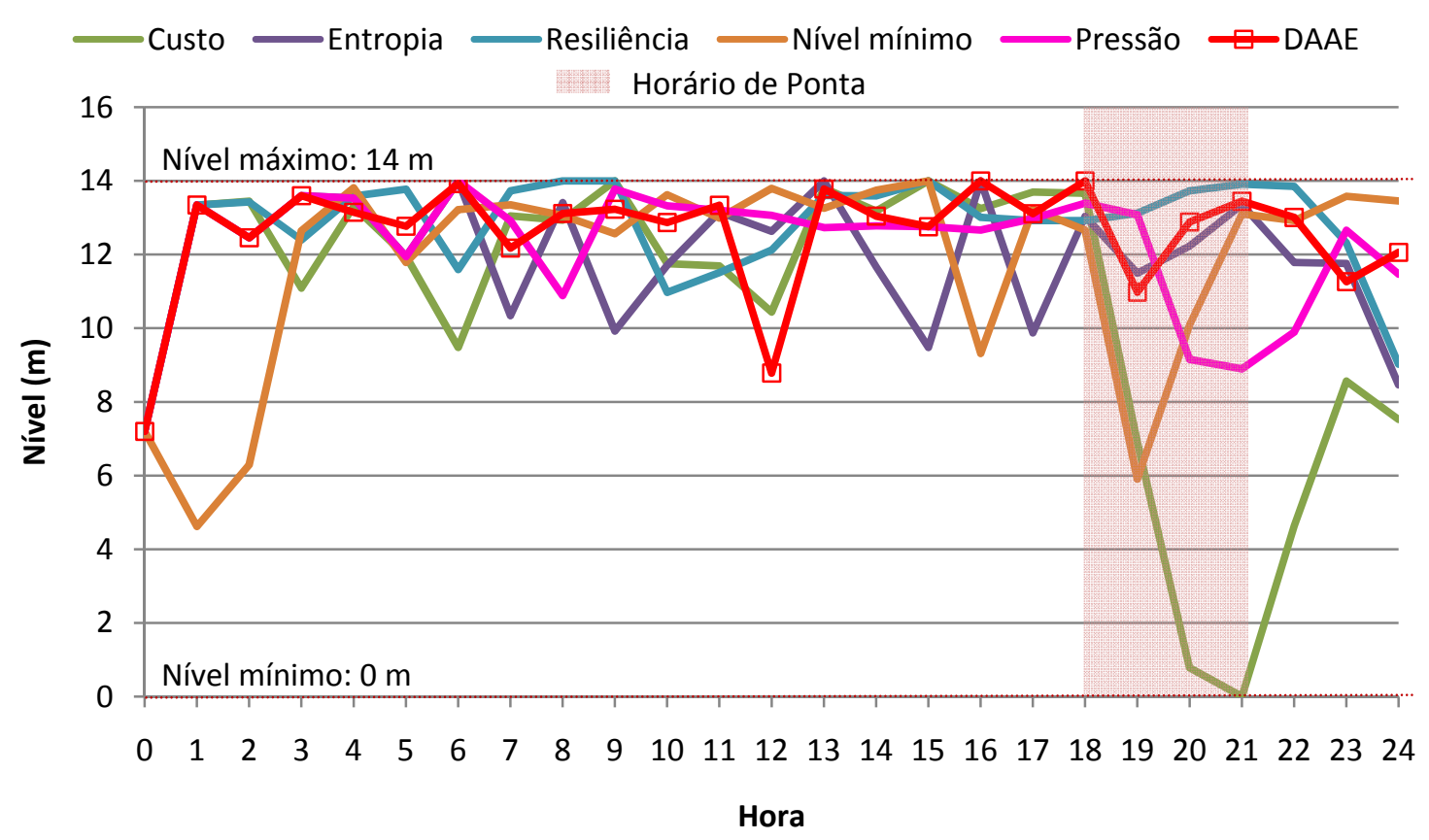

Figura 5-31 - Nível do reservatório R11 Superior para as diferentes soluções Multiobjetivo -Setor Iguatemi 


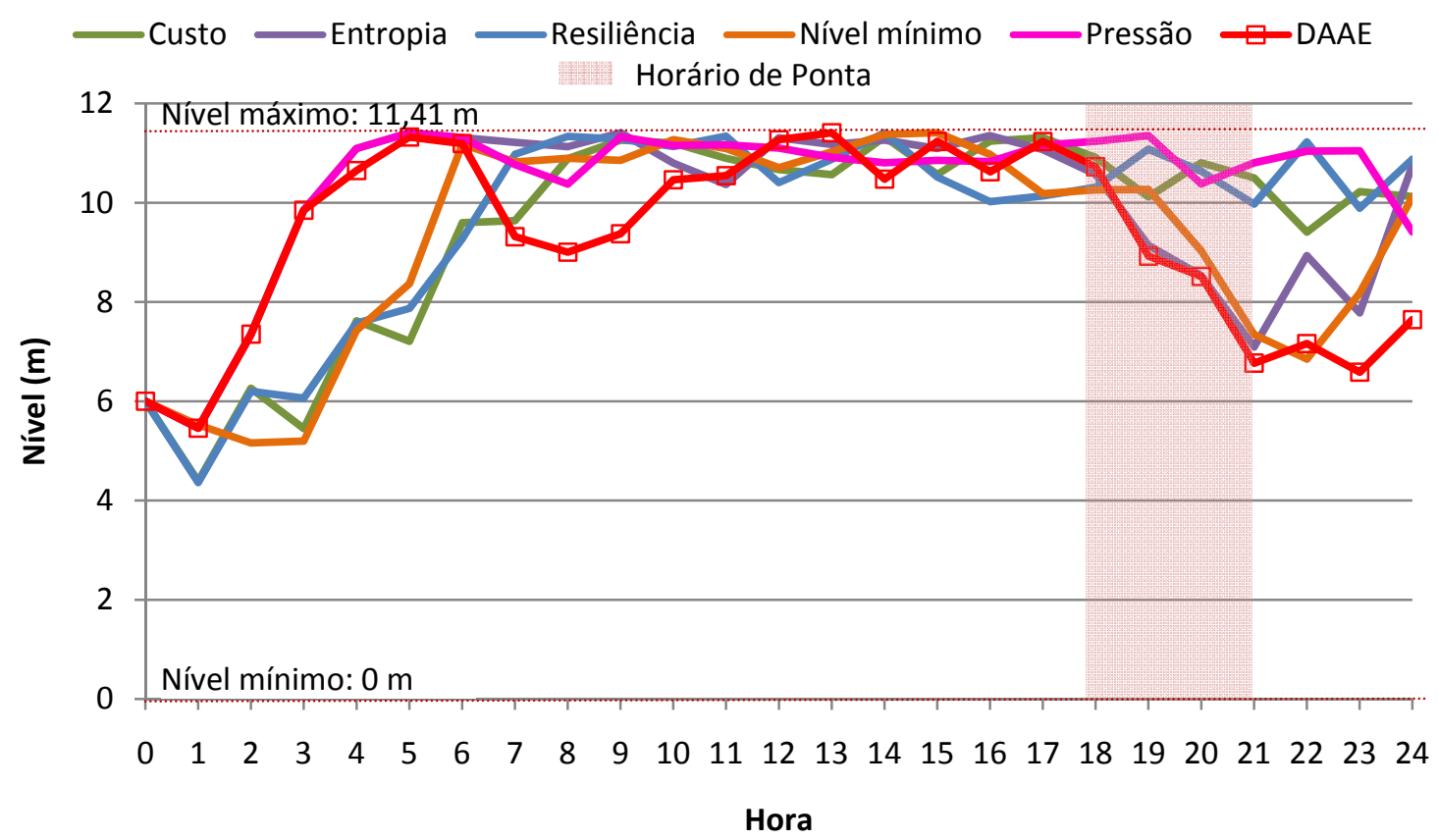

Figura 5-32 - Nível do reservatório R25 para as diferentes soluções Multiobjetivo - Setor Iguatemi

\subsubsection{Setor Martinez}

Na Tabela 5-24 são resumidos os valores das funções objetivo para as diversas estratégias multiobjetivo e da operação praticada pelo DAAE. Nota-se pouca variação dos resultados entre as estratégias otimizadas, principalmente dos valores de entropia, resiliência e pressão excedente. A estratégia 1, que considerou apenas a minimização do custo, gerou o menor consumo de energia e consequentemente o menor custo. A operação praticada pelo DAAE produziu o maior nível mínimo, mas foi também a mais custosa das estratégias, sendo que estratégia 4, que utilizou como funções objetivo o custo e o nível mínimo, produziu nível mínimo muito próximo a um custo mais reduzido. 
Tabela 5-24 - Resumo das Funções Objetivo para a otimização multiobjetivo e operação do DAAE - Setor Martinez

\begin{tabular}{|c|c|c|c|c|c|c|c|c|}
\hline \multirow{2}{*}{$\begin{array}{c}\text { Estratégia } \\
\text { no }\end{array}$} & \multirow[t]{2}{*}{ Função Objetivo } & \multirow{2}{*}{$\begin{array}{l}\text { Custo } \\
\text { (R\$) }\end{array}$} & \multirow[t]{2}{*}{ Entropia } & \multirow[t]{2}{*}{ Resiliência } & \multirow{2}{*}{$\begin{array}{l}\text { Nível } \\
\text { mín. } \\
{ }^{48}(\mathrm{~m})\end{array}$} & \multirow{2}{*}{$\begin{array}{l}\text { Pressão } \\
\text { Exced. } \\
\text { (m.c.a.) }\end{array}$} & \multicolumn{2}{|c|}{$\begin{array}{c}\text { Energia } \\
\text { utilizada (kWh) }\end{array}$} \\
\hline & & & & & & & $24 \mathrm{~h}$ & pico \\
\hline 1 & Custo & 325.28 & 109.77 & 2.72 & 2.60 & 36.76 & 2376 & 0 \\
\hline 2 & Custo+Entropia & 357.58 & 109.94 & 2.80 & 3.16 & 37.56 & 4488 & 0 \\
\hline 3 & Custo+Resiliência & 327.43 & 109.98 & 2.79 & 3.28 & 37.50 & 3696 & 0 \\
\hline 4 & Custo+Nível mínimo & 357.63 & 109.98 & 2.80 & 3.31 & 37.61 & 4488 & 0 \\
\hline 5 & Custo+Pressão & 335.25 & 109.85 & 2.79 & 3.16 & 37.49 & 4224 & 0 \\
\hline Operação & raticada pelo DAAE & 453.51 & 109.94 & 2.80 & 3.51 & 37.61 & 3696 & 264 \\
\hline
\end{tabular}

Neste setor, a operação do DAAE produziu maiores custos do que as demais soluções, pois foi a única que utilizou a bomba durante a hora de ponta, como pode ser constatado pelos resultados da Tabela 5-25.

Tabela 5-25 - Programação das bombas gerada via otimização multiobjetivo - Setor Martinez

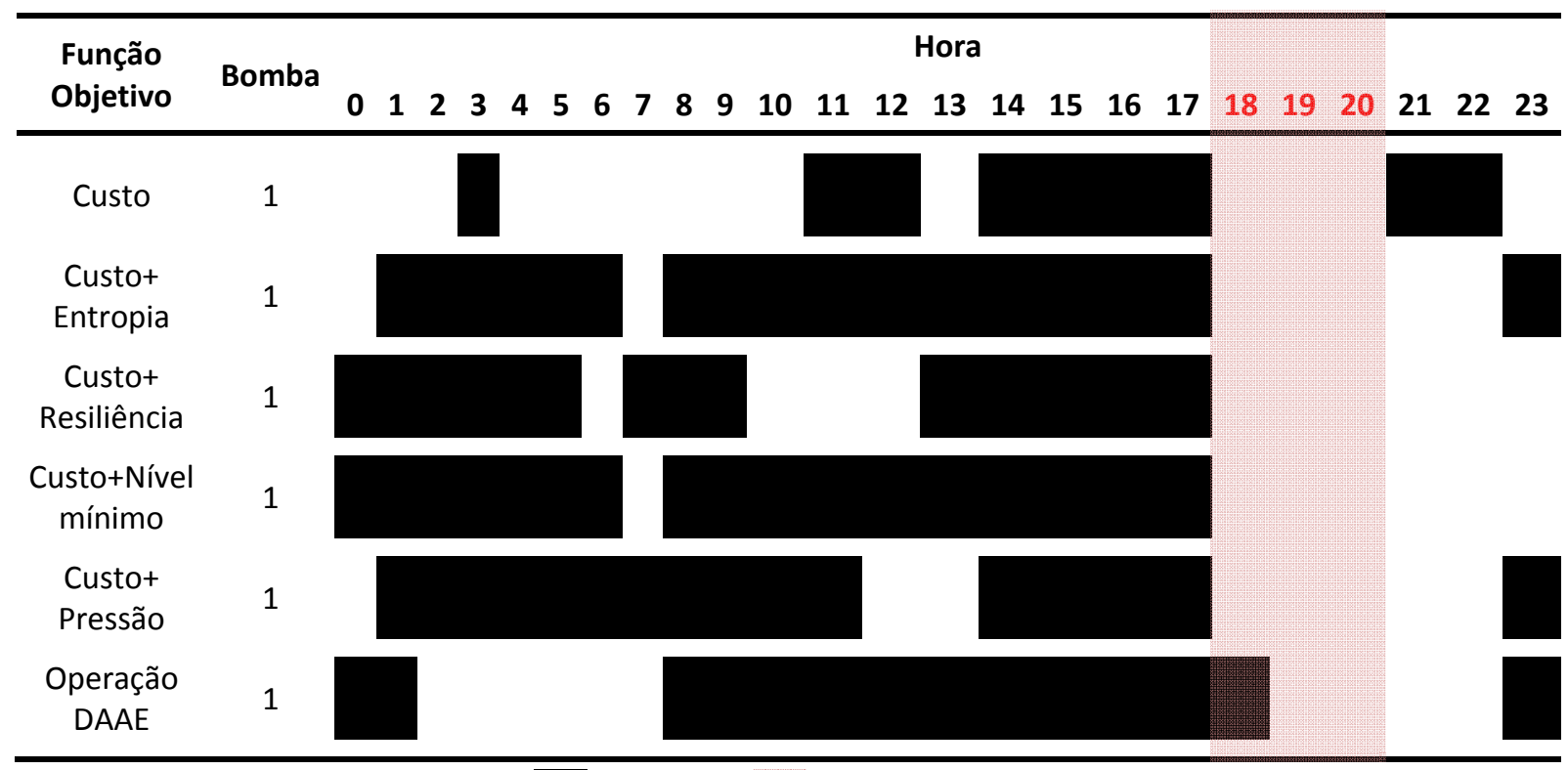

Obs.:

${ }^{48}$ O Nível mínimo foi calculado considerando-se os reservatórios R15 e R29 como um único reservatório, já que ambos recebem água simultaneamente do Poço Standard e abastecem ao mesmo tempo o Setor Martinez 
Analisando-se a Figura 5-33, verifica-se que a estratégia otimizada de menor custo manteve os reservatórios em níveis mais baixos, enquanto que a estratégia 4, que teve como objetivo maximizar o nível mínimo, manteve o nível mais elevado na maior parte do tempo.

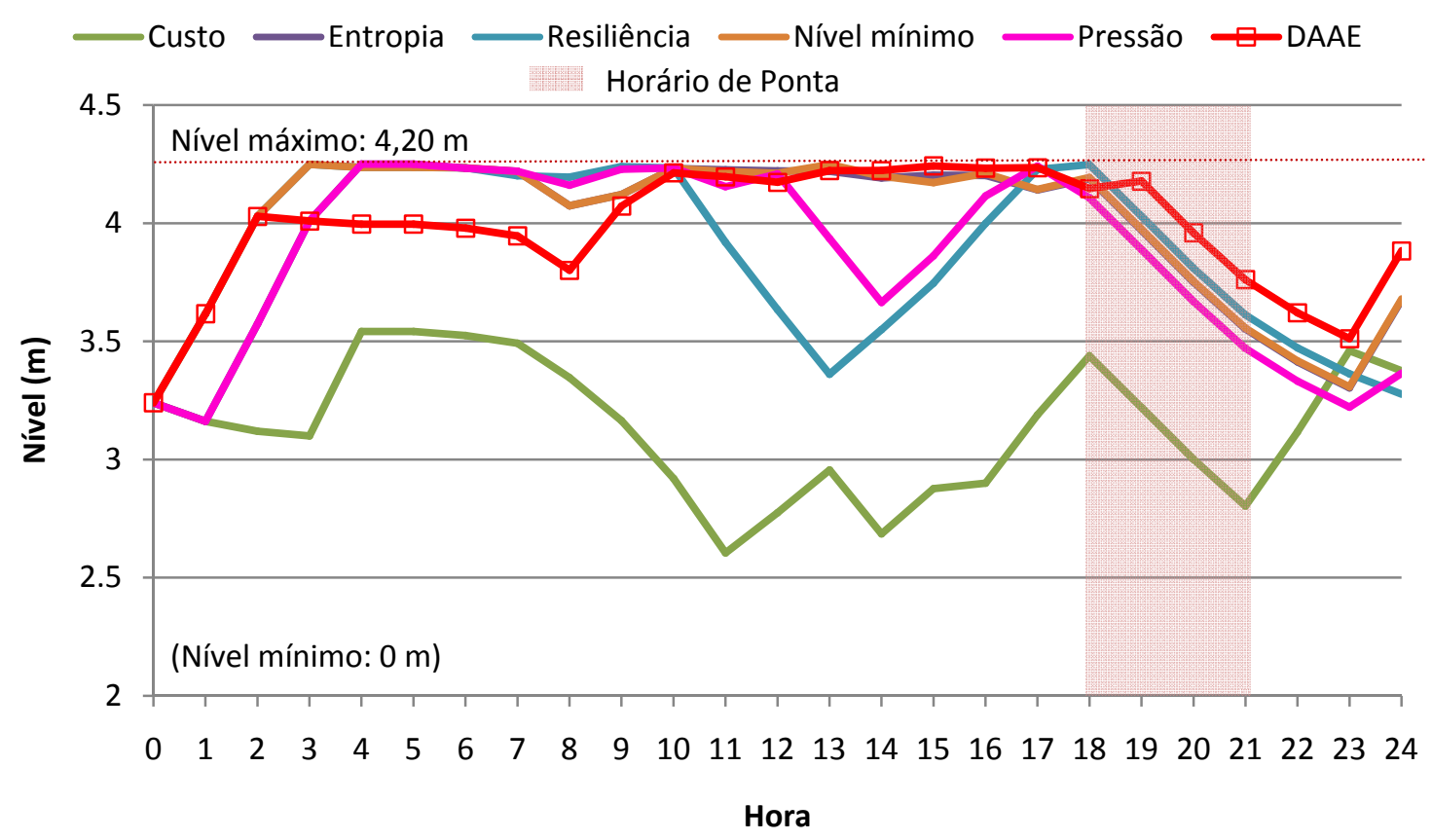

Figura 5-33 - Nível do reservatório R15 para as diferentes soluções Multiobjetivo - Setor Martinez

\subsection{Resultados preliminares da otimização multiobjetivo com aplicação da Abordagem III}

Durante a implementação da otimização multiobjetivo, realizaram-se testes preliminares em conjunto com a aplicação da Abordagem III, definida no item 4.5. Foram consideradas as funções objetivo custo, entropia e resiliência.

Estes testes foram realizados usando-se a rede de abastecimento do setor Iguatemi, sem a calibração das rugosidades, pois foram realizados antes da realização das campanhas de campo para calibração das redes de abastecimento de água. Portanto, tais resultados preliminares não podem ser comparados com os demais resultados produzidos com a rede calibrada.

Foram realizados testes de otimização utilizando população inicial de 100 soluções e 100 gerações, totalizando 10.000 avaliações da função objetivo. 
As funções objetivo foram combinadas para se verificar a relação entre custo e as outras funções objetivo. Os resultados foram resumidos nas Tabelas 5-26 a 5-28, nos quais são apresentadas as melhores soluções da Frente Pareto para cada combinação das funções objetivo.

A primeira coluna especifica as funções objetivo escolhidas para realizar a otimização da operação dessas tabelas contém os valores produzidos para as funções objetivo utilizadas. $\mathrm{Na}$ segunda coluna, especifica-se se foi utilizada a Abordagem I ou III. Na terceira coluna apresenta-se a ordem da solução. Nas colunas seguintes são apresentados, respectivamente, o custo da operação, a entropia, a resiliência e uma observação referente à solução, em que se destacam em quais funções objetivo a solução apresentada se destacam em relação às demais soluções da Frente Pareto, para a mesma combinação de funções objetivo.

Na Tabela 5-26 são apresentados os resultados para a otimização com uma a duas funções objetivos, combinando-se o custo a outra função objetivo. A melhora nos valores de entropia e resiliência é acompanhada pelo aumento no custo da operação em relação à operação mais econômica.

Tabela 5-26 - Resumo dos resultados utilizando 1 a 2 funções objetivo com uso da Abordagem I

\begin{tabular}{lcccccc}
\hline Objetivos & Abordag. & $\begin{array}{c}\text { Solução } \\
\text { No }\end{array}$ & $\begin{array}{c}\text { Custo } \\
\text { (R\$) }\end{array}$ & Entropia & Resiliência & Observação* \\
\hline Custo & $\mathrm{I}$ & 1 & 2024,22 & 154,43 & 1,12 & $\downarrow \mathrm{C}$ \\
\hline Custo + Entropia & $\mathrm{I}$ & 2 & 2069,49 & 155,10 & 1,19 & $\downarrow \mathrm{Ce} \uparrow \mathrm{E}$ \\
\hline Custo + Resiliência & $\mathrm{I}$ & 3 & 2187,59 & 155,06 & 1,22 & $\downarrow \mathrm{Ce} \uparrow \mathrm{R}$ \\
\hline
\end{tabular}

*nota: $\downarrow C$ - Menor custo | $\mathrm{TE}$ - maior entropia | $\mathrm{R}$ - maior resiliência

Na Tabela 5-27 apresentam-se os resultados da otimização multiobjetivo utilizando-se Abordagem III.

Nas Figuras 5-34 e 5-35 são apresentadas as soluções da otimização de objetivo único (minimização do custo) e da Frente Pareto das otimizações multiobjetivo, utilizando-se respectivamente entropia e resiliência associadas ao custo. Em ambos os casos observa-se pequena variabilidade das soluções, seja com ou sem uso da Abordagem III. 
Tabela 5-27 - Resumo dos resultados da otimização multiobjetivo utilizando-se Abordagem III

\begin{tabular}{lcccccc}
\hline Objetivos & Abordag. & $\begin{array}{c}\text { Solução } \\
\text { No }\end{array}$ & $\begin{array}{c}\text { Custo } \\
\text { (R\$) }\end{array}$ & Entropia & Resiliência & Observação* \\
\hline Custo + Entropia & \multirow{2}{*}{ III } & 4 & 2024,22 & 154,43 & 1,12 & $\downarrow \mathrm{C}$ \\
& & 5 & 2468,56 & 154,69 & 1,16 & $\uparrow \mathrm{E}$ \\
\hline Custo + Resiliência & III & 6 & 2024,22 & 154,43 & 1,12 & $\downarrow \mathrm{Ce} \uparrow \mathrm{R}$ \\
\hline
\end{tabular}

*nota: $\downarrow C$ - Menor custo | $\mathrm{TE}$ - maior entropia | $\mathrm{R}$ - maior resiliência

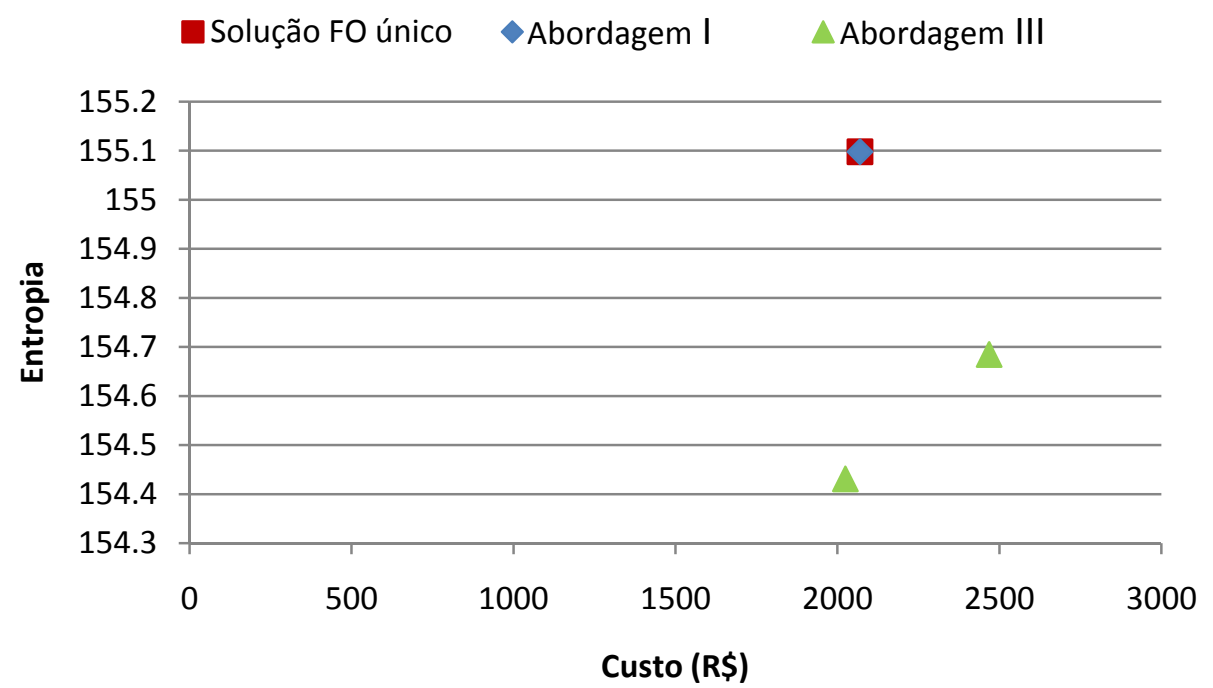

Figura 5-34 - Soluções da Frente Pareto entre Entropia e Custo da operação com da Abordagem I e III

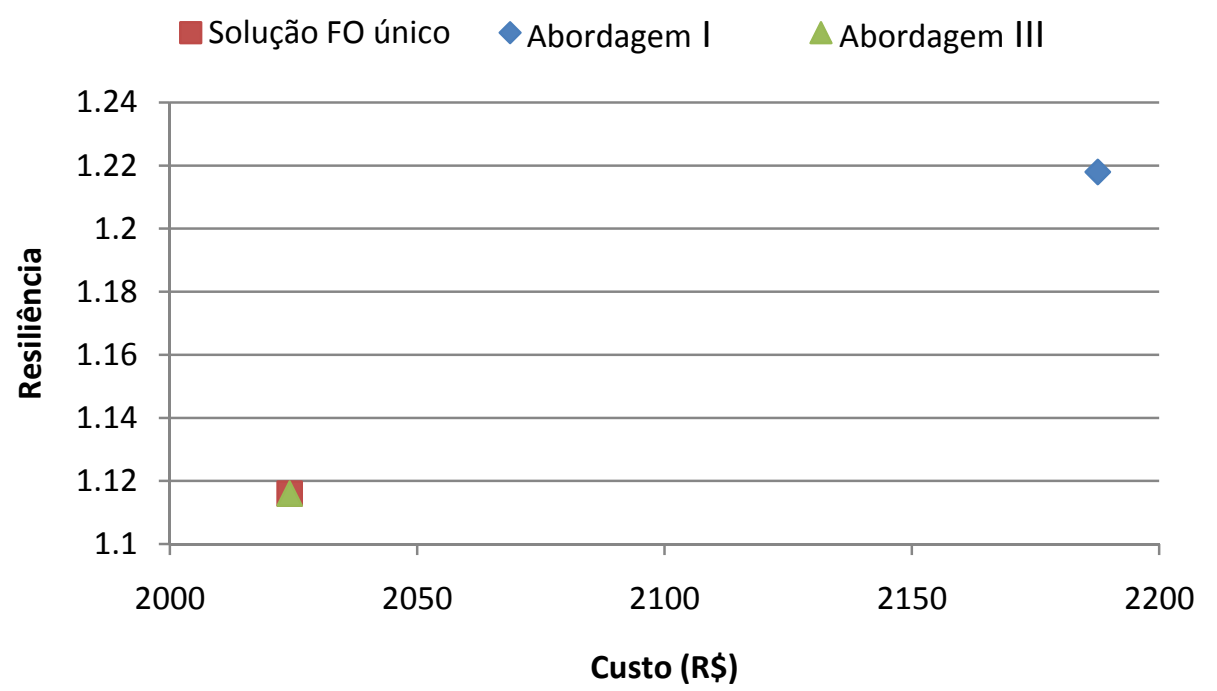

Figura 5-35 - Soluções da Frente Pareto entre Resiliência e Custo da operação com uso da Abordagem I e III 
A fim de ampliar a variabilidade das soluções na frente Pareto, realizou-se nova otimização multiobjetivo utilizando-se 250 e 400 soluções iniciais, utilizando-se a Abordagem III. Manteve-se a carga computacional do processo de otimização fixando-se o número de avaliações da função objetivo em 10.000, resultando respectivamente em 40 e 25 gerações. Os resultados foram ilustrados nas Figura 5-36 e Figura 5-37, empregando-se as funções objetivo entropia e resiliência, além da função custo. Observa-se que quanto maior o número de soluções iniciais, maior a variabilidade de soluções Pareto obtidas.

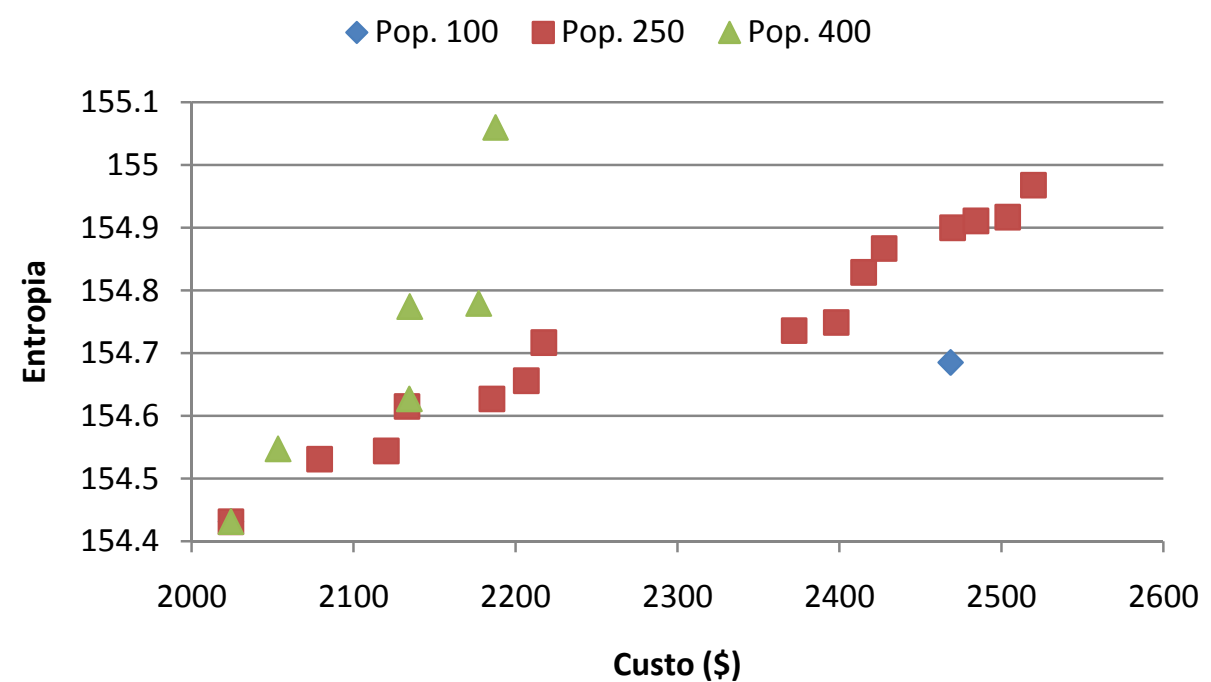

Figura 5-36 - Soluções Multiobjetivo entre Entropia e Custo da operação com diferentes números de soluções iniciais para Abordagem III

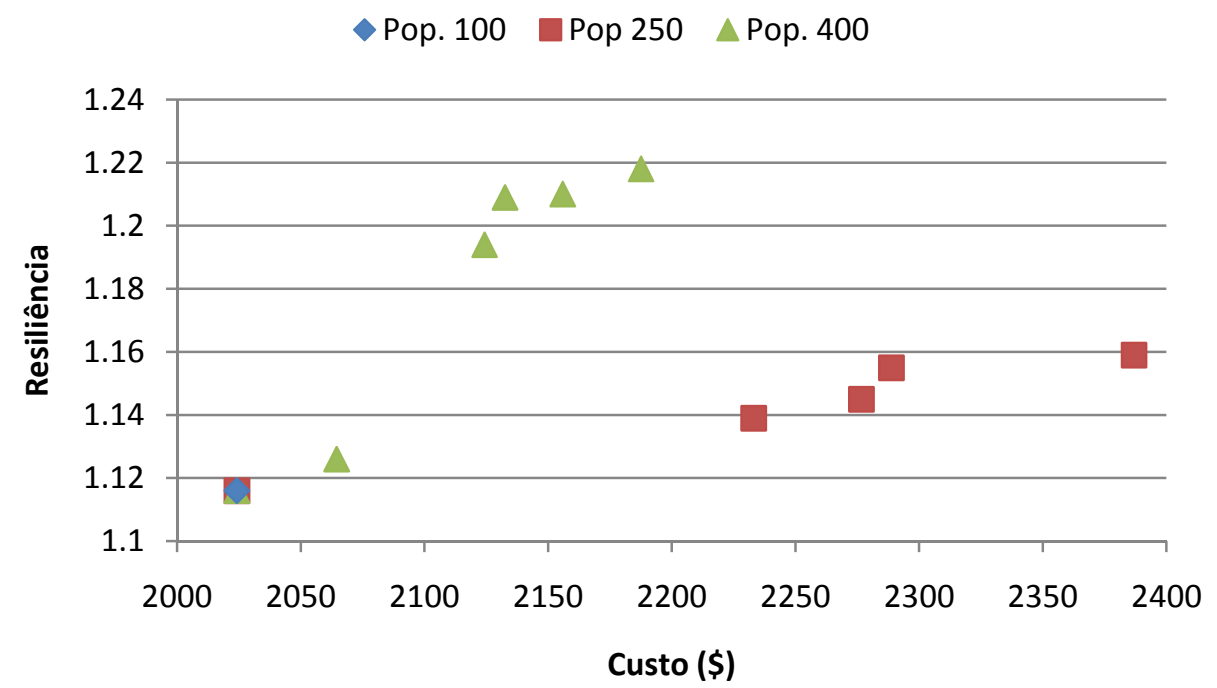

Figura 5-37 - Soluções Multiobjetivo entre Resiliência e Custo da operação com diferentes números de soluções iniciais para Abordagem III 
Nas Tabelas 5-29, 5-30 e 5-31 exibem-se as respectivas estratégias de operação das bombas. A célula hachurada em preto da tabela representa a bomba ligada, enquanto que a célula vazia representa a bomba desligada. Pode-se observar que a maioria das soluções não utilizaram a bomba do reservatório R-11, com exceção da solução número 5. As soluções de menores custos tendem a não utilizar a energia de maior custo, ou seja, o horário de ponta entre as 18:00 e 21:00.

A solução de maior entropia (Número 2), dentre as soluções de número 1 a 6 , utilizou por 24 horas a bomba do Poço Aldo Lupo, e por 22 horas o Poço Iguatemi, mantendo-a desligada por duas horas durante o horário de ponta. Por outro lado, a solução de maior resiliência $\left(\mathrm{N}^{0} 5\right)$ utilizou ambas as bombas por 24 horas.

Realizaram-se também outros testes usando-se três funções objetivos. Nos resultados da Tabela 5-28 são apresentadas as soluções com e sem uso da Abordagem III.

Tabela 5-28 - Resumo dos resultados com 3 funções objetivo utilizando Abordagem I e III

\begin{tabular}{ccccccc}
\hline Objetivos & Abordag. & $\begin{array}{c}\text { Solução } \\
\text { No }\end{array}$ & $\begin{array}{c}\text { Custo } \\
\text { (R\$) }\end{array}$ & Entropia & Resiliência & Observação* \\
\hline $\begin{array}{c}\text { Custo + Entropia + } \\
\text { Resiliência }\end{array}$ & I & 7 & 2187,59 & 155,06 & 1,22 & $\downarrow C, \uparrow E$ e $\uparrow R$ \\
$\begin{array}{c}\text { Custo + Entropia + } \\
\text { Resiliência }\end{array}$ & III & 8 & 2187,59 & 155,06 & 1,22 & $\downarrow C, \uparrow E$ e $\uparrow R$ \\
\hline
\end{tabular}

*nota: $\downarrow C$ - Menor custo | $\mathrm{E}$ - maior entropia | $\mathrm{R}$ - maior resiliência 
Tabela 5-29 - Programação da bomba do reservatório R11 (superior) para as soluções de 1-6 utilizando Abordagem I e III

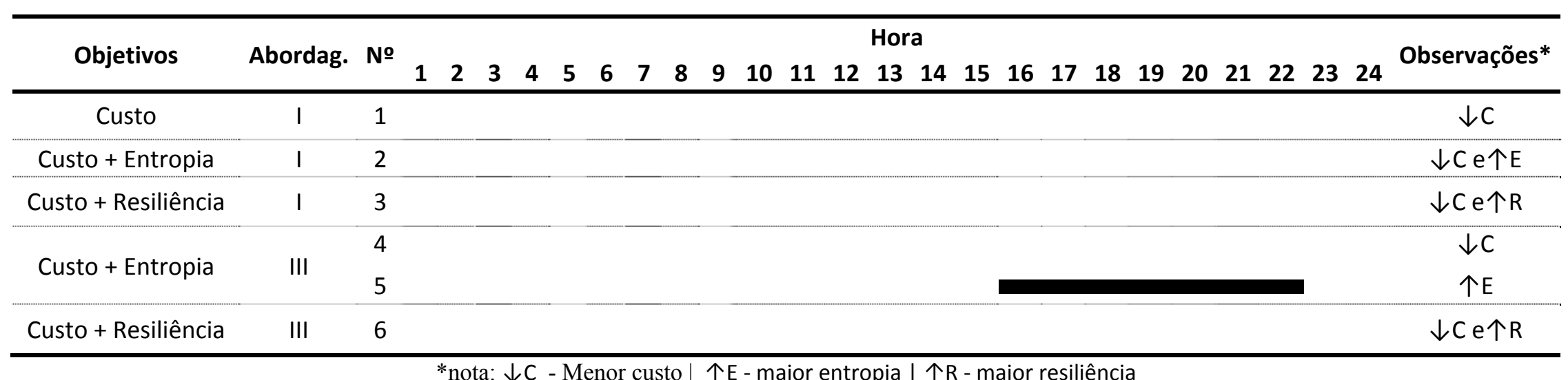

Tabela 5-30 - Programação da bomba do Poço Iguatemi para as soluções de 1-6 utilizando Abordagem I e III

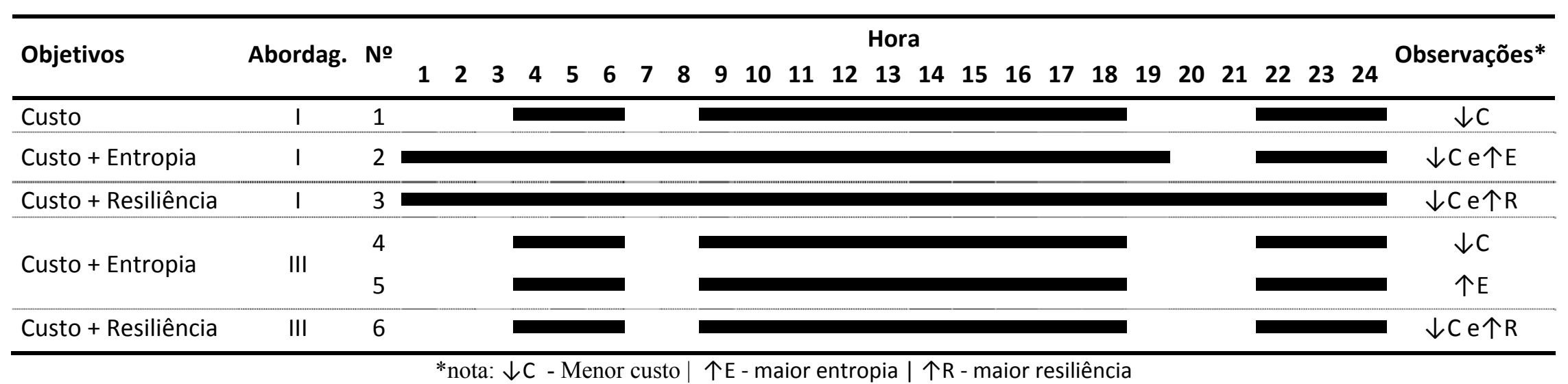

*nota: $\downarrow C$ - Menor custo $\mid \uparrow E$ - maior entropia | $R R$ - maior resiliência 
Tabela 5-31 - Programação da bomba do Poço Aldo Lupo para as soluções de 1-6 utilizando Abordagem I e III

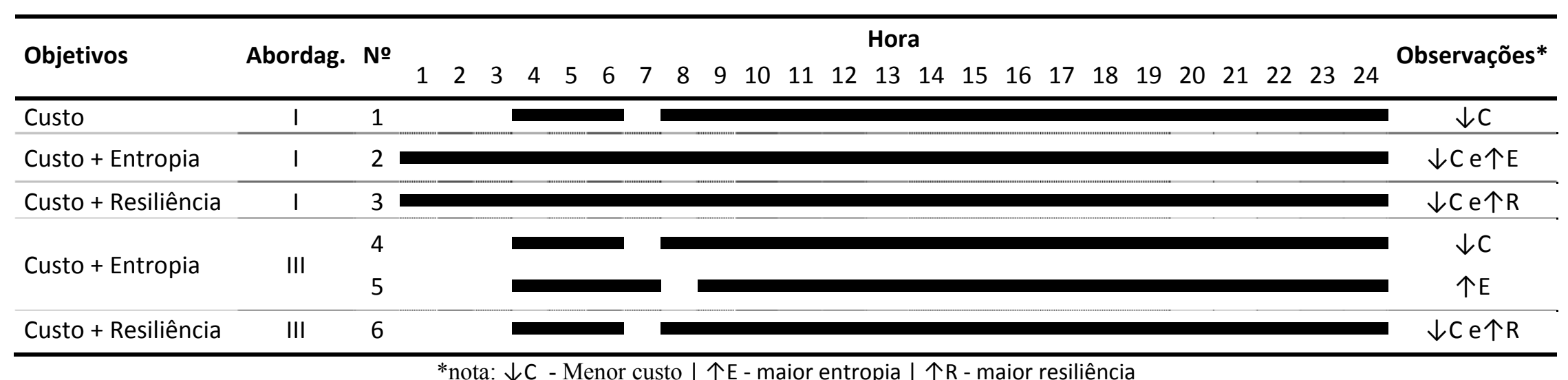


Analisando-se os resultados da Tabela 5-28, nota-se que a função objetivo resiliência domina o processo de otimização, visto que é produzido o mesmo resultado da solução Número 3, em que se considera apenas o custo e a resiliência.

Novamente, verificou-se também para os testes de otimização com 3 funções objetivo a influência do tamanho da população inicial, para os casos em que se utiliza a Abordagem III. Os resultados foram resumidos na Tabela 5-32, na qual se apresenta apenas soluções que pertençam a Frente Pareto.

Observa-se que de modo geral, aumentando-se a população inicial de soluções, consegue-se uma melhor variabilidade das soluções, sendo que na maioria dos casos, utilizando-se 400 soluções iniciais, consegue-se maior variabilidade de soluções.

Tabela 5-32 - Resumo dos resultados otimizando-se o Custo, a Entropia e a Resiliência, com variação da população inicial para Abordagem III

\begin{tabular}{|c|c|c|c|c|}
\hline $\begin{array}{l}\text { População } \\
\text { inicial }\end{array}$ & $\begin{array}{c}\text { Solução } \\
\text { № }\end{array}$ & Custo & Entropia & Resiliência \\
\hline \multirow{2}{*}{100} & 9 & 2187,59 & 155,06 & 1,22 \\
\hline & 10 & 2226,90 & 154,73 & 1,22 \\
\hline \multirow{6}{*}{250} & 11 & 2024,22 & 154,43 & 1,12 \\
\hline & 12 & 2147,19 & 154,42 & 1,18 \\
\hline & 13 & 2158,38 & 154,56 & 1,18 \\
\hline & 14 & 2162,56 & 154,38 & 1,16 \\
\hline & 15 & 2189,90 & 154,73 & 1,20 \\
\hline & 16 & 2232,12 & 154,47 & 1,20 \\
\hline \multirow{10}{*}{400} & 17 & 2024,22 & 154,43 & 1,12 \\
\hline & 18 & 2059,89 & 154,89 & 1,14 \\
\hline & 19 & 2112,68 & 154,83 & 1,18 \\
\hline & 20 & 2145,54 & 154,67 & 1,18 \\
\hline & 21 & 2173,86 & 154,46 & 1,19 \\
\hline & 22 & 2185,81 & 155,01 & 1,21 \\
\hline & 23 & 2186,19 & 155,00 & 1,21 \\
\hline & 24 & 2193,62 & 154,54 & 1,22 \\
\hline & 25 & 2219,11 & 154,50 & 1,21 \\
\hline & 26 & 2241,33 & 154,66 & 1,23 \\
\hline
\end{tabular}


Nas Tabelas 5-33 a 5-35 são representadas as respectivas estratégias de operação das bombas para as soluções 7 e 8 . Verifica-se que ambas as soluções possuem a mesma estratégia operacional da solução número 3, sendo que utilizam por 24h as bombas Aldo Lupo e do Poço Iguatemi.

Com o objetivo de verificar a convergência das soluções, foram plotados os valores das funções objetivo versus a ordem em que a mesma foi avaliada. Foram incluídas apenas as soluções a partir da $801^{\mathrm{a}}$ avaliação da função objetivo. Tais gráficos foram ilustrados nas Figuras 5-38 a 5-42.

$\mathrm{Na}$ otimização considerando-se apenas o custo, percebe-se na Figura 5-38 que as soluções convergiram em cerca de 5.000 avaliações da função objetivo (FO). No correspondente estágio da otimização foi gerada a solução de menor custo.

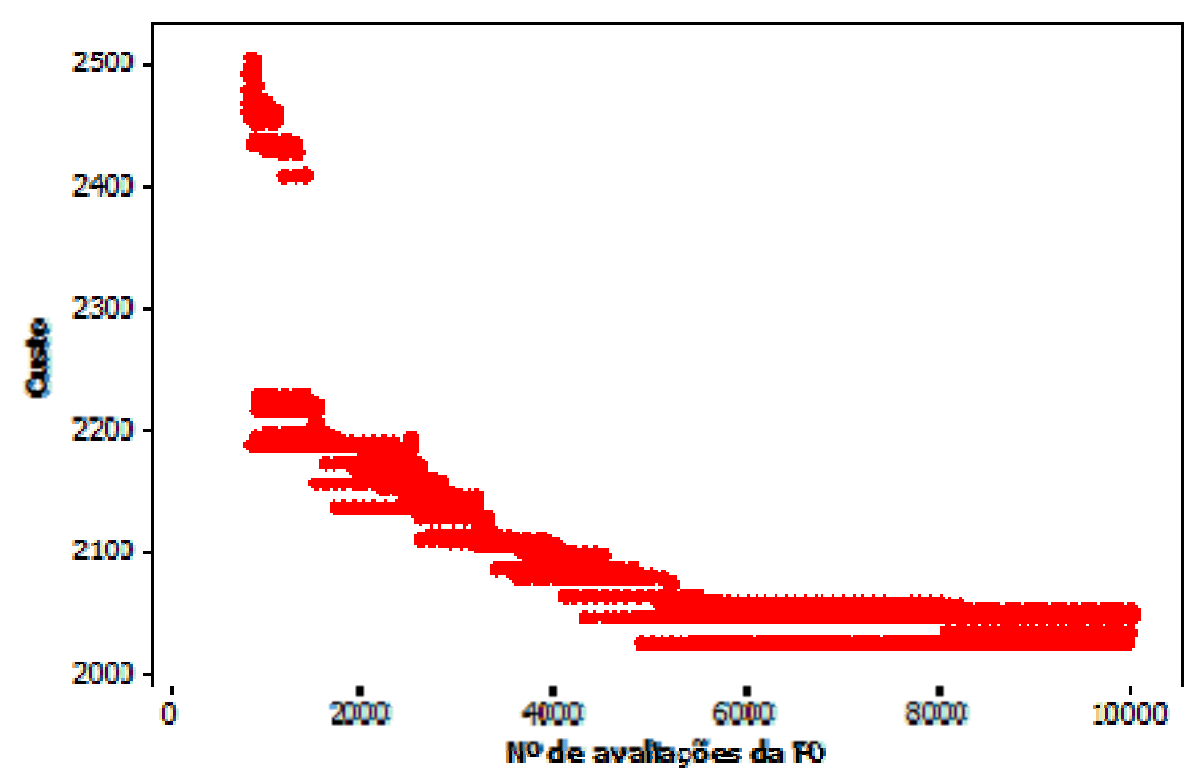

Figura 5-38 - Custo x número de avaliações da Função Objetivo, otimizando-se apenas o custo

Na otimização considerando-se o custo e a entropia, verifica-se ao usar a Abordagem III, houve uma maior dispersão dos valores de custo (Figura 5-39), enquanto que na mesma condição, a entropia convergiu para valores mais baixos (Figura 5-40). 
Tabela 5-33 - Programação do booster entre o reservatório R11 Inferior e R11 Superior para as soluções 10 e 11

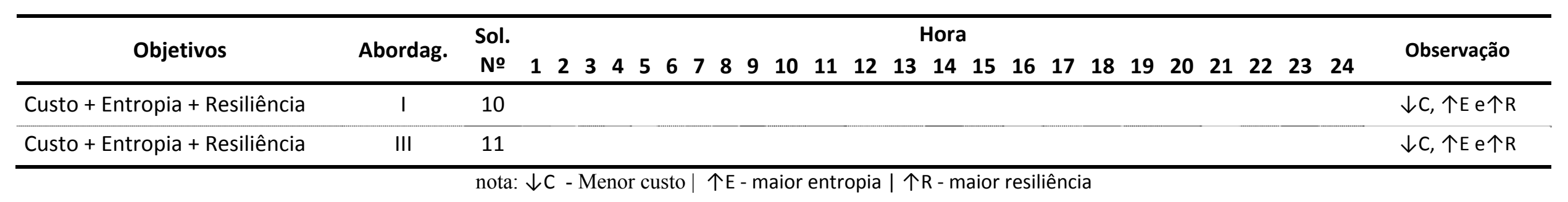

Tabela 5-34 - Programação da bomba do Poço Iguatemi para as soluções 10 e 11

\begin{tabular}{|c|c|c|c|c|c|c|c|c|c|c|c|c|c|c|c|c|c|c|c|c|c|c|}
\hline \multirow{2}{*}{ Objetivos } & \multirow{2}{*}{ Abordag. } & \multirow{2}{*}{$\begin{array}{l}\text { Sol. } \\
\text { № }\end{array}$} & \multicolumn{19}{|c|}{ Hora } & \multirow{2}{*}{ Observação } \\
\hline & & & 123 & $\begin{array}{lll}34 & 5 \\
\end{array}$ & 56 & 78 & 89 & 10 & 11 & 12 & 13 & 14 & 15 & 161 & 171 & 181 & 1920 & $0 \quad 21$ & 122 & $22 \quad 23$ & 24 & \\
\hline Custo + Entropia + Resiliência & 1 & 10 & & & & & & & & & & & & & & & & & & & $\boldsymbol{\square}$ & $\downarrow C, \uparrow E$ e $\uparrow R$ \\
\hline Custo + Entropia + Resiliência & III & 11 & & & & & & & & & & & & & & & & & & & & $\downarrow C, \uparrow E$ e $\uparrow R$ \\
\hline
\end{tabular}

Tabela 5-35 - Programação da bomba do Poço Aldo Lupo para as soluções 10 e 11

\begin{tabular}{|c|c|c|c|c|c|c|c|c|c|c|c|c|c|c|c|c|c|c|c|c|c|}
\hline \multirow{2}{*}{ Objetivos } & \multirow{2}{*}{ Abordag. } & \multirow{2}{*}{$\begin{array}{c}\text { Sol. } \\
\text { № }\end{array}$} & \multicolumn{18}{|c|}{ Hora } & \multirow{2}{*}{ Observação } \\
\hline & & & 12 & 34 & 456 & 67 & 8 & 910 & 11 & 12 & 1314 & 15 & 16 & 17 & 18 & 192 & 2021 & 22 & 23 & 24 & \\
\hline Custo + Entropia + Resiliência & I & 10 & & & & & & & & & & & & & & & & & & & $\downarrow C, \uparrow E$ e $\uparrow R$ \\
\hline
\end{tabular}




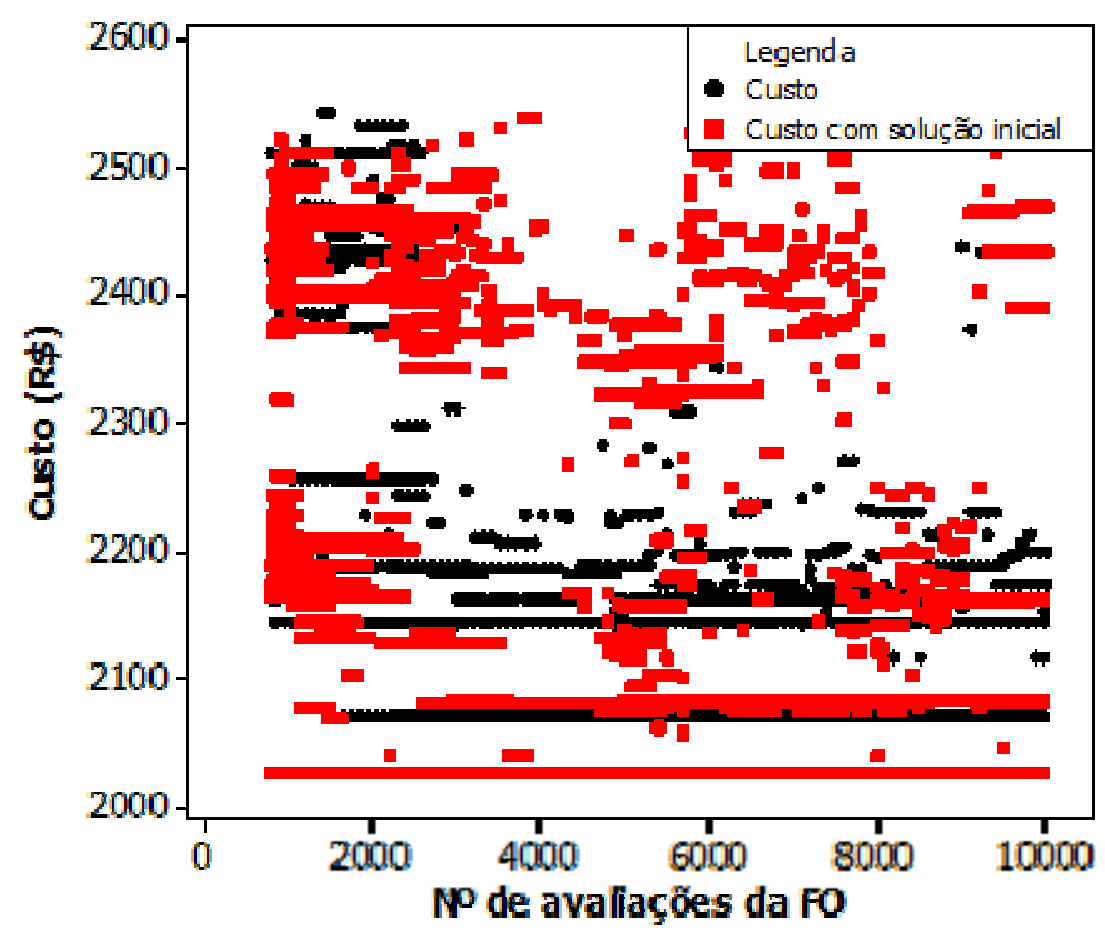

Figura 5-39 - Custo x Número de avaliações da FO, otimizando-se custo e entropia

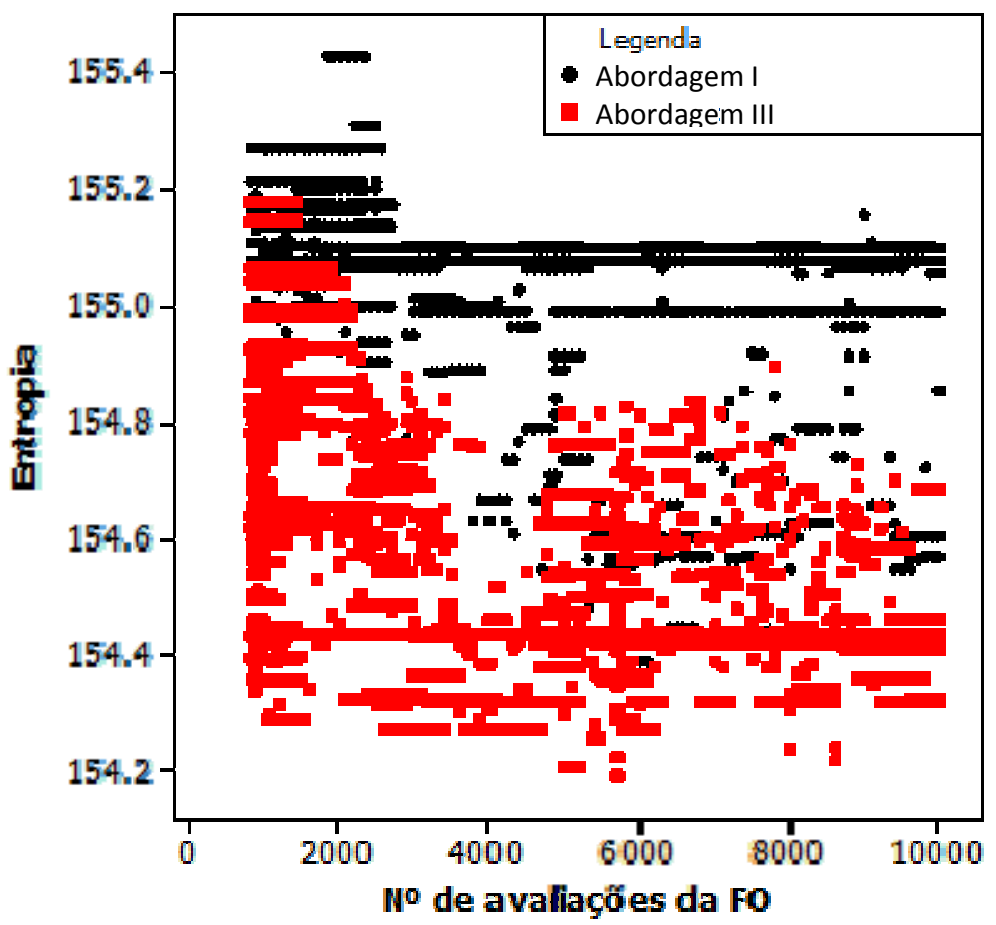

Figura 5-40 - Entropia x Número de avaliações da FO, otimizando-se custo e entropia 
Avaliando-se a otimização realizada considerando-se as funções objetivo custo e resiliência, com o uso Abordagem III, constata-se que o custo converge para valores mais baixos (Figura 5-41), assim como a resiliência (Figura 5-42).

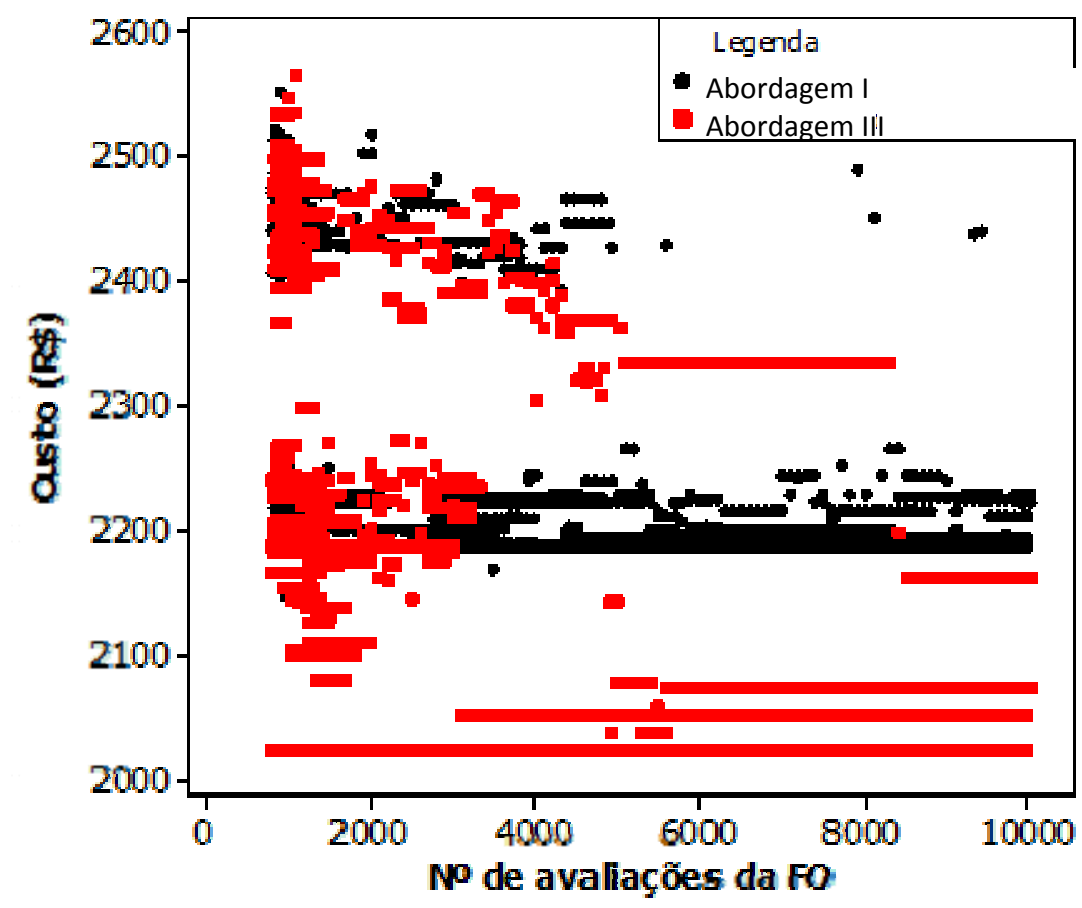

Figura 5-41 - Custo x Número de avaliações da FO, otimizando-se custo e resiliência com uso da Abordagem III

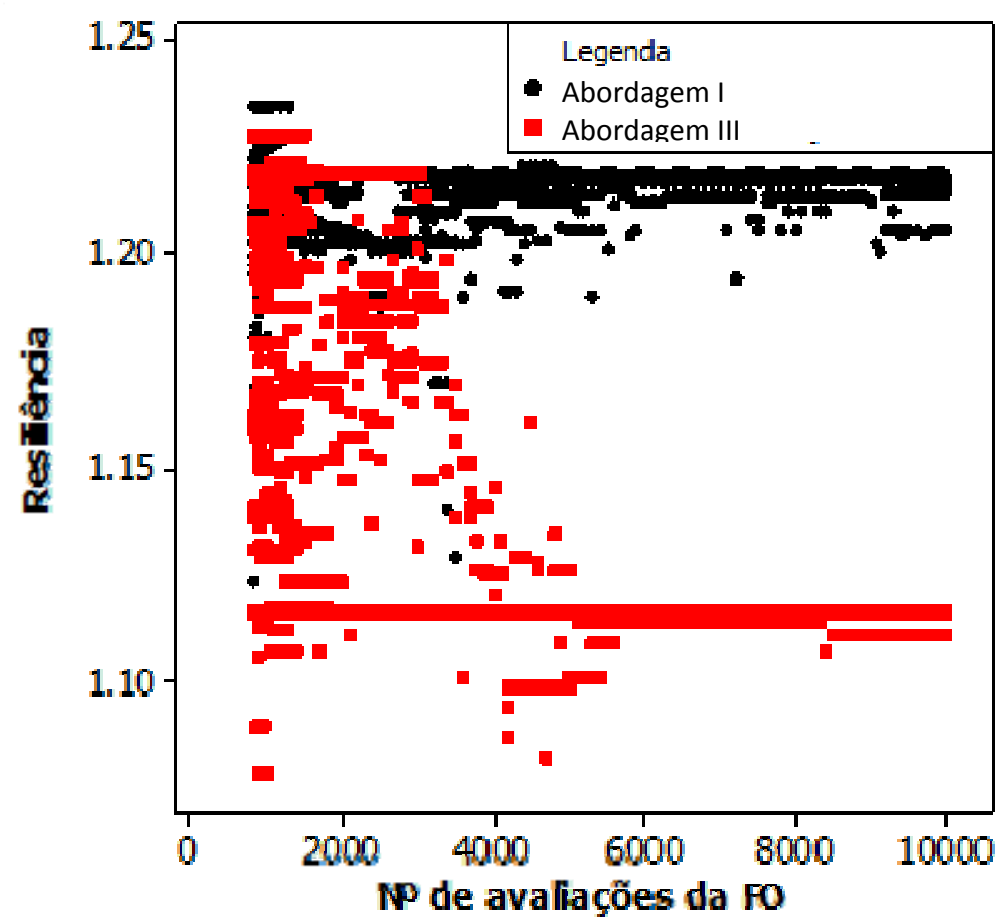

Figura 5-42 - Resiliência x Número de avaliações da FO, otimizandose custo e resiliência com uso da Abordagem III 


\subsection{Aplicação das Abordagens II e III na Otimização Multiobjetivo}

Aplicaram-se as Abordagens II e III definidas no item 4.5, as quais diferem da Abordagem I ao incorporarem soluções iniciais oriundas da otimização de objetivo único ao processo de otimização multiobjetivo. Realizou-se a aplicação das abordagens para os mesmos dias utilizados na otimização multiobjetivo do item 0 .

As soluções de objetivo único produzidas de acordo com as respectivas abordagens foram geradas utilizando-se 2.500 avaliações da função objetivo para um período de 24 horas.

No processo de otimização multiobjetivo, limitou-se cada otimização da operação em tempo real a 1.000 avaliações da FO, para verificar se as estratégias otimizadas seriam capazes de melhorar as soluções mesmo com um menor número de avaliações de função objetivo que a empregada na Abordagem I, que usou 2.500 avaliações da função objetivo. Ademais, não se avaliaram as funções objetivo Entropia e Resiliência Modificada, uma vez que os resultados anteriores demonstraram que tais medidas não são adequadas à otimização da operação em tempo real.

As Tabelas 5-36, 5-37 e 5-38 possibilitam a comparação dos resultados das soluções multiobjetivo para os Setores Eliana, Iguatemi e Martinez respectivamente, com uso das Abordagens I, II e III. Na primeira coluna, especifica-se as funções objetivo escolhidas para serem otimizadas. Na segunda coluna, está a ordem da solução. Na terceira, especifica-se a estratégia utilizada, que pode ser I, II, ou III. Na quarta, quinta e sexta colunas apresentam-se os valores das funções objetivo das soluções, sendo que nas últimas colunas estima-se a energia utilizada durante o período de $24 \mathrm{~h}$ e durante o horário de ponta.

Na Tabela 5-36, que se refere ao Setor Eliana, constata-se que a Abordagem II, considerando o nível mínimo na otimização, produziu níveis mínimos de reservação igual à solução número 1 (Abordagem I) a um custo ligeiramente menor, enquanto que a abordagem III produziu nível mínimo muito inferior. Nas otimizações considerando-se a carga de pressão excedente, as Abordagens II e III produziram-se maiores pressões excedentes que a solução número 4 (Abordagem I), mas com um considerável aumento no custo de consumo energético.

Na Tabela 5-37 são comparados os resultados das soluções resultantes das diferentes abordagens para otimização do Setor Iguatemi. Nota-se que a Abordagem II produziu estratégias de maiores custos que a Abordagem III. Analisando-se a maximização do nível mínimo, as abordagens II e III produziram níveis mínimos maiores que a abordagem I. 
Quanto a otimização considerando a pressão, a Abordagem III produziu custo e pressão excedentes muito próximos a Abordagem I.

Tabela 5-36 - Comparação dos resultados das soluções multiobjetivo com uso das diferentes Abordagens de otimização - Setor Eliana

\begin{tabular}{cccccccc}
\hline $\begin{array}{c}\text { Função } \\
\text { Objetivo }\end{array}$ & $\begin{array}{c}\text { Solução } \\
\text { no }\end{array}$ & Abordagem & $\begin{array}{c}\text { Custo } \\
\text { (R\$) }\end{array}$ & $\begin{array}{c}\text { Nível } \\
\text { mínimo } \\
\text { (m) }\end{array}$ & $\begin{array}{c}\text { Pressão } \\
\text { (m.c.a.) }\end{array}$ & \multicolumn{2}{c}{$\begin{array}{c}\text { Energia utilizada } \\
\text { (kWh) }\end{array}$} \\
\hline Custo+ & 1 & I & 246.58 & 2.99 & 44.54 & 2332 & 106 \\
Nível & 2 & II & 234.58 & 2.99 & 44.45 & 2226 & 106 \\
mínimo & 3 & III & 180.04 & 0.11 & 42.66 & 2544 & 212 \\
\hline \multirow{2}{*}{ Custo+ } & 4 & I & 180.17 & 0.68 & 42.69 & 2650 & 0 \\
Pressão & 5 & II & 308.81 & 4.38 & 44.95 & 2544 & 212 \\
& 6 & III & 294.04 & 2.01 & 44.55 & 2226 & 212 \\
\hline \multicolumn{2}{c}{ Operação praticada pelo DAAE } & 262.08 & 2.47 & 44.38 & 2014 & 212 \\
\hline
\end{tabular}

Tabela 5-37 - Comparação dos resultados das soluções multiobjetivo com uso das diferentes Abordagens de otimização - Setor Iguatemi

\begin{tabular}{|c|c|c|c|c|c|c|c|}
\hline \multirow{2}{*}{$\begin{array}{l}\text { Função } \\
\text { Objetivo }\end{array}$} & \multirow{2}{*}{$\begin{array}{c}\text { Solução } \\
\text { no }\end{array}$} & \multirow[t]{2}{*}{ Abordagem } & \multirow{2}{*}{$\begin{array}{l}\text { Custo } \\
\text { (R\$) }\end{array}$} & \multirow{2}{*}{$\begin{array}{c}\text { Nível } \\
\text { mínimo } \\
\text { (m) }\end{array}$} & \multirow{2}{*}{$\begin{array}{l}\text { Pressão } \\
\text { (m.c.a.) }\end{array}$} & \multicolumn{2}{|c|}{$\begin{array}{c}\text { Energia utilizada } \\
\text { (kWh) }\end{array}$} \\
\hline & & & & & & $24 \mathrm{~h}$ & pico \\
\hline \multirow{3}{*}{$\begin{array}{l}\text { Custo+ } \\
\text { Nível } \\
\text { mínimo }\end{array}$} & 1 & 1 & 521.85 & 9.78 & 36.71 & 4543 & 69 \\
\hline & 2 & ॥ & 937.94 & 12.73 & 36.96 & 7290 & 841 \\
\hline & 3 & III & 601.81 & 11.70 & 37.17 & 6870 & 561 \\
\hline \multirow{3}{*}{$\begin{array}{l}\text { Custo+ } \\
\text { Pressão }\end{array}$} & 4 & I & 766.36 & 14.36 & 37.43 & 4649 & 595 \\
\hline & 5 & ॥ & 944.57 & 11.20 & 37.19 & 7150 & 981 \\
\hline & 6 & III & 779.33 & 15.14 & 37.25 & 5888 & 841 \\
\hline \multicolumn{3}{|c|}{ Operação praticada pelo DAAE } & 601.14 & 14.24 & 37.28 & 5241 & 103 \\
\hline
\end{tabular}

$\mathrm{Na}$ Tabela 5-38 compararam-se os resultados das soluções para Setor Martinez. Na consideração do nível mínimo como função objetivo, as abordagens II e III foram capazes de gerar níveis mínimos próximos à solução número 1 (Abordagem I) a custos ligeiramente reduzidos. Analogamente, no caso da maximização da carga de pressão, produziram-se valores de pressão próximos aos da solução número 4, mas a custo mais elevado, sendo que a operação praticada pelo DAAE produziu a maior carga de pressão excedente dentre as soluções comparadas, porém foi uma das operações mais custosas, juntamente com as das soluções 5 e 6 . 
Tabela 5-38 - Comparação dos resultados das soluções multiobjetivo com uso das diferentes Abordagens de otimização - Setor Martinez

\begin{tabular}{cccccccc}
\hline $\begin{array}{c}\text { Função } \\
\text { Objetivo }\end{array}$ & $\begin{array}{c}\text { Solução } \\
\text { no }\end{array}$ & Abordagem & $\begin{array}{c}\text { Custo } \\
\text { (R\$) }\end{array}$ & $\begin{array}{c}\text { Nível } \\
\text { mínimo } \\
\text { (m) }\end{array}$ & $\begin{array}{c}\text { Pressão } \\
\text { (m.c.a.) }\end{array}$ & \multicolumn{2}{c}{$\begin{array}{c}\text { Energia utilizada } \\
\text { (kWh) }\end{array}$} \\
\hline Custo+ & 1 & I & 357.63 & 3.31 & 37.61 & 4488 & 0 \\
Nível & 2 & II & 346.23 & 3.09 & 37.40 & 3168 & 0 \\
mínimo & 3 & III & 346.26 & 2.89 & 37.15 & 2904 & 0 \\
\hline \multirow{2}{*}{ Custo+ } & 4 & I & 335.25 & 3.16 & 37.49 & 4224 & 0 \\
Pressão & 5 & II & 471.83 & 3.10 & 37.40 & 3696 & 264 \\
& 6 & III & 514.53 & 3.12 & 37.57 & 4488 & 264 \\
\hline \multicolumn{2}{r}{ Operação praticada pelo DAAE } & 453.51 & 3.51 & 37.61 & 3696 & 264 \\
\hline
\end{tabular}




\section{Conclusões}

O presente trabalho representa um esforço para aliar as técnicas consideradas mais promissoras para dar tratamento ao problema da otimização da operação em tempo real, ainda pouco exploradas na literatura especializada, aplicada aos setores Eliana, Iguatemi e Martinez, de abastecimento de água da cidade de Araraquara, SP. Envolveu desenvolvimentos em várias frentes de trabalho, a saber:

- A implementação da rotina computacional que utiliza diferentes ferramentas de otimização simultaneamente (AMALGAM), apontada na literatura como sendo uma técnica recente mais promissora dentre os métodos atualmente em uso;

- O desenvolvimento da interface do AMALGAM com o simulador hidráulico (EPANET);

- Campanhas de campo para aquisição de dados de carga de pressão e vazão para calibração dos modelos hidráulicos dos setores de rede de estudo;

- A construção de modelos calibrados para os setores de rede de estudo;

- O ajuste de rede neural auto-construtiva (DAN2 híbrida) para previsão de demanda, empregando o módulo de previsão de demanda previamente desenvolvido pelo autor (Odan, 2010);

- A construção de metamodelo (rede neural artificial MLP com ajuste adaptativo - AMGA) em substituição ao modelo hidráulico construído com o suporte do EPANET; e

- A otimização da operação em tempo real, propriamente dita, que exigiu a proposição de procedimentos de reparação de soluções.

Os desenvolvimentos nessas frentes de trabalho possibilitaram a extração de diversas conclusões aqui resumidas.

\section{Campanhas de campo e a construção de modelo calibrado}

A obtenção de dados para construção dos modelos das redes foi uma das etapas mais demoradas e trabalhosas desta pesquisa, pois apesar da estrutura existente no DAAE, e da certificação do ISO 9001, ainda assim há problemas nos bancos de dados que se refletem na representação das redes, especialmente a representação das conexões. Para tanto, foram 
necessárias verificações in loco, as quais contaram com o apoio de funcionários da companhia, além de frequente comunicação com os servidores da companhia.

Durante as campanhas de campo foram coletados dados de carga de pressão nos ramais prediais, internos às residências, nas proximidades de pontos previamente estabelecidos. Assim, para minimizar o efeito das perdas de carga localizadas a que tais medidas estão sujeitas por influência do consumo, foi necessário dar preferência aos dados coletados no período noturno e sob a influência de descargas programadas em pontos da rede.

Entretanto, resultados mais fidedignos podem ser obtidos mediante o monitoramento de pressões em pontos da rede diretamente. Da mesma forma, seria conveniente que os consumidores especiais tivessem seus consumos monitorados durante as campanhas de campo e houvesse a possibilidade de monitoramento de maior número de pontos de carga de pressão e vazão na rede. Além disso, aponta-se a necessidade do levantamento das curvas das bombas, visto que, com o passar do tempo, aquelas apresentadas no catálogo do fabricante deixam de representar o comportamento real.

\section{Previsão de Demandas}

As estratégias operacionais produzidas serão tão precisas quanto às estimativas de demanda futura, assim como do modelo utilizado para representar o comportamento hidráulico do sistema. Conforme a necessidade de promover melhorias na previsão de demanda observada por Cunha (2009), o presente trabalho, incrementa confiabilidade à operação ao realizar previsões utilizando ferramenta (DAN2 híbrida) que se mostra mais robusta e independente de estudos de arquitetura necessários às redes neurais MLP convencionais.

\section{Implementação do AMALGAM na otimização da operação em tempo real}

Para viabilizar a identificação de soluções factíveis para a operação em tempo real, do ponto de vista da minimização do número de acionamentos das bombas, do uso das bombas no horário de ponta, dos códigos de erro produzidos pelo EPANET e do não atendimento da restrição de que os níveis finais dos reservatórios devam ser pelo menos iguais aos do início de cada dia, são propostos procedimentos de reparação.

Como resultado, o Método de Otimização AMALGAM mostra-se ser uma ferramenta robusta e eficiente. Na otimização em Tempo Real de objetivo único, considerando-se apenas a minimização do custo do consumo energético, soluções são produzidas de maneira a reduzir em $14 \%, 13 \%$ e $30 \%$, os custos praticados pelo DAAE-Araraquara para o meses de 
maio/2010, setembro/2010 e fevereiro/2010, respectivamente para os Setores Eliana, Iguatemi e Martinez. Além disso, testes para a otimização considerando-se apenas a minimização do custo operacional para as próximas 24 horas demonstram que o método converge em no máximo 2.500 avaliações da função objetivo.

As funções objetivo de entropia e resiliência modificada, muito utilizadas em projetos de redes de abastecimento de água, não se mostram adequadas ao propósito da operação em tempo real, uma vez que se mostram pouco sensíveis às variações nas estratégias operacionais. Um dos motivos dessa insensibilidade se deve ao fato que na otimização da operação, os sistemas de abastecimento não mudam como no caso da otimização de projetos. Além disso, fica evidenciada a dificuldade de avaliar o quanto essas medidas acrescentam confiabilidade à operação. Possivelmente tais medidas de confiabilidade apresentariam maior variabilidade em redes de distribuição mais complexas, com mais reservatórios e setores interligados.

Como esperado, as soluções de menor custo produzidas tendem a promover a melhor exploração do volume dos reservatórios, caracterizado pela oscilação de nível de maneira a permitir o seu esvaziamento nas horas de ponta.

Os resultados mostram ainda que é possível estabelecer soluções de melhor compromisso para os objetivos de mínimo custo e máximo nível operacional mínimo, por razões de segurança. Nota-se que esse último objetivo tem a vantagem de corresponder à intuição dos operadores, de uma forma geral, ao tentar manter níveis elevados nos reservatórios para evitar eventuais problemas de desabastecimento.

As abordagens implementadas para a otimização da operação em tempo real (abordagens II e III) mostraram-se capazes de identificar boas soluções, mesmo com apenas 1000 avaliações da função objetivo, 2,5 vezes menor que o utilizado na Abordagem I para cada atualização da otimização da operação em tempo real, realizada para o horizonte móvel de 24 horas à frente.

Neste trabalho testou-se a substituição do tradicional simulador hidráulico pelo metamodelo, com o objetivo de acelerar o processo de otimização, já que boa parte do tempo de processamento é consumido nas simulações hidráulicas. No entanto, não se obteve sucesso na sua implementação. Tal problema será objeto de investigação deste autor, pois se sabe que na literatura os metamodelos foram aplicados com sucesso na operação em tempo real.

Avanços foram conseguidos na redução do tempo computacional necessário para a identificação de soluções a serem implementadas, quando comparados com os valores reportados por outros autores, como Cunha (2009). A otimização com objetivo único para as 
redes de abastecimento simplificadas envolveu o tempo de processamento da ordem de 1,5 minutos para produzir as estratégias otimizadas das próximas $24 \mathrm{~h}$. No caso da otimização multiobjetivo utilizando-se a rede completa, houve maior variação do tempo de processamento entre os setores de estudo, os quais foram de 1,8, 16,7 e 2,5 minutos para os Setores Eliana, Iguatemi e Martinez, respectivamente, para produzir as estratégias das próximas $24 \mathrm{~h}$.

Pode-se dizer, portanto, que o uso da rede simplificada permite a obtenção de estratégias operacionais otimizadas, ou pelo menos mais atrativas do ponto de vista multiobjetivo (da minimização dos custos e da maximização do nível mínimo dos reservatórios), em tempo hábil para a sua implementação. Além disso, é viável obter as soluções otimizadas mesmo nos casos que necessitarem do uso da rede detalhada.

\section{Trabalhos Futuros}

Recomenda-se que futuros trabalhos de pesquisa investiguem outros métodos de otimização populacionais para serem integrados ao AMALGAM, os quais poderiam melhorar ainda mais a identificação de estratégias otimizadas para a operação em tempo real de sistemas de abastecimento de água.

Realizar estudos mais aprofundados acerca da implementação dos metamodelos para agilizar a otimização da operação em tempo real, já que na literatura os metamodelos foram aplicados com sucesso na otimização da operação.

Sugere-se também o estudo de novas funções objetivo que permitam oferecer ainda mais segurança aos operadores de redes, de modo a encorajá-los a usar os modelos de otimização nas operações dos sistemas de abastecimento de água. 


\section{Referências}

Abe, N. (2013). Identificação de Incertezas em Modelos de Sistemas de Distribuição de Água através da Busca no Espaço de Estados e Aprendizado de Máquina. Tese (Doutorado) a ser apresentada. Escola de Engenharia de São Carlos, Universidade de São Paulo, São Carlos.

Abe, N.; Cheung, P.B. (2009) . Epanet Calibrator - an integrated computational tool to calibrate hydraulic models. In: Joby Boxall; Cedo Maksimovic. (Org.). Integrating Water Systems. London, UK: Taylor \& Francis Group, p. 129-133.

Adamowski, J.F. (2008). Peak Daily Water Demand Forecast Modeling Using Artificial Neural Networks, J. Water Resour. Plng. and Mgmt. 134, pp. 119-128. all. 842 p.

Almeida, R. (2001). Otimização não linear de um Sistema de Abastecimento de Água. Dissertação (Mestrado) - Universidade Estadual de Campinas. 347 p.

Alvisi, S.; Franchini, M.; Marinelli, A. (2007). A short-term, pattern-based model for water-demand forecasting. Journal of Hydroinformatics Vol 9 No 1 pp. 39-50

Aly, A. H.; and Peralta, R. C. (1999). Optimal design of aquifer cleanup systems under uncertainty using a neural network and a genetic algorithm. Water Resour. Res., 35(8), pp. 2523-2532.

Anderson, R.C., Miller, T.A. and Washburn, M.C. (1980). 'Water Savings from Lawn Watering Restrictions During a Drought Year in Fort Collins, Colorado', Water Resour. Bull., 16(4), pp. 642- 645 .

Ang, W-K and Jowitt, P. (2003). Some observations on energy loss and network entropy in water distribution networks, Engineering Optimization, 35: 4, pp. 375-389.

Atkinson, R.; van Zyl, J.E.; Walters, G.A.; Savic, D.A. (2000). Genetic algorithm optimization of level-controlled pumping station operation. In: Water network modelling for optimal design and management, pp. 79-90. Centre for Water Systems, Exeter, U.K.

Awumah, K.; Goulter, I. C. (1992). Maximizing entropy defined reliability of water distribution networks. Engng Optim. 20, pp. 57-80.

Awumah, K.; Goulter, I.C.; Bhatt, S. K. (1991). Entropy-Based Redundancy Measures in Water Distribution Design. Journal of Hydraulic Engineering, v. 117, n. 5, pp. 595-614.

Awumah, K.; Goulter, I.C.; Bhatt, S.K. (1990). Assessment of reliability in water distribution networks using entropybased measures. Stochastic Hydrology and Hydraulics, 4 (4), pp. 325-336. 
Babayan, A.V.; Kapelan, Z.; Savic, D.A.; Walters, G.A. (2005). Least Cost Design of Water Distribution Networks under Demand Uncertainty, ASCE Journal of Water Resources, Planning and Management, 131(5), pp. 375-382.

Bai, R.; Burke, E.K.; Kendall, G. (2008). Heuristic, meta-heuristic and hyper-heuristic approaches for fresh produce inventory control and shelf space allocation. Journal of the Operational Research Society (59), pp 1387-1397.

Bao, Y.; Mays, L.W. (1990). Model for water distribution system reliability. Journal of Hydraulic Engineering Division ASCE 116 9, pp. 1119-1137.

Baxter, C.W.; Zhang, Q.; Stanley, S.J.; Shariff, R.; Tupas, R.T.; Stark, H.L. (2001) Drinking Water Quality and Treatment: The Use of Artificial Neural Networks. Canadian Journal of Civil Engineering. V. 28, pp. 26-35.

Beale, R.; Jackson, T. (1990). Neural computing: an introduction. Bristol , U.K.: Adam Hilger, 1990.

Bilgin, B.; Ozcan, E.; Korkmaz, EE. (2006) An experimental study on hyper-heuristics and final exam scheduling. In: Proc. of the International Conference on the Practice and Theory of Automated Timetabling (PATAT'06), pp 123-140

Boulos, P.F.; Orr, C.H.; de Schaetzen,W.; Chatila, J.G.; Moore, M.; Hsiung, P.; Thomas, D. (2001). Optimal pump operation of water distribution systems using genetic algorithms. In: AWWA Distribution System Symp. Denver, USA: American Water Works Association.

Boulos, P.F.; Wu Z.; Orr C.H.; Moore M.; Hsiung P.; Thomas D. (2000). Optimal pump operation of water distribuion systems using genetic algorithm, H2ONET - Users Guide. MW Software INC.

Braga, A.; Carvalho, A.C.P.L.F. ; Ludermir, T. (2007). Redes Neurais Artificiais: Teoria e Aplicações. 2. ed. Rio de Janeiro: LTC. v. 1. 226 p.

Broad D.R., Maier H.R. and Dandy G.C. (2010) Optimal operations of hydraulically complex water distribution systems using metamodels, Journal of Water Resources Planning and Management, 136(4), 433-443, http://dx.doi.org/10.1061/(ASCE)WR.19435452.0000052 .

Broad, D. R., Dandy G. C., Maier H. R. (2005). Water distribution system optimization using metamodels. Journal of Water Resources Planning and Management, 131(3), 172-180.

Broyden, C.G. (1967). Quasi-Newton methods and their application to function minimization. Mathematics of Computation 21(368):45 
Burke, E.K.; Hyde, M.; Kendall, G.; Ochoa, G.; Ozcan, E. and Qu, R. (2010). Hyperheuristics: A survey of the state of the art. Technical Report No. NOTTCS-TRSUB0906241418-2747, School of Computer Science and Information Technology, University of Nottingham.

Burke, E.K.; Landa Silva, J.D.; and Soubeiga, E. (2003). A hyperheuristic approach for multi-objective optimisation: an extended abstract. In Metaheuristic International Conference MIC'2003, August 2003.

Carrijo, I. B. (2004). Extração de regras operacionais ótimas de sistemas de distribuição de água através de algoritmos genéticos multiobjetivo e aprendizado de máquina. 2004. 217p. Tese (Doutorado). Escola de Engenharia de São Carlos, Universidade de São Paulo, São Carlos.

Coulbeck, B.; Orr, C.H. (1993). Essential considerations in the computer control of water distribution systems, Reliability Engineering \& System Safety, v. 42, n. 1, pp. 55-64. doi: 10.1016/0951-8320(93)90055-4

Coulbeck, B.; Orr, C.H.; Brdys, M. (1988). Real-time optimized control of water distribution systems. International Conference on Control. April, pp. 634-640.

Cowling, P.; Kendall, G.; Soubeiga, E. (2000). A hyperheuristic approach for scheduling a sales summit. In: Selected Papers of the Third International Conference on the Practice And Theory of Automated Timetabling, PATAT 2000, Springer, Konstanz, Germany, Lecture Notes in Computer Science, pp. 176-190

Crainic, T.G.; Toulouse, M. (2008). Explicit and emergent cooperation schemes for search algorithms. In: Learning and Intelligent Optimization (LION II) Conference. Lecture Notes in Computer Science, vol. 5313, pp. 95-109. Springer, Berlin.

Crommelynck, V.; Duquesne, C.; Mercier, M. and Miniussi, C. (1992). Daily and Hourly Water Consumption Forecasting Tools Using Neural Networks. Proc. of the AWWA's Annual Computer Specialty Conference, Nashville, Tennessee, pp. 665-676.

Cullinane, M.J.; Lansey, K.E. and Mays, L.W. (1992). Optimization availability based design of water distribution networks. J. Hydraul. Eng., 118 (3), pp. 420-441.

Cunha, A.A.R. (2009). Otimização Energética da Operação de Sistemas de Abastecimento de Água em Tempo Real.. 181 p. Dissertação Mestrado - Escola de Engenharia, Universidade de São Paulo, São Carlos.

Cybenko, G. (1989). "Approximation by superpositions of a sigmoidal function", Mathematics of Control, Signals, and Systems, vol. 2, pp. 303-314. 
Dandolini, G.A. (1997). Um procedimento para avaliação da saúde financeira de pequenas empresas: estudo de um caso usando redes neuronais artificiais. Dissertação Universidade Federal de Santa Catarina, Florianópolis.

Deb, K. e Goel, T. (2001). Controlled elitist non-dominated sorting genetic algorithms for better convergence, Proceedings of the First International Conference on Evolutionary Multi-Criterion Optimization, pp. 67-81.

Deb, K.; Agrawal, S. (1999). A niched-penalty approach for constraint handling in genetic algorithms. Proc., ICANNGA-99, Portoroz, Slovenia, pp. 123-135.

Deb, K.; Pratap, A.; Agarwal, S.; Meyarivan, T. (2002). A fast and elitist multiobjective genetic algorithm: NSGA-II Evolutionary Computation, IEEE Transactions on In Evolutionary Computation, IEEE Transactions on, Vol. 6, No. 2, pp. 182-197.

Deus, F.D.L. (2010). Geração de cenários de energia natural afluente através da adoção da metodologia do Hipercubo Latino. 122p. Dissertação (Mestrado). Universidade Federal do Rio De Janeiro.

Dryar, H.A. (1944). The effect of weather on the system load, Transactions, AIEE, 63, pp. 1006-1013.

Eberhart, R.C. e Kennedy, J. (1995). A new optimizer using particle swarm theory. Proceedings of the Sixth International Symposium on Micromachine and Human Science, Nagoya, Japan. pp. 39-43.

Falkenberg, A.V. (2005). Previsão de consumo urbano de dgua em curto prazo. Dissertacao (Mestrado), 105 p., Universidade Federal do Parana , Curitiba.

Farmani, R.; Walters, G.A.; and Savic, D.A. (2006). Evolutionary multi-objective optimization of the design and operation of water distribution network: total cost vs. reliability vs. water quality. Journal of Hydroinformatics, 8 (3), pp. 165-179.

Farmer, E.D. and Potton. M. J. (1968). Development of online load-production techniques with results from trials in the south-west region of the CEGB. Proc. of the Institution of Electrical Engineers, vol. 115, N. 10, p.1549-1558.

Ferrero, C.A. (2009). Algoritmo kNN para Previsão de Dados Temporais: Funções de Previsão e Critérios de Seleção de Vizinhos Próximos Aplicados a Variáveis Ambientais em Limnologia. Dissertação. 129 p. Instituto de Ciências Matemáticas e de Computação, Universidade de São Paulo, São Carlos.

Formiga, K. T. M.; Chaudhry, F. H.; Vieira, M. E. A. (2006). Otimização Multiobjetivo de Redes de Abastecimento de Água, In: VI Seminário Iberoamericano sobre 
Sistemas de Abastecimento Urbano de Água (VI SEREA), João Pessoa. Anais do VI Seminário Iberoamericano sobre Sistemas de Abastecimento Urbano de Água.

Fu, G., Kapelan, Z., Reed, P. (2010). Sensitivity analysis to improve water distribution system optimization. 12th annual Water Distribution Systems Analysis conference (WDSA 2010), Tucson, Arizona.

Gelman, A.; Carlin, J.B.; Stern, H.S.; Rubin, D.B. (2003). Bayesian data analysis. CRC press.

Ghiassi, M.; and Saidane, H. (2005). “A dynamic architecture for artificial neural networks." Neurocomputing, 63, pp. 397-413.

Ghiassi, M.; Zimbra, D. K.; and Saidane, H. (2008), "Urban Water Demand Forecasting with a Dynamic Artificial Neural Network Model”, Journal of Water Resources Planning and Management, Vol. 134, No. 2, pp. 138-146

Giacomello, C.; Kapelan, Z.; Nicolini, M. (2012). Fast Hybrid Optimisation Method for Effective Pump Scheduling. ASCE Journal of Water Resources Planning and Management (in press).

Giustolisi, O; Laucelli, D; Colombo, A.F. (2009). Deterministic versus Stochastic Design of Water Distribution Networks. Journal of Water Resources Planning and Management. Vol. 135, no. 2, pp. 117-127.

Goldberg, D.E.; and Kuo, C.H. (1987). "Genetic algorithms in pipeline optimization." J. Computing in Civ. Engrg., ASCE , 1 (2 ), 128-141.a3h J. Comput. Civ. Eng.

Gomez, J.C. and Terashima-Marín, H. (2010). Approximating multi-objective hyperheuristics for solving 2D irregular cutting stock problems. In Proceedings of the 9th Mexican international conference on Artificial intelligence conference on Advances in soft computing, Part II, pp. 349-360.

Goulter, I. (1995). “Analytical and simulation models for reliability analysis in water distribution systems." Improving efficiency and reliability in water distribution systems, E.Cabrera and A. F. Vela, eds., Kluwer Academic, London, pp. 235-266.

Graeser Jr.; H.J. (1958), 'Meter Records in Systems Planning', J. Amer. Water Works Assoc. 50(11), pp. 1395-1402.

Haykin, S. (1999). Neural network - A comprehensive foudantion. $2^{\mathrm{a}}$ ed. New York: Prentice H Giustolisi, O; Laucelli, D; Colombo, A.F. (2009). Deterministic versus Stochastic Design of Water Distribution Networks. Journal of Water Resources Planning and Management. Vol. 135, no. 2, pp. 117-127. 
Howe, C.W. and Linaweaver, F.P. (1967). 'The Impact of Price on Residential Water Demand and Its Relation to Systems Design', Water Resour. Res. 3(1), pp. 13-22.

Hu, X.; Eberhart, R.C.; Yuhui Shi, Y. (2003). Swarm intelligence for permutation optimization: a case study of n-queens problem. Swarm Intelligence Symposium, 2003. SIS '03. Proceedings of the 2003 IEEE , vol., no., pp.243,246, 24-26. DOI: 10.1109/SIS.2003.1202275

Hughes, T.C. (1980), 'Peak Period Design Standards for Small Western U.S. Water Supply', Wat er Resour. Bull. 16(4), pp. 661-667.

Humes, A.F.P.C.; Melo, I.S.H.; Yoshida, L.K. e Martins, W.T. (1984). Noções de cálculo numérico. São Paulo: McGraw-Hill.

Iman, R. L.; Conover, W. J. (1982). A distribution-free approach to inducing rank correlation among input variables, Commun. Stat., 11, pp. $311-334$.

Islam, M.; Sattar, A.; Amin, F.; Xin Yao, Murase, K. (2009). A New Adaptive Merging and Growing Algorithm for Designing Artificial Neural Networks. IEEE Transactions on Systems, Man, and cybernetics- Part B: Cybernetics, vol. 39, no. 3, June 2009.

Jacobs, P.; Goulter, I. C. (1989). Optimization of redundancy in water distribution networks using graph theoretic principles. Engng Optim. 15 (1), pp. 71-82.

Jain, A. and Kumar, A.M. (2007). Hybrid neural network models for hydrologic time series forecasting. Appl. Soft Comput. 7, pp. 585-592.

Jain, A.; Varshney, A.K, Joshi, U.C. (2001). Short-Term Water Demand Forecast Modelling at IIT Kanpur Using Artificial Neural Networks, Water Resources Management 15: pp. 299-321.

Jamieson, D. G.; Shamir, U.; Martinez, F.; Franchini, M. (2007). Conceptual design of a generic, real-time, near-optimal control system for water distribution networks. J. Hydroinformatics 9 (1), pp. 3-14.

Jayaram, N. (2006). Reliability based optimization for water distribution networks. Graduate Thesis, Indian Institute of Technology Madras.

Jayaram, N.; and Srinivasan, K. (2008). Performance-based optimal design and rehabilitation of water distribution networks sing life cycle costing, Water Resour. Res., 44, W01417, doi:10.1029/2006WR005316.

Johnson, V. M.; and Rogers, L. L. (2000). Accuracy of neural network approximators in simulation-optimization. J. Water Resour. Plan. Manage., 126(2), pp. 48-56. 
Jowitt, P.W. e Xu, C. (1992). Demand Forecasting for Water Distribution Systems. Civil Engg Sys. 9, pp. 105-121.

Jowitt, P.W.; Germanopoulos, G. (1992). Optimal Pump Scheduling in Water Supply Network. Journal of Water Resources Planning and Management, v.118, n.4, pp. 416-422.

Kalagnanam, J. R.; and Diwekar, U. M. (1997). An efficient sampling technique for off-line quality control." Technometrics, 39(3), pp. 308-319.

Kang, D. S.; Pasha, M. F. K. and Lansey, K. (2009) 'Approximate methods for uncertainty analysis of water distribution systems', Urban Water Journal, 6: 3, pp. 233 - 249. doi: $10.1080 / 15730620802566844$.

Kapelan, Z.; Savic, D.A.; Walters, G.A. (2005): Multiobjective Design of Water Distribution Systems under Uncertainty, Water Resources Research, 41(11), pp. W11407-1 to W11407-15.

Khinchin, A.I. (1953). The entropy concept in probability theory. Uspekhi Mathematicheskikh Nauk, 8(3), 2-30. Translated by R.A. Silverman and M.D. Friedman. New York, Dover Publications, [1957]. 120 pp. 1-28.

Kumar, R.; Bal, B.K.; Rockett, P.I. (2009). Multiobjective genetic programming approach to evolving heuristics for the bounded diameter minimum spanning tree problem. In: Proceedings of the ACM Genetic and Evolutionary Computation Conference (GECCO '09), Montreal, Canada, pp 309-316.

Kumar, R.; Joshi A.H.; Banka K.K.; Rockett P.I. (2008). Evolution of hyperheuristics for the biobjective 0/1 knapsack problem by multiobjective genetic programming. In: Proceedings of the 10th ACM conference on Genetic and evolutionary computation (GECCO'08), Atlanta, GA, USA, pp. 1227-1234.

Lansey K, Duan N, Mays L, Tung Y-K. (1989).Water distribution system design under uncertainties. ASCE J Water Resour Plann Manage;115(5), pp.630-45.

Lansey, K. E.; Awumah, K. (1994). Optimal Pump Operations Considering Pump Switches. Journal of Water Resources Planning and Management, Vol. 120, N01, pp. 17-35.

Leon, C.; Martin, S.; Jose, M.E. And Luque, J. (2000), 'EXPLORE-Hybrid Expert System for Water Networks Management', J. Water Resour. Plng. and Mgmt. 126(2), pp. 6574.

Leondes, C.T. (1998). Algorithms and architetures. San Diego: Academic Press, vol.1.

López-Ibáñez, M. (2009). Operational Optimisation of Water Distribution Networks. $\mathrm{PhD}$ thesis, School of Engineering and the Built Environment, Edinburgh Napier University, UK, 2009. 
Mäckle, G.; Savic, D.A.; Walters, G.A. (1995). Application of genetic algorithms to pump scheduling for water supply. In: Genetic Algorithms in Engineering Systems: Innovations and Applications, GALESIA'95, vol. 414, pp. 400-405. Sheffield, UK: IEE Conference Publication.

Maidment, D.R. and Parzen, E. (1984), 'Monthly Water Use and its Relationship to Climatic Variables in Texas', Water Resour. Bull. 19(8), pp. 409-418.

Maidment, D.R.; Miaou, S.P. and Crawford, M.M. (1985), 'Transfer Function Models of Daily Urban Water Use', Water Resour. Res. 21(4), pp. 425-432.

Marquardt, D.W. (1963). Journal of the Society for Industrial and Applied Mathematics, Vol. 11, No. 2 (Jun., 1963), pp. 431-441

Martinez, F.; Hernandez, V.; Alonso, J. M.; Rao, Z.; and Alvisi, S. (2007). Optimizing the operation of the Valencia water-distribution network. J. Hydroinform., 9 (1), pp. 65-78.

McCormick, G.; Powell, R.S. (2003). A progressive mixed integer-programming method for pump scheduling. In: Maksimovi'c, C., Butler, D. \& Memon, F.A., eds., Advances in Water Supply Management, pp. 307-313. London, UK.

McKay, M.D.; Conover, W.J.; and Beckman, R.J. (1979). A Comparison o f Three Methods $f$ o $r$ Selecting Values of Input Variables i $\mathrm{n}$ the Analysis o f Output from a Computer Code. Technometrics, 21, pp. 239-245.

Meckesheimer, M.; Booker, A. J.; Barton, R. R.; and Simpson, T. W. (2002). Computationally inexpensive metamodel assessment strategies. AIAA J., 40(10), pp. 20532060.

Miaou, S.P. (1990), ‘A Class of Time Series Urban Water Demand Models with NonLinear Climatic Effects', Water Resour. Res. 26(2), pp. 169-178.

Mousavi, S. J.; and Shourian M. (2010). Adaptive sequentially space-filling metamodeling applied in optimal water quantity allocation at basin scale, Water Resour. Res., 46, W03520, doi:10.1029/2008WR007076.

Nitivattananon, V.; Sadowski, E.C.; Quimpo, R.G. (1996). Optimization of Water Supply System Operation. Journal of Water Resources Planning and Management, v.122, n.5, September/October, pp. 374-384.

Odan, F. K. (2010). Previsão de Demanda para Sistemas de Abastecimento de Água. 77 p. Dissertação (Mestrado) - Escola de Engenharia de São Carlos, Universidade de São Paulo, São Carlos.

Odan, F.K. ; Ferrero, C.A.; Reis, L.F.R.; Monard, M.C. (2009). Análise comparativa dos modelos kNN-TSP e Série de Fourier para previsão de demanda horária para 
abastecimento de água. In: XVIII Simpósio Brasileiro de Recursos Hídricos - ABRH. Anais... Campo Grande, MS. 20 p.

Odan, F.K.; Reis, L.F.R. (2012). Hybrid Water Demand Forecasting Model Associating Artificial Neural Network with Fourier Series. J. Water Resour. Plann. Manage. 138 (3), pp. 245-256.

Oh, H.S. and Yamauchi, H. (1974), 'An Economic Analysis of the Patterns and Trends in Water Consumption within the Service Area of the Honolulu Board of Water Supply', Report No. 84, Hawaii Water Resources Research Center, University of Honolulu, Honolulu, pp. 647-666.

Ormsbee, L. E. and S. L. Reddy (1995). Nonlinear Heuristic for Pump Operations. Journal of Water Resources Planning and Management, 121(4), pp.302-309.

Ostfeld, A. (2004).Reliability analysis of water distribution systems. Journal of Hydroinformatics, 6(4), pp. 281-294.

Ouelhadj, D.; Petrovi, S. (2010). A cooperative hyper-heuristic search framework. Journal of Heuristics (a ser publicado).

Ozcan, E.; Bilgin, B.; Korkmaz, EE. (2006). Hill climbers and mutational heuristics in hyperheuristics. In: Proceedings of the 9th International Conference on Parallel Problem Solving from Nature (PPSN 2006), Reykjavik, Iceland, Lecture Notes in Computer Science, vol 4193, pp 202-211.

Ozcan, E.; Bilgin, B.; Korkmaz, EE. (2008). A Comprehensive Analysis of Hyperheuristics, Intelligent Data Analysis, 12:1, pp. 3-23.

Parsopoulos, K.E. e Vrahatis, M.N. (2002). Particle Swarm Optimization Method in Multiobjective Problems. Proceedings of the ACM 2002 Symposium on Applied Computing (SAC 2002), pp. 603-607.

Pasha, M. F. K.; Lansey. K. (2009).Optimal Pump Scheduling by Linear Programming. ASCE Conf. Proc. 342, 38.

Pedrosa, L.A.F. (2006). Um modelo de Operação de Sistemas Adutores de Abastecimento de Água com vistas a Minimização dos Custos Energéticos. Campina Grande. PB. 174 p. Tese (Doutorado) - Universidade Federal de Campina Grande.

Perry, P.F. (1981). Demand forecasting in water supply networks. Journal of the Hydraulics Division, ASCE, vol. 107, N. HY9, pp. 1077-1087.

Pezeshk, S.; Helweg, O.J. (1996) Adaptive Search Optimization in Reducing Pump Operating Costs. Journal of Water Resources Planning and Management, v. 122, n. 1, pp. 5763. doi: 10.1061/(ASCE)0733-9496(1996)122:1(57). 
PORTO, R.M. (2006). Hidráulica Básica, 4a. edição Projeto. REENGE, EESC/USP.

Prasad, T.D. and Tanyimboh, T.T. (2008). Entropy based design of 'Anytown' water distribution network, Proceedings of the 10th Annual Water Distribution Systems Analysis Conference (WDSA 2008), Kruger National Park, South Africa.

Prasad, T.D.; Park, N.S. (2004). Multiobjective genetic algorithms for design of water distribution networks, J. Water Resour. Plann. Manage., 130(1), pp. 73-82, doi:10.1061/(ASCE)0733-9496(2004)130:1(73).

Pulido-Calvo I.; Gutierrez-Estrada J.C. (2009). Improved irrigation water demand forecasting using a soft-computing hybrid model. Biosystems Engineering, 102(2), pp. 202218.

Quimpo, R.G.; Shamsi, U.M. (1991). Reliability based distribution system maintenance. J. Wat. Res. Plann. Mngmnt Div., ASCE 117 (3), pp. 321-339.

Raad, D. N.; Sinske A.N. and van Vuuren, J.H. (2010). Comparison of four reliability surrogate measures for water distribution systems design, Water Resour. Res., 46, W05524, doi:10.1029/2009WR007785.

Rao, Z.; Salomons, E. (2007). Development of a real-time, near optimal control process for water-distribution networks. J. Hydroinformatics 9 (1), pp. 25-38.

Reca, J.; Martínez, J.; Baños, R. (2007). Application of Several Meta-Heuristic Techniques to the Optimization of Real Looped Water Distribution Networks. Journal of Water Resources Management. 22(10), pp. 1367-1379.

Ribeiro, G.P. (2005). Operação otimizada do sistema adutor metropolitano utilizando algoritmos genéticos. estudo de caso: SAM Leste da Região Metropolitana de São Paulo (R.M.S.P.). 239p. Tese (Doutorado) - Escola Politécnica, Universidade de São Paulo, São Paulo.

Rosenthal, A. (1977). Computing the reliability of complex networks. SIAM J. Appl. Math. 32 (2), pp. 384-393.

Rossman, L.A. (2000). “EPANET 2 users manual.” U.S. Environmental Protection Agency, Cincinnati, Ohio.

Sakarya, A.B.A.; Mays, L.W. (2000). Optimal operation of water distribution pumps considering water quality. Journal of Water Resources Planning and Management, ASCE, 126 (4) pp. 210-220.

Saldarriaga, J.G.; Ochoa, S.; Moreno, M. E.; Romero, N. and Cortés, O.J. (2010) Prioritised rehabilitation of water distribution networks using dissipated power concept to 
reduce non-revenue water, Urban Water Journal, 7: 2, pp. 121-140, doi: $10.1080 / 15730620903447621$.

Saliby E.; Pacheco F. (2002)."An empirical evaluation of sampling methods in risk analysis simulation: quasi-Monte Carlo, descriptive sampling, and latin hypercube sampling," wsc, vol. 2, pp.1606-1610, 2002 Winter Simulation Conference (WSC'02) - Volume 2

Saliby, E. (1990). Descriptive Sampling: a Better Approach to Monte Carlo Simulation. Journal of the Operational Research Society 41(12), pp. 1133-1142.

Salomons, E.; Goryashko, A.; Shamir, U.; Rao, Z.; Alvisi, S. (2007). Optimizing the operation of the Haifa-A network. J. Hydroinform., 9 (1), pp. 51-64.

Segatto, E.C. And Coury, D.V. (2006). Redes neurais artificiais recorrentes aplicadas na correção de sinais distorcidos pela saturação de transformadores de corrente. Sba Controle \& Automação, vol.17, no.4, pp. 424-436.

Setiadi,Y.; Tanyimboh, T.T.; Templeman, A.B. (2005). Modelling errors, entropy and the reliability ofwater distribution systems. Advances in Engineering Software, 36 (11-12), pp. 780-788.

Shamir, U; Salomons, E. (2008). Optimal Real-Time Operation of Urban Water Distribution Systems Using Reduced Models. Journal of Water Resources and Management, Vol. 134, No. 2, pp. 181-185.

Shamsi, U. (1990). Computerized evaluation of water supply reliability. IEEE Transaction on Reliability 39 (1), pp. 35-41.

Shannon, C.E. (1948), "A Mathematical Theory of Communication", Bell Syst. Tech. J., 27, 379-423, 623-656.

Shannon, C.E. (1948). A mathematical theory of communications. Bell Syst. Tech. J. 27 (3), pp. 379-428.

Shinstine, D. S.; Ahmed, I.; Lansey, K. E. (2001). Reliability/availability analysis of municipal water distribution networks: case studies. J. Wat. Res. Plann. Mngmnt Div., ASCE 128 (2), pp. 140-151.

Shvartser, L.; Shamir, U.; E Feldeman, M. (1993). Forecasting hourly water demand by pattern recognition approach. Journal of water resources planning and management, ASCE, vol. 119, N. 6, pp. 611-627.

Silva, C.S. (2003). Previsão Multivariada da Demanda Horária de Água em Sistemas Urbanos de Abastecimento. Tese (Doutorado). Universidade de Campinas. São Paulo. 
Silva, C.S.; Barbosa, P.S.F. (2001). Previsão da Demanda Horária de água em Sistemas Urbanos de Abastecimento. In: XIV Simpósio Brasileiro de Recursos Hídricos, 2001, Aracajú - SE.

Silva, C.S.; Barbosa, P.S.F. (2002a). Modelo de Redes Neurais Artificiais, Aplicado na Previsão da Demanda Média de água em Sistemas de Abastecimento. In: 10o Encontro Nacional de Saneamento Básico e $10^{\circ}$ Simpósio Luso-Brasileiro de Engenharia Sanitária e Ambiental, Braga - PT.

Silva, C.S.; Barbosa, P.S.F. (2002b). Algoritmo do Gradiente Conjugado Escalonado em RNA para a Previsão de Consumo Horário de Água em Sistemas de Abastecimento. In: Seminário - Planejamento, Projeto e Operação de Redes de Abastecimento de Água: O Estado da Arte e Questões Avançadas, João Pessoa-PB, Brasil.

Silva, R.T.; Rocha, W.S. (1999). Caracterização da demanda urbana de água. Brasília, DF.

Sjobom Júnior, A.A.; Oliveira, M.A.A. (2005). Ferramenta para Previsão de Nivel de Reserva'torios em Sistema de Abastecimento de Água. In: 23o Congresso Brasileiro de Engenharia Sanitária e Ambiental, Campo Grande, MS.

Smith, J.A. (1988). A Model of Daily Municipal Water Use for Short-Term Forecasting. Wat er Resour. Res. 24(2), pp. 201-206.

Steiner, R.C. and Smith J.A. (1983), Short-Term Municipal Water Use Forecasting, Paper Presented at the ASCE's National Specialty Conference, Tampa, Florida.

Sterling, M. J. H. \& Coulbeck, B. (1975). A dynamic programming solution to the optimisation of pumping costs. Proc. ICE 59 (2), pp. 813-818.

Storn, R. e Price, K. (1995). Differential Evolution - A simple and efficient adaptive scheme for global optimization over continuous spaces, Technical Report TR-95-012, International Computer Science Institute, Berkeley, CA.

Su, Y. C.; Mays, L. W.; Duan, N.; Lansey, K. E. (1987). Reliability-based optimization model for water distribution systems. J. Hydraul. Engng, ASCE 114 (12), pp. 1539-1556.

Sucupira, I.R. (2007). Um estudo empírico de hiper-heurística. Dissertação (Mestrado) - Instituto de Matemática e Estatística, Universidade de São Paulo, São Paulo. 124p.

Sumer, D. and K. Lansey (2009). Effect of uncertainty on water distribution system model design decisions. Journal of Water Resources Planning and Management 135(1), 3847. doi: 10.1061/(ASCE)0733-9496(2009)135:1(38). 
Tanyimboh T.; Sheahan C. (2002). A maximum entropy based approach to the layout optimization of water distribution systems. Civil Engineering and Environmental Systems Vol 19, No. 3, pp. 223-253.

Tanyimboh, T.T. and Templeman, A.B. (2000). A quantified assessment of the relationship between the reliability and entropy of water distribution systems. Engng Optim. 33, pp. 179-199.

Tanyimboh, T.T.; Setiadi, Y. (2008a). Sensitivity analysis of entropy-constrained designs of water distribution systems. Engineering Optimization, 40 (5), pp. 439-457.

Tanyimboh, T.T.; Setiadi, Y. (2008b). Joint layout, pipe size and hydraulic reliability optimization of water distribution systems. Engineering Optimization, 40 (8), pp. 729-747.

Tanyimboh, T.T.; Templeman, A.B. (1993). Optimum design of flexible water distribution networks. Civil Eng Syst;10(1), pp. 243-58.

Todini, E. (2000). Looped Water Distribution Networks Design Using a Resilience Index BasedHeuristic Approach. Urban Water, Vol. 2, n.3, pp. 115-122.

Todini, E. e Pilati, S. (1987). A gradient method for the analysis of pipe networks. International Conference on Computer Applications for Water Supply and Distribution, Leicester Polytechnic, UK, September 8-10.

Tolay, P. and Kumar, R. (2009). Evolution of hyperheuristics for the biobjective graph coloring problem using multiobjective genetic programming. In Proceedings of the 11th Annual conference on Genetic and evolutionary computation (GECCO '09). ACM, New York, NY, USA, pp. 1939-1940. DOI: 10.1145/1569901.1570247.

Tolson, B.A.; Maier, H.R.; Simpson, A.R.; Lence, B.J. (2004). Reliability-based optimization of water distribution systems using genetic algorithms, ASCE Journal of Water Resources Planning and Management, 130, (1) pp. 63-72.

Trautwein Jr, B. (2004) Avaliação de métodos para previsão de consumo de água para curtíssimo prazo: um estudo de caso para a empresa de saneamento. 107 p. Dissertação. Pontifícia Universidade Católica do Paraná, Curitiba-PR.

Valdes, J.B. and Sastri, T. (1989), 'Rainfall Intervention Analysis for On-Line Applications', J. Water Resour. Plng. and Mgmt. 115(4), pp. 397-415.

Valença, M.J.S. (2009). Fundamentos das Redes Neurais: Exemplos em Java. 2. ed rev ampl. Olinda - PE : Livro Rápido. 384 p.

Vamvakeridou-Lyroudia, L.S.; Walters, G.A.; and Savic, D.A. (2005). Fuzzy Multiobjective Optimization of Water Distribution Networks. Journal of Water Resources Planning and Management, Vol. 131(6), 467-476. 
van Zyl, J.E. (2001). A methodology for improved operational optimization of water distribution systems, Ph.D. thesis, University of Exeter, UK.

van Zyl, J.E.; Savic, D.A.; Walters, G.A. (2004). Operational optimization of water distribution systems using a hybrid genetic algorithm. Journal of Water Resources Planning and Management, ASCE, 130 (2) pp. 160-170.

Vasan, A. and Simonovic, S.P. (2010). Optimisation of water distribution network design using differential evolution, Journal of Water Resources Planning and Management, 136(2), pp. 279-287, doi 10.1061/(ASCE)0733-9496(2010)136:2(279).

Vicente, R. V. (2005). Modelo de operação para centros de controle de sistemas de abastecimento de água - estudo de caso: sistema adutor metropolitano de São Paulo. 163 p. Dissertação (Mestrado). Escola Politécnica, Universidade de São Paulo, São Paulo.

Vrugt J.A.; Robinson, B.A and Hyman, J.M. (2009). Self-adaptive multimethod search for global optimization in real parameter spaces, IEEE Transactions on Evolutionary Computation 13 (2), pp. 243-259.

Vrugt, J. A.; and Robinson, B. A. (2007). Improved evolutionary optimization from genetically adaptive multimethod search. Proc. Natl. Acad. Sci. U.S.A., 104(3), pp. 708-711.

Wagner, J.M.; Shamir, U.; Marks, D.H. (1988a). Water distribution reliability: analytical methods. J. Wat. Res. Plann. Mngmnt Div., ASCE 114 (3), pp. 253-275.

Wagner, J.M.; Shamir, U.; Marks, D.H. (1988b). Water distribution reliability: simulation methods. J. Wat. Res. Plann. Mngmnt Div., ASCE 114 (3), pp. 276-294.

Walski, T. M.; Brill, E. D.; Gessler, J.; Goulter, I. C.; Jeppson, R. M.; Lansey, K.; Han-Lin Lee, Liebman, J. C.; Mays, L.; Morgan, D. R.; and Ormsbee, L. (1987). Battle of the network models:epilogue. Journal of Water Resources Planning and Management, ASCE, 113(2), 191-203.

Walski, T.M. (2001). The Wrong Paradigm-Why Water Distribution Optimization Doesn't Work. Journal of Water Resources Planning and Management, v.122, n.4, July, p. 203-205.

Wang, Y.; Li, B. (2010). Multi-strategy ensemble evolutionary algorithm for dynamic multi-objective optimization, Memetic Comput. 2 (1), pp. 3-24.

Weeks, C.R. and Mcmahon, T.A. (1973), 'A Comparison of Water Utilities in Australia and the U.S.', J. American Water Works Assoc. 65(4), pp. 232-241.

Williams, G.S.; Hazen, A. (1914). Hydraulic tables: the elements of gagings and the friction of water flowing in pipes, aqueducts, sewers, etc., as determined by the Hazen and Williams formula and the flow of water over sharp-edged and irregular weirs, and the quantity 
discharged as determined by Bazin's formula and experimental investigations upon large models. (2nd revised and enlarged ed.), New York: John Wiley and Sons

Wyss, G.D.; Jorgensen, K.H. (1998). A User's Guide to LHS: Sandia's Latin Hypercube Sampling Software. Risk Assessment and Systems Modeling Department - Sandia National Laboratories.

Xu, C.; Goulter, I.C. (1998). Probabilistic model for water distribution reliability. J. Wat. Res. Plann. Mngmnt Div., ASCE 124 (4), pp. 218-228.

Xu, C.; Goulter, I.C. (1999). Reliability based optimal design of water distribution networks. ASCE J Water Res Plan Manage; 125(6), pp. 352-62.

Yan, S. and Minsker B. (2006). "Optimal groundwater remediation design using an Adaptive Neural Network Genetic Algorithm.' 'Water Resour. Res., 42(5).

Yassin-Kassab, A.; Templeman, A.B. and Tanyimboh, T.T. (1999). Calculating Maximum Entropy Flows in Multi-Source, Multi-Demand Networks. Engineering Optimization, 31: 6, pp. 695-729. doi: 10.1080/03052159908941393.

Zahed, K.F. (1990). Previsão de demanda de consumo em tempo real no desenvolvimento operacional de sistemas de distribuição de água. Tese de doutorado, Escola Politécnica da Universidade de São Paulo. São Paulo.

Zanini, A. (2000). Redes Neurais e Regressão Dinâmica: um modelo híbrido para previsão de curto prazo da demanda de gasolina automotiva no Brasil. 85 p. Dissertação. Pontifícia Universidade Católica do Rio de Janeiro, Rio de Janeiro.

Zessler, U.; Shamir, U. (1989) Optimal Operation of Water Distribution Systems. Journal of Water Resources Planning and Management, v. 115, n. 6, pp. 735-752.

Zhang, G.P. (2003). Time series forecasting using a hybrid ARIMA and neural network model, Neurocomputing 50, pp. 159-175.

Zhang, J.; Song, R.; Bhaskar, N.R. E French, M.N. (2006). Short-Term Water Demand Forecasting: A Case Study. ASCE Conf. Proc. 247, 49, pp 1-14. 